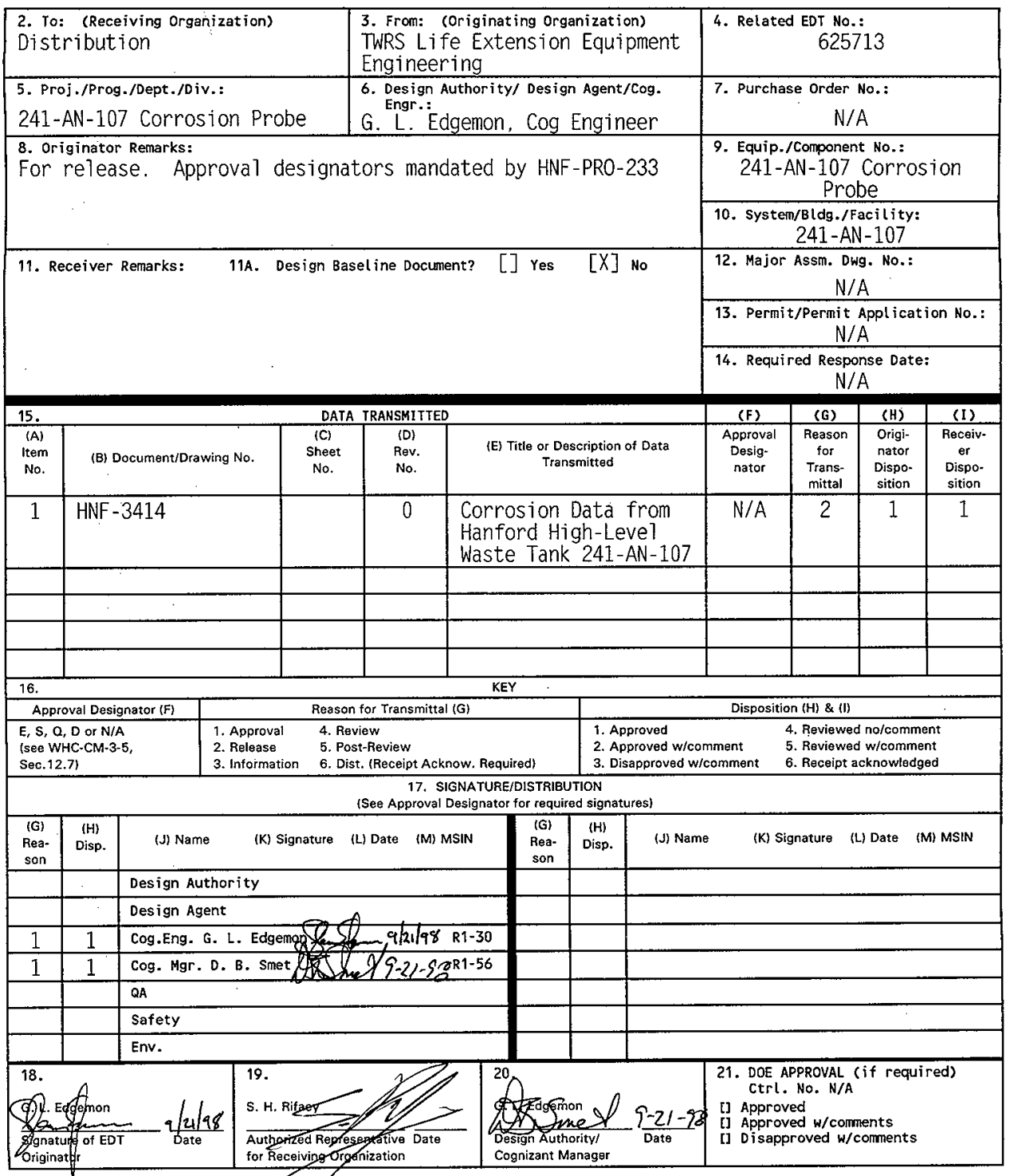




\section{Corrosion Data from Hanford High-Level Waste Tank 241-AN-107}

G. L. Edgemon

Lockheed Martin Hanford Corporation, Richland, WA 99352

U.S. Department of Energy Contract DE-AC06-96RL13200

EDT/ECN: 625713

Org Code: 74711

UC: 604

B\&R Code: EW4010000

Charge Code: N16B1

Total Pages: 170

D. 9.2080

Key Words: Electrochemical noise, corrosion monitoring. corrosion, pitting, stress corrosion cracking, localized corrosion, tank monitoring

Abstract: Document describes first year of operation of 241-AN-107 electrochemical noise based corrosion monitoring system. Data and system status are presented.

TRADEMARK DISCLAIMER. Reference here in to any specific commercial product, process, or service by trade name, trademark, manufacturer, or otherwise, does not necessarily constitute or imply its endorsement, recormendation, or favoring by the United States Government or any agency thereof or its contractors or subcontractors.

Printed in the United States of America. To obtain copies of this document, contact: Document Control Services, P.O. Box 950, Mailstop H6-08, Richland WA 99352, Phone (509) 372-2420; Fax (509) 376-4989.
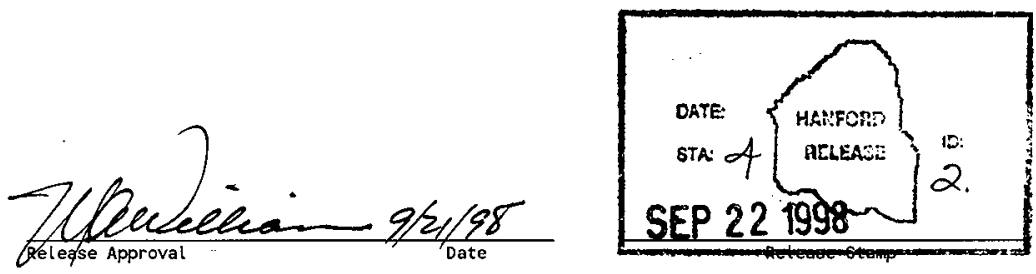

\section{Approved for Public Release}


CORROSION DATA FROM HANFORD HIGH-LEVEL WASTE TANK 241-AN-107

\author{
G. L. Edgemon \\ Lockheed Martin Hanford Corporation \\ P. O. Box 1500, MSIN: R1-30 \\ Richland, Washington 99352-3372
}




\section{TABLE OF CONTENTS}

EXECUTIVE SUMMARY

INTRODUCTION AND BACKGROUND.

SUPERNATE SUMMARY STATISTICAL DATA - PRESENTATION AND ANALYSIS................. 15

Mean Potential Noise- Supernate C-rings (Channels 4, 6 and 8)............................................. 16

Standard Deviation of Potential Noise - Supernate C-rings (Channels 4, 6 and 8)........................ 17

Mean Current Noise - Supernate C-rings (Channeis 4, 6 and 8)............................................... 17

Standard Deviation of Current Noise - Supernate C-rings (Channels 4, 6 and 8) ......................... 18

Pitting Index - Supernate C-rings (Channels 4, 6 and 8).............................................................. 19

Resistance Noise - Supernate C-rings (Channels 4, 6 and 8) .................................................. 19

$\mathrm{R}_{\mathrm{n}}$ Based Uniform Corrosion Rates - Supernate C-rings (Channels 4, 6 and 8) ............................2 20

Mean Potential Noise- Supernate Pins (Channels 3, 5 and 7) ................................................... 20

Standard Deviation of Potential Noise - Supernate Pins (Channels 3, 5 and 7) …….................... 21

Mean Current Noise - Supernate Pins (Channels 3, 5 and 7) ........................................................ 21

Standard Deviation of Current Noise - Supernate Pins (Channels 3, 5 and 7).............................22

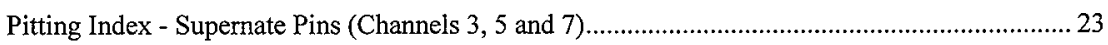

Resistance Noise - Supernate Pins (Channels 3, 5 and 7) ................................................................ 23

$\mathrm{R}_{\mathrm{n}}$ Based Uniform Corrosion Rates - Supernate Pins (Channels 3, 5 and 7) ............................... 23

VAPOR SPACE SUMMARY STATISTICAL DATA - PRESENTATION AND ANALYSIS ............ 24

Mean Potential Noise- Vapor Space C-rings (Channel 2)................................................................ 24

Standard Deviation of Potential Noise - Vapor Space C-rings (Channel 2) ................................... 24

Mean Current Noise - Vapor Space C-rings (Channel 2) ......................................................... 25

Standard Deviation of Current Noise - Vapor Space C-rings (Channel 2) .........................................25

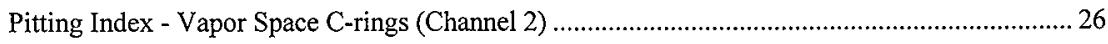

Resistance Noise - Vapor Space C-rings (Channel 2).................................................................. 26

$\mathrm{R}_{n}$ Based Uniform Corrosion Rates - Vapor Space C-rings (Channel 2) ...................................... 26

Mean Potential Noise - Vapor Space Pins (Channel 1) ............................................................ 27

Standard Deviation of Potential Noise - Vapor Space Pins (Channel 1) ...................................... 27 


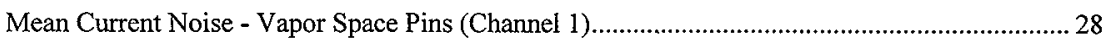

Standard Deviation of Current Noise - Vapor Space Pins (Channel 1) ............................................. 28

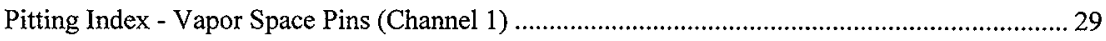

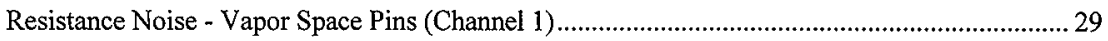

$\mathrm{R}_{\mathrm{n}}$ Based Uniform Corrosion Rates - Vapor Space Pins (Channel 1) .............................................. 29

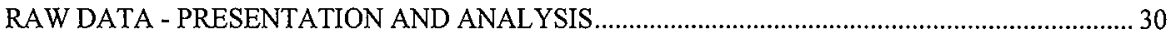

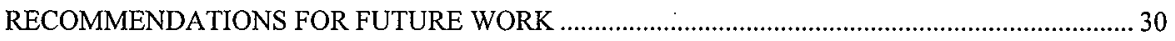

CONCLUSIONS

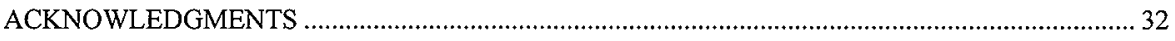

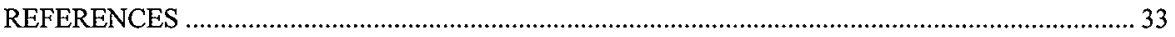

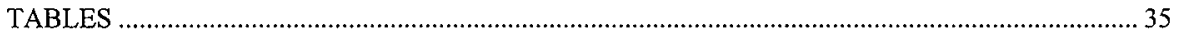

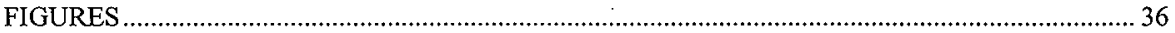




\section{TABLE OF FIGURES}

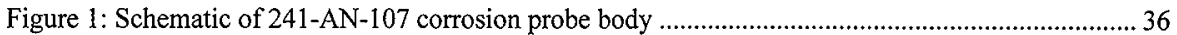

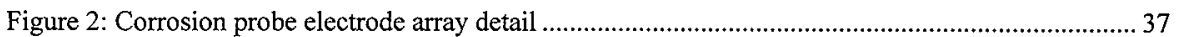

Figure 3: Schematic of 241-AN-107 electrochemical noise based corrosion monitoring

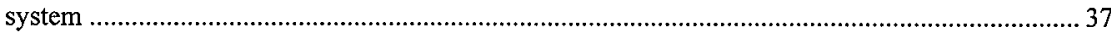

Figure 4: Mean potential noise for C-ring electrodes on channel 4 ( $6.5 \mathrm{~m}$ from tank floor).................... 38

Figure 5: Mean potential noise for C-ring electrodes on channel 6 ( $4.0 \mathrm{~m}$ from tank floor)................... 38

Figure 6: Mean potential noise for C-ring electrodes on channel 8 ( $1.4 \mathrm{~m}$ from tank floor)................... 39

Figure 7: Standard deviation of potential noise for C-ring electrodes on channel $4(6.5 \mathrm{~m}$

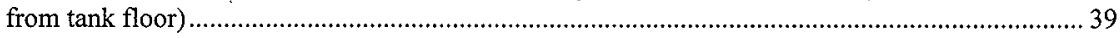

Figure 8: Standard deviation of potential noise for C-ring electrodes on channel 6 (4.0 m from tank floor)

Figure 9: Standard deviation of potential noise for C-ring electrodes on channel $8(1.4 \mathrm{~m}$ from tank floor) 40

Figure 10: Mean current noise for C-ring electrodes on channel 4 (6.5 m from tank floor) ................... 41

Figure 11: Mean current noise for C-ring electrodes on channel 6 (4.0 m from tank floor) ................... 41

Figure 12: Mean current noise for C-ring electrodes on channel 8 (1.4 m from tank floor) .................... 42

Figure 13: Standard deviation of current noise for C-ring electrodes on channel $4(6.5 \mathrm{~m}$ from tank floor).

Figure 14: Standard deviation of current noise for C-ring electrodes on channel $6(4.0 \mathrm{~m}$ from tank floor)

Figure 15: Standard deviation of current noise for C-ring electrodes on channel $8(1.4 \mathrm{~m}$ from tank floor) 43

Figure 16: Pitting index for C-ring electrodes on channel 4 ( $6.5 \mathrm{~m}$ from tank floor $) \ldots \ldots \ldots \ldots \ldots \ldots \ldots \ldots \ldots \ldots . . . . . . . . . . . . .44$

Figure 17: Pitting index for C-ring electrodes on channel 6 (4.0 m from tank floor)

Figure 18: Pitting index for C-ring electrodes on channel 8 (1.4 $\mathrm{m}$ from tank floor)

Figure 19: Resistance noise for C-ring electrodes on channel 4 (6.5 m from tank floor)........................ 45

Figure 20: Resistance noise for C-ring electrodes on channel 6 (4.0 m from tank floor)....................... 46

Figure 21: Resistance noise for C-ring electrodes on channel 8 (1.4 $\mathrm{m}$ from tank floor).......................... 46

Figure 22: Uniform corrosion rate from noise data for C-ring electrodes on channel 4 (6.5

$\mathrm{m}$ from tank floor).

Figure 23: Uniform corrosion rate from noise data for C-ring electrodes on channel 6 (4.0 $\mathrm{m}$ from tank floor)

Figure 24: Uniform corrosion rate from noise data for C-ring electrodes on channel 8 (1.4

$\mathrm{m}$ from tank floor) 48

Figure 25: Mean potential noise for pin electrodes on channel 3 ( $6.6 \mathrm{~m}$ from tank floor) .48

Figure 26: Mean potential noise for pin electrodes on channel 5 ( $4.2 \mathrm{~m}$ from tank floor) 
Figure 27: Mean potential noise for pin electrodes on channel $7(1.5 \mathrm{~m}$ from tank floor) 49

Figure 28: Standard deviation of potential noise for pin electrodes on channel $3(6.6 \mathrm{~m}$ from tank floor) 50

Figure 29: Standard deviation of potential noise for pin electrodes on channel $5(4.2 \mathrm{~m}$ from tank floor) 50

Figure 30: Standard deviation of potential noise for pin electrodes on channel 7 (1.5 m from tank floor) 51

Figure 31: Mean current noise for pin electrodes on channel 3 ( $6.6 \mathrm{~m}$ from tank floor) $. . . \ldots \ldots \ldots \ldots \ldots \ldots \ldots . . . . . . . . . .51$

Figure 32: Mean current noise for pin electrodes on channel 5 ( $4.2 \mathrm{~m}$ from tank floor)........................ 52

Figure 33: Mean current noise for pin electrodes on channel 7 (1.5 $\mathrm{m}$ from tank floor). 52

Figure 34: Standard deviation of current noise for pin electrodes on channel $3(6.6 \mathrm{~m}$ from tank floor)

Figure 35: Standard deviation of current noise for pin electrodes on channel $5(4.2 \mathrm{~m}$ from tank floor).

Figure 36: Standard deviation of current noise for pin electrodes on channel $7(1.5 \mathrm{~m}$ from tank floor). 54

Figure 37: Pitting index for pin electrodes on channel 3 ( $6.6 \mathrm{~m}$ from tank floor) ................................ 54

Figure 38: Pitting index for pin electrodes on channel 5 ( $4.2 \mathrm{~m}$ from tank floor) ................................. 55

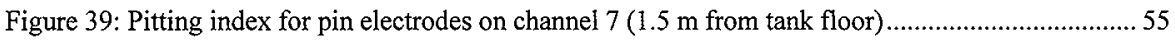

Figure 40: Resistance noise for pin electrodes on channel 3 ( $6.6 \mathrm{~m}$ from tank floor) ............................. 56

Figure 41: Resistance noise for pin electrodes on channel 5 (4.2 m from tank floor) .............................. 56

Figure 42: Resistance noise for pin electrodes on channel 7 ( $1.5 \mathrm{~m}$ from tank floor) ........................... 57

Figure 43: Uniform corrosion rate from noise data for pin electrodes on channel 3 ( $6.6 \mathrm{~m}$ from tank floor)

Figure 44: Uniform corrosion rate from noise data for pin electrodes on channel 5 (4.2 m from tank floor)

Figure 45: Uniform corrosion rate from noise data for pin electrodes on channel 7 (1.5 m from tank floor)

Figure 46: Mean potential noise for C-ring electrodes in vapor space on channel 2 (10.7 $\mathrm{m}$ from tank floor).

Figure 47: Standard deviation of potential noise for C-ring electrodes in vapor space on channel 2 (10.7 $\mathrm{m}$ from tank floor).....

Figure 48: Mean current noise for C-ring electrodes in vapor space on channel $2(10.7 \mathrm{~m}$ from tank floor).

Figure 49: Standard deviation of current noise for C-ring electrodes in vapor space on channel 2 ( $10.7 \mathrm{~m}$ from tank floor)

Figure 50: Pitting index for C-ring electrodes in vapor space on channel $2(10.7 \mathrm{~m}$ from tank floor).

Figure 51: Resistance noise for C-ring electrodes in vapor space on channel $2(10.7 \mathrm{~m}$ from tank floor). 
Figure 52: Uniform corrosion rate from $\mathrm{EN}$ for $\mathrm{C}$-ring electrodes in vapor space on channel 2 (10.7 $\mathrm{m}$ from tank floor)....

Figure 53: Mean potential noise for pin electrodes in vapor space on channel $1(10.9 \mathrm{~m}$ from tank floor).

Figure 54: Standard deviation of potential noise for pin electrodes in vapor space on channel 1 (10.9 $\mathrm{m}$ from tank floor).

Figure 55: Mean current noise for pin electrodes in vapor space on channel $1(10.9 \mathrm{~m}$ from tank floor).

Figure 56: Standard deviation of current noise for pin electrodes in vapor space on channel 1 (10.9 $\mathrm{m}$ from tank floor)

Figure 57: Pitting index for pin electrodes in vapor space on channel 1 (10.9 m from tank floor).

Figure 58: Resistance noise for pin electrodes in vapor space on channel $1(10.9 \mathrm{~m}$ from tank floor).......

Figure 59: Uniform corrosion rate from noise data for pin electrodes in vapor space on channel 1 (10.9 $\mathrm{m}$ from tank floor)

Figure 60: Typical raw potential and raw current data files: pin electrodes in vapor space on channel 1 - September 1997

Figure 61: Typical raw potential and raw current data files: pin electrodes in vapor space on channel 1 - October 1997

Figure 62: Typical raw potential and raw current data files: pin electrodes in vapor space on channel 1 - November 1997

Figure 63: Typical raw potential and raw current data files: pin electrodes in vapor space on channel 1 - December 1997.

Figure 64: Typical raw potential and raw current data files: pin electrodes in vapor space on channel 1 - January 1998

Figure 65: Typical raw potential and raw current data files: pin electrodes in vapor space on channel 1 - February 1998

Figure 66: Typical raw potential and raw current data files: pin electrodes in vapor space on channel 1 - March 1998

Figure 67: Typical raw potential and raw current data files: pin electrodes in vapor space on channel 1 - April 1998

Figure 68: Typical raw potential and raw current data files: pin electrodes in vapor space on channel 1 - May 1998.

Figure 69: Typical raw potential and raw current data files: pin electrodes in vapor space on channel 1 - June 1998. 75

Figure 70: Typical raw potential and raw current data files: pin electrodes in vapor space on channel 1 - July 1998 .

Figure 71: Typical raw potential and raw current data files: pin electrodes in vapor space on channel 1 - August 1998 
Figure 72: Typical raw potential and raw current data files: pin electrodes in vapor space

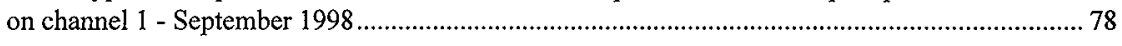

Figure 73: Typical raw potential and raw current data files: $C$-ring electrodes in vapor

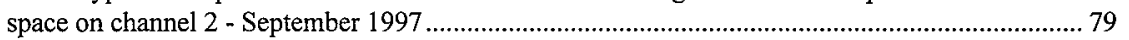

Figure 74: Typical raw potential and raw current data files: C-ring electrodes in vapor

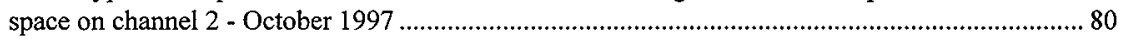

Figure 75: Typical raw potential and raw current data files: $C$-ring electrodes in vapor

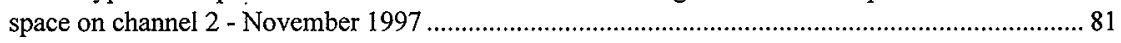

Figure 76: Typical raw potential and raw current data files: C-ring electrodes in vapor

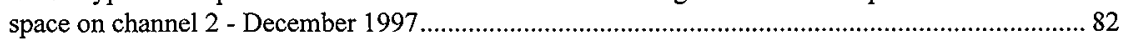

Figure 77: Typical raw potential and raw current data files: C-ring electrodes in vapor

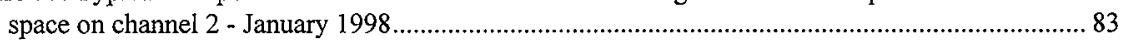

Figure 78: Typical raw potential and raw current data files: $C$-ring electrodes in vapor

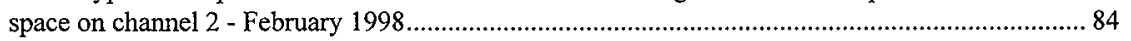

Figure 79: Typical raw potential and raw current data files: $C$-ring electrodes in vapor

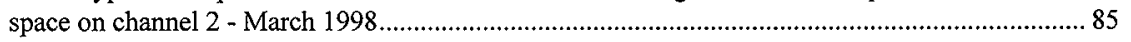

Figure 80: Typical raw potential and raw current data files: C-ring electrodes in vapor

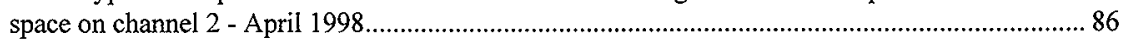

Figure 81: Typical raw potential and raw current data files: C-ring electrodes in vapor

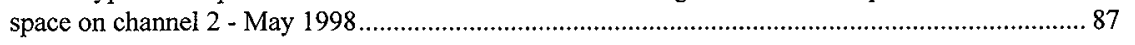

Figure 82: Typical raw potential and raw current data files: $C$-ring electrodes in vapor

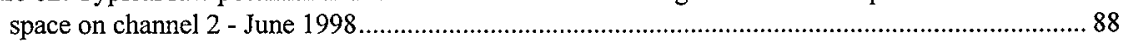

Figure 83: Typical raw potential and raw current data files: $C$-ring electrodes in vapor

Figure 84: Typical raw potential and raw current data files: C-ring electrodes in vapor

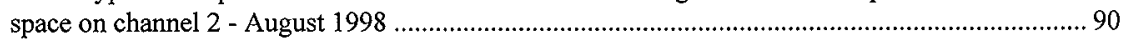

Figure 85: Typical raw potential and raw current data files: $\mathrm{C}$-ring electrodes in vapor

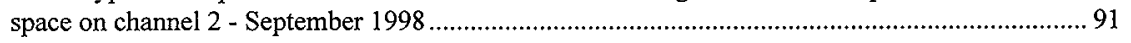

Figure 86: Typical raw potential and raw current data files: pin electrodes in supernate on

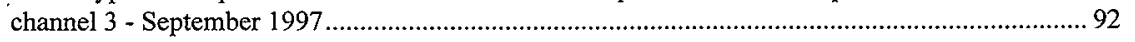

Figure 87: Typical raw potential and raw current data files: pin electrodes in supernate on

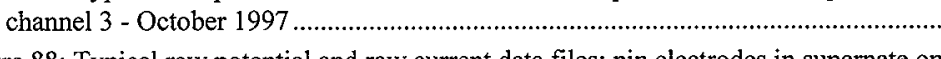

Figure 88: Typical raw potential and raw current data files: pin electrodes in supernate on

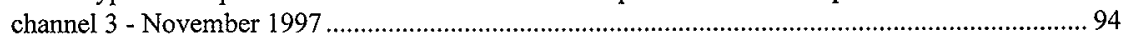

Figure 89: Typical raw potential and raw current data files: pin electrodes in supernate on

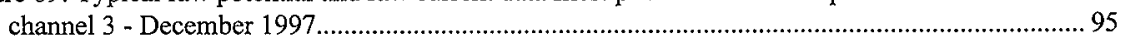

Figure 90: Typical raw potential and raw current data files: pin electrodes in supernate on

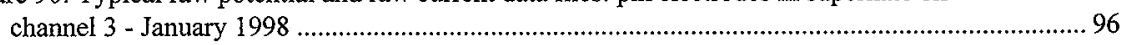

Figure 91: Typical raw potential and raw current data files: pin electrodes in supernate on channel 3 - February 1998 
Figure 92: Typical raw potential and raw current data files: pin electrodes in supernate on channel 3 - March 1998

Figure 93: Typical raw potential and raw current data files: pin electrodes in supernate on channel 3 - April 1998

Figure 94: Typical raw potential and raw current data files: pin electrodes in supernate on channel 3 - May 1998

Figure 95: Typical raw potential and raw current data files: pin electrodes in supernate on channel 3 - June 1998.

Figure 96: Typical raw potential and raw current data files: pin electrodes in supernate on channel 3 - July 1998

Figure 97: Typical raw potential and raw current data files: pin electrodes in supernate on channel 3 - August 1998

Figure 98: Typical raw potential and raw current data files: pin electrodes in supernate on channel 3 - September 1998

Figure 99: Typical raw potential and raw current data files: C-ring electrodes in supernate on channel 4 - September 1997

Figure 100: Typical raw potential and raw current data files: C-ring electrodes in supernate on channel 4 - October 1997

Figure 101: Typical raw potential and raw current data files: C-ring electrodes in supernate on channel 4 - November $1997 .$.

Figure 102: Typical raw potential and raw current data files: C-ring electrodes in supernate on channel 4 - December 1997

Figure 103: Typical raw potential and raw current data files: C-ring electrodes in supernate on channel 4 - January 1998

Figure 104: Typical raw potential and raw current data files: C-ring electrodes in supernate on channel 4 - February 1998

Figure 105: Typical raw potential and raw current data files: C-ring electrodes in supernate on channel 4 - March 1998

Figure 106: Typical raw potential and raw current data files: $C$-ring electrodes in supernate on channel 4 - April 1998

Figure 107: Typical raw potential and raw current data files: C-ring electrodes in supernate on channel 4 - May 1998

Figure 108: Typical raw potential and raw current data files: $\mathrm{C}$-ring electrodes in supernate on channel 4 - June 1998

Figure 109: Typical raw potential and raw current data files: C-ring electrodes in supernate on channel 4 - July 1998

Figure 110: Typical raw potential and raw current data files: C-ring electrodes in supernate on channel 4 - August 1998

Figure 111: Typical raw potential and raw current data files: C-ring electrodes in supernate on channel 4 - September 1998 
Figure 112: Typical raw potential and raw current data files: pin electrodes in supernate on channel 5 - September 1997.

Figure 113: Typical raw potential and raw current data files: pin electrodes in supernate on channel 5 - October 1997

Figure 114: Typical raw potential and raw current data files: pin electrodes in supernate on channel 5 - November 1997

Figure 115: Typical raw potential and raw current data files: pin electrodes in supernate on channel 5 - December 1997.

Figure 116: Typical raw potential and raw current data files: pin electrodes in supernate on channel 5 - January 1998

Figure 117: Typical raw potential and raw current data files: pin electrodes in supernate on channel 5 - February 1998

Figure 118: Typical raw potential and raw current data files: pin electrodes in supernate on channel 5 - March 1998

Figure 119: Typical raw potential and raw current data files: pin electrodes in supernate on channel 5 - April 1998

Figure 120: Typical raw potential and raw current data files: pin electrodes in supernate on channel 5 - May 1998.

Figure 121: Typical raw potential and raw current data files: pin electrodes in supernate on channel 5 - June 1998

Figure 122: Typical raw potential and raw current data files: pin electrodes in supernate on channel 5 - July 1998

Figure 123: Typical raw potential and raw current data files: pin electrodes in supernate on channel 5 - August 1998

Figure 124: Typical raw potential and raw current data files: pin electrodes in supernate on channel 5 - September 1998

Figure 125: Typical raw potential and raw current data files: C-ring electrodes in supernate on channel 6 - September 1997

Figure 126: Typical raw potential and raw current data files: C-ring electrodes in supernate on channel 6 - October 1997

Figure 127: Typical raw potential and raw current data files: C-ring electrodes in supernate on channel 6 - November 1997

Figure 128: Typical raw potential and raw current data files: C-ring electrodes in supernate on channel 6 - December 1997.

Figure 129: Typical raw potential and raw current data files: C-ring electrodes in supernate on channel 6 - January 1998

Figure 130: Typical raw potential and raw current data files: C-ring electrodes in supernate on channel 6 - February 1998

Figure 131: Typical raw potential and raw current data files: $\mathrm{C}$-ring electrodes in supernate on channel 6 - March 1998 
Figure 132: Typical raw potential and raw current data files: C-ring electrodes in supernate on channel 6 - April 1998

Figure 133: Typical raw potential and raw current data files: C-ring electrodes in supernate on channel 6 - May 1998

Figure 134: Typical raw potential and raw current data files: C-ring electrodes in supernate on channel 6 - June 1998

Figure 135: Typical raw potential and raw current data files: C-ring electrodes in supernate on channel 6 - July 1998

Figure 136: Typical raw potential and raw current data files: C-ring electrodes in supernate on channel 6 - August 1998

Figure 137: Typical raw potential and raw current data files: C-ring electrodes in supernate on channel 6 - September 1998.

Figure 138: Typical raw potential and raw current data files: pin electrodes in supernate on channel 7 - September 1997

Figure 139: Typical raw potential and raw current data files: pin electrodes in supernate on channel 7 - October 1997

Figure 140: Typical raw potential and raw current data files: pin electrodes in supernate on channel 7 - November 1997

Figure 141: Typical raw potential and raw current data files: pin electrodes in supernate on channel 7 - December 1997.

Figure 142: Typical raw potential and raw current data files: pin electrodes in supernate on channel 7 - January 1998

Figure 143: Typical raw potential and raw current data files: pin electrodes in supernate on channel 7 - February 1998

Figure 144: Typical raw potential and raw current data files: pin electrodes in supernate on channel 7 - March 1998

Figure 145: Typical raw potential and raw current data files: pin electrodes in supernate on channel 7 - April 1998

Figure 146: Typical raw potential and raw current data files: pin electrodes in supernate on channel 7 - May 1998.

Figure 147: Typical raw potential and raw current data files: pin electrodes in supernate on channel 7 - June 1998.

Figure 148: Typical raw potential and raw current data files: pin electrodes in supernate on channel 7 - July 1998

Figure 149: Typical raw potential and raw current data files: pin electrodes in supernate on channel 7 - August 1998

Figure 150: Typical raw potential and raw current data files: pin electrodes in supernate on channel 7 - September 1998

Figure 151: Typical raw potential and raw current data files: C-ring electrodes in supernate on channel 8 - September 1997. 
Figure 152: Typical raw potential and raw current data files: C-ring electrodes in supernate on channel 8 - October 1997

Figure 153: Typical raw potential and raw current data files: C-ring electrodes in supernate on channel 8 - November 1997.

Figure 154: Typical raw potential and raw current data files: C-ring electrodes in supernate on channel 8 - December 1997

Figure 155: Typical raw potential and raw current data files: C-ring electrodes in supernate on channel 8 - January 1998

Figure 156: Typical raw potential and raw current data files: C-ring electrodes in supernate on channel 8 - February 1998

Figure 157: Typical raw potential and raw current data files: $\mathrm{C}$-ring electrodes in supernate on channel 8 - March 1998

Figure 158: Typical raw potential and raw current data files: C-ring electrodes in supernate on channel 8 - April 1998

Figure 159: Typical raw potential and raw current data files: C-ring electrodes in supernate on channel 8 - May 1998

Figure 160: Typical raw potential and raw current data files: C-ring electrodes in supernate on channel 8 - June 1998

Figure 161: Typical raw potential and raw current data files: C-ring electrodes in supernate on channel 8 - July 1998

Figure 162: Typical raw potential and raw current data files: C-ring electrodes in supernate on channel 8 - August 1998

Figure 163: Typical raw potential and raw current data files: C-ring electrodes in supernate on channel 8 - September 1998. 
HNF-3414, Rev. 0

\section{EXECUTIVE SUMMARY}

Corrosion monitoring of double-shell tanks at the site is currently provided by process knowledge and tank waste chemistry sampling. Tanks found to be within chemistry specification limits are considered to be safe from excessive corrosion damage. The recent discovery of five low hydroxide (out of corrosion specification) tanks at Hanford indicates that the current system of chemistry sampling is inadequate to fully support corrosion control.

In an effort to improve corrosion monitoring and control, An eight-channel electrochemical noise (EN) based corrosion monitoring system was successfully designed, fabricated and installed into double-shell tank 241-AN-107 in September 1997. This system has collected over 67,000 data files and has operated reliably for approximately one year. It is a "first of its kind" system in the world and could prevent unnecessary sodium hydroxide additions to tank 241-AN-107. This system is a larger scale version of a prototype system installed in double-shell tank 241-AZ-101 in August 1996. The 241-AN-107 system monitors fluctuations in current and potential caused by corrosion occurring on electrode arrays immersed in the waste tank. The electrode arrays are made of the same material (archived ASTM A-537 CL 1 carbon steel) as the waste tank. The system monitors eight channels: six positioned at different elevations in the supernate and two positioned in the vapor space above the waste. The system is capable of detecting the onset of pitting and stress corrosion cracking should tank waste conditions change to allow these mechanisms to occur. The system also supports the use of linear polarization resistance testing for determination of uniform corrosion rate. By monitoring and analyzing the data from these techniques, dominant corrosion mechanisms in 241AN-107 have been determined.

Despite the success in getting the system designed, installed and operating, no funding was provided for troubleshooting and data analysis for nearly a year following installation. Upon inspection it was found that most of the data collected to date is suspected of being corrupted to some degree by an unknown source of interference. Since data on all channels is affected periodicaliy at approximately the same time (vapor space electrodes periodically show the same signal as electrodes in the supernate), it is assumed that the source of these disruptions is external to the tank and not related to corrosion of the tank. The source of these disruptions must be found and eliminated before accurate data collection can be assured. Grounding and cable shielding deficiencies are suspected to be closely related to this problem.

For reasons not currently understood, data collected between 11/25/97 and 1/17/98 do not appear to be affected by the disturbances and signal interference that plague much of the rest of the data collected to date. Both summary statistical data and raw data collected during this time period indicate that uniform corrosion is the dominant active corrosion mechanism in tank 241-AN-107.

Both summary statistical data and raw data collected during periods of data disruption and disturbance also indicate that uniform corrosion is the dominant active corrosion mechanism in tank 241-AN-107.

Uniform corrosion rates have been calculated from EN data. Despite correction for surface area differences and number of electrodes per channel, uniform corrosion rates calculated from noise data collected on small pin-type electrodes (channels 3,5 and 7) do not agree with uniform corrosion rates determined from noise data collected on larger $\mathrm{C}$-ring electrodes (channels 4, 6 and 8). Between 11/25/97 and 1/17/98, C-rings in 
the supernate showed an average uniform corrosion rate of approximately 7 mils per year (mpy). Pin electrodes in the supernate over the same time period showed a uniform corrosion rate of less than 1 mpy. Which value is correct and the source of the difference have not yet been determined.

Discovery and elimination of the source of the data disturbances and the conduction of standardized LPR tests to confirm uniform corrosion rates would likely return the full functionality of the 241-AN-107 corrosion monitoring system.

\section{INTRODUCTION AND BACKGROUND}

The Hanford Site has 177 underground waste tanks that store approximately 253 million liters of radioactive waste from 50 years of plutonium production [1]. Twenty-eight (28) tanks have a double shell and are constructed of welded ASTM A537-Class 1 (UNS K02400), ASTM A515-Grade 60 (UNS K02401), or ASTM A516-Grade 60 (UNS K02100) material. The inner tanks of the double-shell tanks (DSTs) were stress relieved following fabrication. One hundred forty-nine (149) tanks have a single shell, also constructed of welded mild steel, but not stress relieved following fabrication. Tank waste is in liquid, solid, and sludge forms. Tanks also contain a vapor space above the solid and liquid waste regions. The composition of the waste varies from tank to tank but generally has a high $\mathrm{pH}(>12)$ and contains sodium nitrate, sodium hydroxide, sodium nitrite, and other minor radioactive constituents resulting from plutonium separation processes [1-4]. Leaks began to appear in the single-shell tanks shortly after the introduction of nitrate-based wastes in the 1950s. Leaks are now confirmed or suspected to be present in a significant number of single-shell tanks [1]. The probable modes of corrosion failures are reported as nitrate stress corrosion cracking (SCC) and pitting [2].

Corrosion monitoring of DSTs is currently provided at the Hanford Site by process knowledge and tank waste chemistry sampling [1-4]. Tanks found to be within chemistry specification limits are considered to be safe from excessive corrosion damage. The recent discovery of five low hydroxide (out of corrosion specification) tanks at Hanford indicates that the current system of chemistry sampling is inadequate to support corrosion control. Tank samples are infrequent and analyses are difficult and expensive. Furthermore, waste streams that are exempt from the corrosion control specifications complicate process knowledge. In-tank, real-time measurement of waste corrosivity is needed to provide an acceptable level of corrosion control information.

Available technologies such as the electrochemical noise (EN) technique for corrosion monitoring have progressed to a point where it is now feasible to detect and monitor the forms of corrosion most likely to affect Hanford DSTs [5-22]. Previous efforts to monitor internal corrosion of high-level nuclear waste tank systems have included the linear polarization resistance (LPR) and electrical resistance techniques [23, 24]. These techniques are most effective for monitoring uniform corrosion, but are not well suited for detection of localized corrosion. The Savannah River Site (SRS) investigated the characterization of electrochemical noise (EN) for monitoring waste tank corrosion in 1993, but the tests were not conclusive [25]. The SRS effort has recently been revived and additional testing is underway. A two-year laboratory study was launched at Hanford in 1995 to provide a technical basis for applying EN based corrosion monitoring systems to nuclear waste tanks [26-28]. Personnel at the Hanford Site, Oak Ridge National Laboratory, Pacific Northwest National Laboratory, and several instrumentation manufacturers participated in the 
program. This testing program conclusively demonstrated the ability to use EN based corrosion monitoring systems to detect and discriminate between forms of localized corrosion and led to the development and deployment of a prototype corrosion monitoring system into DST 241-AZ-101 in August 1996. Based on the performance of the prototype system, a larger scale system was designed and installed in DST 241-AN107 in September 1997.

\section{1-AN-107 SYSTEM DESIGN AND CONFIGURATION}

The 241-AN-107 monitoring system is designed, like most EN based corrosion-monitoring systems, to measure instantaneous fluctuations in corrosion current and potential between three nominally identical electrodes (a working, a counter, and a pseudo-reference electrode) of the material of interest immersed in the environment of interest. Time-dependent fluctuations in corrosion current between the working and counter electrodes are described by electrochemical current noise. Time-dependent fluctuations of the difference in the corrosion potential between the working/counter electrode assembly and the pseudoreference electrode are described by electrochemical potential noise. Since a zero resistance ammeter (ZRA) electrically joins the working and counter electrodes, potential differences are measured between the working/counter electrode assembly and the pseudo-reference electrode. It has been shown that each type of corrosion phenomenon presents a unique relationship between corrosion current and potential transients in the temporal data [5-22, 26-28]. Other methods of analysis involve transforming temporal data to the frequency domain for analysis [29]. As of the time of the preparation of this report, no frequency analysis of the EN data from the 241-AN-107 system is expected. However, statistical analysis techniques will be employed.

The 241-AN-107 corrosion monitoring system is designed to detect the onset of localized corrosion phenomena if tank conditions should change to allow these phenomena to occur. In addition, it could be used to monitor and optimize the effectiveness of upcoming sodium hydroxide corrosion inhibitor additions.

Prior to its fabrication, the following design goals were established for the 241-AN-107 corrosion monitoring system:

- Provide at least five years of service

- $\quad$ Fit through 10.2-cm diameter riser

- Facilitate remote data acquisition and system control through Hanford's Local Area Network (LAN)

- Facilitate decontamination by minimizing liquid retention

- Withstand temperature ranges up to $100^{\circ} \mathrm{C}$

- Withstand liquid phase $\mathrm{pH}$ ranges from 7 to 14

- Withstand radiation levels up to $1000 \mathrm{R} / \mathrm{hr}$

- Withstand liquid phase flow rates up to $1.0 \mathrm{~m} / \mathrm{s}$

The majority of the in-tank portion of the probe is constructed from 2.5 -cm diameter schedule XXS AISI 304L stainless steel (UNS 30403) pipe for extended service in the waste tank environment. It fits through a nominal $10.2-\mathrm{cm}$ diameter tank riser and is approximately $16 \mathrm{~m}$ in length. The upper $123-\mathrm{cm}$ of the probe is constructed of 9.5 -cm diameter AISI 304L piping filled with low density concrete to serve as a shield plug for the riser. A schematic of the probe is shown in Figure 1. 
The probe has four two-channel electrode arrays. Arrays are positioned at approximately $6.0 \mathrm{~m}, 10 \mathrm{~m}, 13$ $\mathrm{m}$, and $15 \mathrm{~m}$ from the top of the riser. See Table 1 for exact elevations of electrode arrays with respect to the bottom of the tank and to the top of the riser. The eight total channels will allow corrosion monitoring in the vapor space and the supernate phase of the tank. Each channel on the probe utilizes three nominally identical electrodes of either a C-ring (ASTM G-38) or bullet-shaped pin type geometry fabricated from archived ASTM A537-Class 1 tank steel (leftover from the 241-AP farm construction). Pin type electrodes expose approximately $5 \mathrm{~cm}^{2}$ of surface area to the waste. Four channels will utilize pin type electrodes. In addition to pins, four channels will use $\mathrm{C}$-ring electrodes. Each $\mathrm{C}$-ring electrode exposes approximately 44 $\mathrm{cm}^{2}$ of surface area to the waste. C-ring electrodes are also fabricated from archived ASTM A537-Class 1 steel. One electrode of each C-ring array is pre-cracked by cyclic fatigue and strained beyond the proportional limit prior to immersion in the waste to assist in monitoring stress corrosion cracking should it occur. Pre-cracks are approximately $0.5 \mathrm{~mm}$ in depth. The other electrodes will not be strained. A typical electrode array is shown in Figure 2.

A 25-conductor full-shielded data cable extends through the length of the interior of the sealed pipe. At each electrode array, three conductors are removed from the shielding and attached to commercially available glass-lined feed-throughs, one conductor per feed-through. Glass-lined feed-throughs were used to penetrate the probe tree pipe wall while maintaining electrical isolation between the electrodes and the pipe wall. Electrodes are isolated from the glass to metal seal through the use of peroxide cured ethylene propylene (EPDM) gaskets suitable for use in radiation environments. The shielded cable terminates at the top to the probe tree assembly in a weather tight box. Approximately $90 \mathrm{~m}$ of above ground cable runs from the top of the probe to the corrosion monitoring instrumentation located in the 241-AN-271 instrument building. The aboveground cabling utilizes a grounded shield to protect the signal from external electrical interference and will use shunt-diode type intrinsic safety barriers to meet site safety requirements for waste intrusive instrumentation. All intrinsic safety barriers, drain wires and the overall cable shield are grounded to the tank riser at one location.

The corrosion monitoring instrumentation utilizes a DENIS eight channel corrosion monitoring system and associated software manufactured by Capcis March Limited (CML). ${ }^{1}$ The corrosion monitoring system is housed in a weather resistant box measuring approximately $0.6 \mathrm{~m}$ on all sides. This box sits in the 241-AN271 instrument building and is operated remotely via the Hanford LAN. A desktop computer and monitor will sit on top of the instrument for data collection. A schematic of the system is shown in Figure 3.

\section{SUPERNATE SUMMARY STATISTICAL DATA - PRESENTATION AND ANALYSIS}

Although it is not strictly possible to distinguish between forms of corrosion using statistical data alone, statistical analyses of raw data files are useful in identifying time periods of change in corrosion behavior, upsets in the data collection process, or periods of equipment malfunction/failure. Mean potential noise, standard deviation of potential noise, mean current noise, standard deviation of current noise, resistance noise, pitting index, and uniform corrosion rate were calculated for each set of electrodes on the corrosion

${ }^{1}$ DENIS is a registered trademark of Capcis March Ltd., Manchester, UK. 
probe. Each of the points on the summary statistical data plots presented in this report represents a statistical manipulation of 450 raw data points originally collected at one-second intervals on a given channel. Summary statistical data for C-ring electrodes immersed in the supernate phase of the waste (channels 4, 6 and 8), pin type electrodes immersed in the supernate phase of the waste (channels 3,5 and 7), C-ring electrodes exposed to the vapor space above the supernate (channel 2), and pin type electrodes immersed to the vapor space above the supernate (channel 1) will be presented. See Table 1 for exact elevations of electrode arrays with respect to the bottom of the tank and to the top of the riser.

Preliminary inspection of the summary statistical data contained in this report immediately reveals that the dominant features of each plot are periodic disturbances in the data visible throughout the collection period with the exception of the period of time between 11/25/97 and 1/17/98. Since nine months of system operation were allowed to elapse before funding was provided to analyze data, troubleshoot, or monitor system performance, the source of these disturbances has not yet been determined. However, since the disturbances simultaneously appear in both current and potential statistical data at approximately the same time on all channels from the vapor space to the bottom of the tank, it is highly unlikely that these large fluctuations in data are due to corrosion phenomena. Efforts are currently underway to locate the source of these disturbances. Due to the unknown nature of the source of these disturbances and the unknown effects they may have on the data collected to date, this report will focus primarily on data collected during the period of time between $11 / 25 / 97$ and $1 / 17 / 98$ when these disturbances were at a minimum.

Mean Potential Noise- Supernate C-rings (Channels 4, 6 and 8)

Plots of mean potential noise for channels 4,6 and 8 over the first year of operation are shown in Figures $4-6$ respectively. Over the first year of operation, average mean potential values were approximately $1 \mathrm{mV}$, $3 \mathrm{mV}$, and $0 \mathrm{mV}$ for channels 4,6 and 8 respectively. However, these values are corrupted to an unknown degree by data disturbances throughout the collection period. The average mean potential for each channel between $11 / 25 / 97$ and $1 / 17 / 98$ was approximately $0 \mathrm{mV}$.

Since the majority of data points collected to date are suspect to some degree, analyses contained in this document will focus on what appears to be uncorrupted data collected between 11/25/97 and 1/17/98. During this period of time, the trend and behavior of the mean potential noise data were typical of carbon steel electrodes immersed in a high $\mathrm{pH}$, passivating tank waste solution $[26-28,30]$. The initial slopes of the mean potential curves for all three channels are related to initial differences in potential between the pseudo-reference electrode and the counter/working electrode assembly. The electrodes on channel 8 displayed the highest initial potential difference of the C-ring electrodes immersed in the supernate.

Potential differences in electrodes made of the same material are caused by a variety of reasons including differences in surface finish, differences in grain size, differences in grain boundary chemistry, small variations in composition, and in the case of channels 4,6 and 8 , differences in stress levels between electrodes. Since only the working electrode is stressed in each channel, the working electrode in each channel should remain slightly more active than the other two electrodes. Based on the hardware/software settings on the 241-AN-107 EN equipment, the potential difference should settle at a slightly positive value due to the difference in stress between the pseudo-reference electrode and the working/counter assembly. However, as the passive state of the electrodes becomes more stable over time, the potential difference 
between electrodes should continue to decrease. Barring any crack advance or other electrode surface disturbance, passivation and equilibration of potential between electrodes will generally produce a slow movement in mean potential toward a stable value near zero, as seen in Figures $4-6$. If the potential difference were to stay at consistently positive values, it could be an indication that the working electrodes is corroding preferentially with respect to the pseudo-reference electrode and could be suffering from intergranular attack, a precursor for intergranular stress corrosion cracking (IGSCC) in carbon steels [26-28, 30 ]. If the potential difference were to stay consistentiy negative, it could be assumed that the pseudoreference electrode is corroding preferentially to the counter/working electrode assembly and could be suffering from intergranular or other localized attack. In either case, raw data must be examined before making a corrosion mechanism determination. Based on mean potential data, IGSCC and other forms of localized corrosion do not appear to be an immediate concern on the C-ring channels $(4,6$, and 8$)$ on the 241-AN-107 probe.

\section{Standard Deviation of Potential Noise - Supernate C-rings (Channels 4,6 and 8)}

Plots of the standard deviation of potential noise for channels 4,6 and 8 over the first year of operation are shown in Figures 7 - 9 respectively. The average standard deviation of potential value for each channel over the first year of operation was approximately $0.02 \mathrm{mV}$. However, like mean potential these data are also corrupted to an unknown degree by disturbances in the data visible throughout the collection period with the exception of the period of time between $11 / 25 / 97$ and 1/17/98. During the data disruptions, standard deviation of potential reached levels over $3 \mathrm{mV}$. The average standard deviation of potential for each channel between $11 / 25 / 97$ and $1 / 17 / 98$ was approximately an order of magnitude lower than the overall average for the $\mathrm{C}$-ring channels.

During the period of time between $11 / 25 / 97$ and $1 / 17 / 98$, the trend and behavior of the standard deviation of potential noise data were typical of carbon steel electrodes immersed in a high $\mathrm{pH}$, passivating tank waste solution $[26-28,30]$. Small constant values of standard deviation of potential are consistent with uniform corrosion at low rates in passive systems. Any major onset of localized corrosion should cause a disruption in the standard deviation data. Since the only significant disruptions in the standard deviation data are common to all channels, these disruptions are not regarded as being the result of corrosion phenomena.

Standard deviation data proved to be one of the most effective screening tools for data being generated in a similar system in tank 241-AZ-101 [30]. As evidenced by Figures 7-9, no large disturbances in standard deviation of potential data can be observed during the brief period of time the data appears uncorrupted by outside sources. If the assumption is made that the data recorded between 11/25/97 and 1/17/98 is typical of the rest of the operation of the probe, the standard deviation of potential data indicates that uniform corrosion is the dominant corrosion mechanism in tank 241-AN-107 at this time.

Mean Current Noise - Supernate C-rings (Channels 4, 6 and 8)

Mean current noise for channels 4, 6 and 8 over the first year of operation is shown in Figures $10-12$ respectively. Over the first year of operation, average mean current values were approximately $18 \mathrm{nA}, 13$ $\mathrm{nA}$, and $39 \mathrm{nA}$ for channels 4,6 and 8 respectively. However, these values are corrupted to an unknown 
degree by data disturbances throughout the collection period. Between 11/25/97 and 1/17/98, average mean potential values were approximately $10 \mathrm{nA},-4 \mathrm{nA}$, and $6 \mathrm{nA}$ for channels 4,6 and 8 respectively.

Between $11 / 25 / 97$ and $1 / 17 / 98$, the trend and behavior of the mean current noise data were typical of carbon steel electrodes immersed in a high $\mathrm{pH}$, passivating tank waste solution $[26-28,30]$. The initial slopes of the mean current curves for all three channels are related to direction of corrosion current flow due to initial differences in potential between the counter and working electrodes. Since these electrodes are connected to each other through a zero resistance ammeter (ZRA), a potential difference between the two electrodes will set up a current flow between the two electrodes when immersed in a conductive solution.

Potential differences in electrodes made of the same material are caused by a variety of reasons including differences in surface finish, differences in grain size, differences in grain boundary chemistry, small variations in composition, and in the case of channels 4,6 and 8 , differences in stress levels between electrodes. Since only the working electrode is stressed in each channel, the working electrode in each channel should remain slightly more active than the other two electrodes (working electrode is more anodic with respect to unstressed electrodes). Based on the hardware/software settings on the 241-AN-107 EN equipment, the mean current level should settle at a slightly negative value due to the difference in stress between the working and counter electrodes. However, as the passive state of the electrodes becomes more stable over time mean current flowing between the counter and working electrodes should approach zero. Barring any crack advance or other electrode surface disturbance, passivation and equilibration of potential between electrodes will generally produce a slow movement in mean current toward a stable value near zero, as seen in Figures $10-12$. If the mean current levels were to remain consistently negative, it could be assumed that the working electrode is corroding preferentially to the counter electrode and could be suffering from intergranular attack, a precursor for intergranular stress corrosion cracking (IGSCC) in carbon steels $[26-28,30]$. If the mean current levels were to stay consistently positive, it could be assumed that the counter electrode is corroding preferentially to the working electrode and could be suffering from intergranular or other localized attack. In either case, raw data must be examined before making a corrosion mechanism determination. At the present time, mean current data indicates that uniform corrosion is the dominant form of corrosion occurring on the C-ring channels $(4,6$, and 8$)$ on the 241-AN-107 probe.

Standard Deviation of Current Noise - Supernate C-rings (Channels 4, 6 and 8)

Plots of the standard deviation of current noise for channels 4,6 and 8 over the first year of operation are shown in Figures $13-15$ respectively. Interestingly, standard deviation of current noise data did not display the disturbances in data seen throughout the collection period in other statistical parameters. An average of the standard deviation of current data on each channel over the first year of operation and during the period of time between $11 / 25 / 97$ and $1 / 17 / 98$ results in the same value - approximately $41 \mathrm{nA}$. It is not known at this time why the standard deviation of current data have not been affected by the disturbances that have plagued the other data collected to date.

The trend and behavior of the standard deviation of current noise data were typical of carbon steel electrodes immersed in a high $\mathrm{pH}$, passivating tank waste solution [26-28,30]. Systems such as these passivate slowly over time. Higher corrosion rates produce higher levels of standard deviation of current. Therefore, standard deviation data will be larger at the onset of immersion and continue to drop off to smaller and 
smaller values as the electrodes passivate and reach equilibrium. This behavior is evidenced by the negative slopes of the curves shown in Figures 13 - 15. Small values of standard deviation of current are consistent with uniform corrosion at low rates in passive systems. Any major onset of localized corrosion should cause a disruption in the standard deviation data. Since no such disruptions are obvious in the standard deviation of current data collected to date, the standard deviation of current data indicates that uniform corrosion is the dominant corrosion mechanism in tank 241-AN-107 at this time.

Pitting Index - Supernate C-rings (Channels 4, 6 and 8)

The Pitting Index (PI) parameter has a maximum value of 1.0 and is defined as,

$$
\mathrm{PI}=\sigma_{\mathrm{I}} / \mathrm{I}_{\mathrm{ms}}
$$

where $\sigma_{\mathrm{I}}$ is the standard deviation of current and $\mathrm{I}_{\mathrm{rms}}$ is the root mean square of current flowing between the counter and working electrodes. Values of PI close to 1.0 are reported to indicate the onset of localized corrosion, whereas lower values indicate uniform corrosion [6-9]. Plots of PI over the first year of operation are shown for channels 4,6 and 8 in Figures 16 - 18 respectively. The average PI value for each channel over the first year of operation was approximately 0.8 . The average PI value for each channel between $11 / 25 / 97$ and $1 / 17 / 98$ was approximately 1.0 . PI data were the most clearly impacted by the disturbances that affected most of the summary statistical data.

Although high PI values are reported to be, and in many instances are, capable of indicating the occurrence of localized corrosion, the value of $I_{\text {mms }}$ must be taken into account before broad conclusions can be drawn from PI data. Inspection of equation 1 shows that low $I_{\text {ms }}$ current values will also drive PI values up toward 1.0. Thus, as with other statistical data, raw data must be examined and correlated with PI data to get a true feel for what is going on in the system being observed. Although PI data taken alone, especially that collected between 11/25/97 and 1/17/98 would lead to the conclusion that tank 241-AN-107 is suffering from localized corrosion on a grand scale, raw data (to be presented later) demonstrate that this is not case.

Resistance Noise - Supernate C-rings (Channels 4,6 and 8)

The resistance noise $\left(R_{n}\right)$ for a system is defined as,

$$
R_{n}=\sigma_{\text {EPN }} / \sigma_{\mathrm{ECN}}
$$

where $\sigma_{\mathrm{EPN}}$ is the standard deviation of potential and $\sigma_{\mathrm{ECN}}$ is the standard deviation of current. Trends in $R_{\mathrm{n}}$ over the first year of operation for channels 4,6 and 8 are shown in Figures $19-21$ respectively. Over the first year of operation, average $R_{n}$ values were approximately $384 \Omega, 524 \Omega$, and $495 \Omega$ for channels 4,6 
HNF-3414, Rev. 0

and 8 respectively. Between $11 / 25 / 97$ and $1 / 17 / 98$, average $R_{n}$ values were $53 \Omega, 60 \Omega$, and $80 \Omega$ for channels 3,5 and 7 respectively.

The value of $\mathrm{R}_{\mathrm{n}}$ for a system is typically low and stable during uniform corrosion and higher during localized corrosion. The low $R_{n}$ values recorded between $11 / 25 / 97$ and $1 / 17 / 98$ indicate that uniform corrosion is the dominant corrosion mechanism in 241-AN-107.

$R_{n}$ Based Uniform Corrosion Rates - Supernate C-rings (Channels 4, 6 and 8)

Values of $R_{n}$ calculated from EN data can be used in place of $R_{p}$ in conjunction with the Stern-Geary equation and Faraday's laws to calculate uniform corrosion rates. However, when computing corrosion rates from $R_{n}$ data collected on a standard three electrode EN probe, the value of $R_{n}$ must be modified to account for surface area of the electrodes and the fact that the potential noise signal is being collected from two electrodes rather than one. Equation 3 shows $R_{n}$ for use in uniform corrosion rate calculations,

$$
\mathrm{R}_{\mathrm{n}}=\left(\sigma_{\mathrm{EPN}} / \sigma_{\mathrm{ECN}}\right)(\mathrm{A} / \sqrt{ } 2)
$$

where $\sigma_{\mathrm{EPN}}$ is the standard deviation of potential, $\sigma_{\mathrm{ECN}}$ is the standard deviation of current, and $\mathrm{A}$ is the surface area of one electrode. Uniform corrosion rate data is shown for channels 4,6 and 8 in Figures 22 - 24 respectively. Over the first year of operation, average uniform corrosion rates were approximately 6 mpy, 4 mpy, and 4 mpy for channels 4,6 and 8 respectively. Between $11 / 25 / 97$ and $1 / 17 / 98$, uniform corrosion rates were approximately $9 \mathrm{mpy}, 7 \mathrm{mpy}$, and $6 \mathrm{mpy}$ for channels 3,5 and 7 . Since this period of time is characterized by raw data indicative of uniform corrosion, it should produce the most accurate corrosion rate information. Given the nature of the accuracy of uniform corrosion rate determinations made from EN data, a series of more traditional standardized LPR based corrosion rate measurements to verify corrosion rates generated from EN data are needed to add confidence to the EN based results.

Mean Potential Noise- Supernate Pins (Channels 3, 5 and 7)

Plots of mean potential noise for channels 3,5 and 7 over the first year of operation are shown in Figures $25-27$ respectively. Over the first year of operation, average mean potential values were approximately $21 \mathrm{mV}, 9 \mathrm{mV}$, and $13 \mathrm{mV}$ for channels 3,5 and 7 respectively. However, these values are corrupted to an unknown degree by data disturbances throughout the collection period. Between 11/25/97 and 1/17/98, average mean potentials were approximately $18 \mathrm{mV}, 13 \mathrm{mV}$, and $13 \mathrm{mV}$ for channels 3,5 and 7 respectively.

From $11 / 25 / 97$ to $1 / 17 / 98$ the trend and behavior of the mean potential noise data were typical of carbon steel electrodes immersed in a high pH, passivating tank waste solution [26-28,30]. The initial slopes of the mean potential curves for all three channels are related to initial differences in potential between the pseudo-reference electrode and the counter/working electrode assembly. Potential differences in unstressed electrodes made of the same material are caused by a variety of reasons including differences in surface finish, differences in grain size, differences in grain boundary chemistry, and small variations in composition. None of the pin electrodes on channels 3,5 or 7 are stressed. Therefore, as the passive state 
of the electrodes becomes more stable over time the potential difference between electrodes should continue to decrease. Barring any pit initiation or other electrode surface disturbance, passivation and equilibration of potential between electrodes should keep the mean potential close to a value of zero. If the potential difference were to stay consistently positive, it could be an indication that the working or counter electrode is corroding preferentially to the pseudo-reference electrode and could be suffering from intergranular or other localized attack. If the potential difference were to stay consistently negative, it could be assumed that the pseudo-reference electrode is corroding preferentially to the working/counter electrode assembly and could be suffering from intergranular or other localized attack. In either case, raw data must be examined before making a corrosion mechanism determination. At the present time, uniform corrosion appears to be the dominant form of corrosion occurring based on the mean potential data from the pin channels $(3,5$ and 7) on the 241-AN-107 probe.

Standard Deviation of Potential Noise - Supernate Pins (Channels 3, 5 and 7)

Plots of the standard deviation of potential noise for channels 3,5 and 7 over the first year of operation are shown in Figures 28 - 30 respectively. The average standard deviation of potential for each channel over the first year of operation was approximately $1 \mathrm{mV}$. However, like mean potential data these values are also corrupted to an unknown degree by disturbances in the data visible throughout the collection period with the exception of the period of time between 11/25/97 and 1/17/98. During the data disruptions, the standard deviation of potential reached over $14 \mathrm{mV}$. The average standard deviation of potential for each channel between $11 / 25 / 97$ and $1 / 17 / 98$ was approximately $0.5 \mathrm{mV}$.

Between $11 / 25 / 97$ and $1 / 17 / 98$, the trend and behavior of the standard deviation of potential noise data were typical of carbon steel electrodes immersed in a high $\mathrm{pH}$, passivating tank waste solution [26-28,30]. Small constant values of standard deviation of potential are consistent with uniform corrosion at low rates in passive systems. Any major onset of localized corrosion should cause a disruption in the standard deviation data. Since the only significant disruptions in the standard deviation data are common to all channels, these disruptions are not regarded as being the result of corrosion phenomena.

Standard deviation data proved to be one of the most effective screening tools for data being generated in a similar system in tank 241-AZ-101 [30]. As evidenced by Figures $28-30$, no large disturbances in standard deviation of potential data can be observed during the brief period of time the data appears uncorrupted by outside sources. If the assumption is made that the data recorded between 11/25/97 and $1 / 17 / 98$ is typical of the rest of the operation of the probe, the standard deviation of potential data indicates that uniform corrosion is the dominant corrosion mechanism in tank 241-AN-107 at this time.

Mean Current Noise - Supernate Pins (Channels 3, 5 and 7)

Plots of mean current noise for channels 3,5 and 7 over the first year of operation are shown in Figures 31 - 33 respectively. Over the first year of operation, average mean current values were $-3 \mathrm{nA},-7 \mathrm{nA}$, and -5 nA for channels 3, 5 and 7 respectively. However, these values are corrupted to an unknown degree by data disturbances throughout the collection period. Between $11 / 25 / 97$ and 1/17/98, average mean current values were approximately $-3 \mathrm{nA},-1 \mathrm{nA},-2 \mathrm{nA}$ for channels 3,5 and 7 respectively. 
During the period of time between 11/25/97 and 1/17/98, the trend and behavior of the mean current noise data were typical of carbon steel electrodes immersed in a high $\mathrm{pH}$, passivating tank waste solution [26-28, 30]. The initial slopes of the mean current curves for all three channels are related to direction of corrosion current flow due to initial differences in potential between the counter and working electrodes. Since these electrodes are connected to each other through a zero resistance ammeter (ZRA), a potential difference between the two electrodes will set up a current flow between the two electrodes when immersed in a conductive solution. Potential differences in electrodes made of the same material are caused by a variety of reasons including differences in surface finish, differences in grain size, differences in grain boundary chemistry, small variations in composition, and in the case of channels 3,5 and 7, differences in stress levels between electrodes. Since none of the electrodes are stressed in each channel, the working electrode in each channel should be no more active than the other two electrodes. Barring any pit initiation or other electrode surface disturbance, passivation and equilibration of potential between will yield a mean current value of approximately zero. If the mean current levels were to become consistently negative, it could indicate that the working electrode is corroding preferentially to the counter electrode and could be suffering from pitting, intergranular attack, or other localized corrosion. If the mean current levels were to become consistently positive, it could indicate that the counter electrode is corroding preferentially to the working electrode and could be suffering from pitting, intergranular attack or other forms of localized corrosion. Raw data must be reviewed before any corrosion mechanism determination can be made. At the present time, uniform corrosion appears to be the dominant mode of corrosion on the pin channels $(3,5$ and 7$)$ based on mean current noise data.

Standard Deviation of Current Noise - Supernate Pins (Channels 3, 5 and 7)

Plots of the standard deviation of current noise for channels 3,5 and 7 over the first year of operation are shown in Figures $34-36$ respectively. As with the C-ring electrodes, standard deviation of current noise data for the pin electrode channels did not display the disturbances in data seen throughout the collection period in other statistical parameters. An average of the standard deviation of current data on each channel over the first year of operation and during the period of time between $11 / 25 / 97$ and $1 / 17 / 98$ results in the same value - approximately $36 \mathrm{nA}$. It is not known at this time why the standard deviation of current data have not been affected by the disturbances that have plagued the other data collected to date.

The trend and behavior of the standard deviation of current noise data were typical of carbon steel electrodes immersed in a high $\mathrm{pH}$, passivating tank waste solution [26-28,30]. Systems such as this passivate slowly over time. Therefore, standard deviation data will be larger at the onset of immersion and continue to drop off to smaller and smaller values as the electrodes passivate and reach equilibrium. This behavior is evidenced by the negative slopes of the curves shown in Figures $34-36$. Small values of standard deviation of current are consistent with uniform corrosion at low rates in passive systems. Any major onset of localized corrosion should cause a disruption in the standard deviation data. Since no such disruptions are obvious in the standard deviation of current data collected to date, the standard deviation of current data indicates that uniform corrosion is the dominant corrosion mechanism in tank 241-AN-107 at this time. 
HNF-3414, Rev. 0

Pitting Index - Supernate Pins (Channels 3, 5 and 7)

Plots of PI over the first year of operation are shown for channels 3, 5 and 7 in Figures 37 - 39 respectively. The average PI value for each channel over the first year of operation was approximately 1.0 . The average PI value for each channel between $11 / 25 / 97$ and $1 / 17 / 98$ was also approximately 1.0. As with other statistical parameters, PI data were impacted by the data disturbances.

Although high PI values are reported to be, and in many instances are, capable of indicating the occurrence of localized corrosion, the value of $\mathrm{I}_{\text {mss }}$ must be taken into account before broad conclusions can be drawn from PI data. Low $\mathrm{I}_{\mathrm{ms}}$ current values will also drive PI values up toward 1.0. Thus, as with other statistical data, raw data must be examined and correlated with PI data to get a true feel for what is going on in the system being observed. Although PI data taken alone, especially that collected between 11/25/97 and $1 / 17 / 98$ would lead to the conclusion that tank $241-\mathrm{AN}-107$ is suffering from localized corrosion on a grand scale, raw data (to be presented later) demonstrates that this is not case.

Resistance Noise - Supernate Pins (Channels 3, 5 and 7)

Trends in $R_{n}$ over the first year of operation for channels 3, 5 and 7 are shown in Figures $40-42$ respectively. Over the first year of operation, average $R_{n}$ values were $3 \mathrm{k} \Omega, 2 \mathrm{k} \Omega$, and $2 \mathrm{k} \Omega$ for channels 3,5 and 7 respectively. Between $11 / 25 / 97$ and $1 / 17 / 98$, average $R_{n}$ values were approximately $2.5 \mathrm{k} \Omega, 1.5$ $\mathrm{k} \Omega$, and $1.5 \mathrm{k} \Omega$ for channels 3,5 and 7 respectively.

The value of $\mathrm{R}_{\mathrm{n}}$ for a system is typically low and stable during uniform corrosion and higher during localized corrosion. The low $R_{n}$ values recorded between $11 / 25 / 97$ and $1 / 17 / 98$ indicate that uniform corrosion is the dominant corrosion mechanism in 241-AN-107.

$\mathrm{R}_{\mathrm{n}}$ Based Uniform Corrosion Rates - Supernate Pins (Channels 3, 5 and 7)

Values of $R_{n}$ can be used in place of $R_{p}$ in conjunction with the Stern-Geary equation and Faraday's laws to calculate uniform corrosion rates. However, when computing corrosion rates from $R_{n}$ data collected on a standard three electrode EN probe, the value of $R_{n}$ must be modified to account for surface area of the electrodes and the fact that the potential noise signal is being collected from two electrodes rather than one. Uniform corrosion rate data is shown for channels 3, 5 and 7 in Figures $43-45$ respectively. Uniform corrosion rates recorded on the pin electrodes were substantially lower than rates measured using the larger $\mathrm{C}$-ring electrodes. Although electrode area has been compensated for in the calculations, the difference in rates between electrode geometries persists. It is not known why the smaller pin electrodes do not generate the same rate information as the larger $\mathrm{C}$-ring electrodes. Over the first year of operation, average corrosion rates were approximately $0.2 \mathrm{mpy}, 0.4 \mathrm{mpy}$, and 0.7 for channels 3,5 and 7 respectively. Between $11 / 25 / 97$ and $1 / 17 / 98$, average corrosion rates were approximately $0.1 \mathrm{mpy}, 0.2 \mathrm{mpy}$, and $0.2 \mathrm{mpy}$ for channels 3,5 and 7 respectively. Since this period of time is characterized by raw data indicative of uniform corrosion, it should produce the most accurate corrosion rate information. 
Given the nature of the accuracy of uniform corrosion rate determinations made from EN data, it is not wholly appropriate to show corrosion rates to the level of accuracy stated above, especially given the discrepancy between rates generated from $\mathrm{C}$-ring data and pin electrode data. A series of more traditional standardized LPR based corrosion rate measurements to verify corrosion rates generated from EN data are needed to add confidence to the $\mathrm{EN}$ based results.

\section{VAPOR SPACE SUMMARY STATISTICAL DATA - PRESENTATION AND ANALYSIS}

\section{Mean Potential Noise- Vapor Space C-rings (Channel 2)}

A plot of mean potential noise for channel 2 over the first year of operation is shown in Figure 46. The average of mean potential data for the entire exposure was approximately $-4 \mathrm{mV}$. However, this value is corrupted to an unknown degree by data disturbances throughout the collection period. The average of mean potential data collected between $11 / 25 / 97$ and $1 / 17 / 98$ was approximately $0 \mathrm{mV}$.

Since the majority of data points collected to date are suspect to some degree, analyses contained in this document will focus on what appears to be uncorrupted data collected between 11/25/97 and 1/17/98. During this period of time, the trend and behavior of the mean potential noise data on channel 2 were typical of carbon steel electrodes positioned in a low humidity vapor space undergoing uniform corrosion. The low average value and lack of fluctuation of the mean potential collected data between 11/25/97 and 1/17/98 are due to the minimal amount of electrolyte to form a conductive path between surfaces of the pseudo-reference electrode and the counter/working electrode assembly. This behavior mimics the behavior of similar vapor space electrodes contained on the prototype corrosion probe in Hanford tank 241-AZ-101 [30]. The only real disturbances in the data are the result of unknown data disruptions and must be disregarded until a better understanding of their origin is ascertained. If the potential difference were to stay at consistently positive values, it could be an indication that the working electrodes is corroding preferentially with respect to the pseudo-reference electrode and could be suffering from intergranular attack, a precursor for intergranular stress corrosion cracking (IGSCC) in carbon steels [26-28,30]. If the potential difference were to stay consistently negative, it could be assumed that the pseudo-reference electrode is corroding preferentially to the counter/working electrode assembly and could be suffering from intergranular or other localized attack. In either case, raw data must be examined before making a corrosion mechanism determination. At the present time, IGSCC and other forms of localized corrosion do not appear to be an immediate concern on the C-ring channel in the vapor space of 241-AN-107, at least in areas that are not constantly or periodically wetted near the waste surface.

Standard Deviation of Potential Noise - Vapor Space C-rings (Channel 2)

A plot of the standard deviation of potential noise for channel 2 over the first year of operation is shown in Figure 47. The average of standard deviation of potential data over the full year was approximately 0.03 $\mathrm{mV}$. However, like mean potential data this value is also corrupted to an unknown degree by disturbances in the data visible throughout the collection period with the exception of the period of time between $11 / 25 / 97$ and $1 / 17 / 98$. During the data disruptions, standard deviation of potential values reached values 
of over $4 \mathrm{mV}$. The average of standard deviation of potential data between 11/25/97 and 1/17/98 was approximately an order of magnitude lower than the overall average.

Between $11 / 25 / 97$ and $1 / 17 / 98$, the trend and behavior of the standard deviation of potential noise data were typical of carbon steel electrodes located in a relatively dry vapor space environment. Small constant values of standard deviation of potential are consistent with uniform corrosion at low rates. Any major onset of localized corrosion should cause a disruption in the standard deviation data. Since the only significant disruptions in the standard deviation data are common to all channels, these disruptions are not regarded as being the result of corrosion phenomena. No large disturbances in standard deviation of potential data can be observed during the brief period of time the data appears uncorrupted by outside sources. The standard deviation of potential data from channel 2 indicates that uniform corrosion is the dominant corrosion mechanism in the vapor space above tank $241-\mathrm{AN}-107$, at least in areas that are not constantly or periodically wetted near the waste surface.

\section{Mean Current Noise - Vapor Space C-rings (Channel 2)}

A plot of mean current noise for channel 2 over the first year of operation is shown in Figure 48. The average of mean current data for the first year of operation was approximately $-48 \mathrm{nA}$. The average of mean current data collected between $11 / 25 / 97$ and $1 / 17 / 98$ was approximately $-2 \mathrm{nA}$.

Between 11/25/97 and 1/17/98, the trend and behavior of the mean current noise data were typical of carbon steel electrodes in a low humidity vapor space. The low humidity of the environment does not facilitate conductivity between the electrodes. Therefore, mean current values are low. Since only the working electrode is stressed on this channel, it should remain slightly more active than the other two electrodes (working electrode is more anodic with respect to unstressed electrodes). Based on the hardware/software settings on the 241-AN-107 EN equipment, the mean current level should settle at a slightly negative value due to the difference in stress between the working and counter electrodes. If the mean current levels were to remain consistently negative, it could be assumed that the working electrode is corroding preferentially to the counter electrode and could be suffering from intergranular attack, a precursor for intergranular stress corrosion cracking (IGSCC) in carbon steels [26-28, 30]. If the mean current levels were to stay consistently positive, it could be assumed that the counter electrode is corroding preferentially to the working electrode and could be suffering from intergranular or other localized attack. In either case, raw data must be examined before making a corrosion mechanism determination. Mean current noise data collected to date indicates that uniform corrosion is the dominant corrosion mechanism in the vapor space above 241-AN107 , at least in areas that are not constantly or periodically wetted near the waste surface.

\section{Standard Deviation of Current Noise - Vapor Space C-rings (Channel 2)}

A plot of the standard deviation of current noise for channel 2 over the first year of operation is shown in Figure 49. Unlike standard deviation of current noise collected on electrodes immersed in the supernate, standard deviation of current noise data collected on vapor space electrodes displayed the disturbances in data seen throughout the collection period in other statistical parameters. The average of the standard deviation of current data over the first year of operation was $0.7 \mathrm{nA}$. The average of the standard deviation 
of current data between $11 / 25 / 97$ and $1 / 17 / 98$ was $0.2 \mathrm{nA}$. It is not known at this time why the standard deviation of current data is affected in the vapor space but not in the supernate at this time.

The trend and behavior of the standard deviation of current noise data were typical of carbon steel electrodes exposed to a low humidity vapor space environment. Small values of standard deviation of current are consistent with uniform corrosion at low rates. Any major onset of localized corrosion should cause a disruption in the standard deviation data. Since no such disruptions are obvious between 11/25/97 and $1 / 17 / 98$, uniform corrosion is likely the dominant corrosion mechanism in the bulk of the vapor space above tank 241-AN-107, at least in areas that are not constantly or periodically wetted near the waste surface.

Pitting Index - Vapor Space C-rings (Channel 2)

A plot of PI over the first year of operation is shown for channel 2 in Figure 50. The average of all PI values for channel 2 was approximately 0.2 . The average of PI values between $11 / 25 / 97$ and 1/17/98 was also approximately 0.2 .

Although high PI values are reported to be, and in many instances are, capable of indicating the occurrence of localized corrosion, the value of $\mathrm{I}_{\mathrm{ms}}$ must be taken into account before broad conclusions can be drawn from PI data. Low $\mathrm{I}_{\mathrm{mm}}$ current values will also drive PI values up toward 1.0. Thus, as with other statistical data, raw data must be examined and correlated with PI data to get a true feel for what is going on in the system being observed. PI data in conjunction with raw data (to be presented later) demonstrates that uniform corrosion is the dominant corrosion mechanism in the headspace above the waste in tank 241-AN107 , at least in areas that are not constantly or periodically wetted near the waste surface.

Resistance Noise - Vapor Space C-rings (Channel 2)

$R_{n}$ data collected over the first year of operation for channel 2 is shown in Figure 51. The average of $R_{n}$ data collected on channel 2 over the first year of operation was $3 \mathrm{k} \Omega$. The average $R_{n}$ value for the time period ranging from $11 / 25 / 97$ to $1 / 17 / 98$ was approximately $2 \mathrm{k} \Omega$.

The value of $R_{n}$ for a system is typically low and stable during uniform corrosion and higher during localized corrosion. Since $R_{n}$ is a measure of the resistance to charge transfer, electrodes exposed to vapor space environments should display higher $R_{n}$ values than electrodes immersed in highly conductive liquid waste. The low, steady $R_{n}$ values recorded between $11 / 25 / 97$ and $1 / 17 / 98$ indicate that uniform corrosion is the dominant corrosion mechanism in the vapor space above 241-AN-107, at least in areas that are not constantly or periodically wetted near the waste surface.

$\mathrm{R}_{\mathrm{n}}$ Based Uniform Corrosion Rates - Vapor Space C-rings (Channel 2)

As shown in Figure 52, the average corrosion rate for channel 2 over the first year of operation was approximately 0.02 mpy. Data taken only from the time period between $11 / 25 / 97$ and $1 / 17 / 98$ also show a value of approximately $0.02 \mathrm{mpy}$. Given the nature of the accuracy of uniform corrosion rate 
determinations made from EN data, it is fairly ludicrous to show corrosion rates to two decimal places, especially on calculations for vapor space electrodes where solution resistance $\left(R_{\varsigma}\right)$ is substantial but ignored in the present calculation. Stated accuracy is for descriptive purposes only. Although equipment is available, funding to perform suitable measurements of $R_{s}$ for this system has not yet been provided. Similarly, funding has not been made available to verify corrosion rates generated from EN data by conducting a series of more traditional standardized LPR based corrosion rate measurements. These measurements would substantially improve corrosion rate measurements in the vapor space above the waste in Hanford tanks. Based on psychrometric and photographic data from the double shell tanks, actual corrosion rates on wall surfaces in the vapor space above $241-\mathrm{AN}-107$ are likely very low, at least in areas that are not constantly or periodically wetted near the waste surface.

\section{Mean Potential Noise - Vapor Space Pins (Channel 1)}

A plot of mean potential noise for channel 1 over the first year of operation is shown in Figure 53. The average mean potential for channel one over the first year of operation was approximately $-3 \mathrm{mV}$. However, this value is corrupted to an unknown degree by data disturbances throughout the collection period. Between $11 / 25 / 97$ and $1 / 17 / 98$ mean potential averaged $-5 \mathrm{mV}$.

Between $11 / 25 / 97$ and $1 / 17 / 98$, the trend and behavior of the mean potential noise data on channel 1 were typical of carbon steel electrodes positioned in a low humidity vapor space undergoing uniform corrosion. The low average value and lack of significant fluctuation of the mean potential collected data between $11 / 25 / 97$ and $1 / 17 / 98$ are due to the minimal amount of electrolyte to form a conductive path between surfaces of the pseudo-reference electrode and the counter/working electrode assembly. This behavior mimics the behavior of similar vapor space electrodes contained on the prototype corrosion probe in Hanford tank 241-AZ-101 [30]. The only real disturbances in the data are the result of unknown data disruptions and must be disregarded until a better understanding of their origin is ascertained. If the potential difference were to stay at consistently positive values, it could be an indication that the working electrode is corroding preferentially with respect to the pseudo-reference and could be suffering from intergranular or other localized attack. If the potential difference were to stay consistently negative, it could be assumed that the pseudo-reference electrode is corroding preferentially to the counter/working electrode assembly and could be suffering from intergranular or other localized attack. In either case, raw data must be examined before making a corrosion mechanism determination. At the present time, IGSCC and other forms of localized corrosion do not appear to be an immediate concern on the C-ring channel in the vapor space of 241-AN107. Uniform corrosion appears to be the dominant corrosion mechanism occurring on the tank walls of the vapor space, at least in areas that are not constantly or periodically wetted near the waste surface.

Standard Deviation of Potential Noise - Vapor Space Pins (Channel 1)

A plot of the standard deviation of potential noise for channel 1 over the first year of operation is shown in Figure 54. Standard deviation of potential averaged approximately $0.36 \mathrm{mV}$ over the first year of operation. However, like mean potential data this value is also corrupted to an unknown degree by distarbances in the data visible throughout the collection period with the exception of the period of time between 11/25/97 and $1 / 17 / 98$. During the data disruptions, standard deviation of potential values reached values of over $30 \mathrm{mV}$. 
Between $11 / 25 / 97$ and $1 / 17 / 98$, the average value of mean potential was approximately half of the overall average.

Between $11 / 25 / 97$ and $1 / 17 / 98$, the trend and behavior of the standard deviation of potential noise data were typical of carbon steel electrodes located in a relatively dry vapor space environment. Small constant values of standard deviation of potential are consistent with uniform corrosion at low rates. Any major onset of localized corrosion should cause a disruption in the standard deviation data. Since the only significant disruptions in the standard deviation data are common to all channels, these disruptions are not regarded as being the result of corrosion phenomena. No large disturbances in standard deviation of potential data can be observed during the brief period of time the data appears uncorrupted by outside sources. The standard deviation of potential data from channel 1 indicates that uniform corrosion is the dominant corrosion mechanism in the vapor space above tank 241-AN-107 at this time, at least in areas that are not constantly or periodically wetted near the waste surface.

Mean Current Noise - Vapor Space Pins (Channel 1)

A plot of mean current noise for channel 1 over the first year of operation is shown in Figure 55. The average of mean current data for the first year of operation was approximately $-0.6 \mathrm{nA}$. The average of mean current data collected between $11 / 25 / 97$ and $1 / 17 / 98$ was approximately $-1 \mathrm{nA}$.

Between $11 / 25 / 97$ and $1 / 17 / 98$, the trend and behavior of the mean current noise data were typical of carbon steel electrodes in a low humidity vapor space. The low humidity of the environment does not facilitate conductivity between the electrodes. Therefore, mean current values are low. Since none of the electrodes are stressed on this channel, mean current should stabilize around zero. If the mean current levels were to remain consistently negative, it could be assumed that the working electrode is corroding preferentially to the counter electrode and could be suffering from intergranular attack or other localized attack. If the mean current levels were to stay consistently positive, it could be assumed that the counter electrode is corroding preferentially to the working electrode and could be suffering from intergranular or other localized attack. In either case, raw data must be examined before making a corrosion mechanism determination. Mean current noise data collected to date indicates that uniform corrosion is the dominant corrosion mechanism on the wall surface in the vapor space above $241-\mathrm{AN}-107$, at least in areas that are not constantly or periodically wetted near the waste surface.

Standard Deviation of Current Noise - Vapor Space Pins (Channel 1)

A plot of the standard deviation of current noise for channel 1 over the first year of operation is shown in Figure 56. Unlike standard deviation of current noise collected on electrodes immersed in the supernate, standard deviation of current noise data collected on vapor space electrodes displayed the disturbances in data seen throughout the collection period in other statistical parameters. However, the effects of these disturbances were not as severe on the pin type electrodes of channel 1 as they were on the C-ring electrodes on channel 2. The average of the standard deviation of current data over the first year of operation was 0.2 $\mathrm{nA}$. The average of the standard deviation of current data between $11 / 25 / 97$ and $1 / 17 / 98$ was also $0.2 \mathrm{nA}$. 
The trend and behavior of the standard deviation of current noise data were typical of carbon steel electrodes exposed to a low humidity vapor space environment. Small values of standard deviation of current are consistent with uniform corrosion at low rates. Any major onset of localized corrosion should cause a disruption in the standard deviation data. Since no such disruptions are obvious between 11/25/97 and $1 / 17 / 98$, uniform corrosion is likely the dominant corrosion mechanism on the wall surfaces of the vapor space above tank $241-\mathrm{AN}-107$ waste, at least in areas that are not constantly or periodically wetted near the waste surface.

Pitting Index - Vapor Space Pins (Channel 1)

A plot of PI over the first year of operation is shown for channel 1 in Figure 57. The average of PI data over the first year of operation was approximately 0.2 . The average of PI data collected between 11/25/97 and $1 / 17 / 98$ was also approximately 0.2 .

Although high PI values are reported to be, and in many instances are, capable of indicating the occurrence of localized corrosion, the value of $\mathrm{I}_{\mathrm{mm}}$ must be taken into account before broad conclusions can be drawn from PI data. Low $\mathrm{I}_{\mathrm{mms}}$ current values will also drive PI values up toward 1.0. Thus, as with other statistical data, raw data must be examined and correlated with PI data to get a true feel for what is going on in the system being observed. PI data in conjunction with raw data (to be presented later) demonstrates that uniform corrosion is the dominant corrosion mechanism in the headspace above the waste in tank 241-AN107 , at least in areas that are not constantly or periodically wetted near the waste surface.

Resistance Noise - Vapor Space Pins (Channel 1)

$R_{n}$ data collected over the first year of operation for channel 1 is shown in Figure 58. The average of $R_{n}$ data collected on channel 1 over the first year was approximately $2 M \Omega$. The average of $R_{n}$ data collected between $11 / 25 / 97$ and $1 / 17 / 98$ was approximately $1 \mathrm{M} \Omega$.

The value of $R_{n}$ for a system is typically low and stable during uniform corrosion and higher during localized corrosion. Since $R_{n}$ is a measure of the resistance to charge transfer, electrodes exposed to vapor space environments should display higher $R_{n}$ values than electrodes immersed in highly conductive liquid waste. The lower $R_{n}$ values recorded between $11 / 25 / 97$ and $1 / 17 / 98$ indicate that uniform corrosion is the dominant corrosion mechanism in 241-AN-107, at least in areas that are not constantly or periodically wetted near the waste surface.

$R_{n}$ Based Uniform Corrosion Rates - Vapor Space Pins (Channel 1)

As shown in Figure 59, the average corrosion rate for channel 1 over the first year of operation was approximately 0.002 mpy. The average of data taken between $11 / 25 / 97$ and $1 / 17 / 98$ was approximately $0.001 \mathrm{mpy}$. Given the nature of the accuracy of uniform corrosion rate determinations made from EN data, it is ridiculous to show corrosion rates to three decimal places, especially on calculations for vapor space electrodes where solution resistance $\left(R_{s}\right)$ is substantial but ignored in the present calculation. Stated 
accuracy is for descriptive purposes only. Although equipment is available, funding to perform suitable measurements of $R_{s}$ for this system has not yet been provided. Similarly, funding has not been made available to verify corrosion rates generated from EN data by conducting a series of more traditional standardized LPR based corrosion rate measurements. These measurements would substantially improve corrosion rate measurements in the vapor space above the waste in Hanford tanks. Based on psychrometric and photographic data from the double shell tanks, actual corrosion rates on wall surfaces in the vapor space above 241-AN-107 are likely very low, at least in areas that are not constantly or periodically wetted near the waste surface.

\section{RAW DATA - PRESENTATION AND ANALYSIS}

One of the greatest potential problems with the use of $\mathrm{EN}$ as a corrosion monitoring technique is the large volume of raw data produced. Since over 67,000 raw data files with 450 points of data per file have been collected to date on the 241-AN-107 corrosion monitoring system, it is not practical or necessary to present all the raw data. However, it is possible to present representative data from each channel. Prior to the selection of the files for presentation, many of the raw data files were analyzed, especially those in the period of time between $11 / 25 / 97$ and $1 / 17 / 98$ and at the start of some of the larger disruptions in data. None of the raw data files examined to date have presented any substantial indication of localized corrosion, either stress corrosion cracking or pitting. Based on this analysis, uniform corrosion is most likely the dominant mode of corrosion occurring in tank 241-AN-107.

Raw data will be presented in sets of two plots per figure, a plot of potential versus time followed by a plot of current versus time. Time scales are the same on all plots. Each plot displays 450 points collected at one second intervals. Plots are full scaled for maximum detail in each case. Figures $60-72$ present representative raw current and potential data collected from the pin type electrodes in the vapor space from each month of operation on channel 1. Figures $73-85$ present representative raw current and potential data collected from the C-ring type electrodes in the vapor space from each month of operation on channel 2. Figures 86 - 98 present representative raw current and potential data collected from the pin type electrodes immersed in the supernate from each month of operation on channel 3. Figures $99-111$ present representative raw current and potential data collected from the C-ring type electrodes immersed in the supernate from each month of operation on channel 4. Figures 112 - 124 present representative raw current and potential data collected from the pin type electrodes immersed in the supernate from each month of operation on channel 5. Figures 125 - 137 present representative raw current and potential data collected from the C-ring type electrodes immersed in the supernate from each month of operation on channel 6. Figures $138-150$ present representative raw current and potential data collected from the pin type electrodes immersed in the supernate from each month of operation on channel 7. Figures $151-163$ present representative raw current and potential data collected from the C-ring type electrodes immersed in the supernate from each month of operation on channel 8 .

\section{RECOMMENDATIONS FOR FUTURE WORK}

The 241-AN-107 corrosion monitoring system is a "one of a kind" system. Up until September 1997, no full scale EN based corrosion monitoring system had ever been installed or operated in a defense nuclear 
waste tank environment anywhere in the world. Despite the obvious complexity of getting such a system to operate properly, funding for the project only covered the design, fabrication and installation activities. Funding for troubleshooting and data analysis was not provided for 10 months following installation. The most obvious result of this shortcoming is the corruption of most of the data collected to date by an unknown electrical or mechanical disturbance or malfunction of the EN equipment or surrounding equipment. The most obvious priority for the future is identifying and eliminating the data disruptions without compromising the quality of the raw data. Review of tank farm records, system process and electrical diagrams, and operator logbooks will be required in this effort. Electrical troubleshooting of the EN equipment and other adjacent and nearby equipment will also be necessary. Other recommendations to improve the functionality of the system are as follows:

- Using the installed cables and equipment, verify the ability of the EN equipment to accurately measure a known current and voltage source representative of the signal magnitudes generated by the corroding electrodes within the tank. Simple constant current and constant voltage sources could be used for this operation. Values should be in the range of a few millivolts and a few hundred nanoamps. Constant current and voltage sources should be measured through the cable and through the intrinsic safety barriers that are installed on the cables. It is essential to know that signal loss is not substantial over the long length of cable and through the intrinsic safety barriers before any faith can be put in the EN measurements.

- Perform a series of standardized LPR tests to determine uniform corrosion rates at different levels within the waste tank. Compare the results of the LPR tests with corrosion rates calculated from EN data to critically assess the ability to use EN data for the purpose of calculating corrosion rates in the future.

- Using the data collected from the standardized LPR tests, determine the reasons behind the difference in corrosion rates calculated from EN data from pin electrodes $\left(5 \mathrm{~cm}^{2}\right)$ and C-ring electrodes $\left(44 \mathrm{~cm}^{2}\right)$.

- A series of laboratory tests to better understand EN data collected from the vapor space above the waste should be conducted. No laboratory work on EN electrodes in simulated nuclear waste tank vapor spaces has been conducted. Therefore, analysis of existing vapor space corrosion data is difficult if not impossible. During this work, more accurate estimations of $R_{s}$ and other parameters necessary for understanding vapor space corrosion rates should also be determined. Similarly, the minimum level of moisture in the vapor space necessary to allow corrosion signal measurement should be established.

- Automate data analysis. Data analysis on the 241-AN-107 system is currently manually performed using spreadsheets and graphing packages. Software that is capable of automating some of the data preparation for analysis would reduce the time necessary for analysis.

\section{CONCLUSIONS}

- An eight-channel EN based corrosion monitoring system was successfully designed, fabricated and installed into double-shell tank 241-AN-107 in September 1997. This system has collected over 67,000 data files and has operated reliably for approximately one year. It is a "first of its kind" system in the world and could prevent unnecessary sodium hydroxide additions to tank 241-AN-107.

- Most of the data collected to date is suspected of being corrupted to some degree by an unknown source of interference. Since data on all channels is affected periodically at approximately the same time, it is assumed that the source of these disruptions is external to the tank and not related to corrosion of the 
tank. Because the degree of corruption caused by these disturbances is unknown, the source of these disruptions must be found and eliminated before accurate data collection can be assured.

- Standard deviation of current summary statistical data for both pin and C-ring type electrodes were not disrupted by the external data interferences. All other summary statistical data files were impacted by these disturbances at one point or another.

- Data collected between 11/25/97 and 1/17/98 do not appear to be affected by the disturbances and signal interference that plague much of the rest of the data collected to date. Both summary statistical data and raw data collected during this time period indicate that uniform corrosion is the dominant active corrosion mechanism in tank 241-AN-107.

- Both summary statistical data and raw data collected during periods of data disruption and disturbance also indicate that uniform corrosion is the dominant active corrosion mechanism in tank 241-AN-107.

- Despite correction for surface area differences, uniform corrosion rates calculated from noise data collected on small pin-type electrodes (channels 3, 5 and 7) do not agree with uniform corrosion rates determined from noise data collected on larger C-ring electrodes (channels 4,6 and 8). Between $11 / 25 / 97$ and $1 / 17 / 98$, C-rings in the supernate showed an average uniform corrosion rate of approximately $7 \mathrm{mpy}$. Pin electrodes in the supernate over the same time period showed a uniform corrosion rate of less than $1 \mathrm{mpy}$. Which value is correct and the source of the difference have not yet been determined.

- Similar raw and statistical data were collected from each of the three C-ring channels immersed in the supernate. Similar raw and statistical data were collected from each of the three pin-type electrodes immersed in the supernate. This suggests that the waste is chemically homogeneous and not vertically stratified to a significant extent in 241-AN-107.

- Discovery and elimination of the source of the data disturbances and the conduction of standardized LPR tests to confirm uniform corrosion rates would likely return the full functionality of the 241-AN-107 corrosion monitoring system.

\section{ACKNOWLEDGMENTS}

This work represents the cooperative efforts of many people and organizations from extremely diverse backgrounds and ranges of interest. Without the collaborative efforts of these individuals, there would still be no corrosion monitoring at the Hanford Site. The laboratory tests leading to the development of this system were conducted over the course of four years by personnel from the Materials and Corrosion Engineering group within Lockheed Martin Hanford Corporation, the Corrosion Science and Technology Group at Oak Ridge National Laboratory, and the Materials Development group of the Structural Materials Research Section at Pacific Northwest National Laboratory. Much of the design and fabrication of the down-hole system and aboveground cabling was performed by Mr. Troy Stokes, Mr. Mike Gimera and others at Hiline Engineering \& Fabrication. The technical support of Mr. J. L. Nelson of Lockheed Martin Hanford Corporation, Dr. G. E. C. Bell of M. J. Schiff \& Associates, Dr. K. E. Lawson of The Mentor_1 Group, Dr. A. N. Rothwell of $\mathrm{C}^{3} \mathrm{Ltd}$., is also gratefully acknowledged. 


\section{REFERENCES}

[1] P.C. Ohl, J.D. Thomson, and F.R. Vollert, "Corrosion Considerations for Life Management of Hanford High Level Waste Tanks", CORROSION/94, paper no. 142, (Houston, TX: NACE International, 1994).

[2] D.C. Lini, "Compilation of Hanford Corrosion Studies", Atlantic Richfield Hanford Company Report, ARH-ST-111, UC-70, July, 1975.

[3] J.R. Divine, W.M. Bowen, D.B. Mackey, D.J. Bates, and, K.H. Pool, "Prediction Equations for Corrosion Rates of A537 and A516 Steels in Double Shell Slurry, Future PUREX, and Hanford Facilities Wastes", Pacific Northwest Laboratory Report, PNL-5488, June, 1985.

[4] W.C Carlos, "Recommendations for Erosion/Corrosion Allowance for Multi-Function Waste Tank Facility Tanks", CORROSION/95, paper no. 449, (Houston, TX: NACE International, 1995).

[5] U. Bertocci, "Electrochemical Noise Analysis and Its Application to Corrosion", CORROSION/89, paper no. 24, (Houston, TX: NACE International, 1989).

[6] J.L. Dawson, D.M. Farrell, P.J. Aylott, and K. Hladky, "Corrosion Monitoring Using Electrochemical Noise Measurements", CORROSION/89, paper no. 31, (Houston, TX: NACE International, 1989).

[7] D.A. Eden, A. N. Rothwell, and J.L. Dawson, "Electrochemical Noise for Detection of Susceptibility to Stress Corrosion Cracking", CORROSION/91, paper no. 444, (Houston, TX: NACE International, 1991).

[8] D.M. Farrell, Industrial Corrosion 9, (1991): p. 7.

[9] A.N. Rothwell, T.G. Walsh, and W.M. Cox, "On Line Corrosion Investigation and Surveillance Chemical Plant Case Studies", CORROSION/91, paper no. 170, (Houston, TX: NACE International, 1991).

[10] J.L. Dawson, et al., "On-line Monitoring of Continuous Process Plants", ed. D. Butcher, (Ellis Horwood, NY, 1983).

[11] D.M. Farrell, W.M. Cox, and D. Gearey, "Multi-System Corrosion Monitoring in a Cyclic Reheat Test Facility; Phase 1", Electric Power Research Institute Report, CS-5776, 1988.

[12] D.M. Farrell, W.M. Cox and D. Gearey, "Multi-System Corrosion Monitoring in FGD Systems; Phase 2", Electric Power Research Institute Report, CS-5734, 1988. 
[13] B.C. Syrett and W.M. Cox, in: Proc. First Int. Symposium on Electrochemical Noise Measurements for Corrosion Applications, ASTM STP 1277, eds. J.R. Kearns, J.R. Scully, P.R. Roberge, D.L. Reichert, and J.L. Dawson, (American Society for Testing and Materials, Philadelphia, PA, 1996) p. 173.

[14] C.A. Lotto and R.A. Cottis, Corrosion 45, (1989): p. 136.

[15] J. B. Esposito, D. H. Roarty, S. A. Tarabek, G. P. Quirk, and K. E. Lawson in: Proc. of Int. Symposium on Plant Aging and Life Predictions of Corrodible Structures, (May 15 - 18, 1995, Sapporo, Japan)

[16] A. Legat and V. Dolecek, "Corrosion Monitoring System Based on Measurements and Analysis of Electrochemical Noise", CORROSION/94, paper no. 319, (Houston, TX: NACE International, 1994).

[17] P. C. Pistorius, Corrosion 53, (1997): p. 273.

[18] D. A. Eden, "Electrochemical Noise - The First Two Octaves", CORROSION/98, paper no. 386, (Houston, TX: NACE International, 1998).

[19] M. Bemish, J. Sikora, E. Sikora, B. A. Shaw, "A New Electrochemical Noise Technique for Monitoring the Localized Corrosion of 304 Stainless Steel in Chloride-Containing Solutions", CORROSION/98, paper no. 370, (Houston, TX: NACE International, 1998).

[20] M. Tullmin and C. M. Hanson, "Electrochemical Noise Measurements on Carbon and Stainless Steel Reinforcing Steels", CORROSION/98, paper no. 372, (Houston, TX: NACE International, 1998).

[21] K. Hladky and J. L. Dawson, Corrosion Science 23, (1982): p. 231.

[22] Y. Watanabe and T. Kondo, "Current and Potential Fluctuation Characteristics in IGSCC Processes of Stainless Steels", CORROSION/98, paper no. 376, (Houston, TX: NACE International, 1998).

[23] J.L. Nelson, "Hanford DST Corrosion Monitoring Instrument Tree", CORROSION/95, paper no. 440, (Houston, TX: NACE International, 1995).

[24] R.K. Shukla, A.J. Perkins, P.M. Bourgeois, R.J. Jaramins, W.G. Secen, and, D.J. Stroud, "Corrosion Monitoring of High Level Waste Storage Tank 8-D2 at the West Valley Demonstration Project", CORROSION/94, paper no. 121, (Houston, TX: NACE International, 1994).

[25] J.I. Mickalonis, R.J. Jacko, G.P. Quirk, and D.A. Eden, in: Proc. First Int. Symposium on Electrochemical Noise Measurements for Corrosion Applications, ASTM STP 1277, eds. J.R. Kearns, J.R. Scully, P.R. Roberge, D.L. Reichert, and J.L. Dawson, (American Society for Testing and Materials, Philadelphia, PA, 1996) p. 201. 
[26] G.L. Edgemon and G.E.C. Bell, "Technical Basis for Electrochemical Noise Based Corrosion Monitoring of Underground Nuclear Waste Storage Tanks", Westinghouse Hanford Company Report, WHC-SD-WM-TI-772, November, 1996.

[27] G. L. Edgemon, M. J. Danielson, G. E. C. Bell, J. Nuc. Mat'l 245, (1997): p. 201.

[28] G.L. Edgemon, P.C. Ohl, G.E.C. Bell, and D.F. Wilson, "Detection of Localized and General Corrosion of Mild Steel in Simulated Defense Nuclear Waste Solutions Using Electrochemical Noise Analysis", Westinghouse Hanford Company Report, WHC-SA-3016-FP, 1995.

[29] L. Beaunier, J. Frydman, C. Gabrielli, F. Huet, M. Keddam, in: Proc. First Int. Symposium on Electrochemical Noise Measurements for Corrosion Applications, ASTM STP 1277, eds. J.R. Kearns, J.R. Scully, P.R. Roberge, D.L. Reichert, and J.L. Dawson, (American Society for Testing and Materials, Philadelphia, PA, 1996) p. 114.

[30] G.L. Edgemon, J.L. Nelson, P.C. Ohl, and G.E.C. Bell, "Hanford Prototype Corrosion Probe Operational Experience", CORROSION/97, paper no. 124, (Houston, TX: NACE International, 1997).

[31] D. L. Reichert in: Proc. First Int. Symposium on Electrochemical Noise Measurements for Corrosion Applications, ASTM STP 1277, eds. J.R. Kearns, J.R. Scully, P.R. Roberge, D.L. Reichert, and J.L. Dawson, (American Society for Testing and Materials, Philadelphia, PA, 1996) p. 79.

\section{TABLES}

TABLE 1: CHANNEL ELEVATIONS FOR 241-AN-107 CORROSION PROBE

\begin{tabular}{|c|c|c|c|}
\hline Channel & Electrode Type & Distance from Riser Top (m) & Distance from Tank Bottom (m) \\
\hline 1 & Pin & 6.0 & 10.9 \\
\hline 2 & C-ring & 6.2 & 10.7 \\
\hline 3 & Pin & 10.3 & 6.6 \\
\hline 4 & C-ring & 10.4 & 6.5 \\
\hline 5 & Pin & 12.7 & 4.2 \\
\hline 6 & C-ring & 12.9 & 4.0 \\
\hline 7 & Pin & 15.5 & 1.5 \\
\hline 8 & C-ring & 15.6 & 1.4 \\
\hline
\end{tabular}




\section{FIGURES}

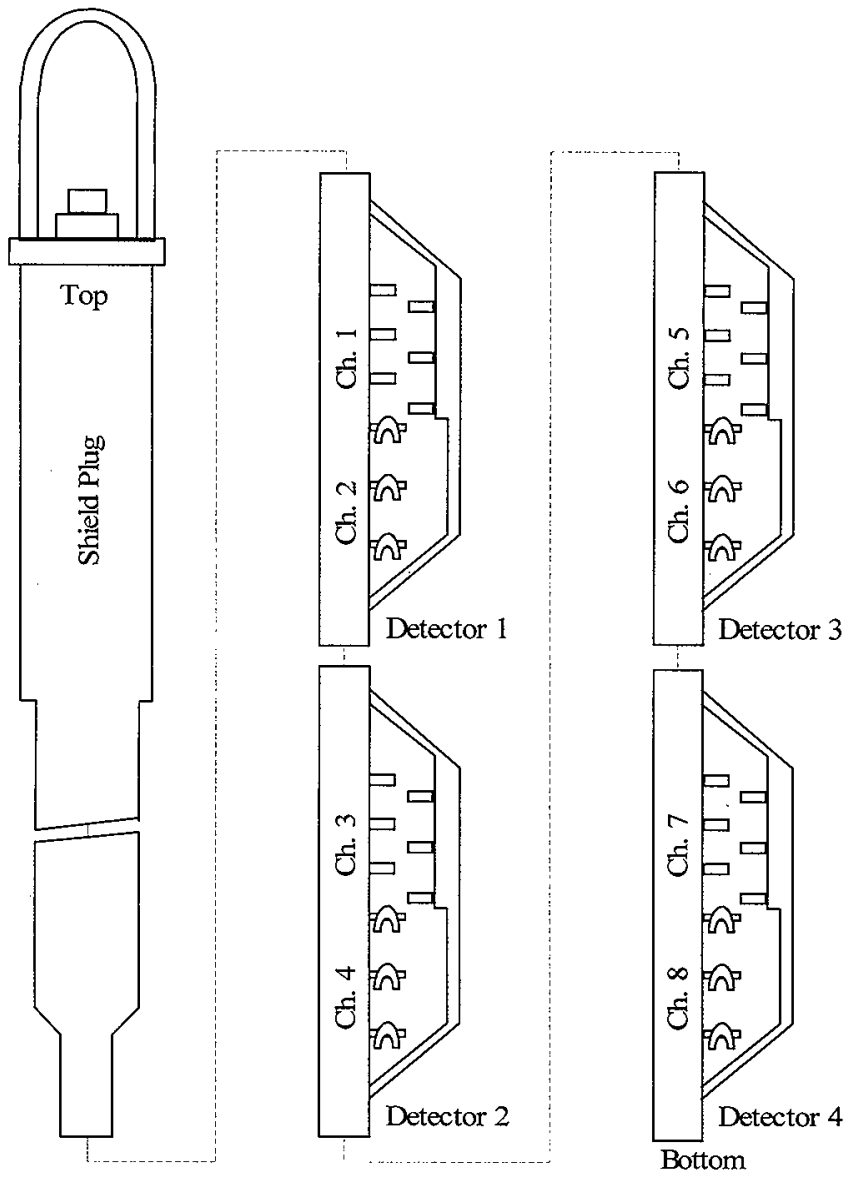

Figure 1: Schematic of 241-AN-107 corrosion probe body 


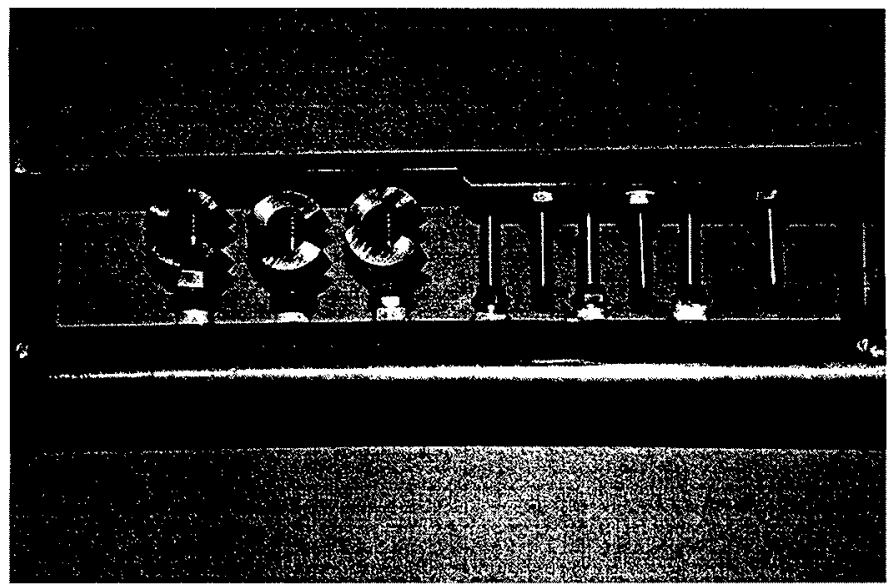

Figure 2: Corrosion probe electrode array detail

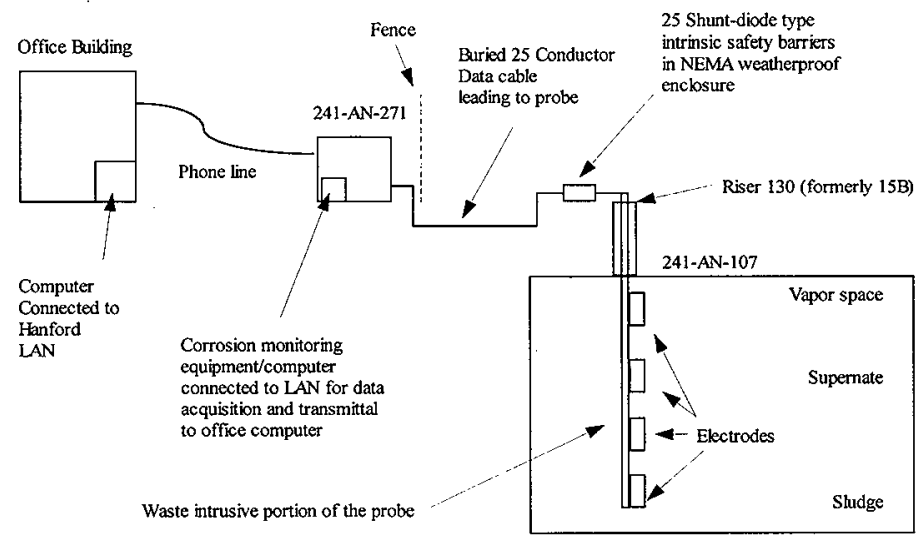

Figure 3: Schematic of 241-AN-107 electrochemical noise based corrosion monitoring system 


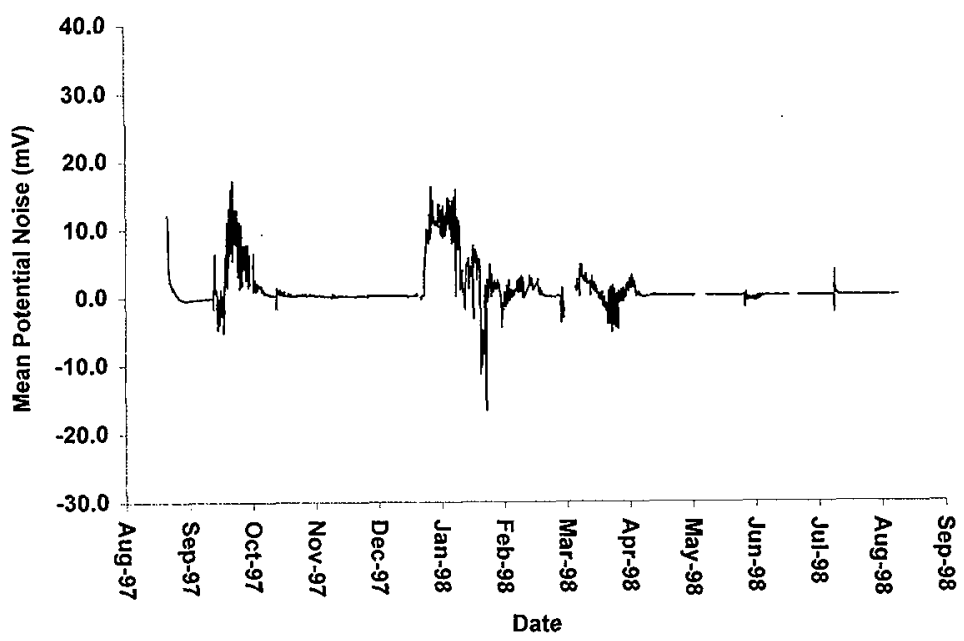

Figure 4: Mean potential noise for C-ring electrodes on channel $4(6.5 \mathrm{~m}$ from tank floor)

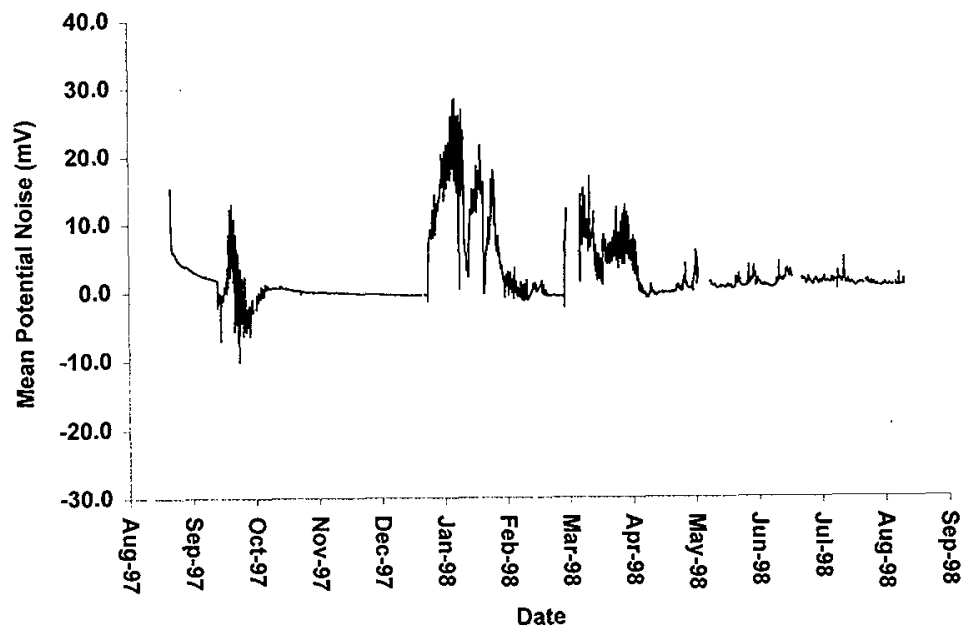

Figure 5: Mean potential noise for C-ring electrodes on channel 6 ( $4.0 \mathrm{~m}$ from tank floor) 

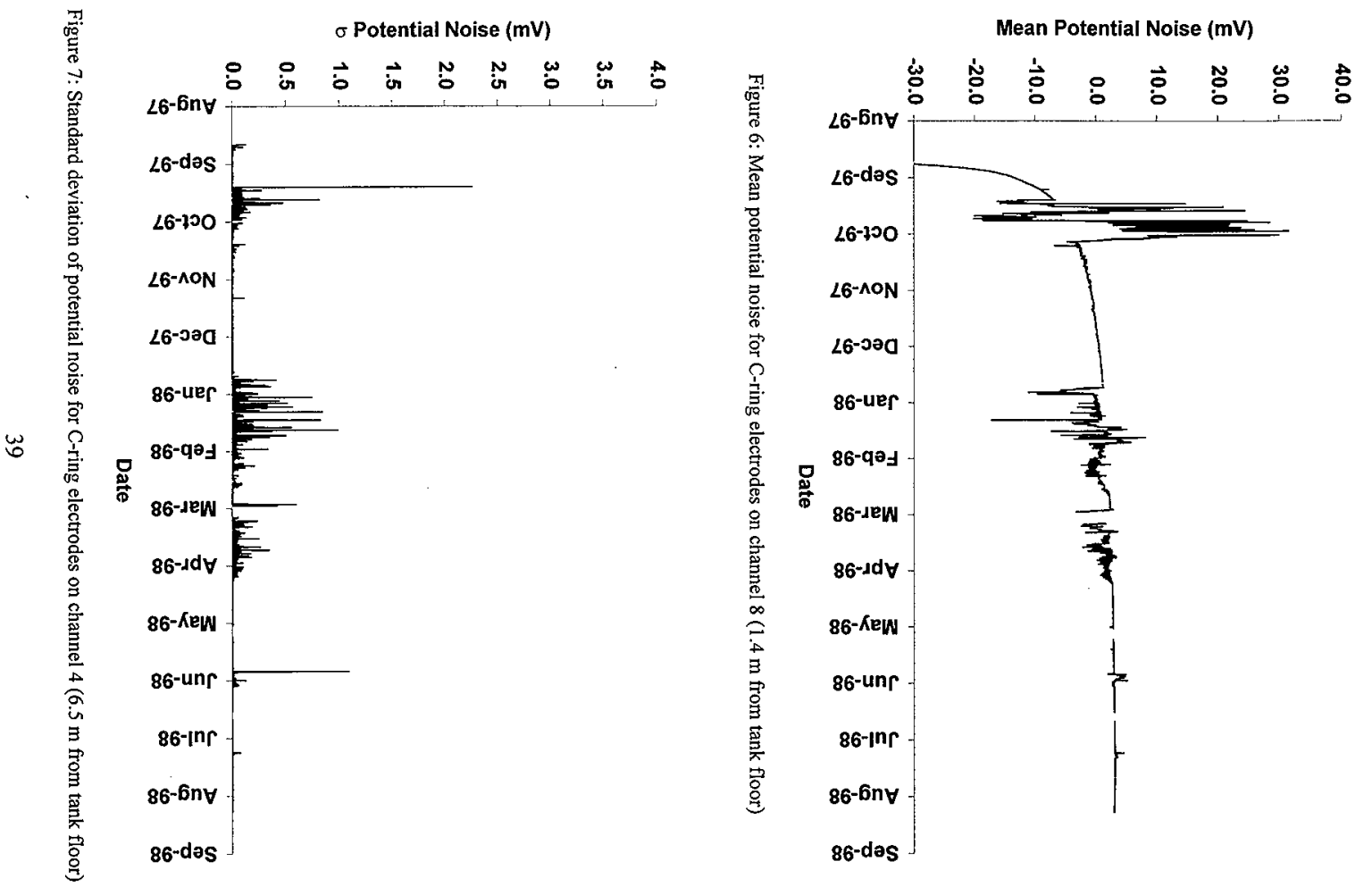


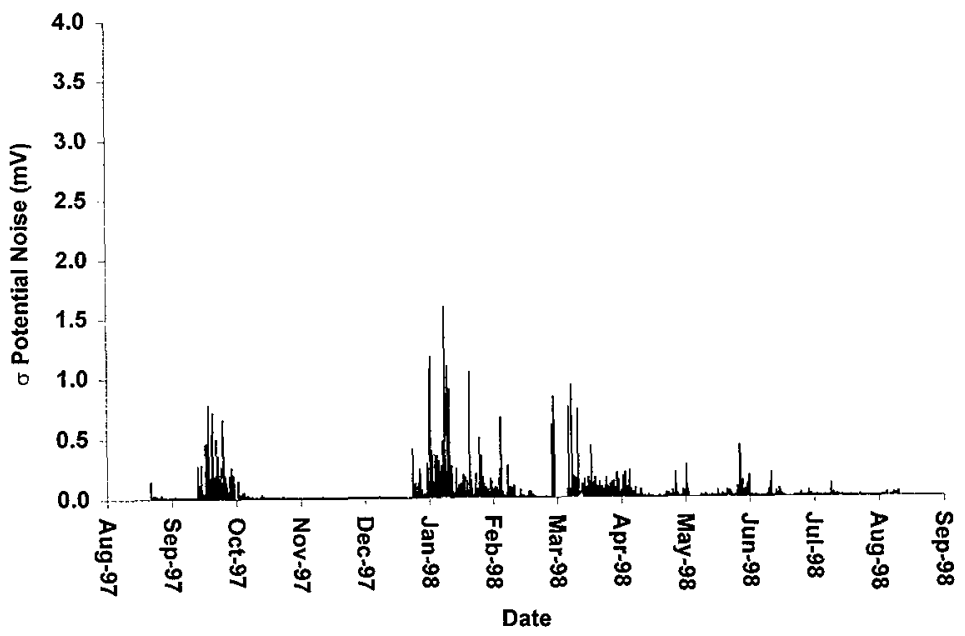

Figure 8: Standard deviation of potential noise for C-ring electrodes on channel 6 (4.0 $\mathrm{m}$ from tank floor)

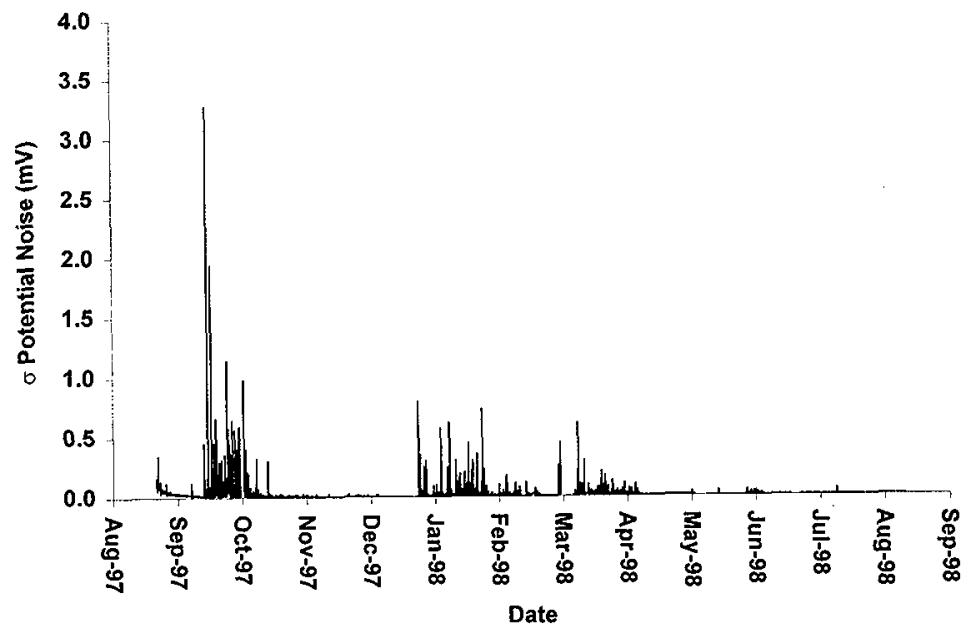

Figure 9: Standard deviation of potential noise for C-ring electrodes on channel 8 (1.4 m from tank floor) 

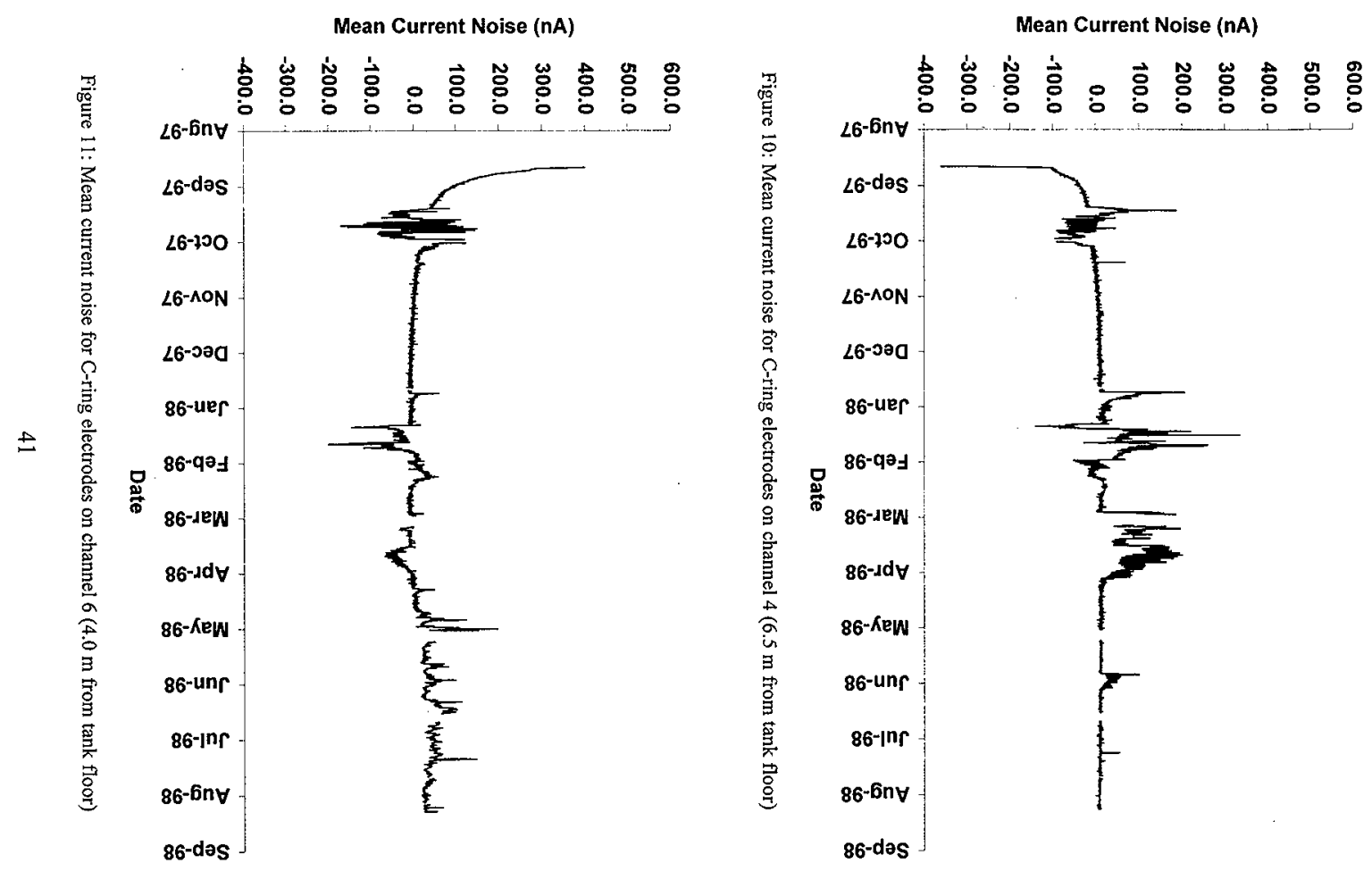


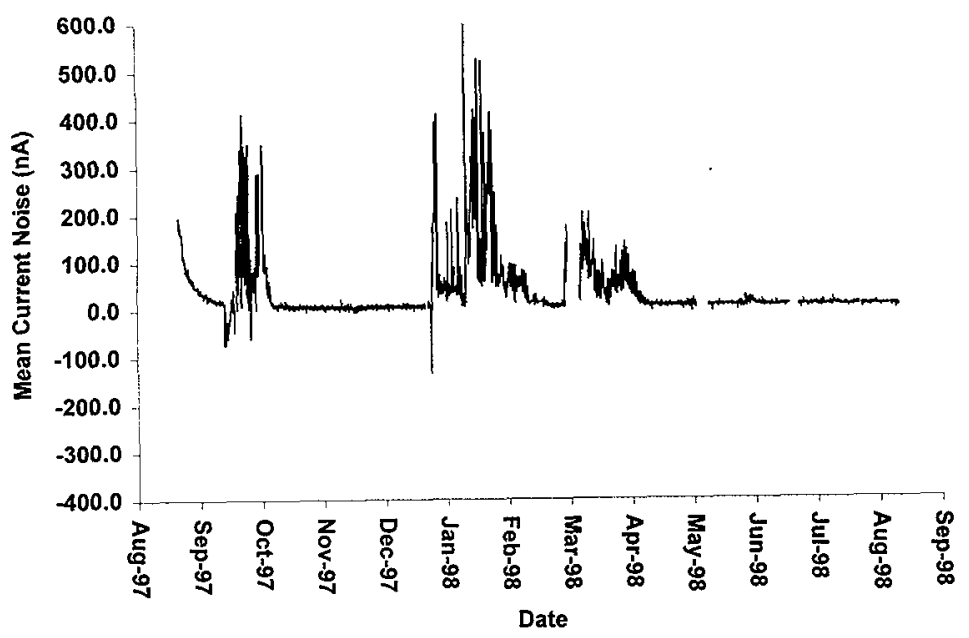

Figure 12: Mean current noise for C-ring electrodes on channel 8 (1.4 m from tank floor)

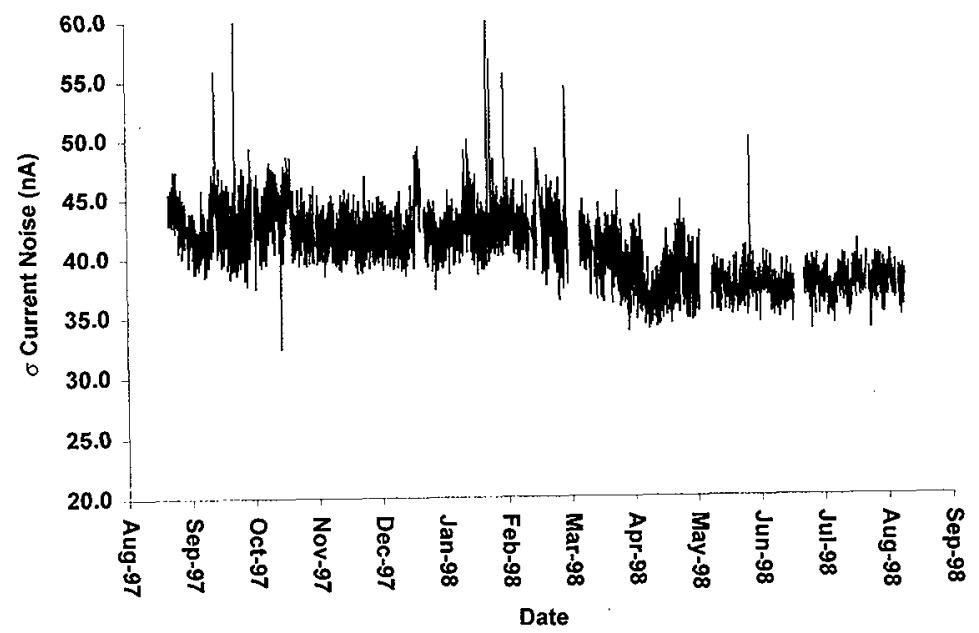

Figure 13: Standard deviation of current noise for C-ring electrodes on channel 4 ( $6.5 \mathrm{~m}$ from tank floor) 


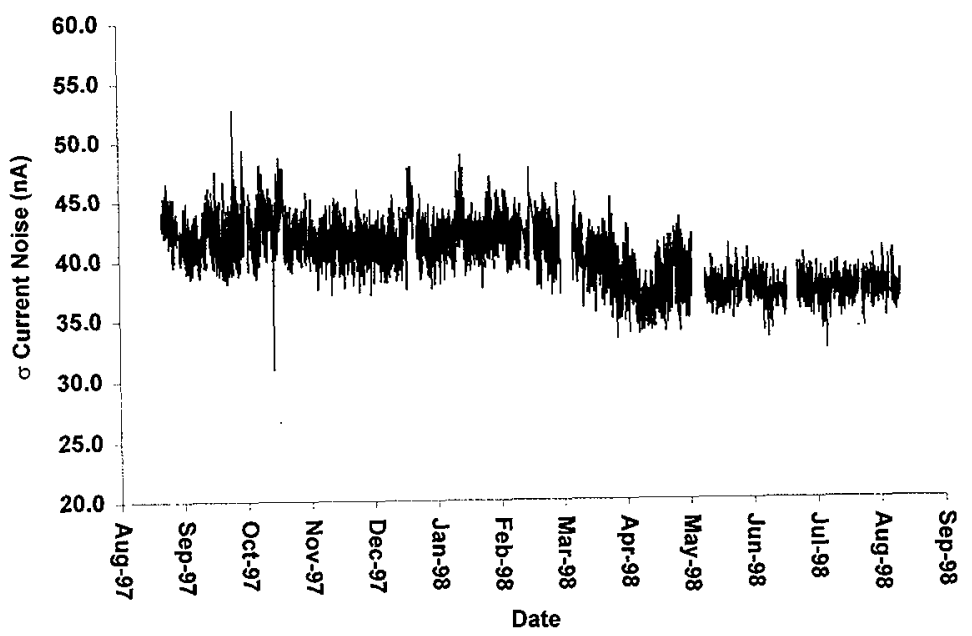

Figure 14: Standard deviation of current noise for C-ring electrodes on channel 6 ( $4.0 \mathrm{~m}$ from tank floor)

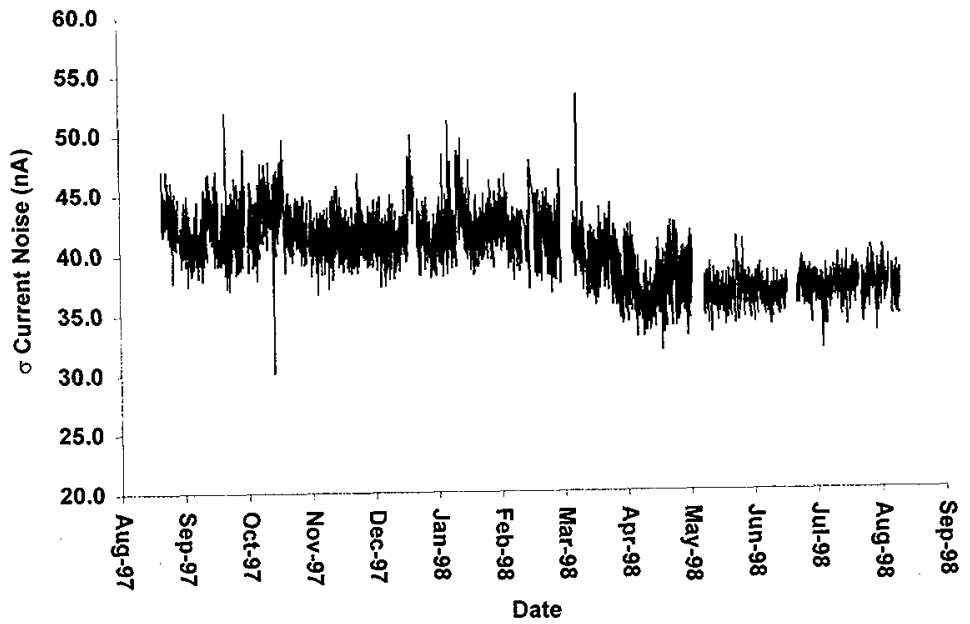

Figure 15: Standard deviation of current noise for C-ring electrodes on channel 8 ( $1.4 \mathrm{~m}$ from tank floor) 


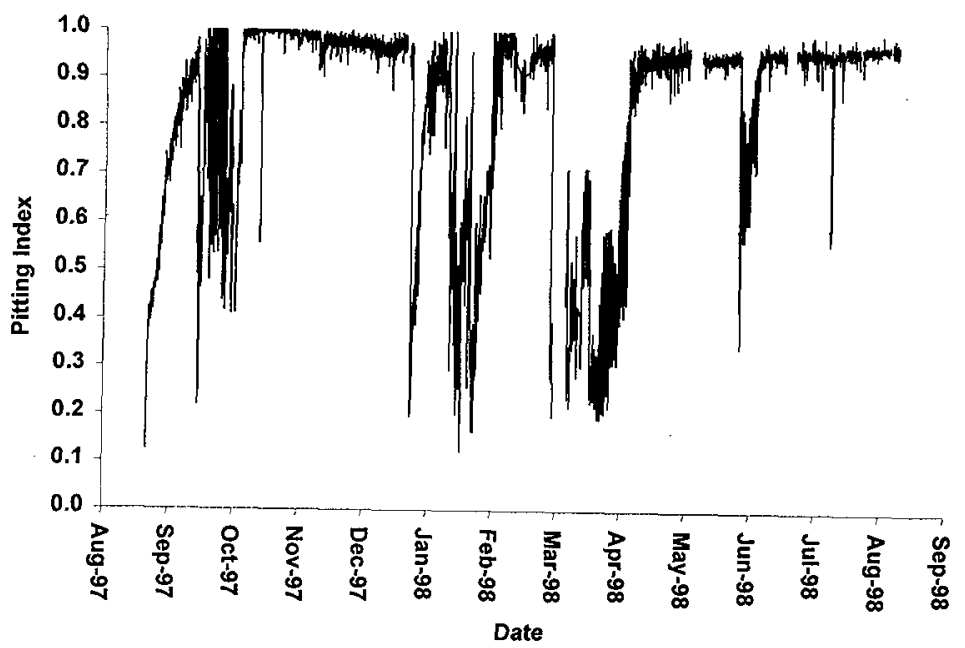

Figure 16: Pitting index for C-ring electrodes on channel 4 (6.5 $\mathrm{m}$ from tank floor)

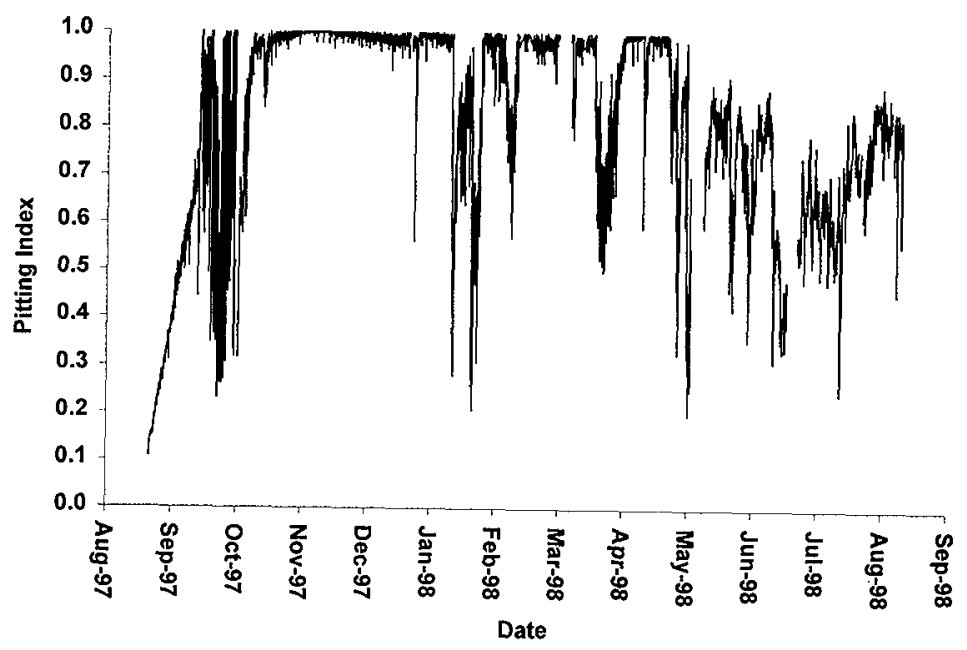

Figure 17: Pitting index for C-ring electrodes on channel 6 (4.0 m from tank floor) 


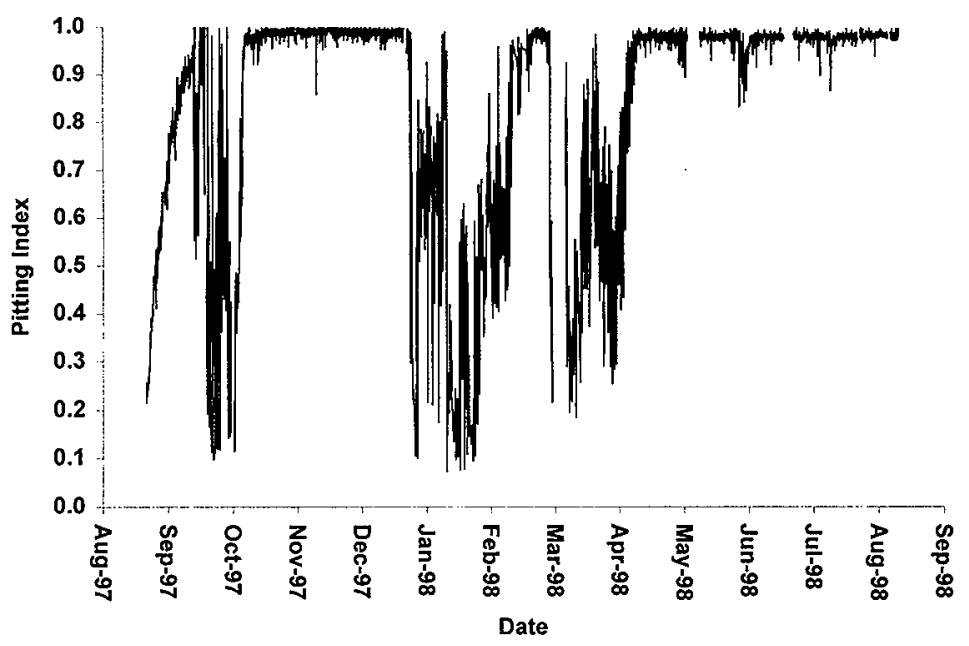

Figure 18: Pitting index for C-ring electrodes on channel $8(1.4 \mathrm{~m}$ from tank floor)

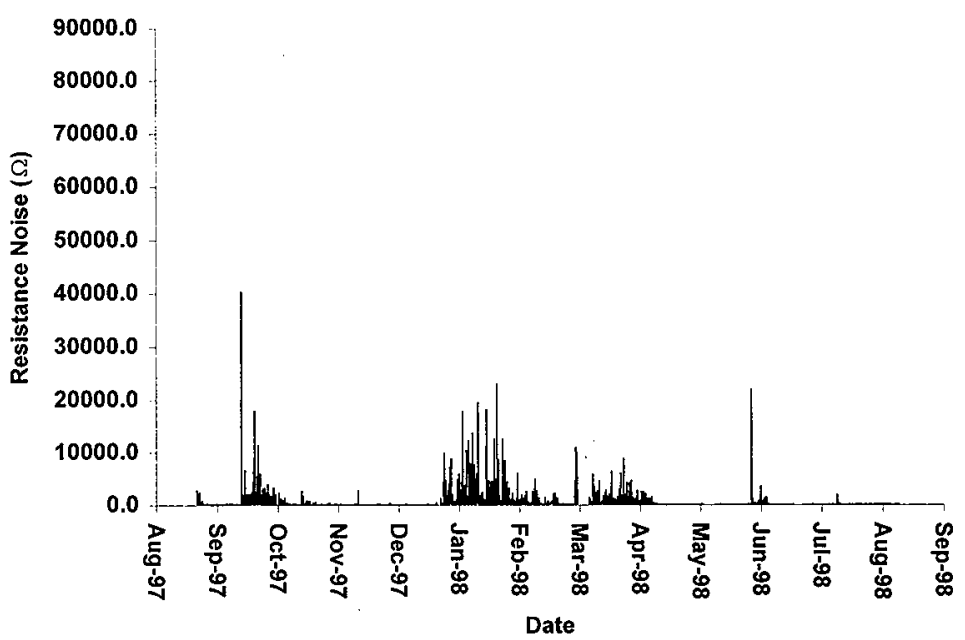

Figure 19: Resistance noise for C-ring electrodes on channel 4 ( $6.5 \mathrm{~m}$ from tank floor) 


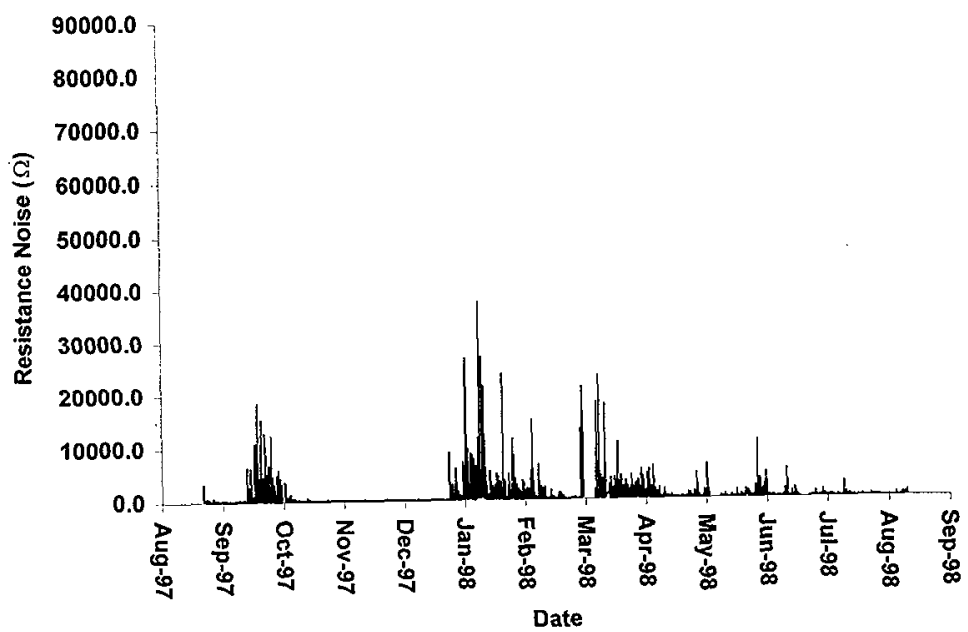

Figure 20: Resistance noise for C-ring electrodes on channel $6(4.0 \mathrm{~m}$ from tank floor)

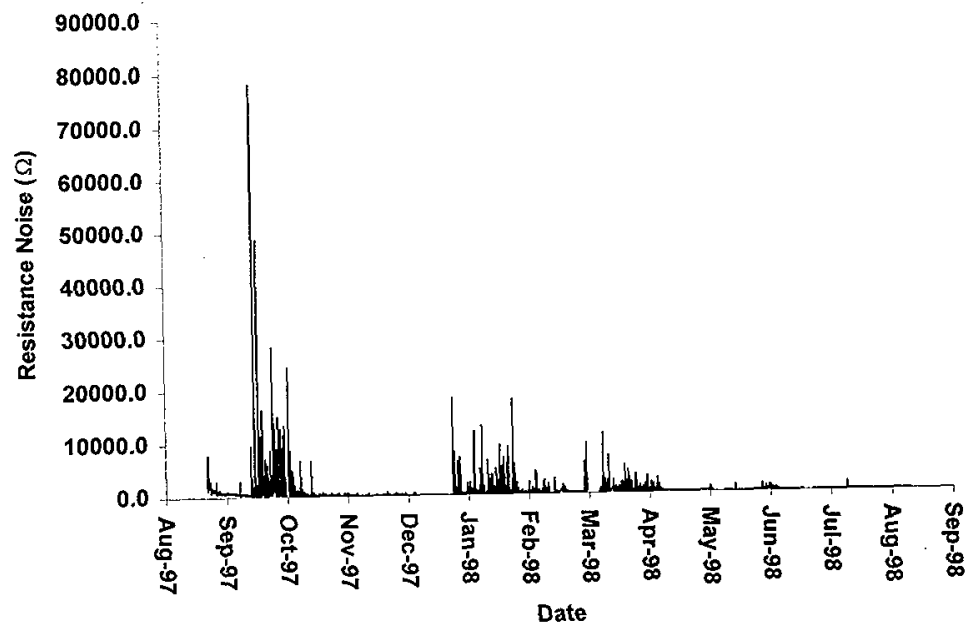

Figure 21: Resistance noise for C-ring electrodes on channel 8 ( $1.4 \mathrm{~m}$ from tank floor) 


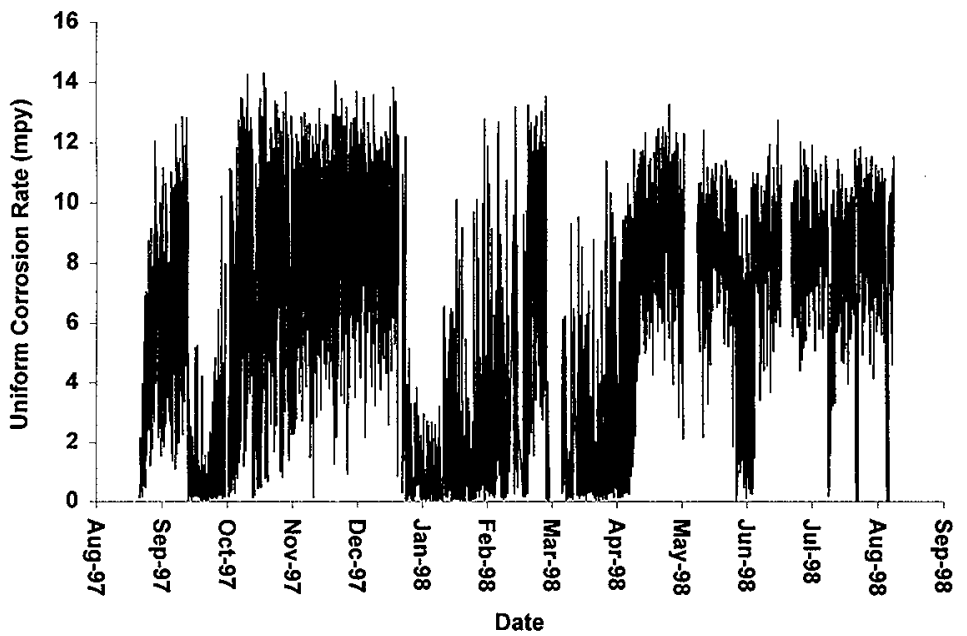

Figure 22: Uniform corrosion rate from noise data for C-ring electrodes on channel 4 ( $6.5 \mathrm{~m}$ from tank floor)

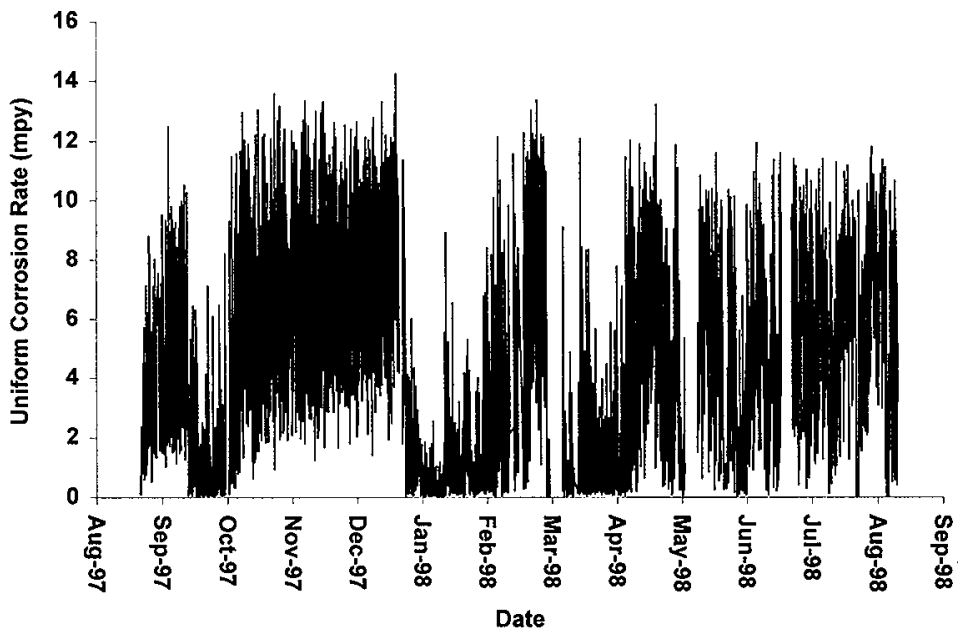

Figure 23: Uniform corrosion rate from noise data for C-ring electrodes on channel 6 ( $4.0 \mathrm{~m}$ from tank floor) 

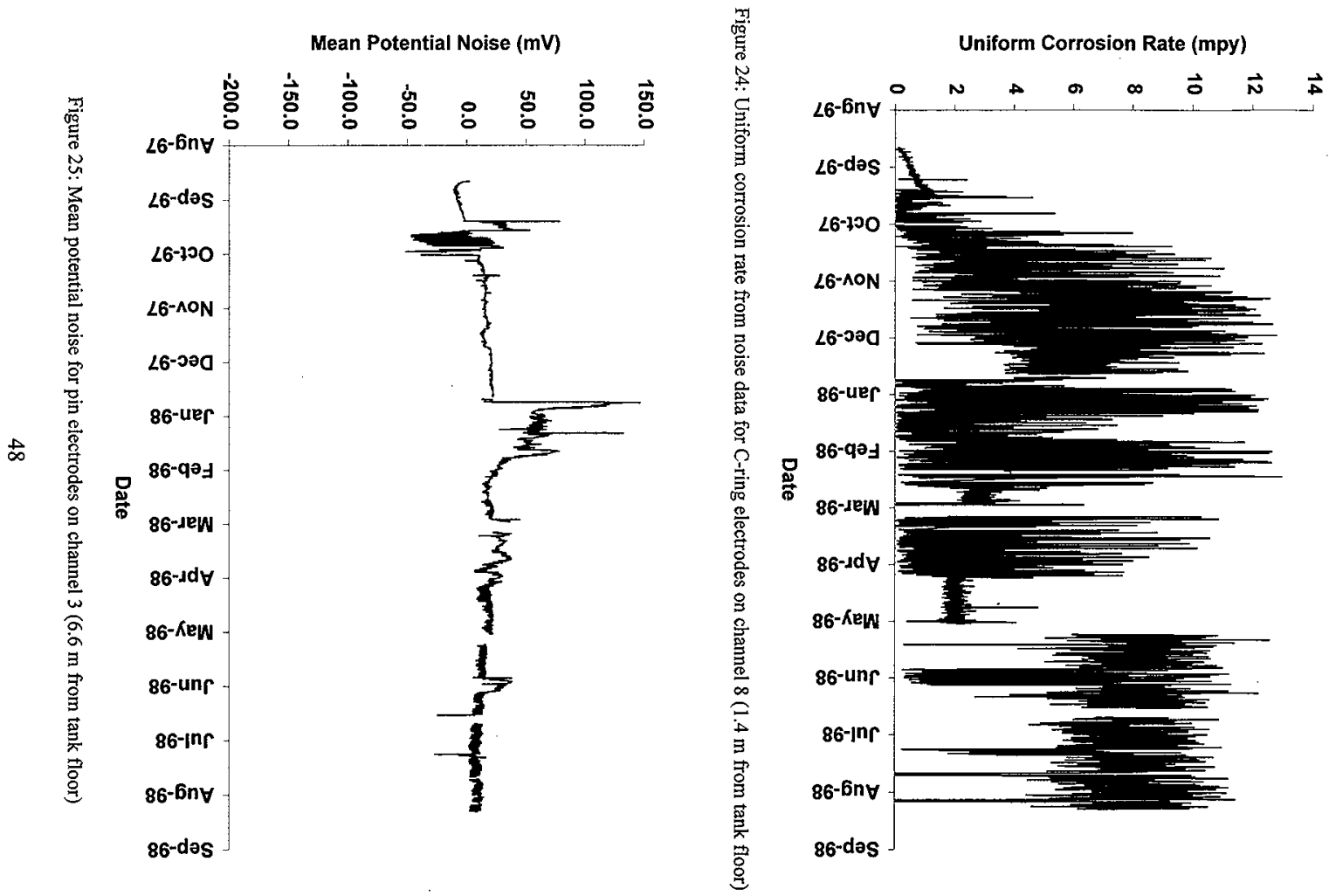

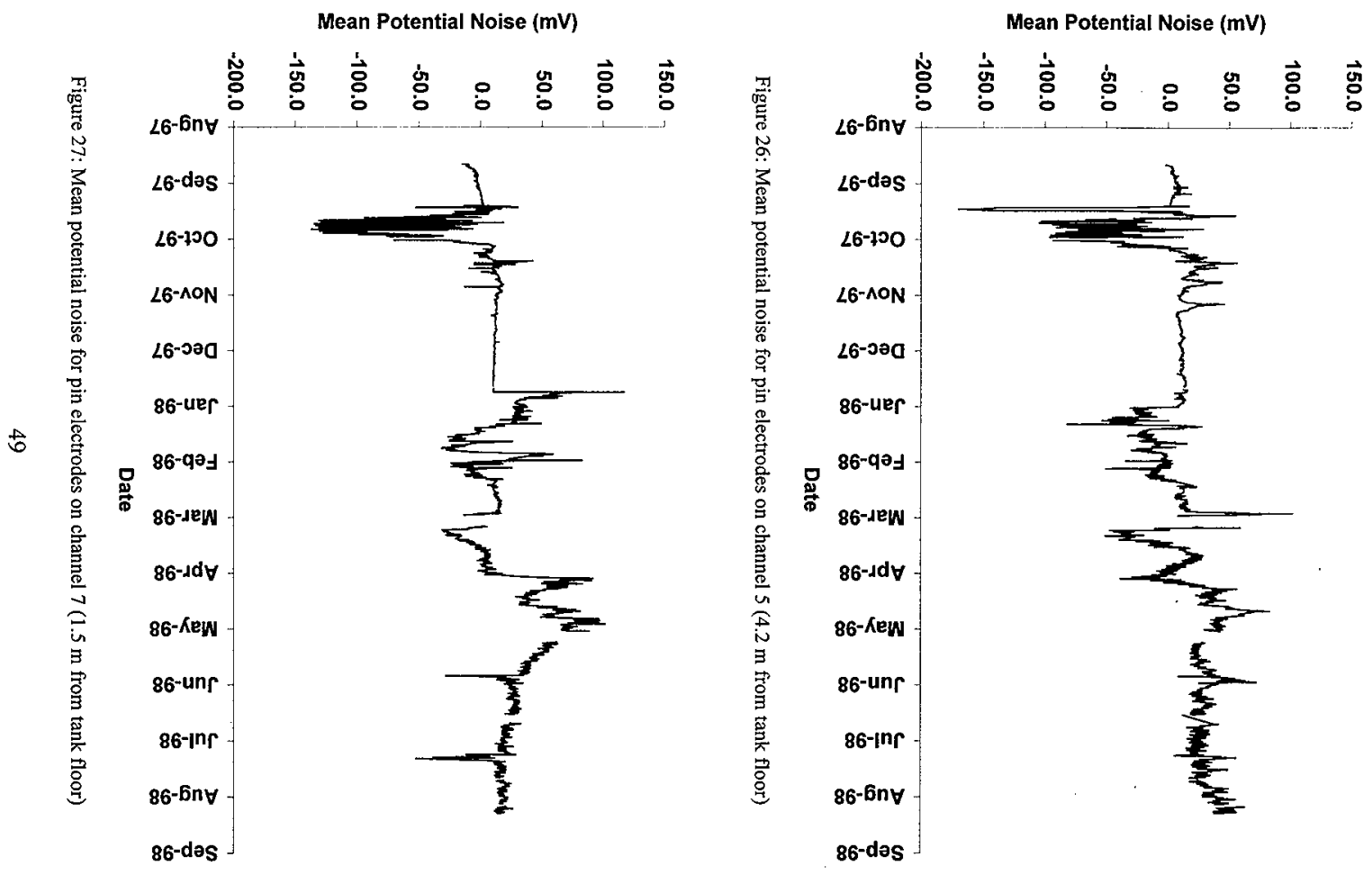


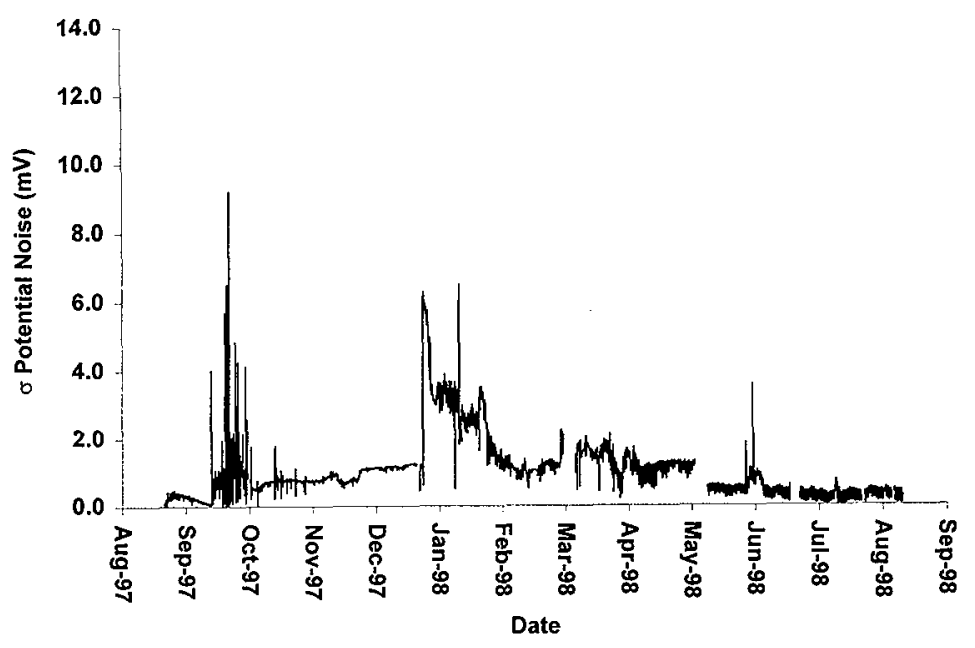

Figure 28: Standard deviation of potential noise for pin electrodes on channel 3 ( $6.6 \mathrm{~m}$ from tank floor)

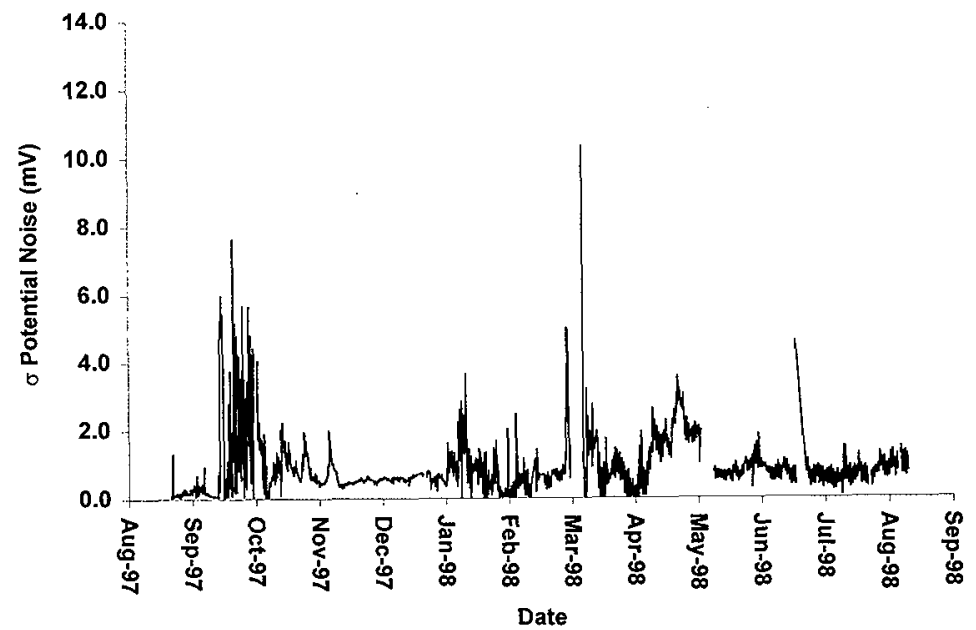

Figure 29: Standard deviation of potential noise for pin electrodes on channel 5 (4.2 $\mathrm{m}$ from tank floor) 


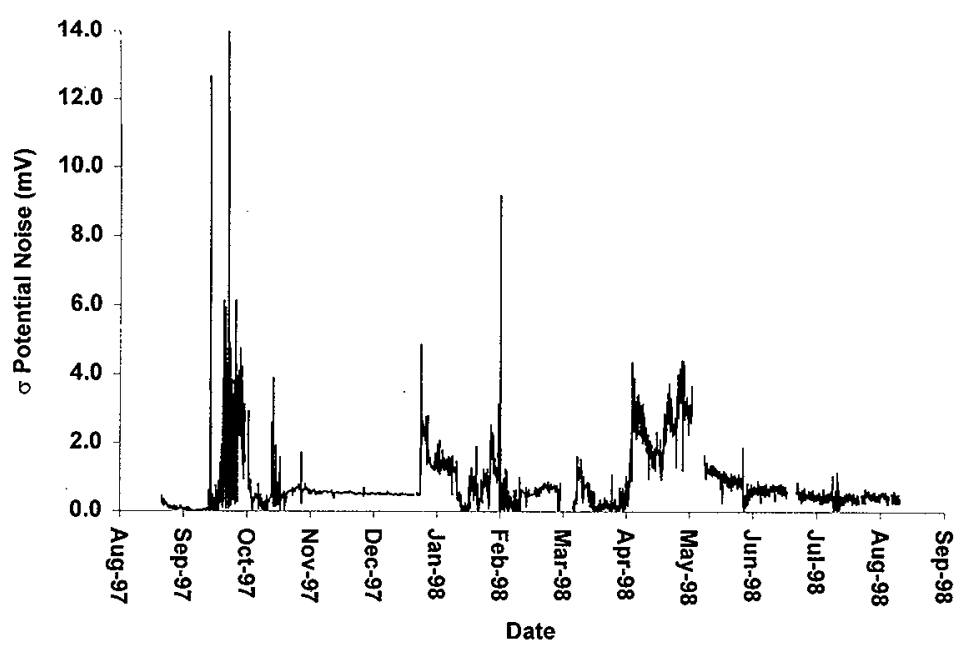

Figure 30: Standard deviation of potential noise for pin electrodes on channel 7 ( $1.5 \mathrm{~m}$ from tank floor)

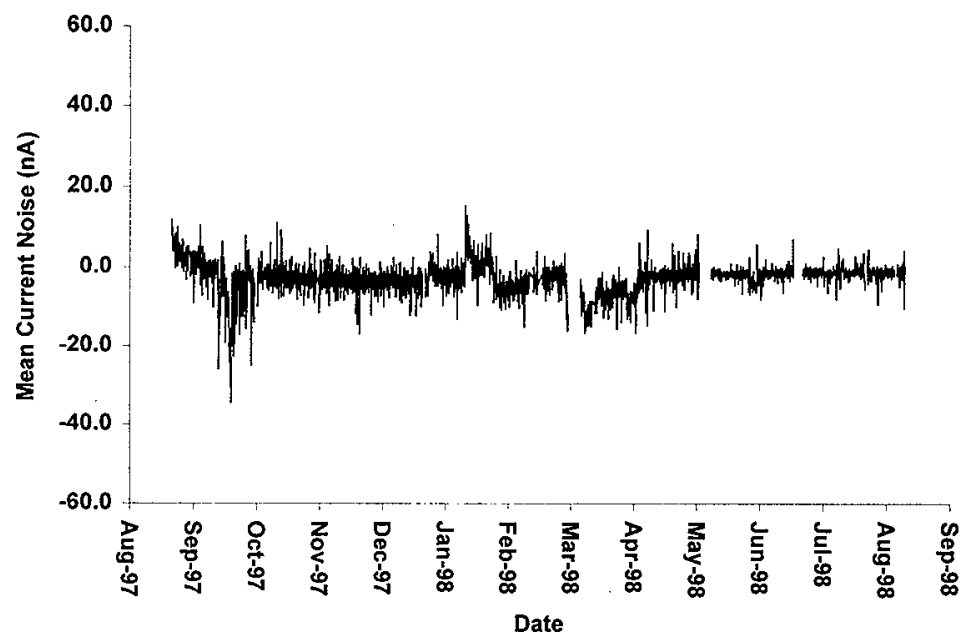

Figure 31: Mean current noise for pin electrodes on channel 3 (6.6 $\mathrm{m}$ from tank floor) 

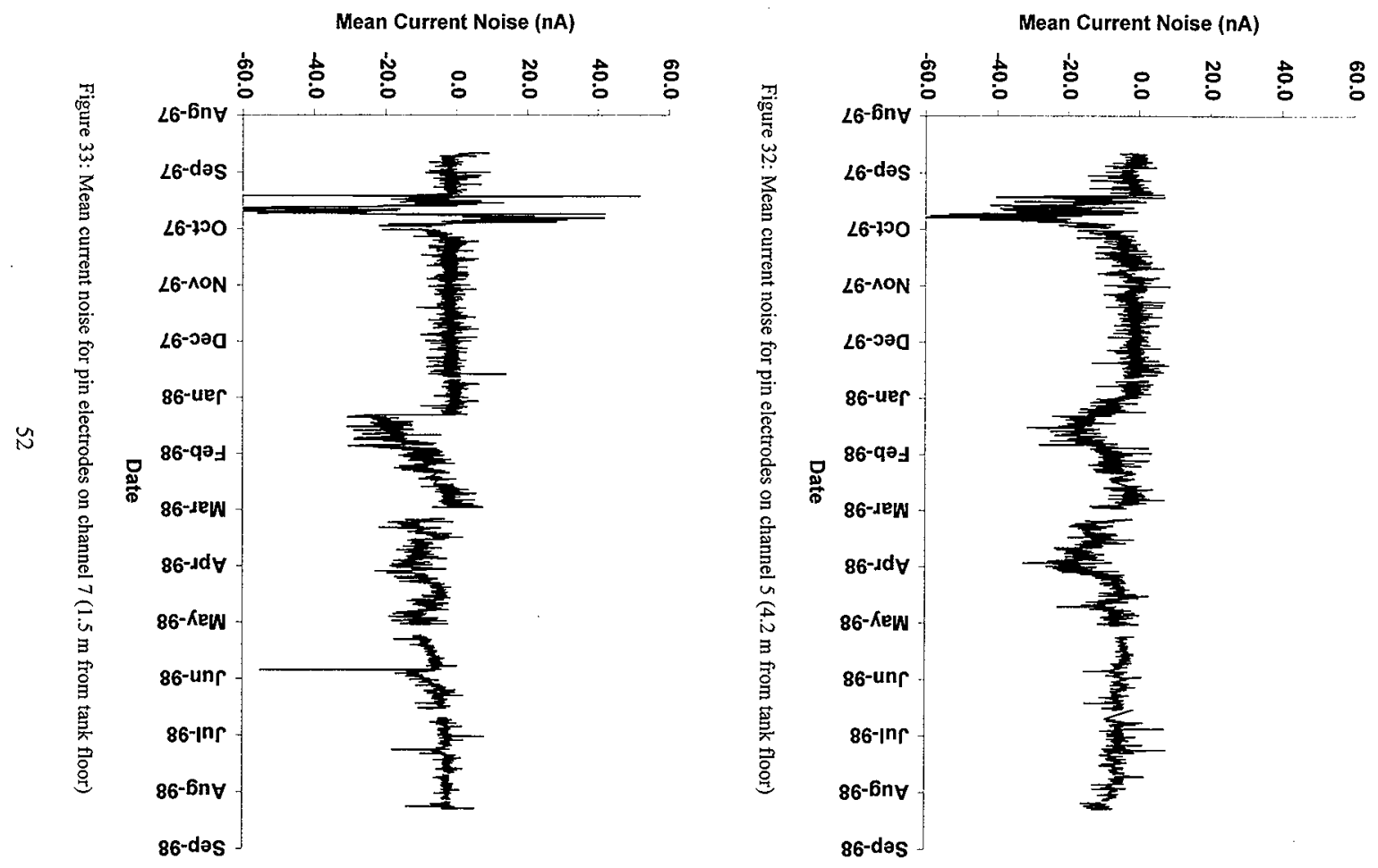


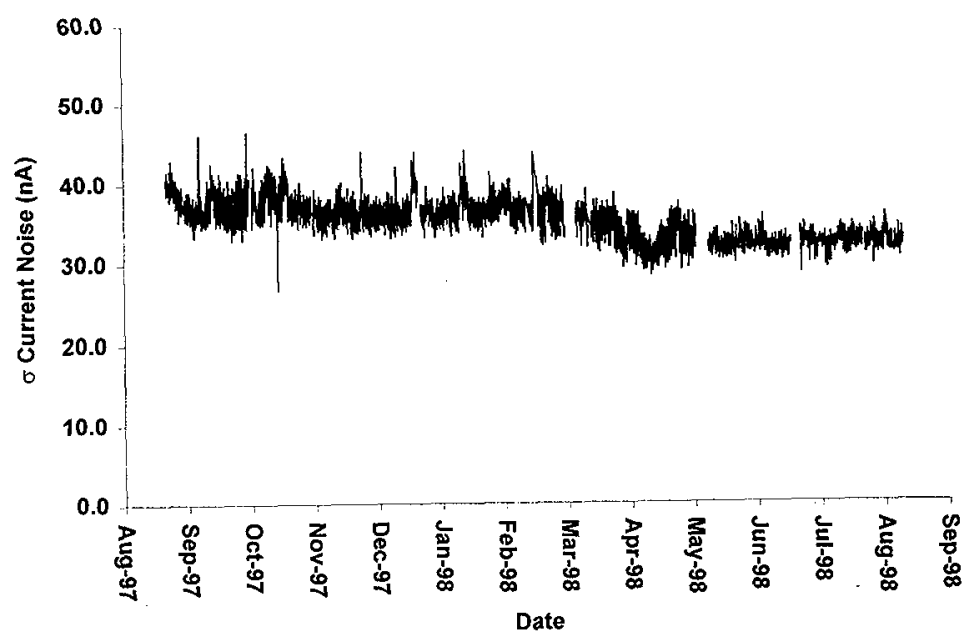

Figure 34: Standard deviation of current noise for pin electrodes on channel 3 (6.6 $\mathrm{m}$ from tank floor)

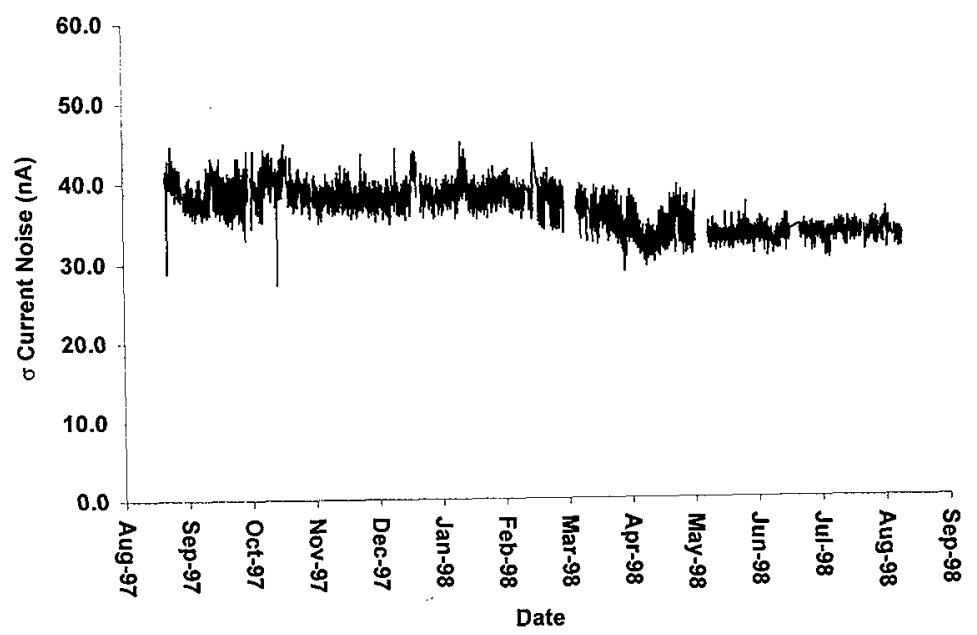

Figure 35: Standard deviation of current noise for pin electrodes on channel 5 ( $4.2 \mathrm{~m}$ from tank floor) 


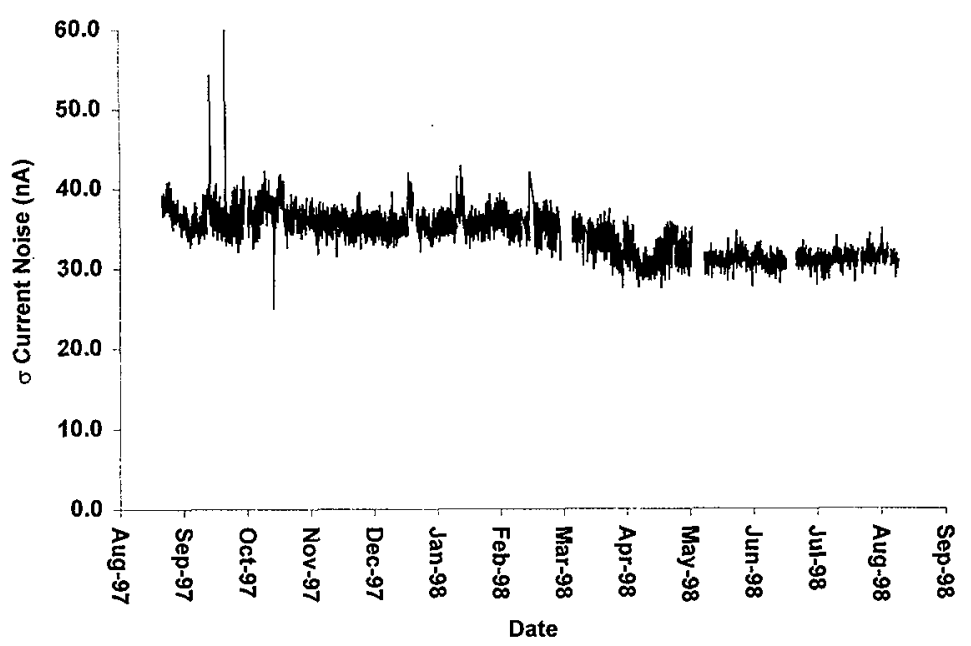

Figure 36: Standard deviation of current noise for pin electrodes on channel 7 ( $1.5 \mathrm{~m}$ from tank floor)

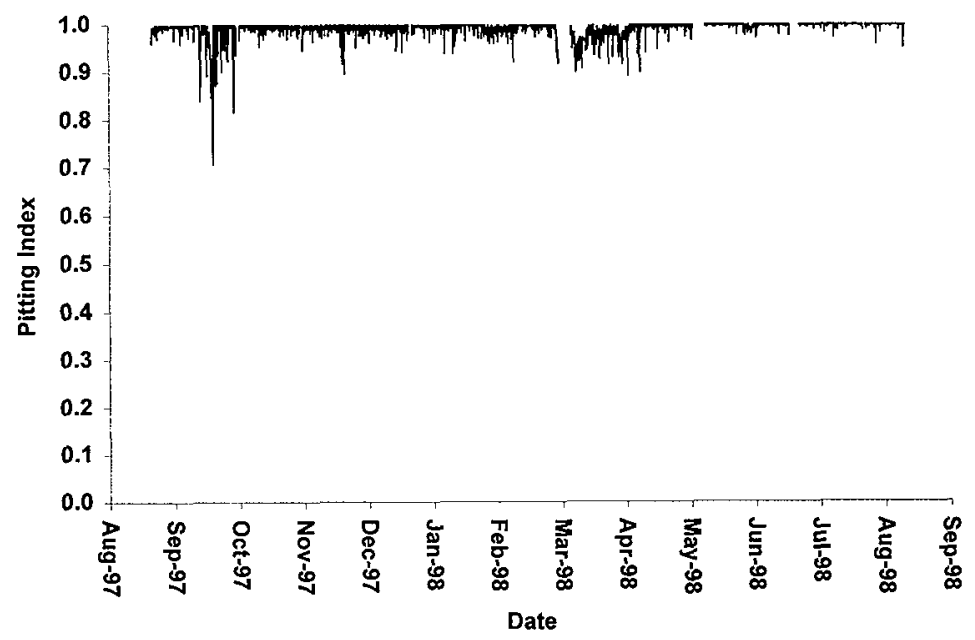

Figure 37: Pitting index for pin electrodes on channel 3 (6.6 $\mathrm{m}$ from tank floor) 
Pitting Index

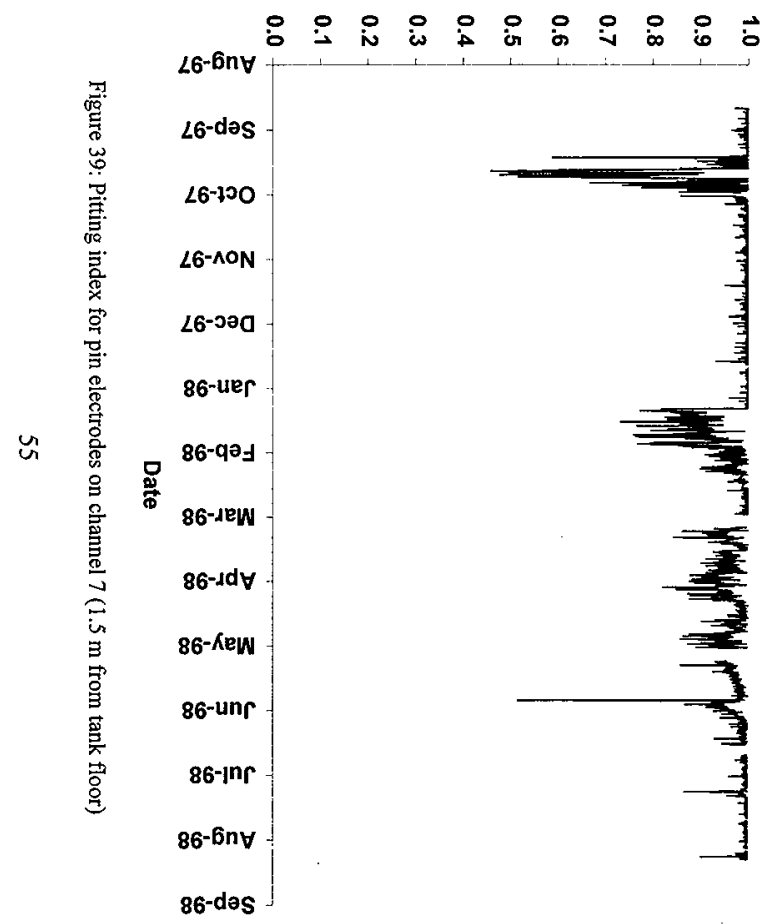

Pitting Index

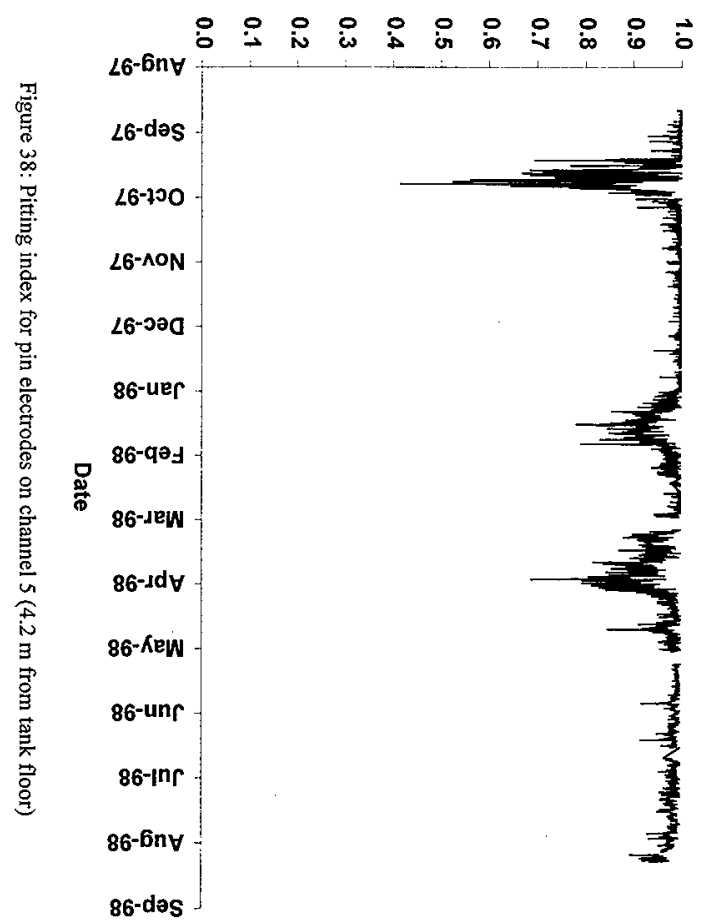




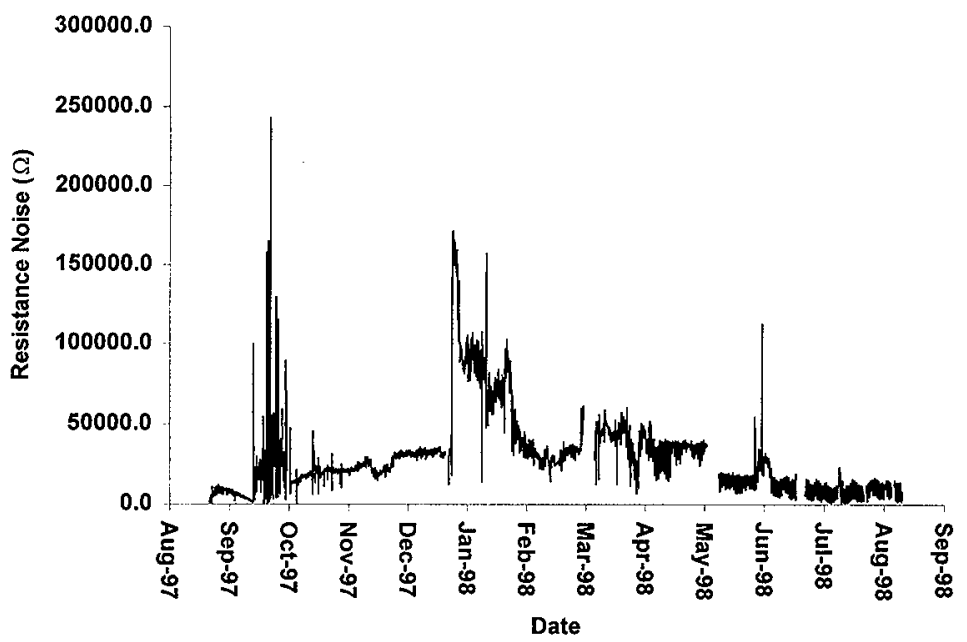

Figure 40: Resistance noise for pin electrodes on channel 3 ( $6.6 \mathrm{~m}$ from tank floor)

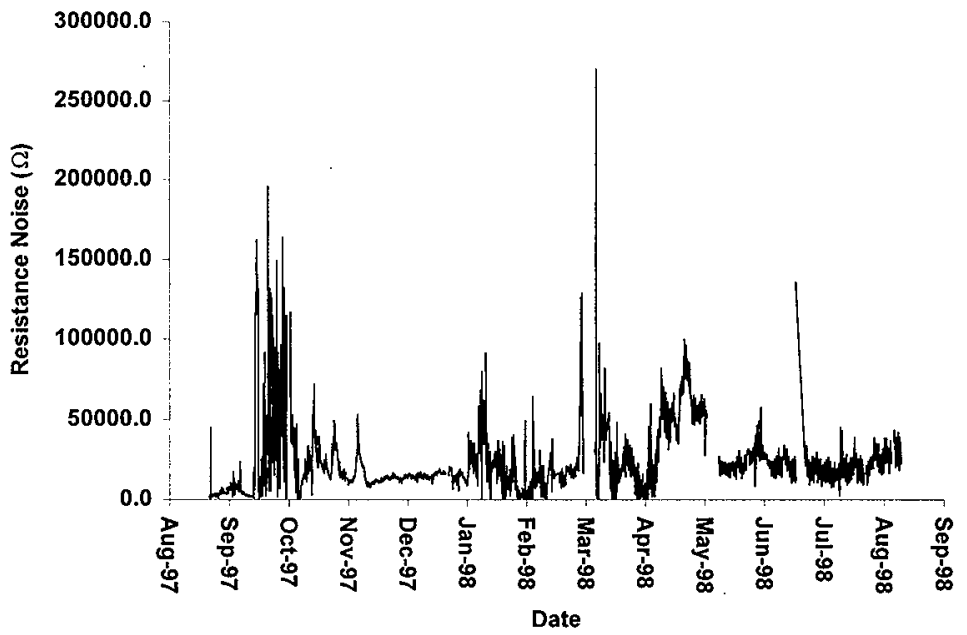

Figure 41: Resistance noise for pin electrodes on channel 5 (4.2 $\mathrm{m}$ from tank floor) 
HNF-3414, Rev. 0

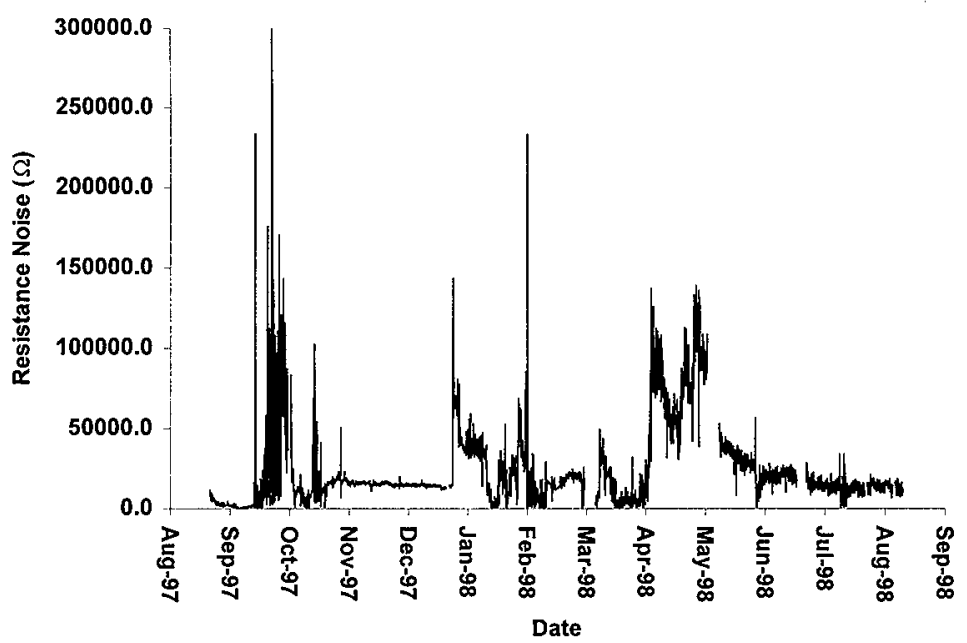

Figure 42: Resistance noise for pin electrodes on channel 7 ( $1.5 \mathrm{~m}$ from tank floor)

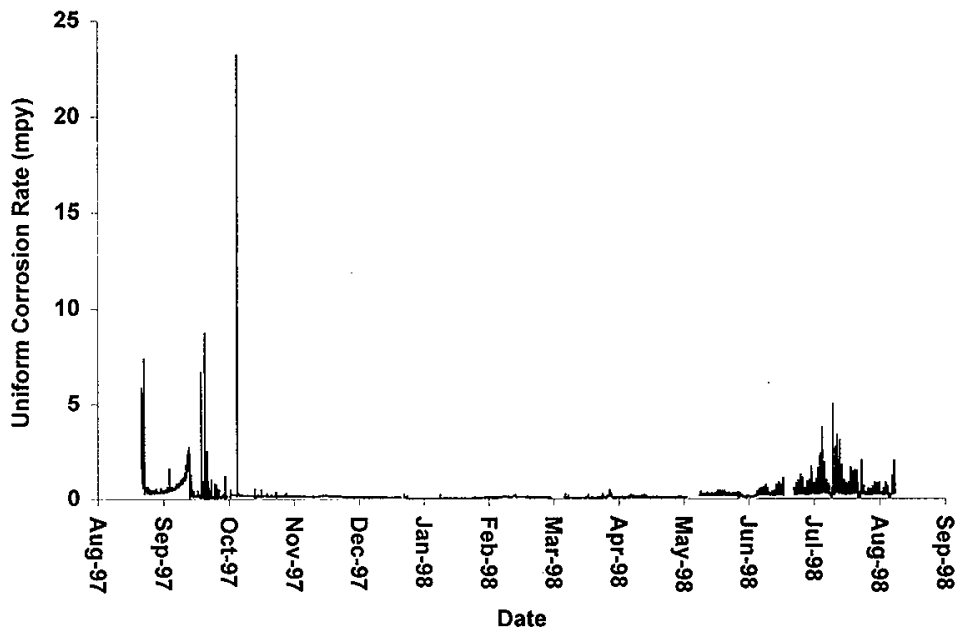

Figure 43: Uniform corrosion rate from noise data for pin electrodes on channel 3 (6.6 $\mathrm{m}$ from tank floor) 


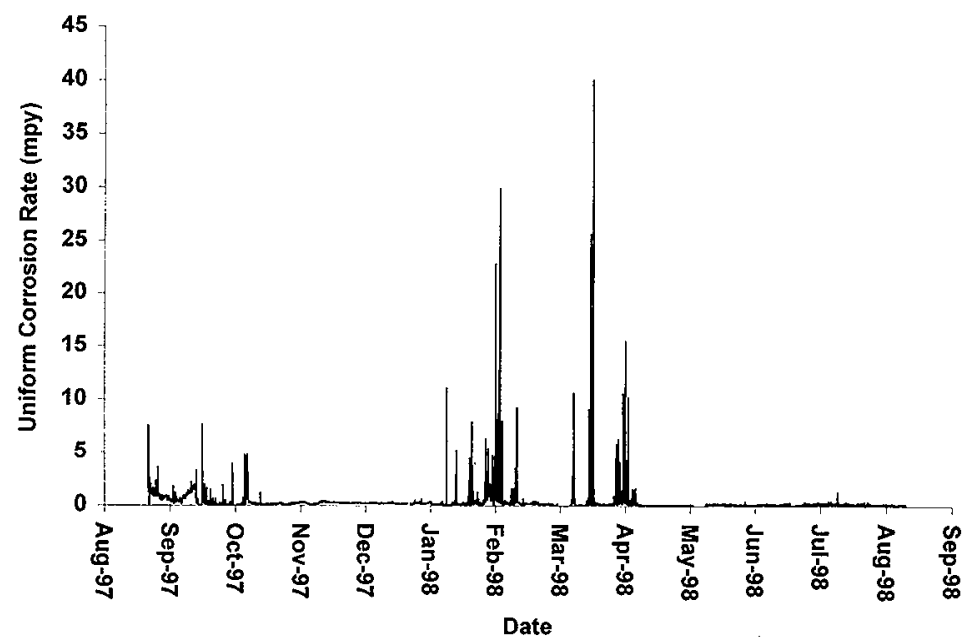

Figure 44: Uniform corrosion rate from noise data for pin electrodes on channel 5 (4.2 $\mathrm{m}$ from tank floor)

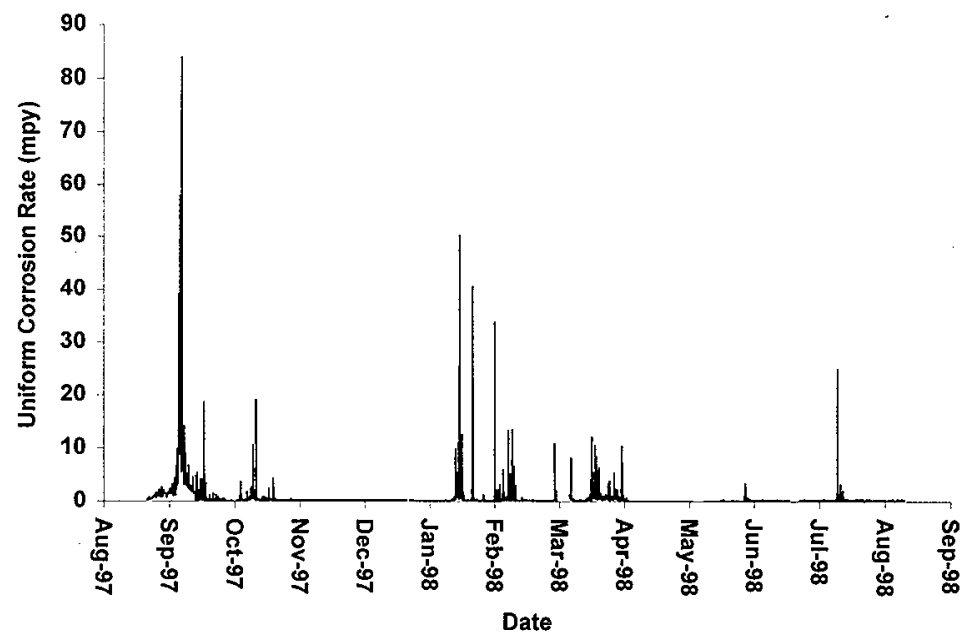

Figure 45: Uniform corrosion rate from noise data for pin electrodes on channel 7 ( $1.5 \mathrm{~m}$ from tank floor) 
HNF-3414, Rev. 0

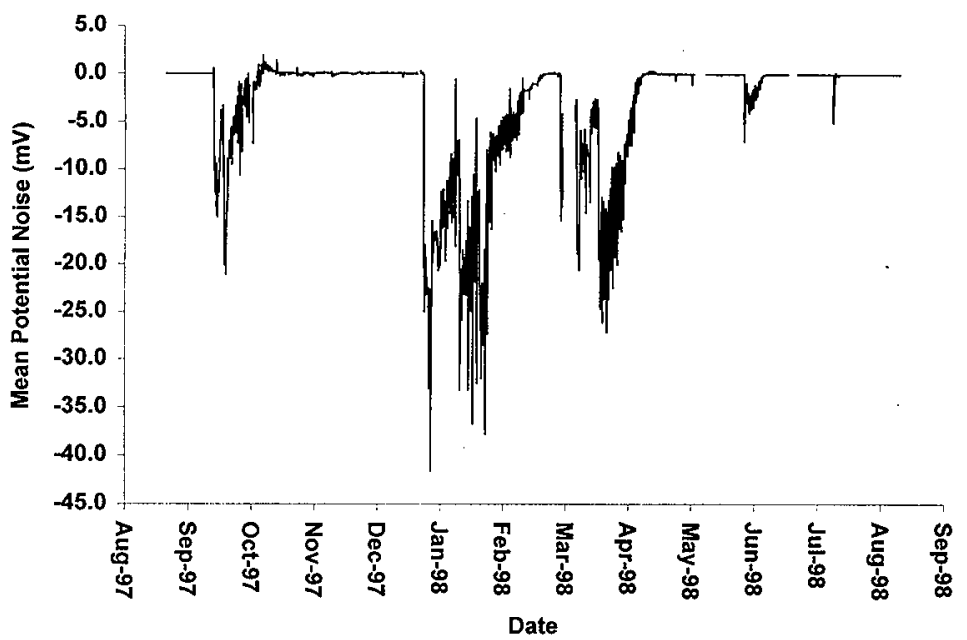

Figure 46: Mean potential noise for C-ring electrodes in vapor space on channel 2 (10.7 $\mathrm{m}$ from tank floor)

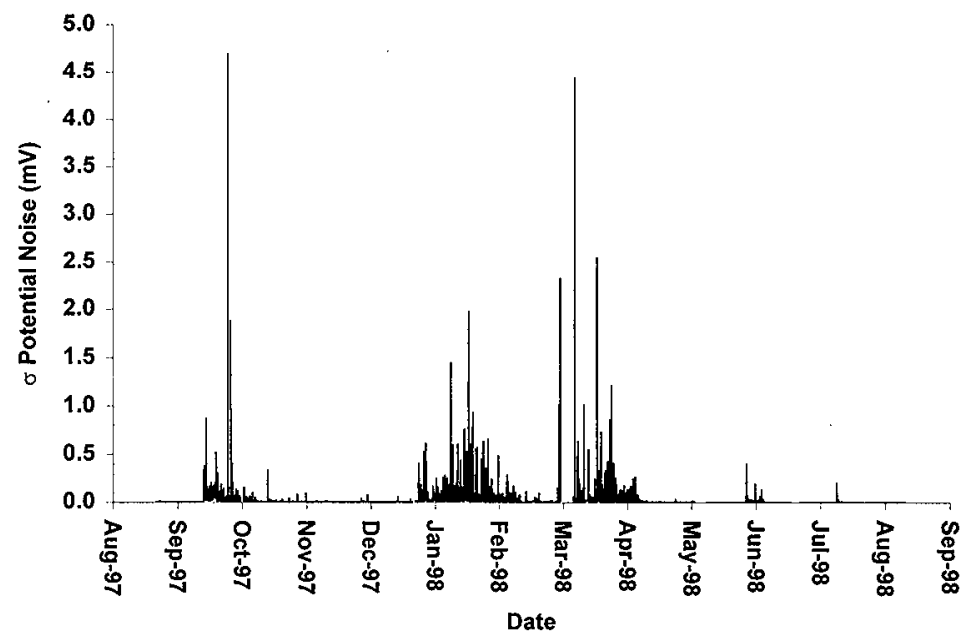

Figure 47: Standard deviation of potential noise for C-ring electrodes in vapor space on channel 2 (10.7 $\mathrm{m}$ from tank floor) 
HNF-3414, Rev. 0

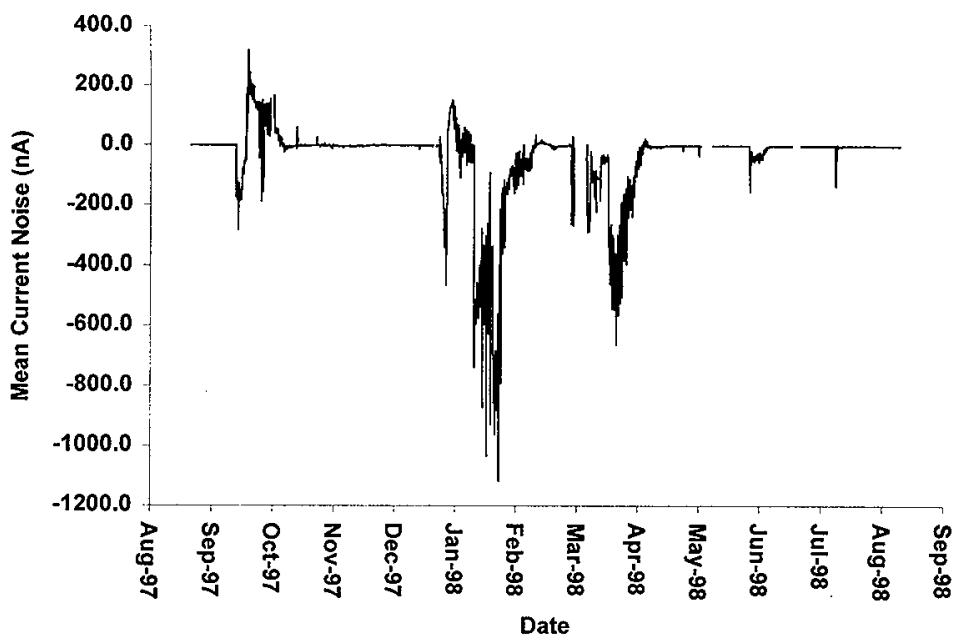

Figure 48: Mean current noise for C-ring electrodes in vapor space on channel 2 (10.7 $\mathrm{m}$ from tank floor)

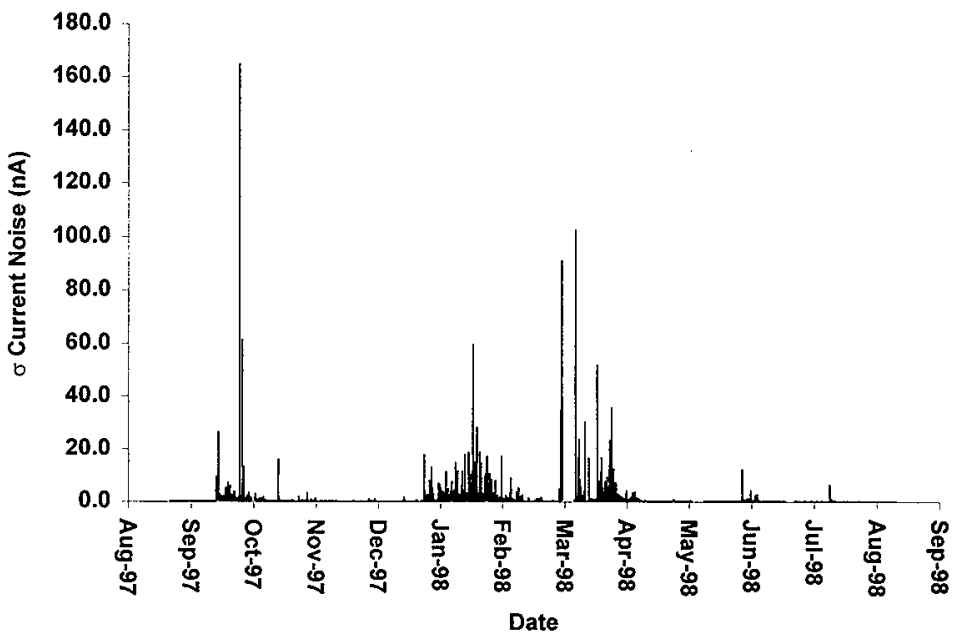

Figure 49: Standard deviation of current noise for C-ring electrodes in vapor space on channel $2(10.7 \mathrm{~m}$ from tank floor) 


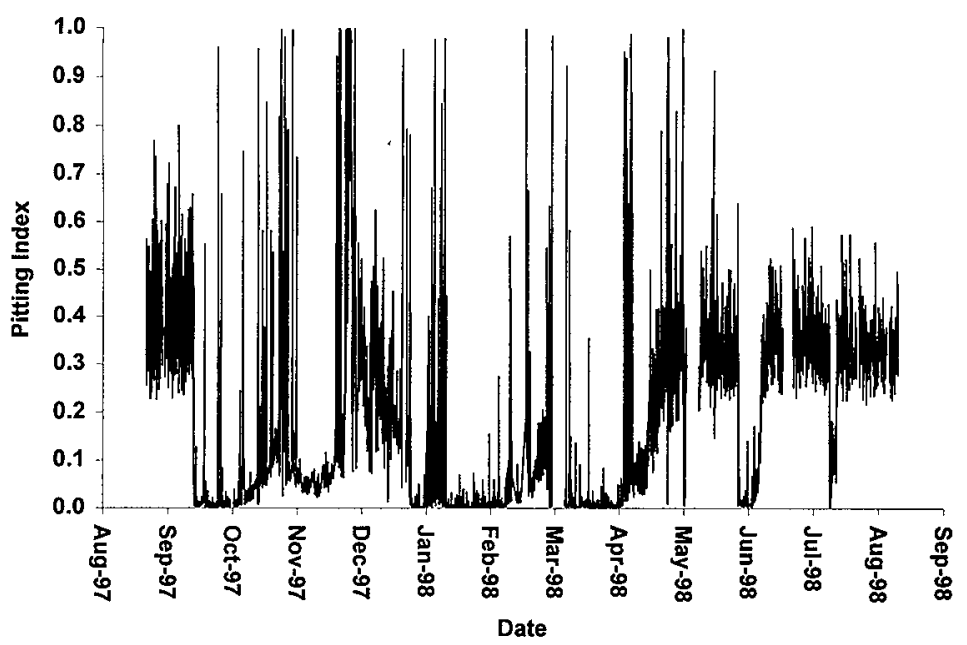

Figure 50: Pitting index for C-ring electrodes in vapor space on channel $2(10.7 \mathrm{~m}$ from tank floor)

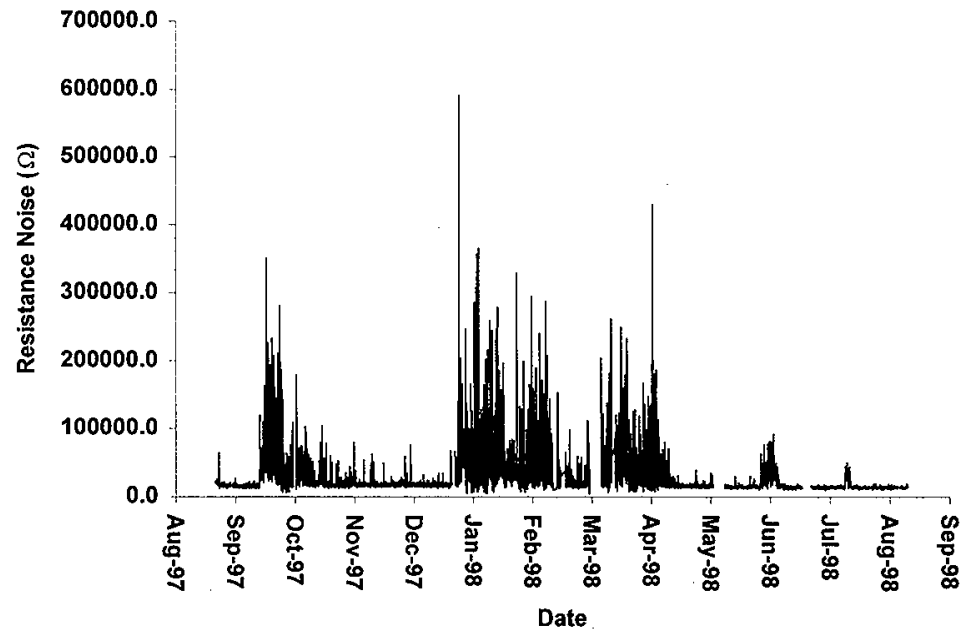

Figure 51: Resistance noise for C-ring electrodes in vapor space on channel $2(10.7 \mathrm{~m}$ from tank floor) 


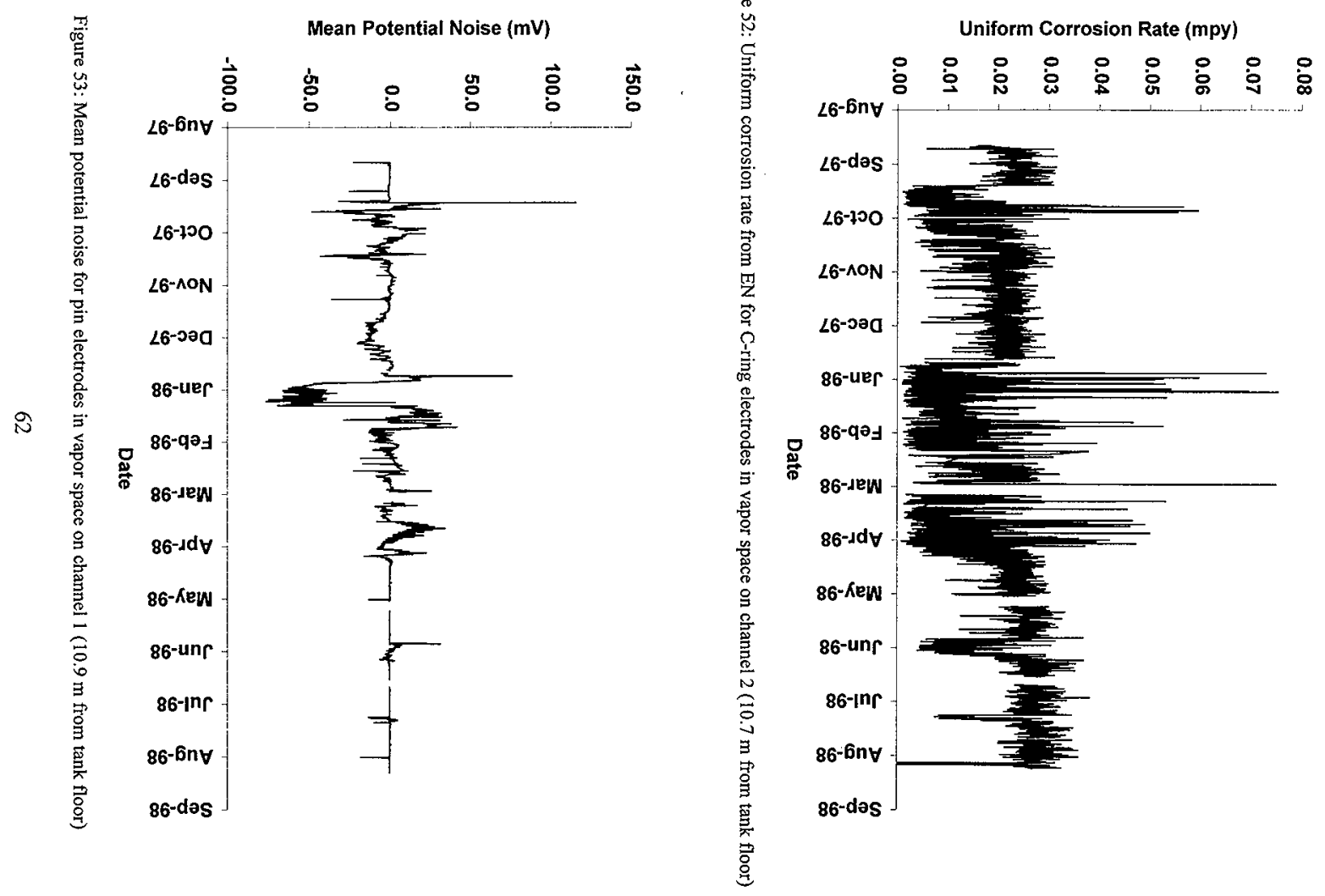




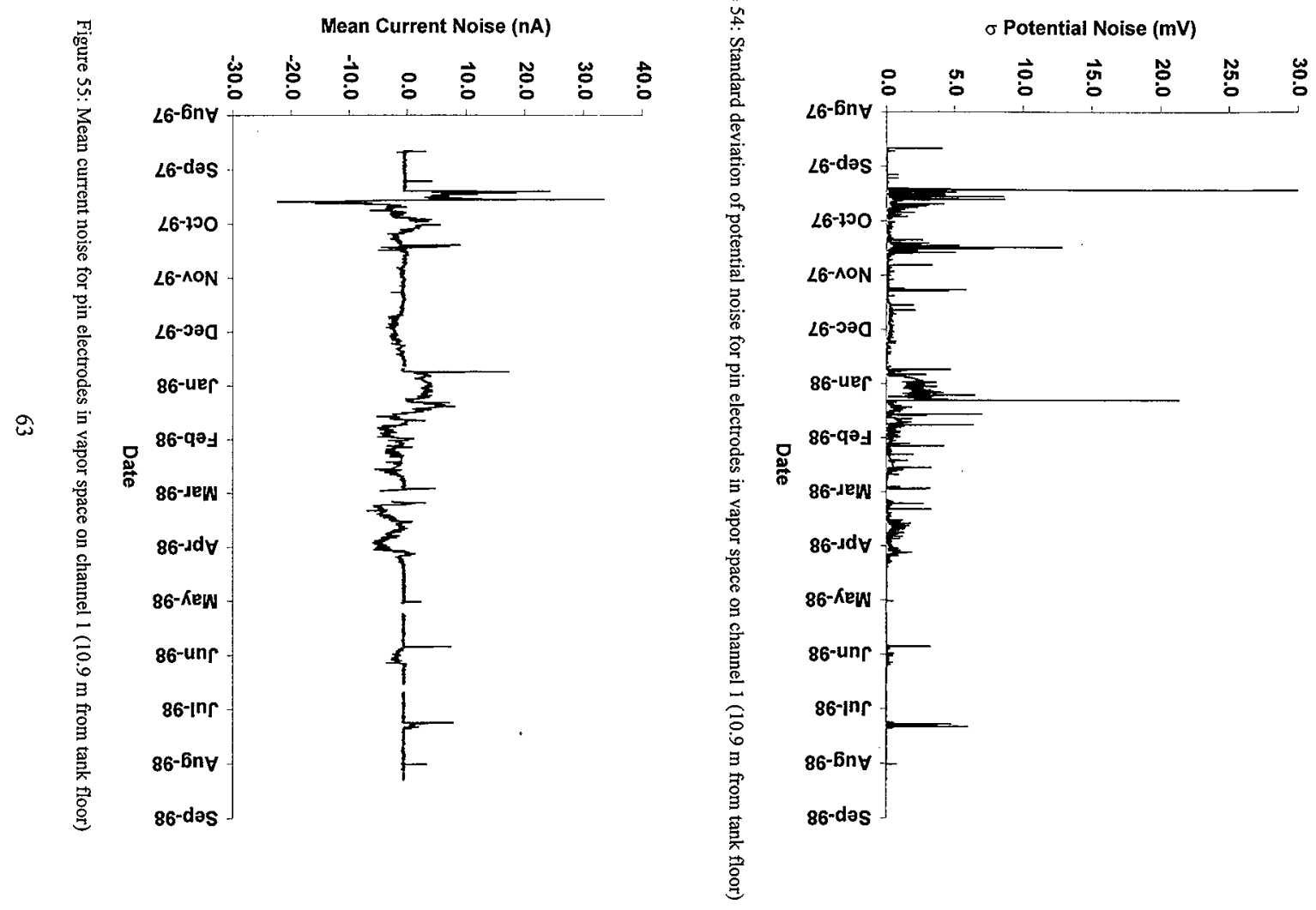


Pitting Index

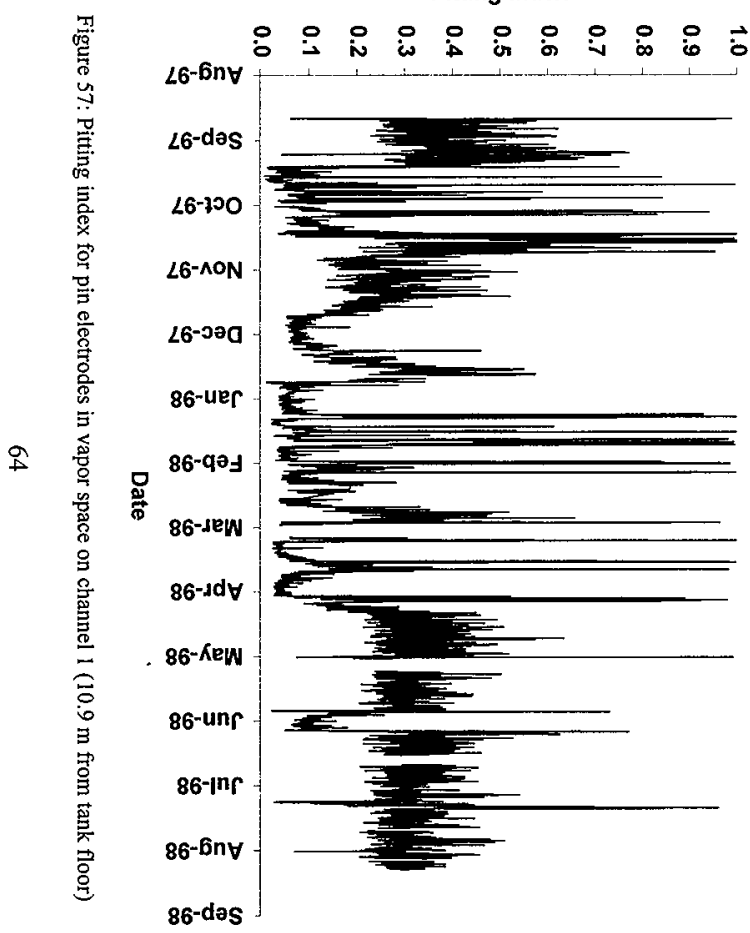

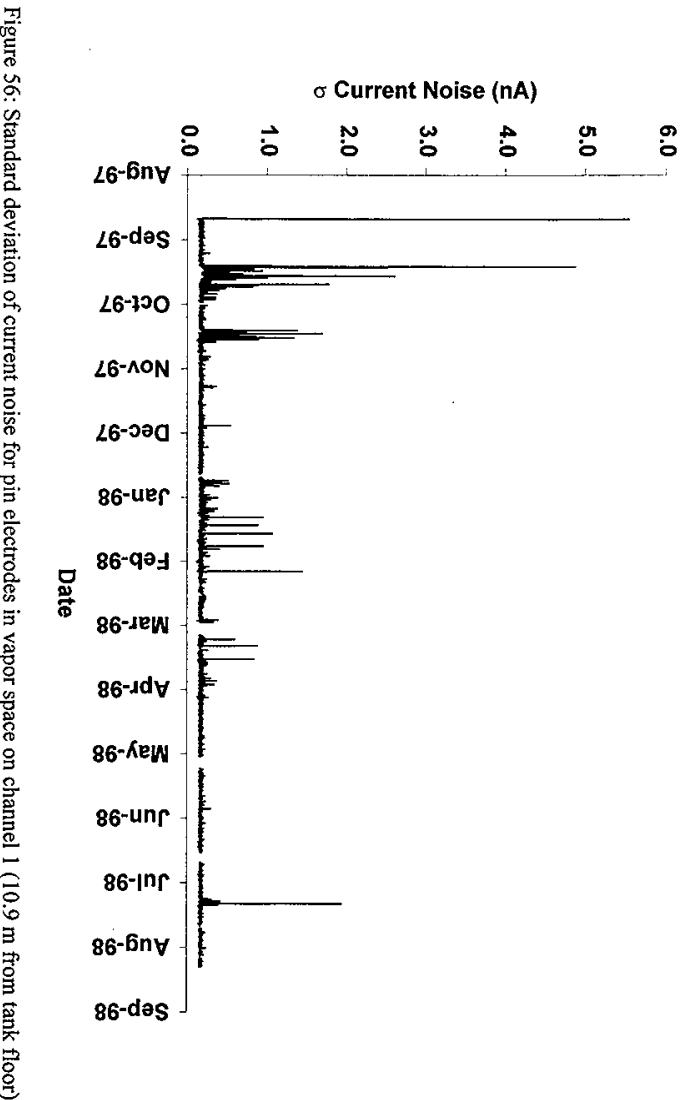


HNF-3414, Rev. 0

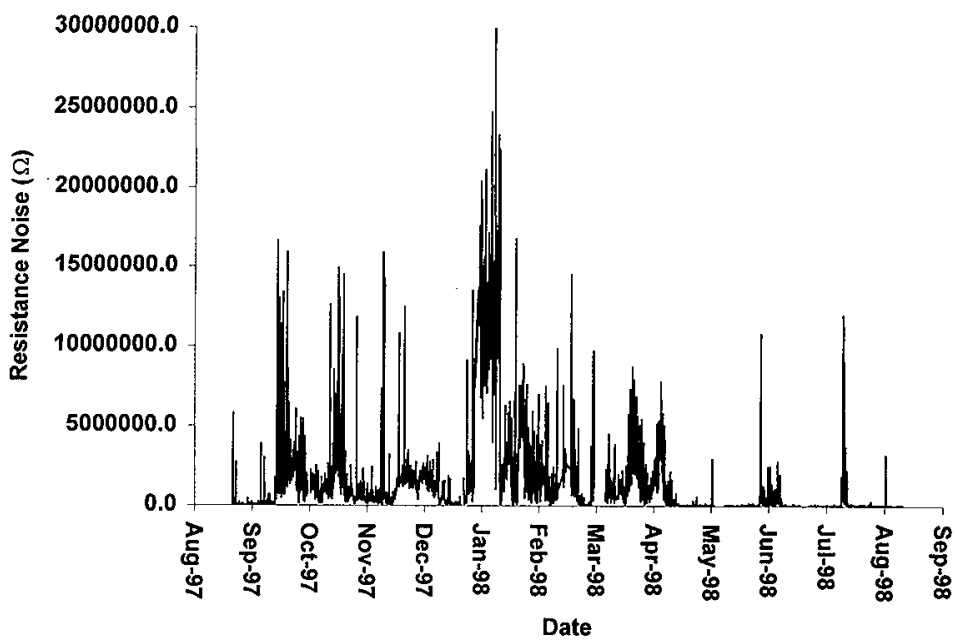

Figure 58: Resistance noise for pin electrodes in vapor space on channel 1 (10.9 $\mathrm{m}$ from tank floor)

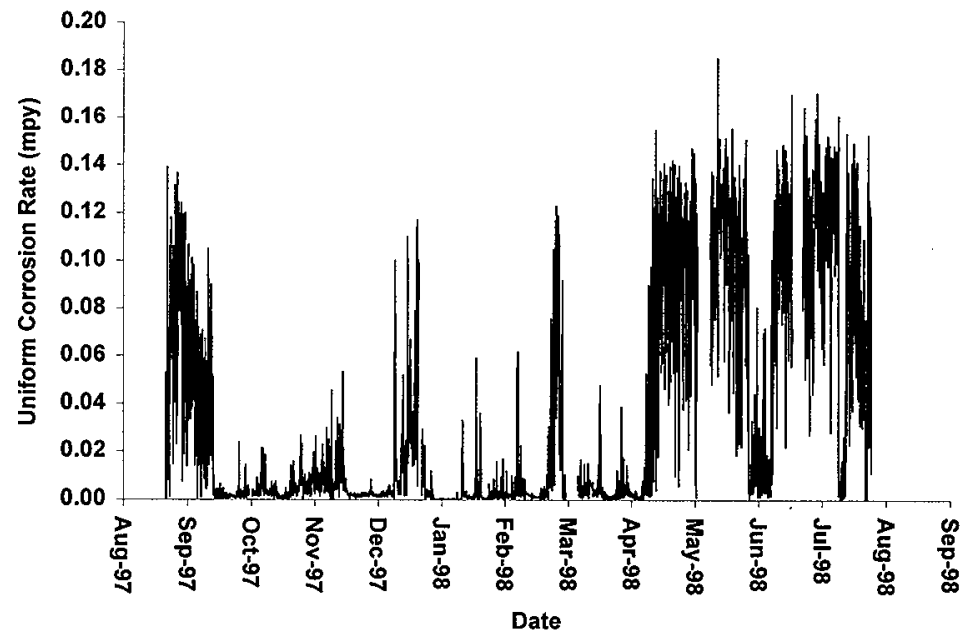

Figure 59: Uniform corrosion rate from noise data for pin electrodes in vapor space on channel 1 (10.9 $\mathrm{m}$ from tank floor) 

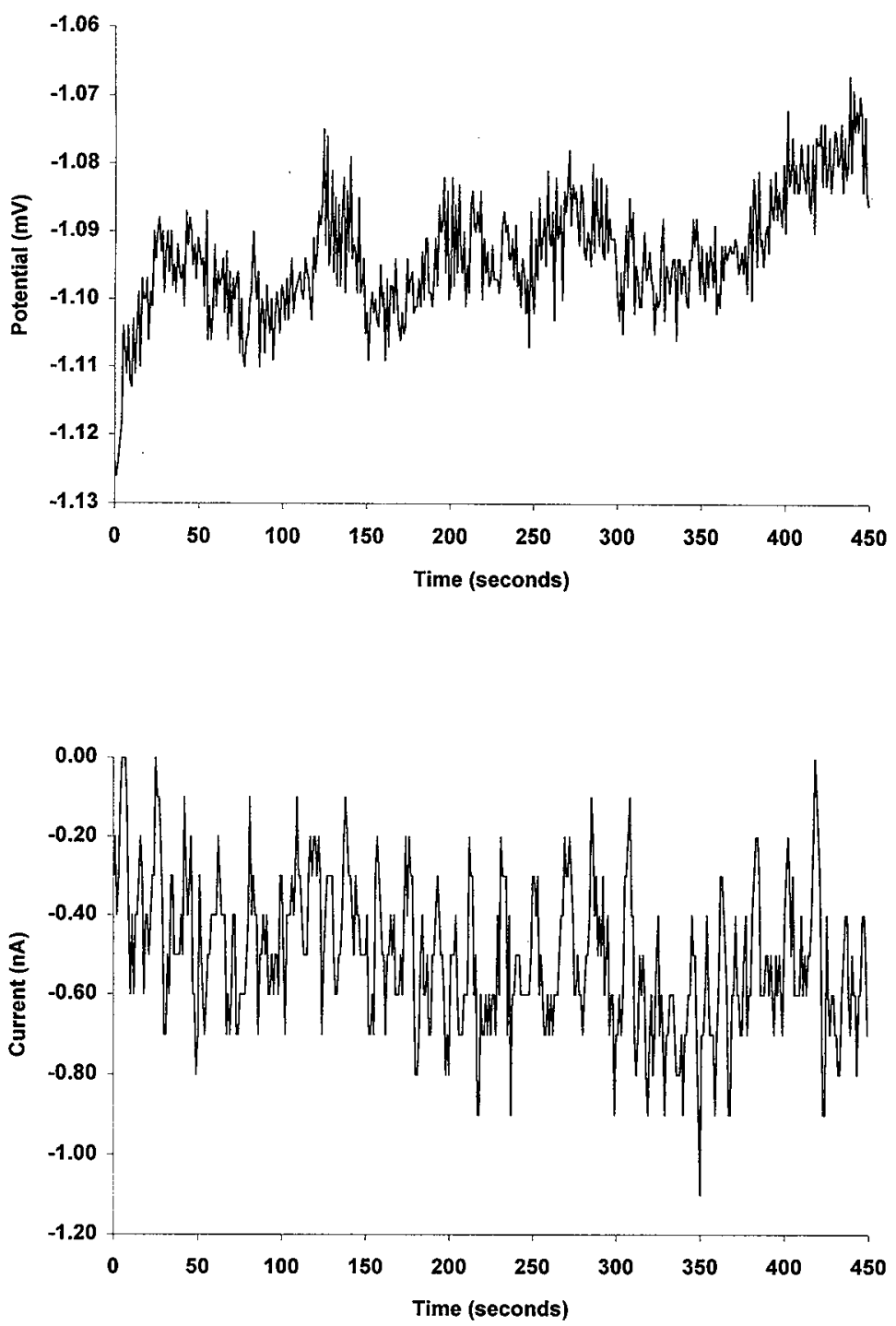

Figure 60: Typical raw potential and raw current data files: pin electrodes in vapor space on channel 1 - September 1997 

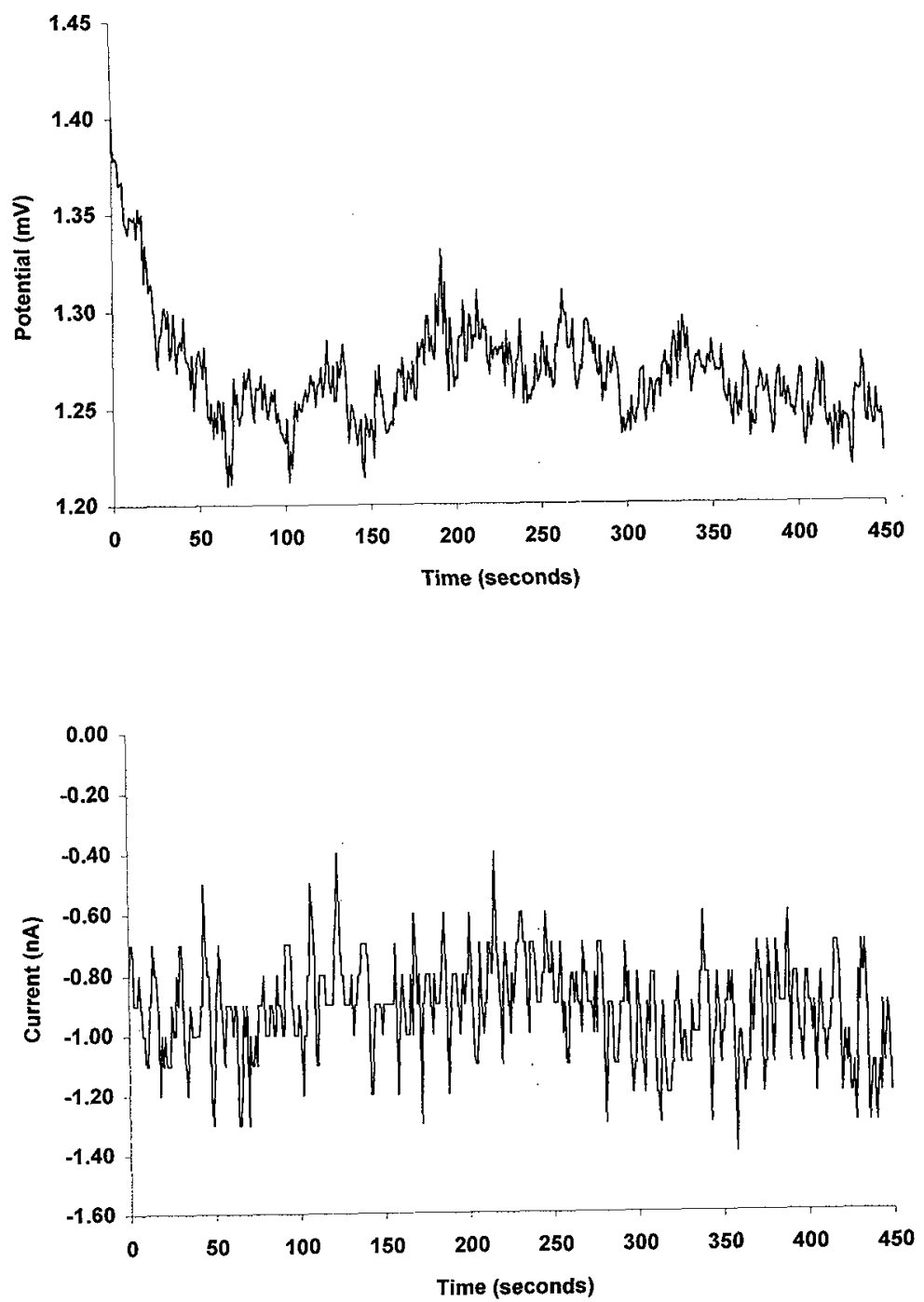

Figure 61: Typical raw potential and raw current data files: pin electrodes in vapor space on channel 1 - October 1997 
HNF-3414, Rev. 0
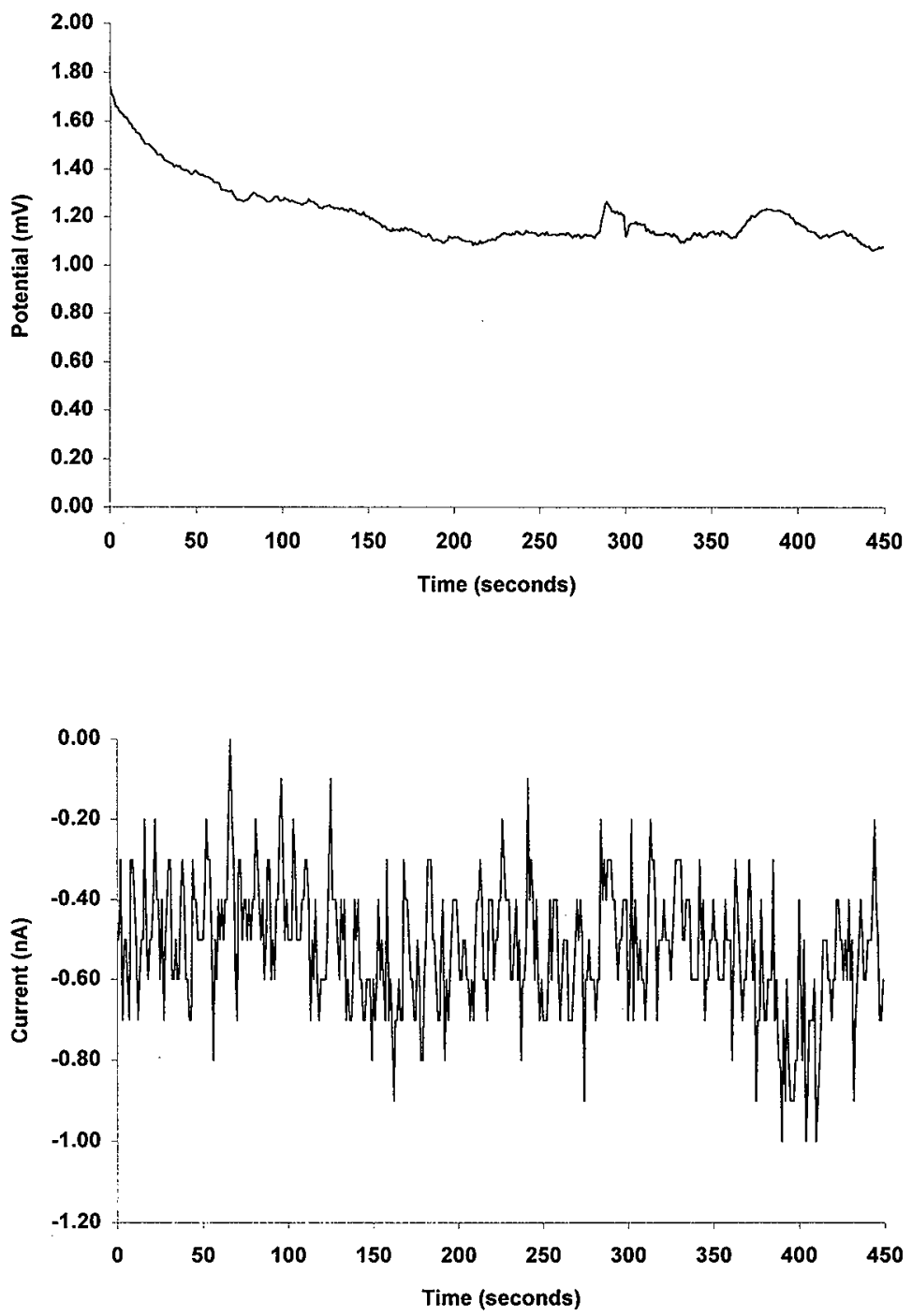

Figure 62: Typical raw potential and raw current data files: pin electrodes in vapor space on channel 1 - November 1997 
HNF-3414, Rev. 0
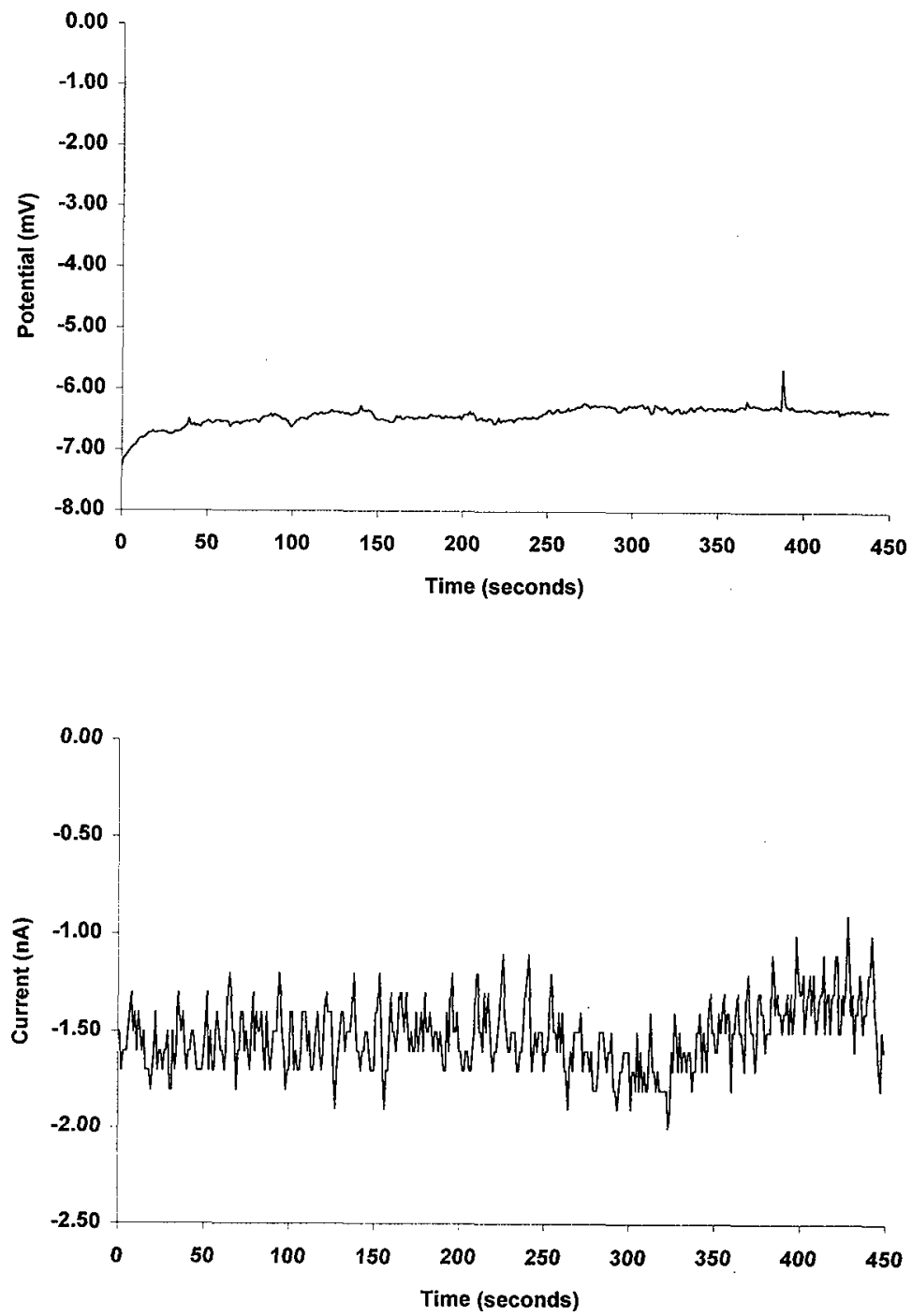

Figure 63: Typical raw potential and raw current data files: pin electrodes in vapor space on channel 1 - December 1997 

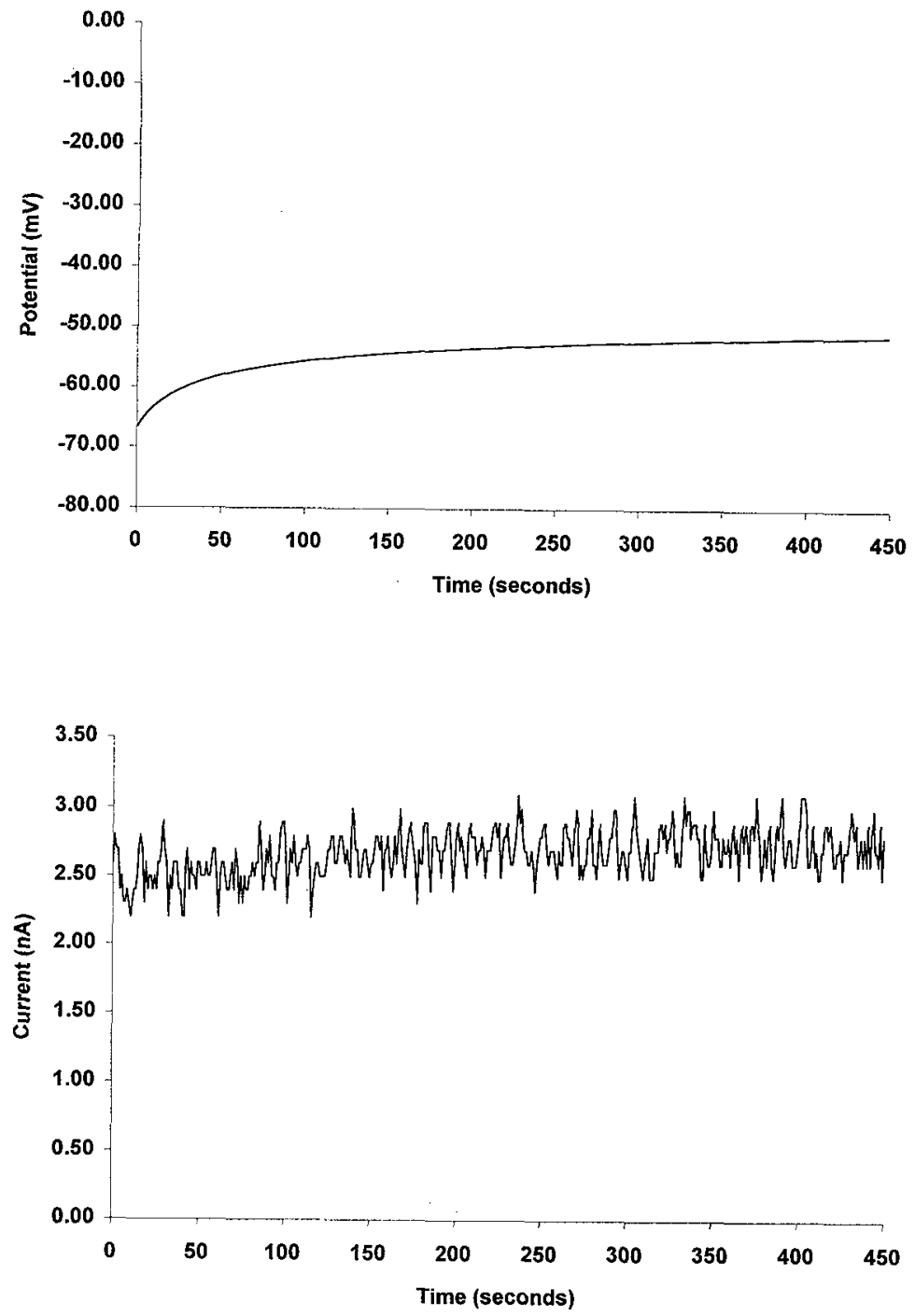

Figure 64: Typical raw potential and raw current data files: pin electrodes in vapor space on channel 1 - January 1998 
HNF-3414, Rev. 0
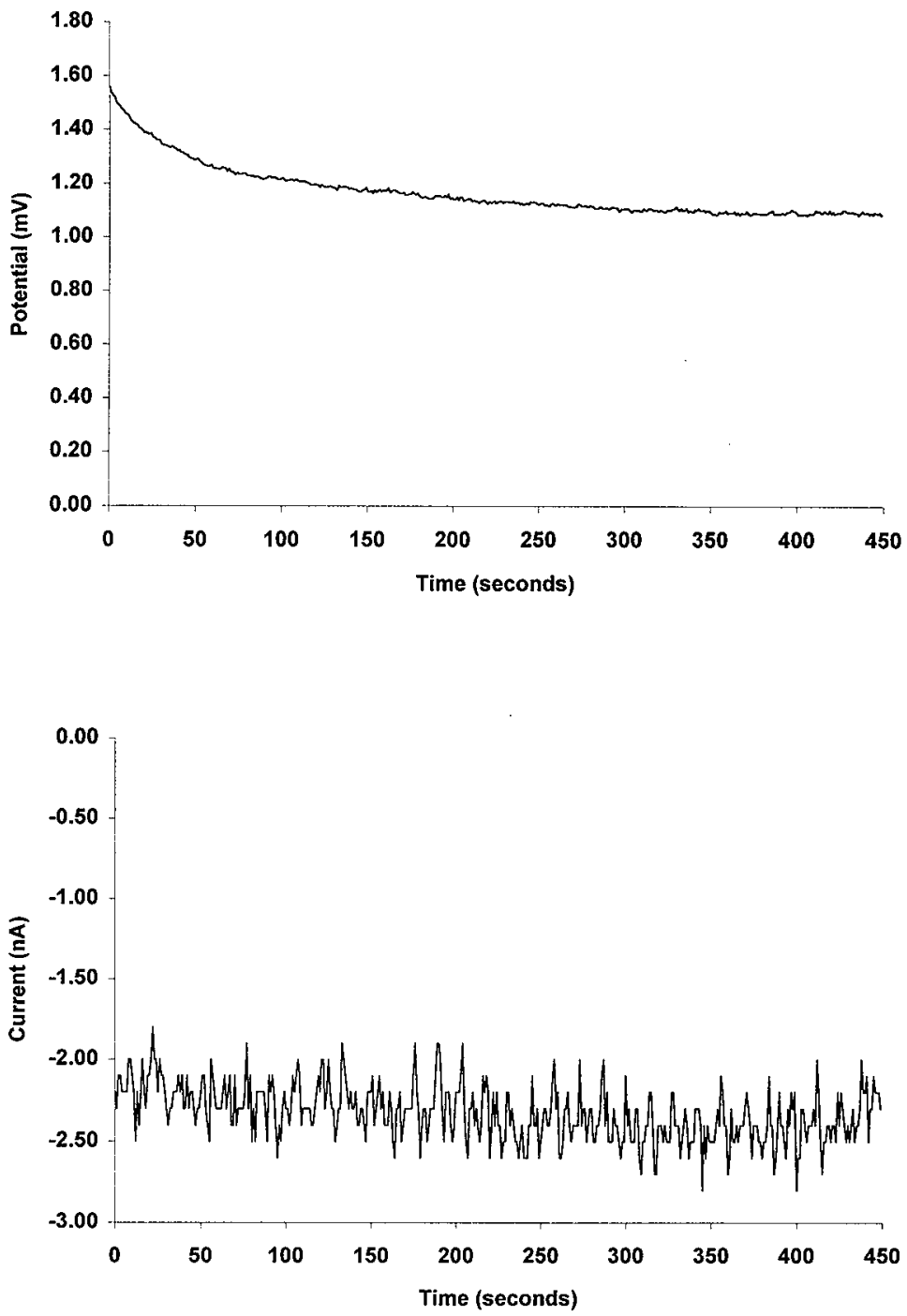

Figure 65: Typical raw potential and raw current data files: pin electrodes in vapor space on channel 1 - February 1998 

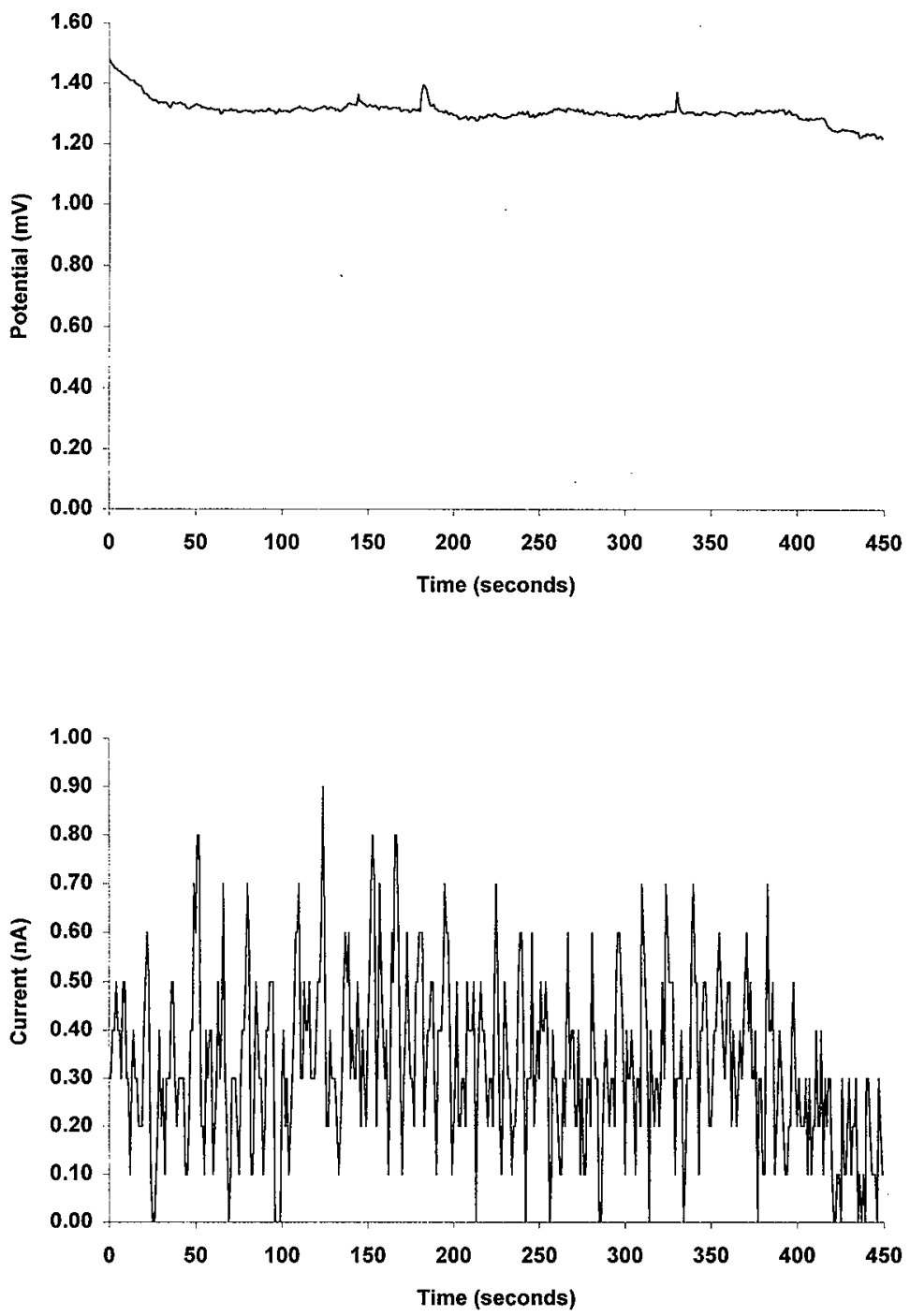

Figure 66: Typical raw potential and raw current data files: pin electrodes in vapor space on channel 1 - March 1998 

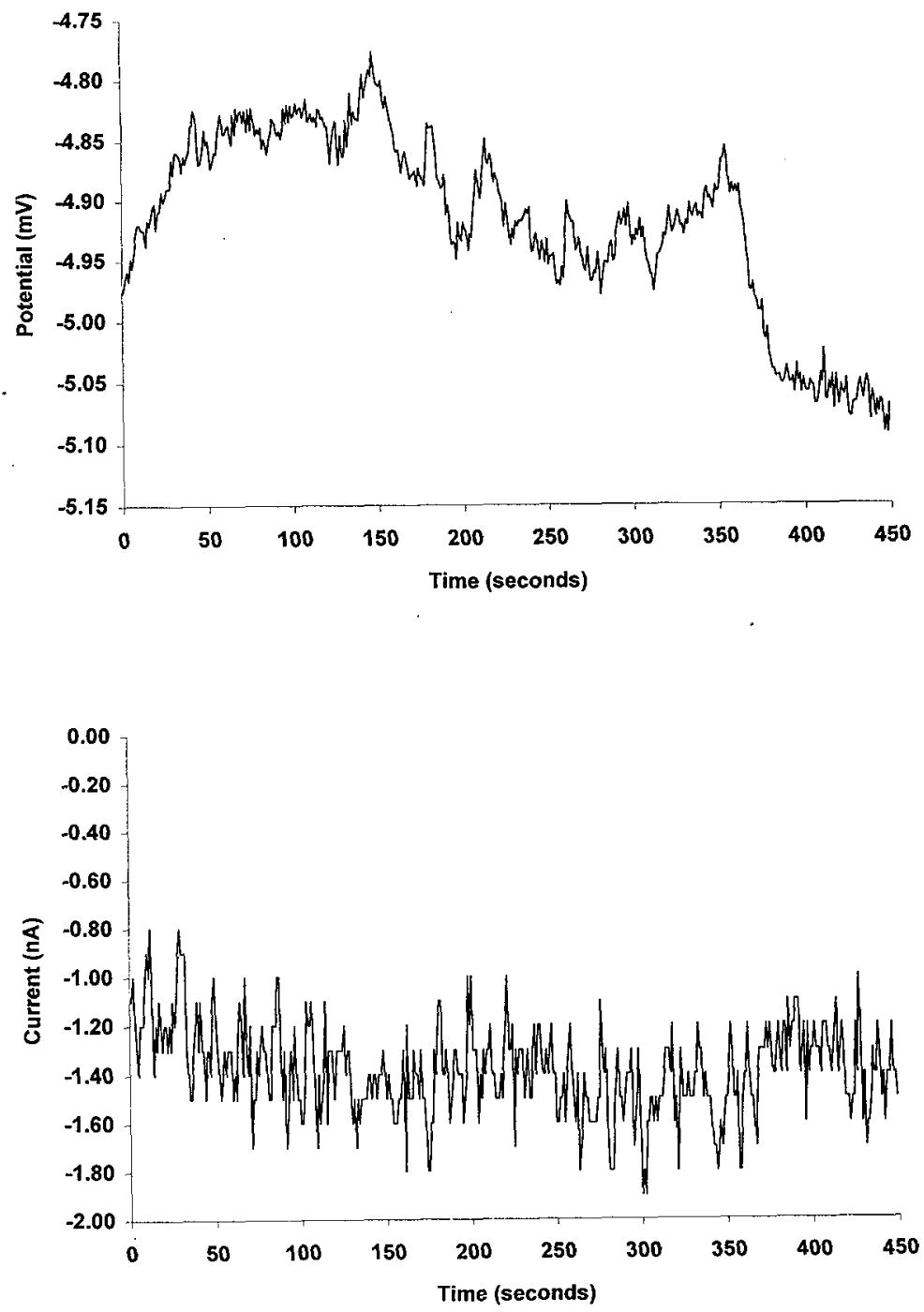

Figure 67: Typical raw potential and raw current data files: pin electrodes in vapor space on channel 1 - April 1998 

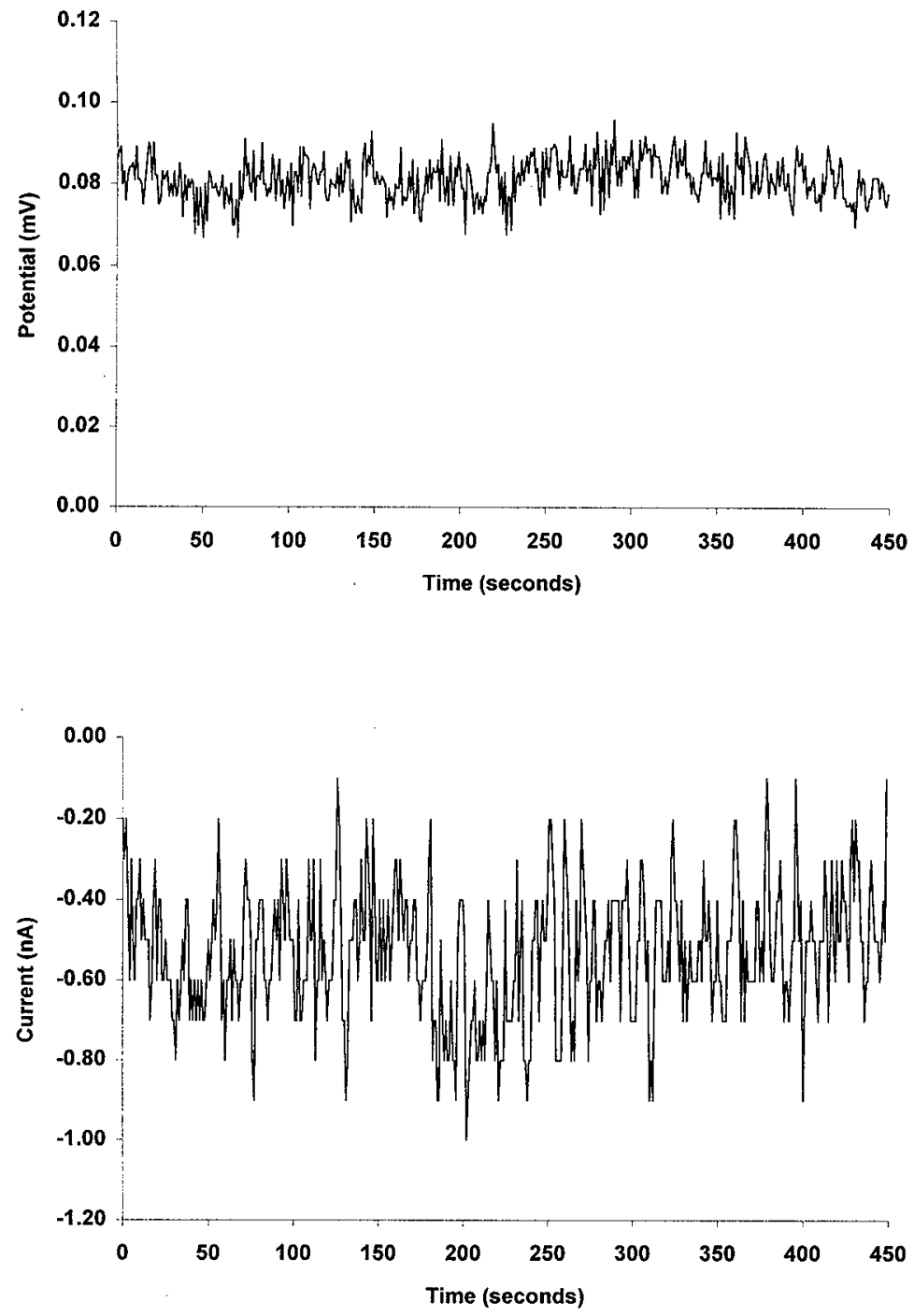

Figure 68: Typical raw potential and raw current data files: pin electrodes in vapor space on channel 1 - May 1998 

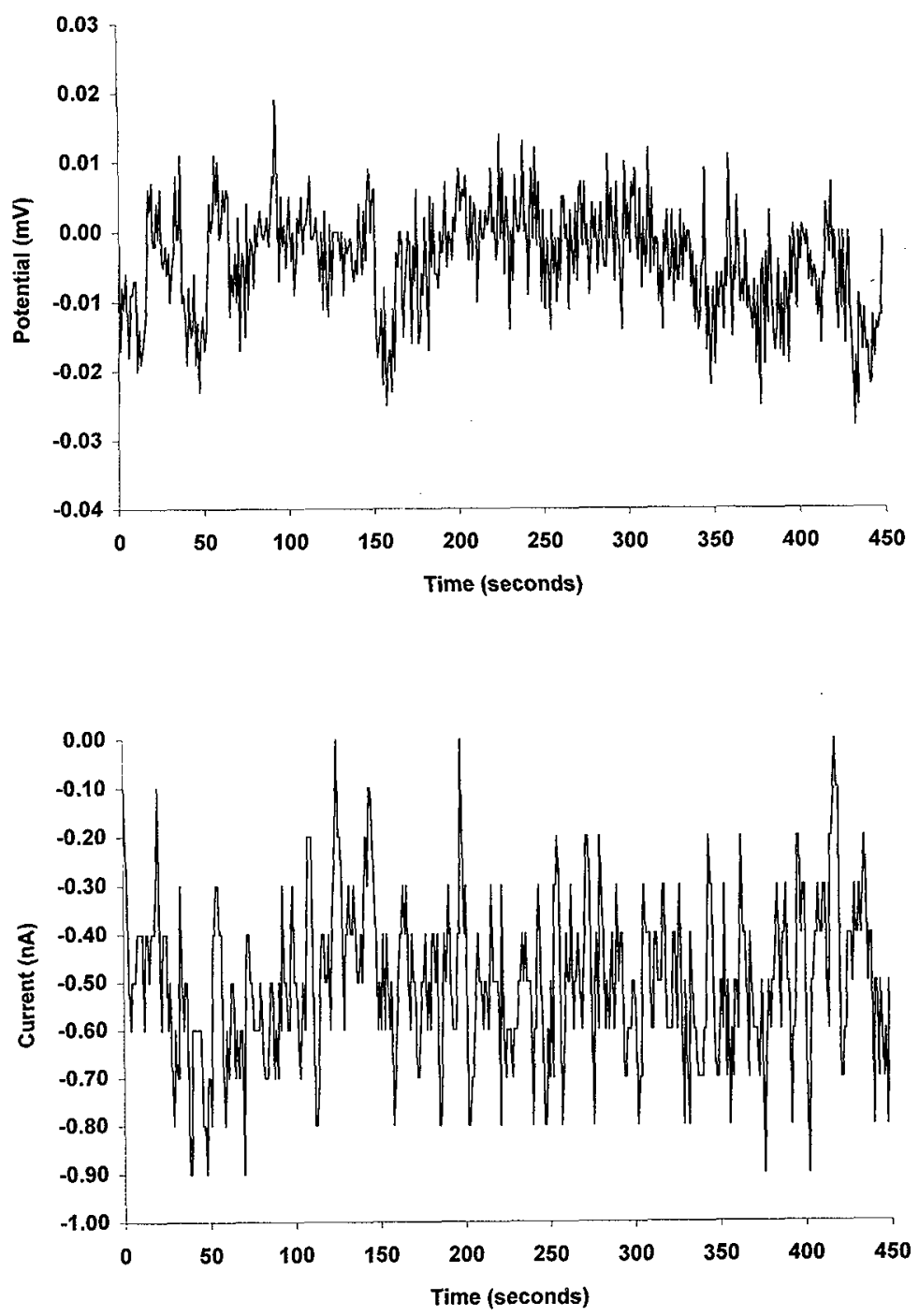

Figure 69: Typical raw potential and raw current data files: pin electrodes in vapor space on channel 1 - June 1998 

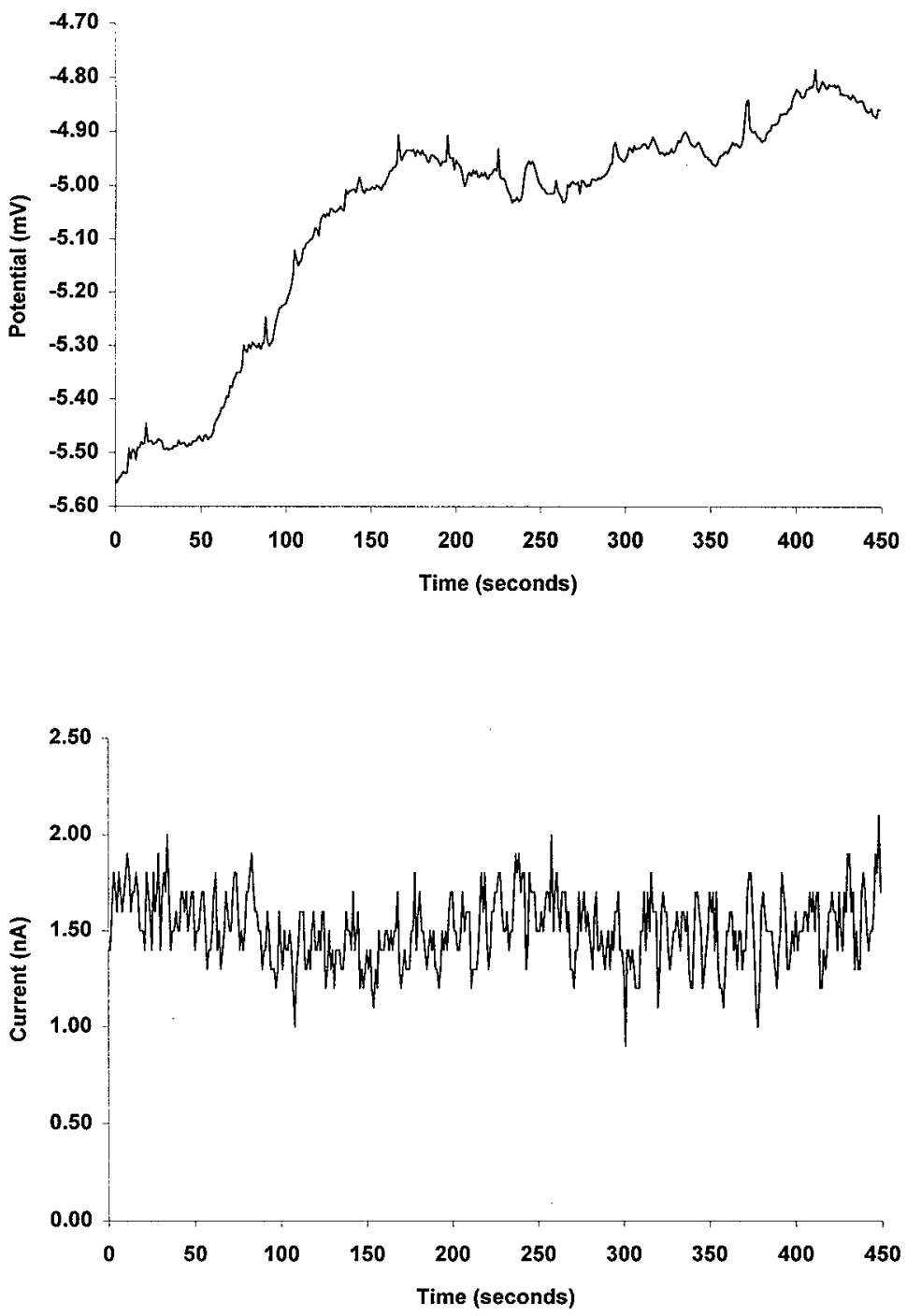

Figure 70: Typical raw potential and raw current data files: pin electrodes in vapor space on channel 1 - July 1998 

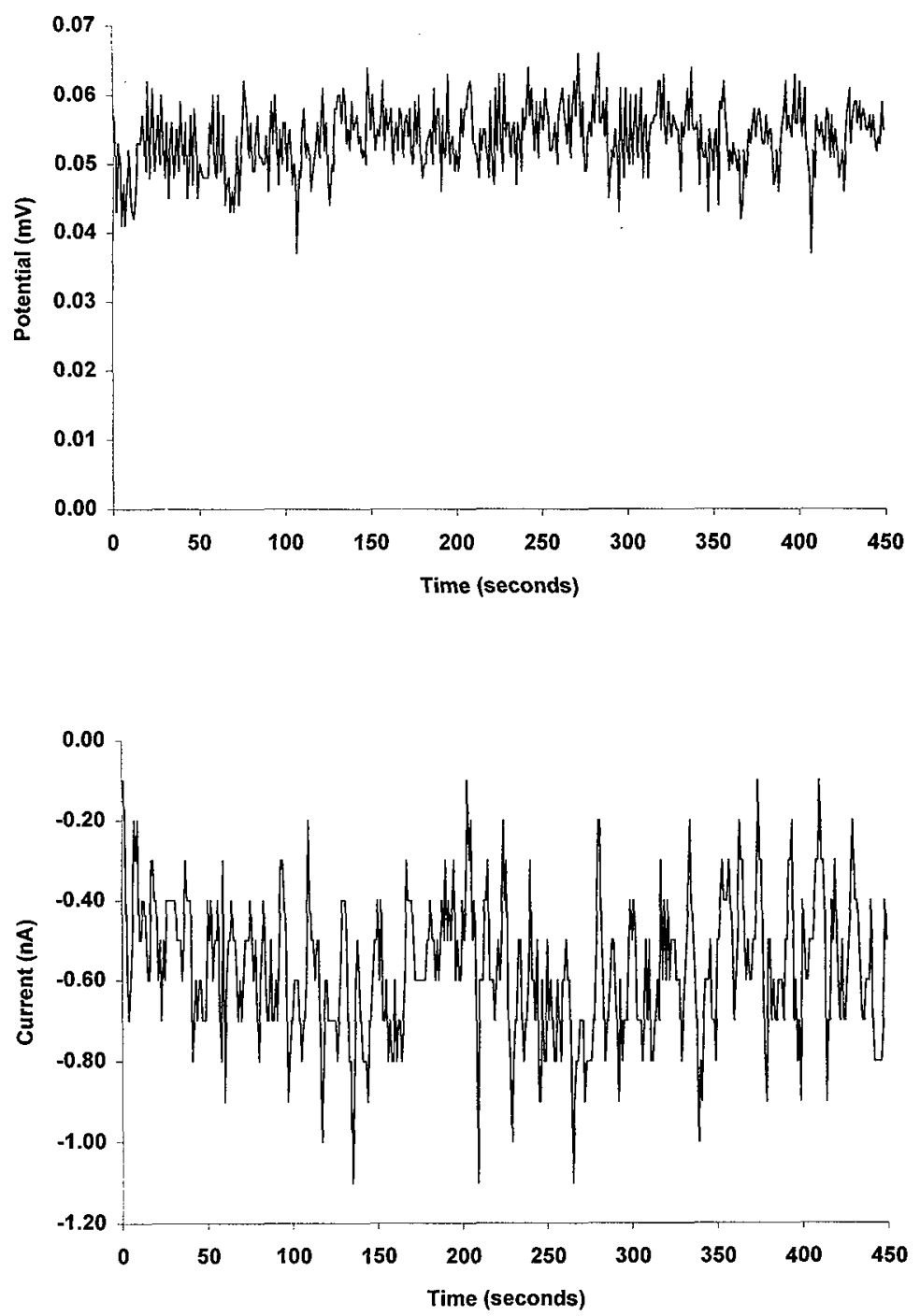

Figure 71: Typical raw potential and raw current data files: pin electrodes in vapor space on channel 1 - August 1998 

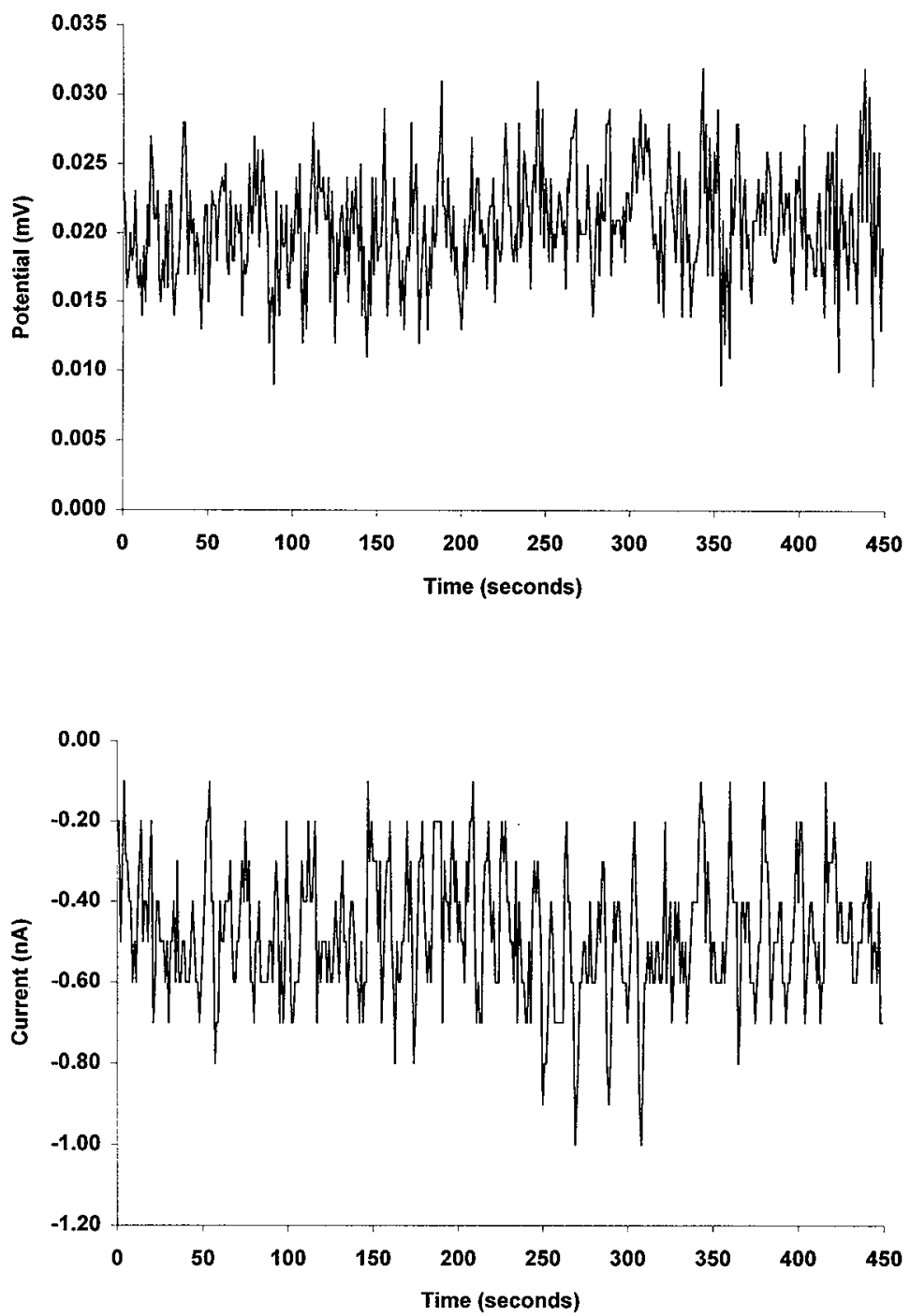

Figure 72: Typical raw potential and raw current data files: pin electrodes in vapor space on channel 1 - September 1998 

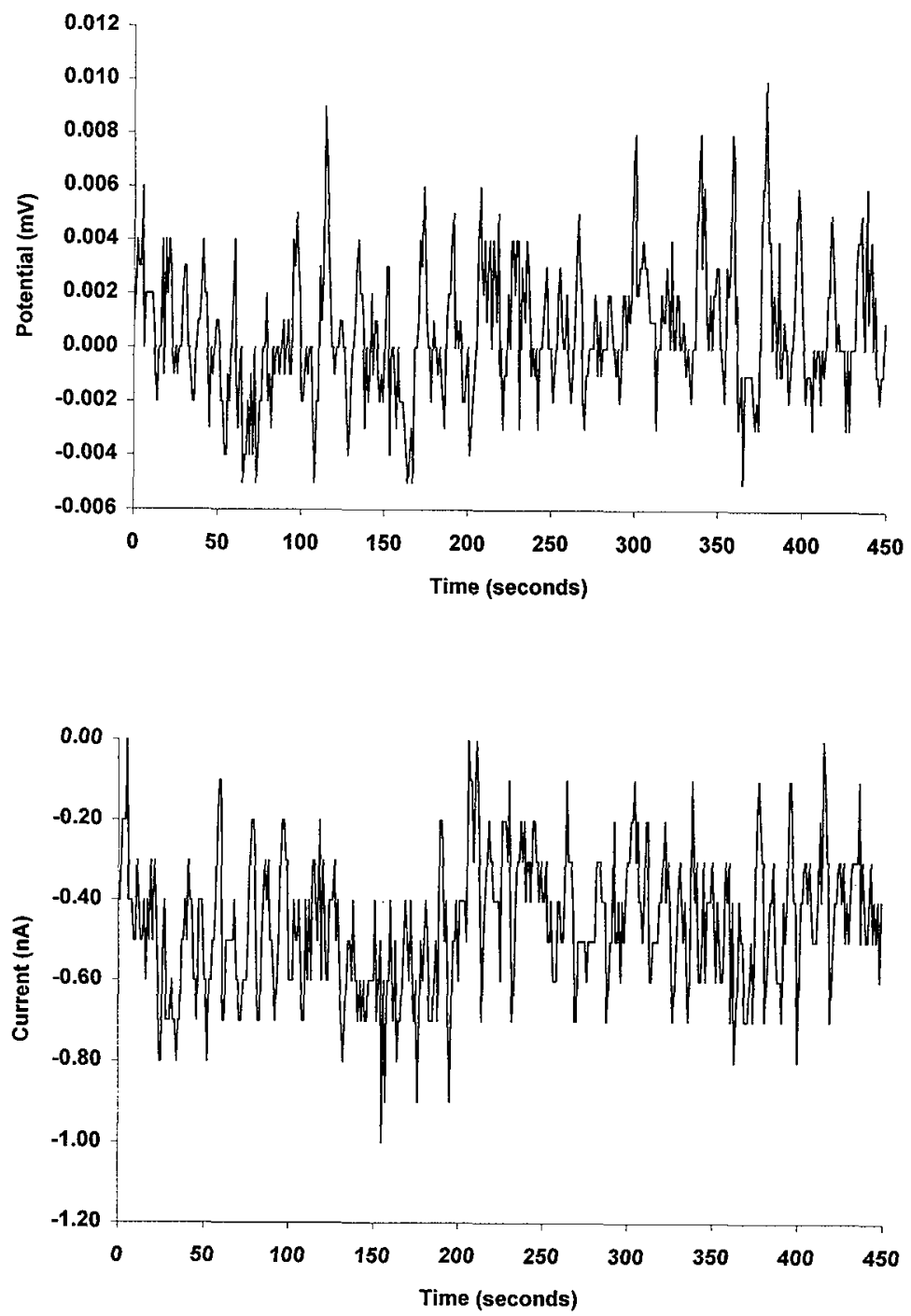

Figure 73: Typical raw potential and raw current data files: C-ring electrodes in vapor space on channel 2 - September 1997. 

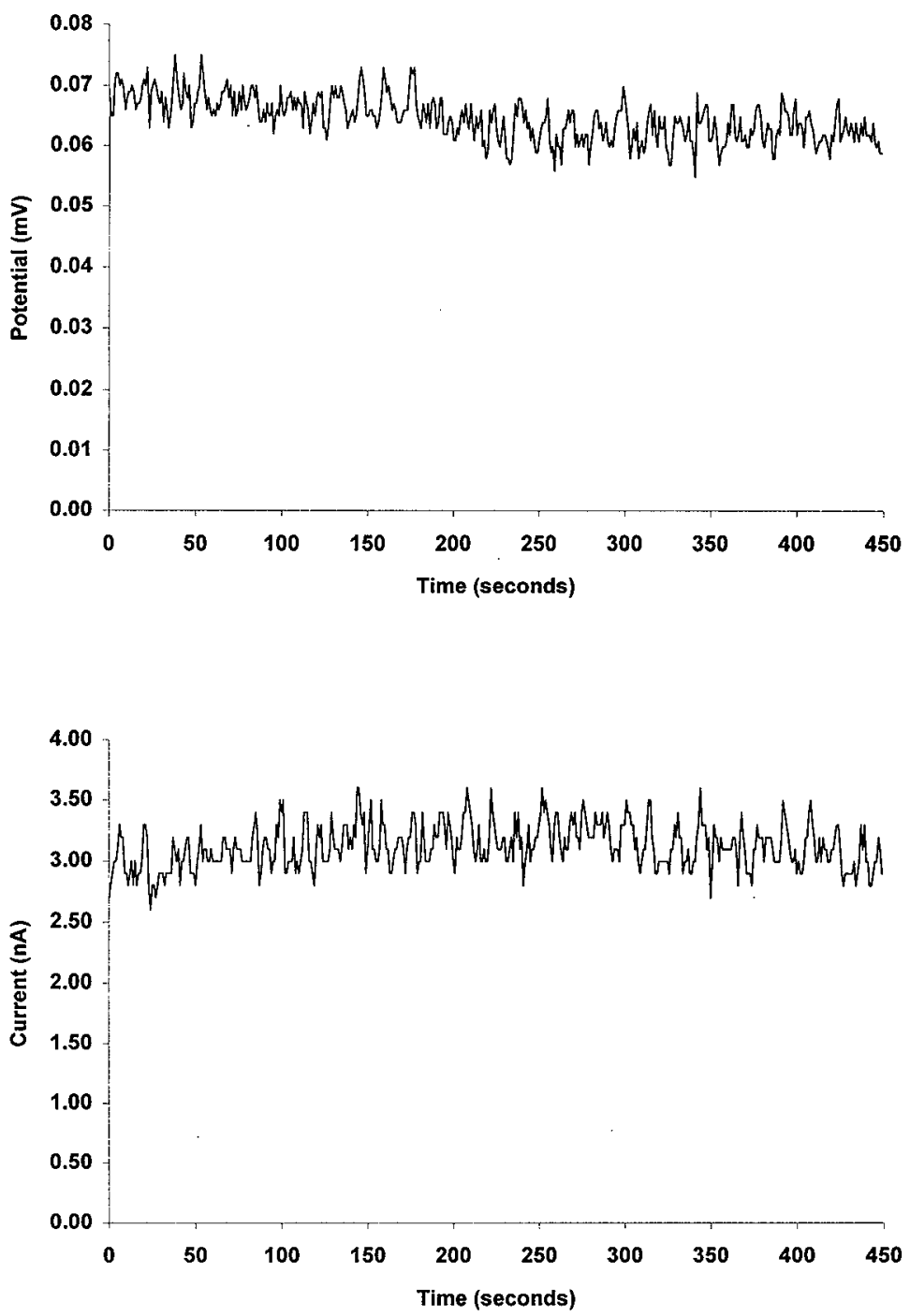

Figure 74: Typical raw potential and raw current data files: C-ring electrodes in vapor space on channel 2 - October 1997 

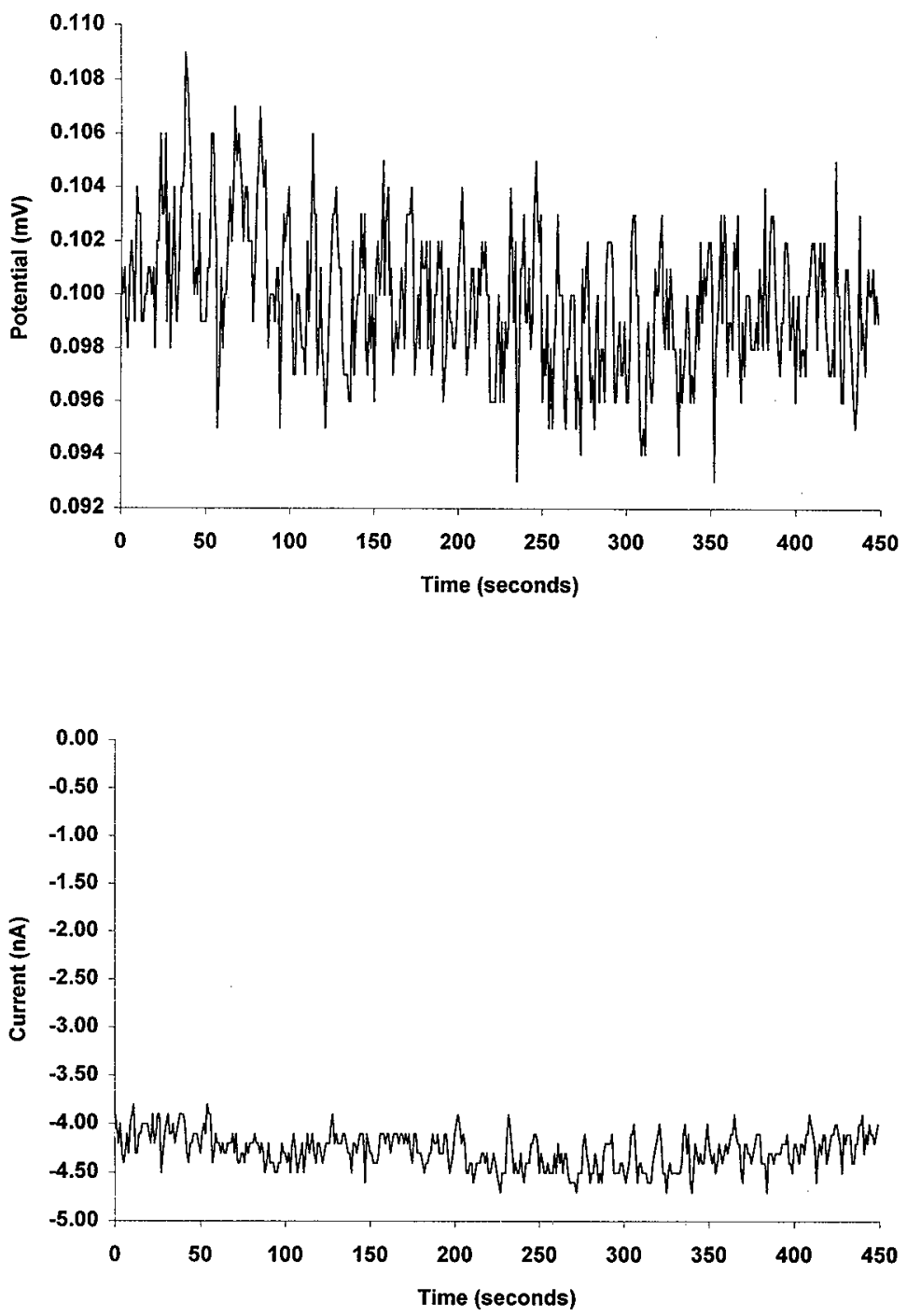

Figure 75: Typical raw potential and raw current data files: C-ring electrodes in vapor space on channel 2 - November 1997 

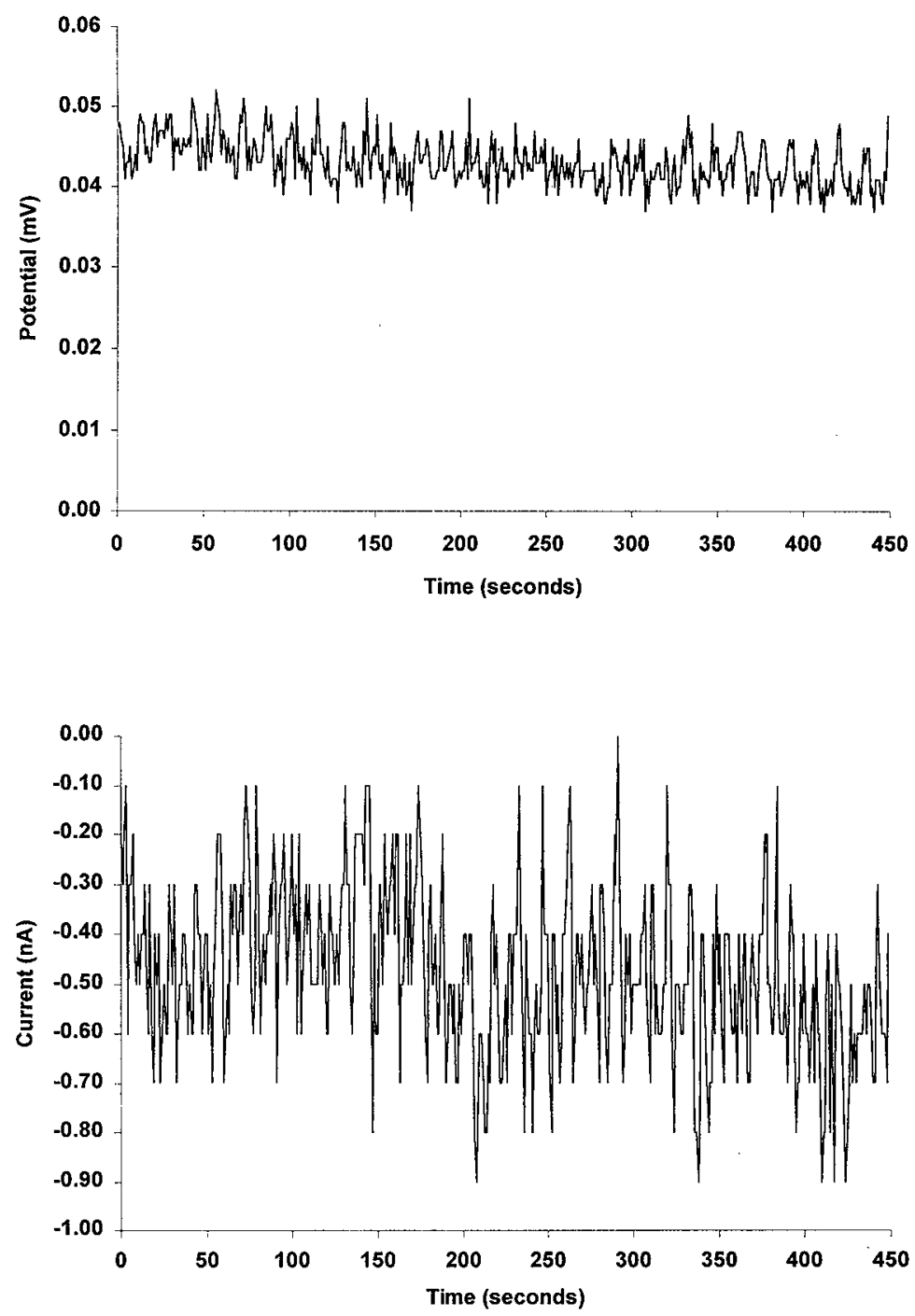

Figure 76: Typical raw potential and raw current data files: $\mathrm{C}$-ring electrodes in vapor space on channel 2 - December 1997 

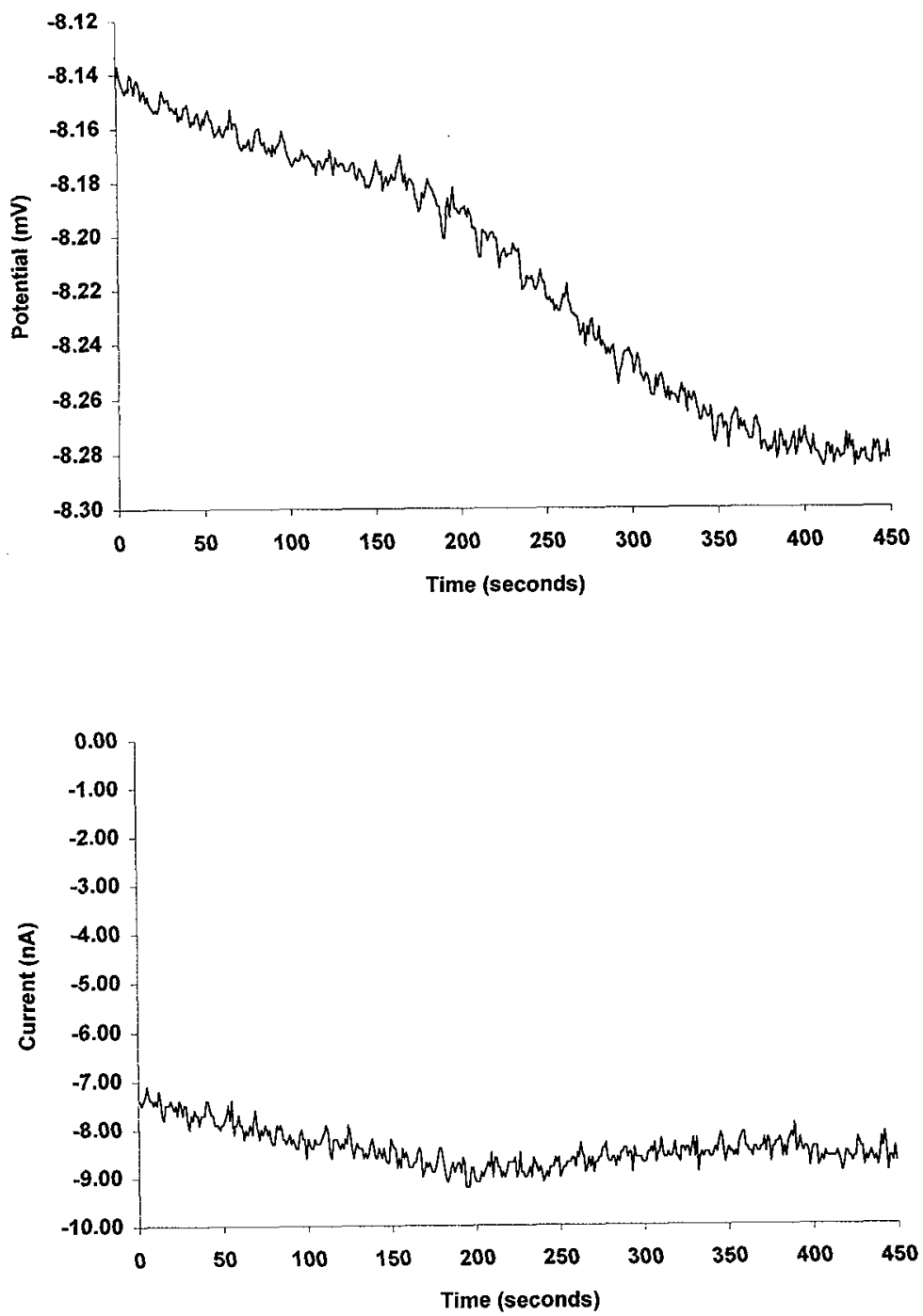

Figure 77: Typical raw potential and raw current data files: C-ring electrodes in vapor space on channel 2 - January 1998 

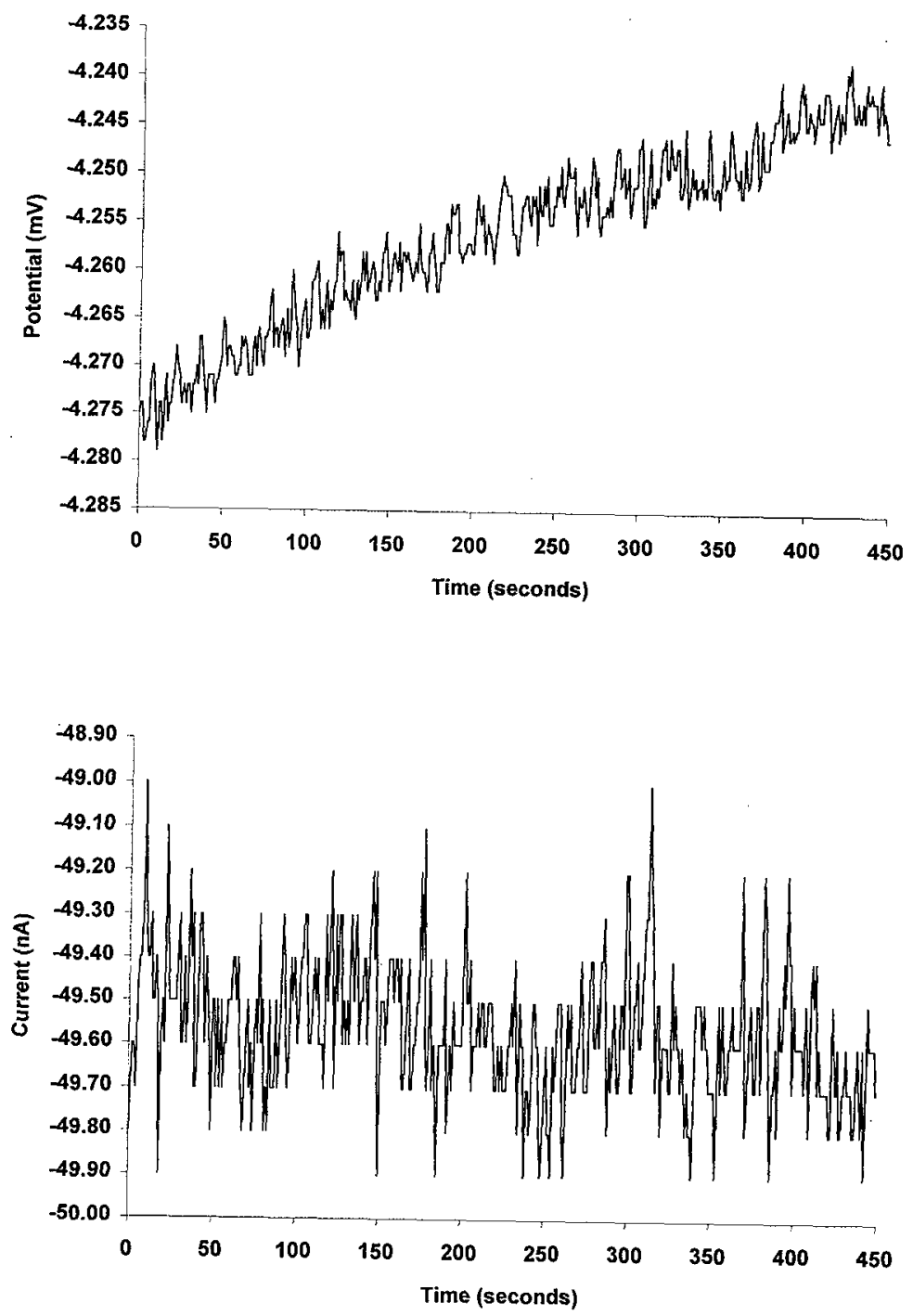

Figure 78: Typical raw potential and raw current data files: C-ring electrodes in vapor space on channel 2 - February 1998 

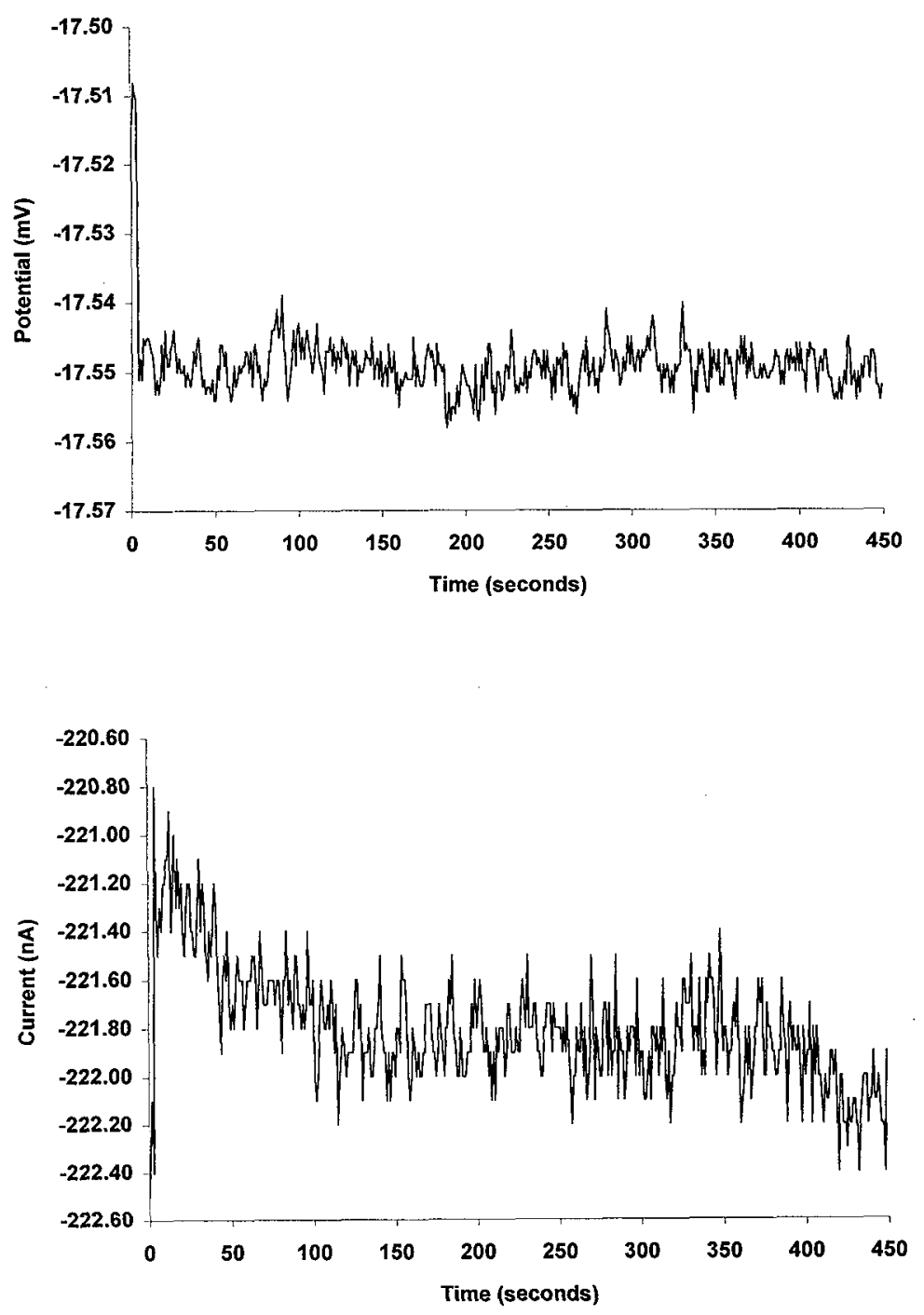

Figure 79: Typical raw potential and raw current data files: C-ring electrodes in vapor space on channel 2 - March 1998 

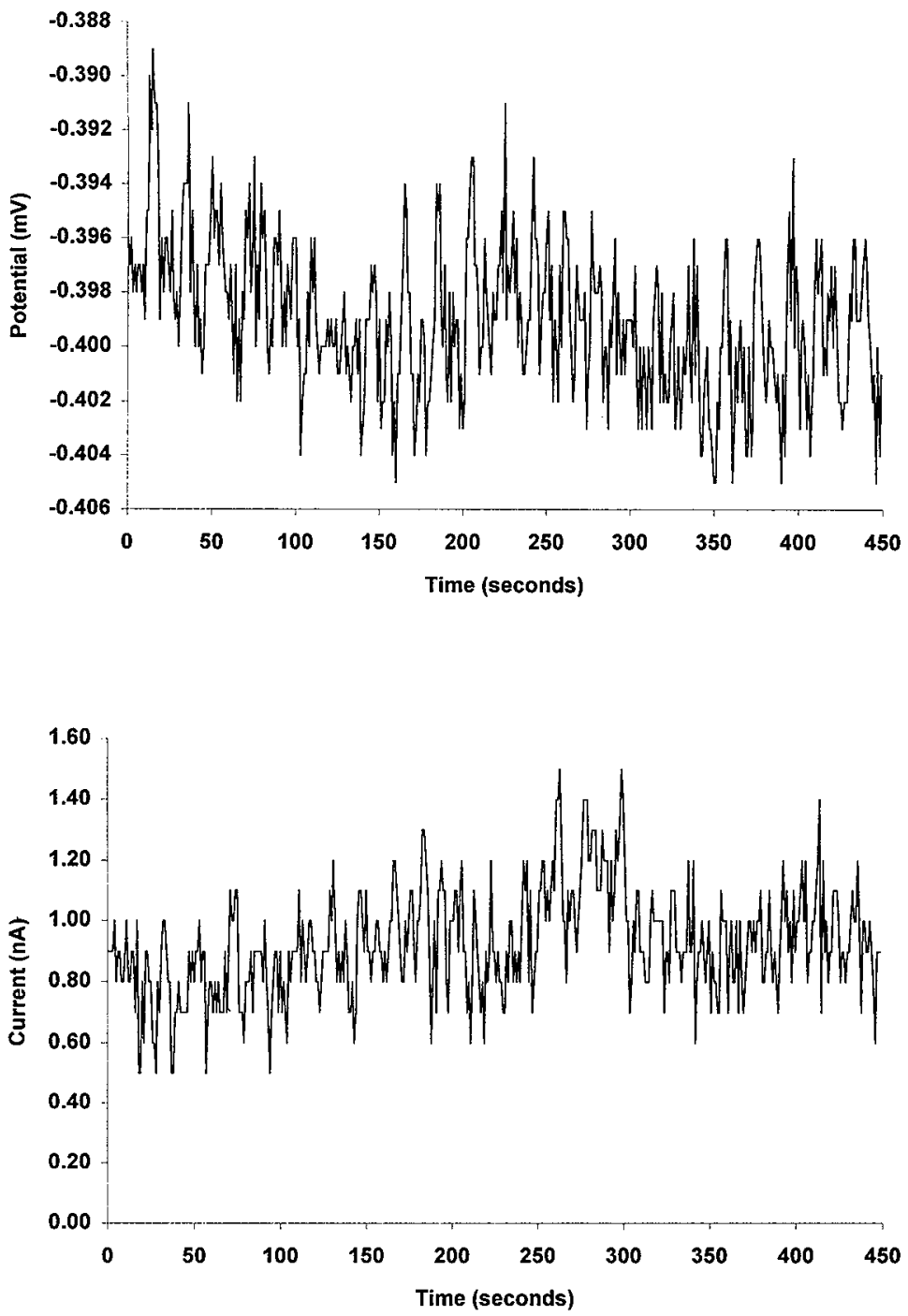

Figure 80: Typical raw potential and raw current data files: C-ring electrodes in vapor space on channel 2 - April 1998 
HNF-3414, Rev. 0
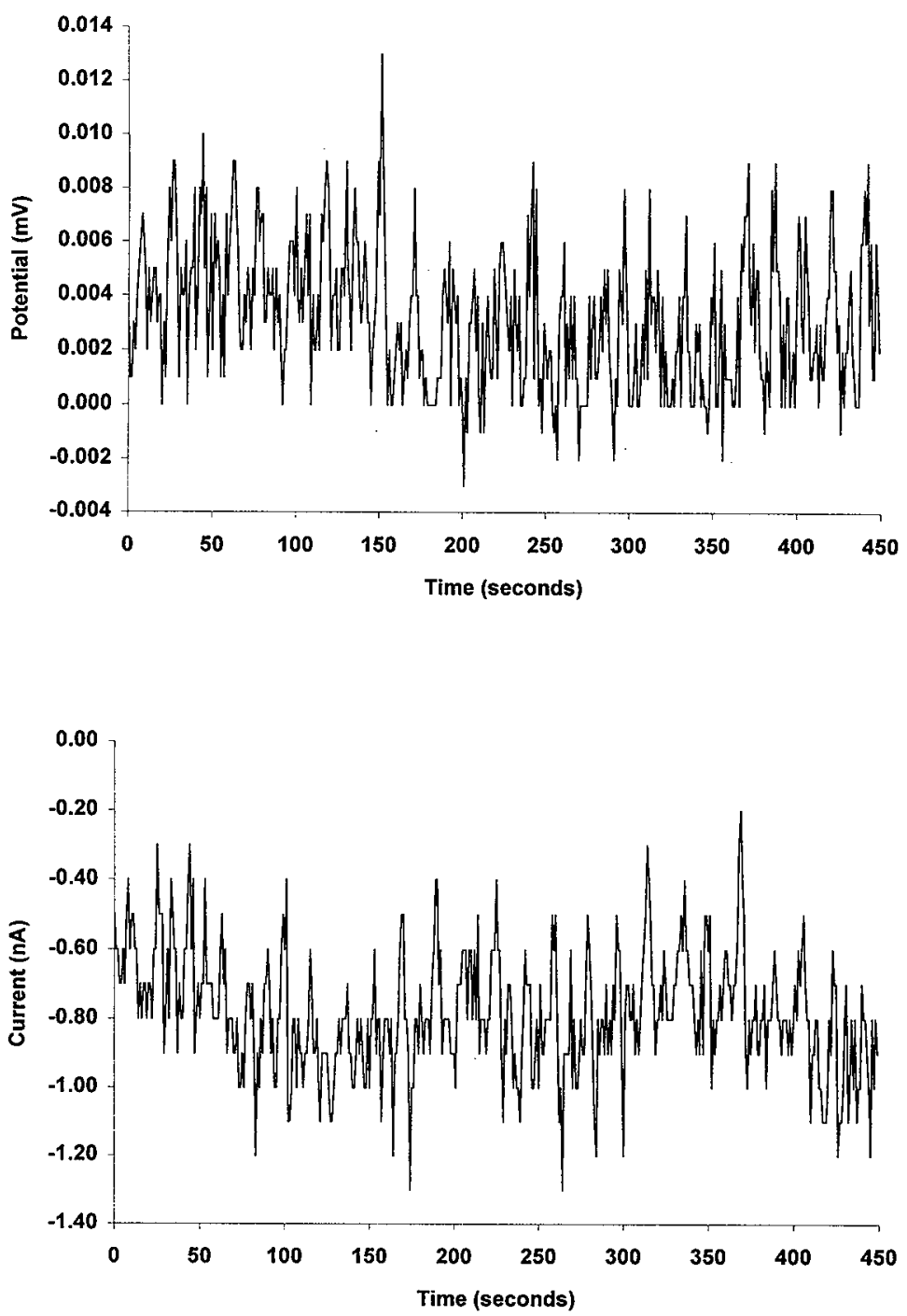

Figure 81: Typical raw potential and raw current data files: C-ring electrodes in vapor space on channel 2 - May 1998 

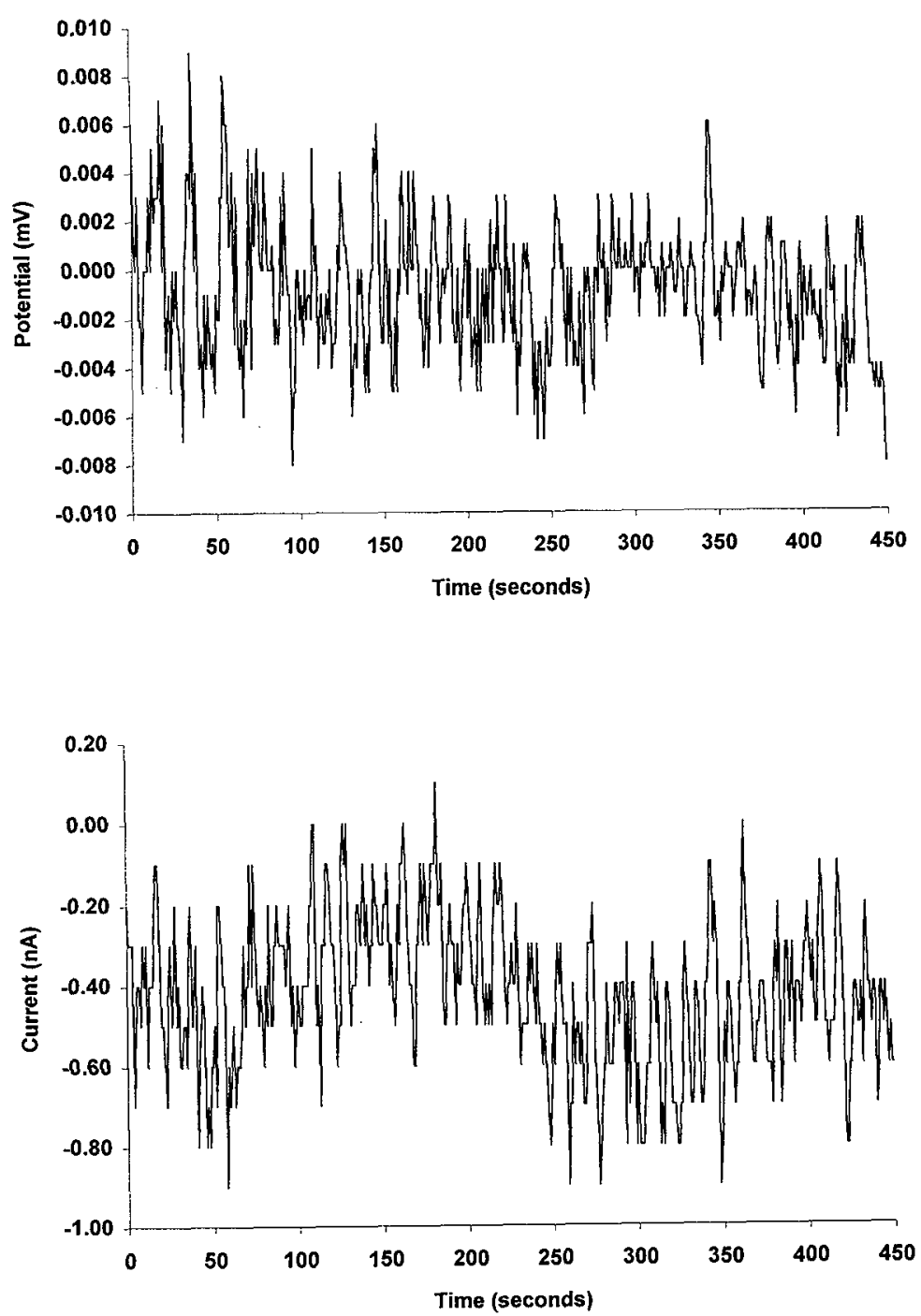

Figure 82: Typical raw potential and raw current data files: C-ring electrodes in vapor space on channel 2 - June 1998 

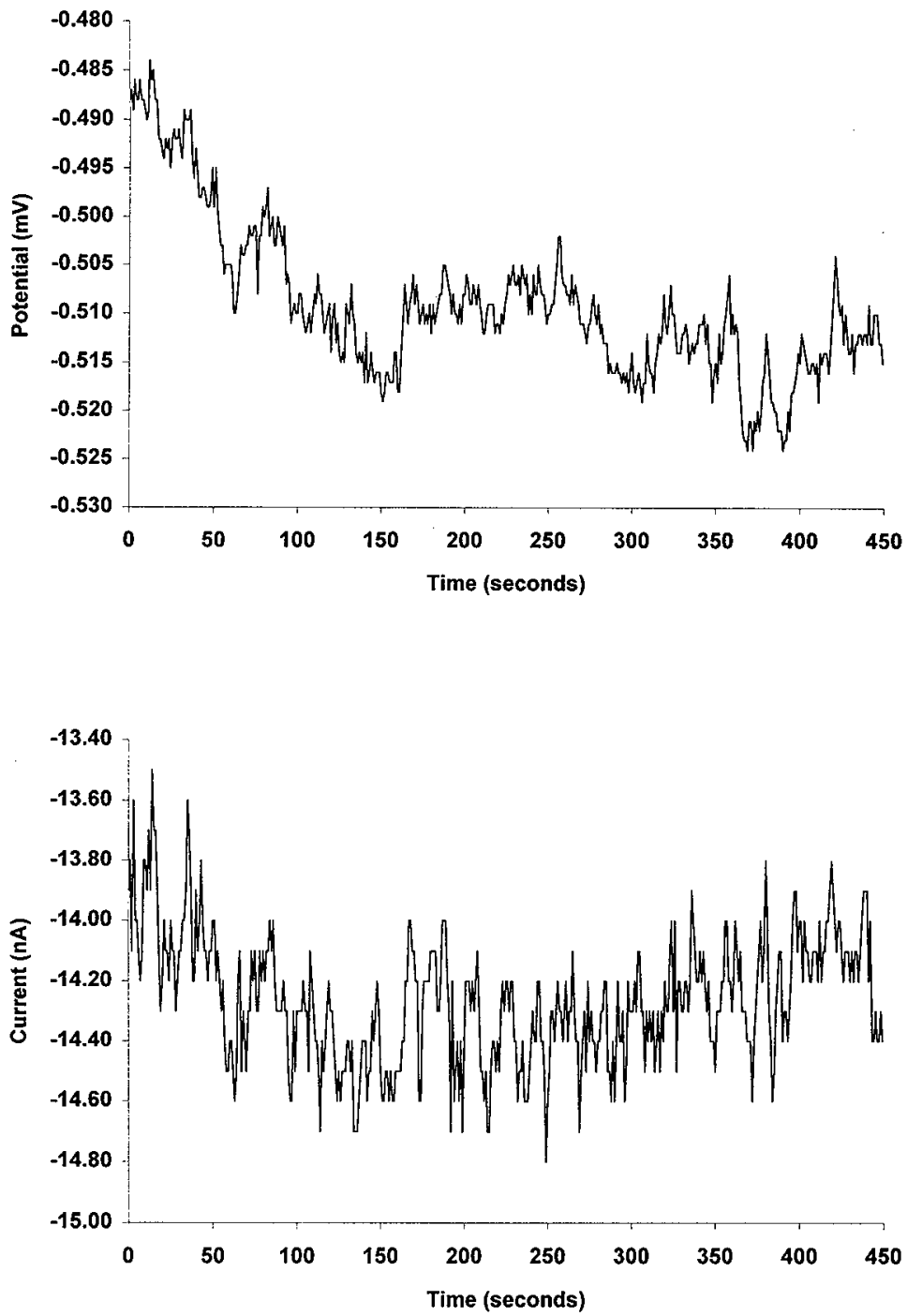

Figure 83: Typical raw potential and raw current data files: C-ring electrodes in vapor space on channel 2 - July 1998 

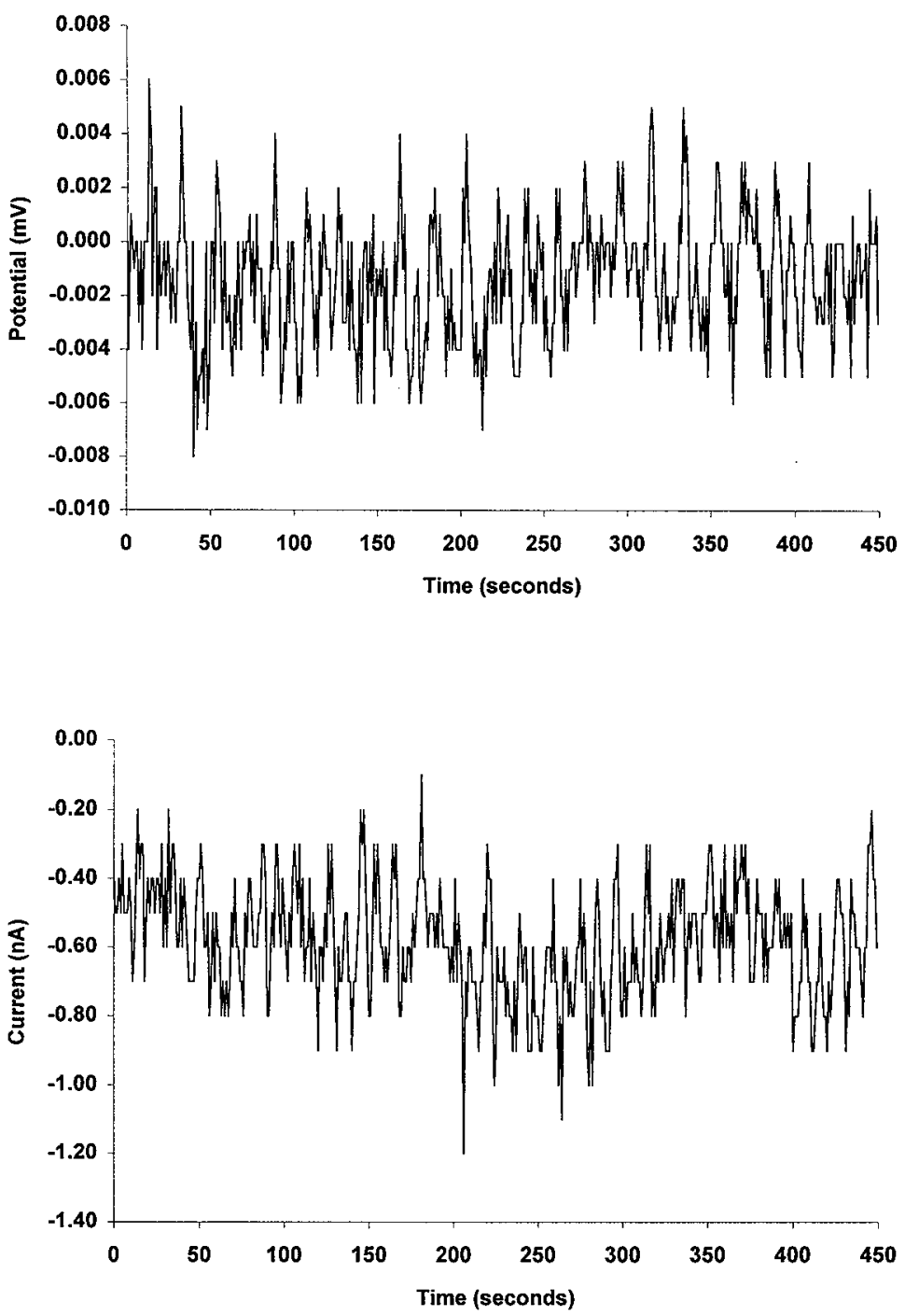

Figure 84: Typical raw potential and raw current data files: C-ring electrodes in vapor space on channel 2 - August 1998 

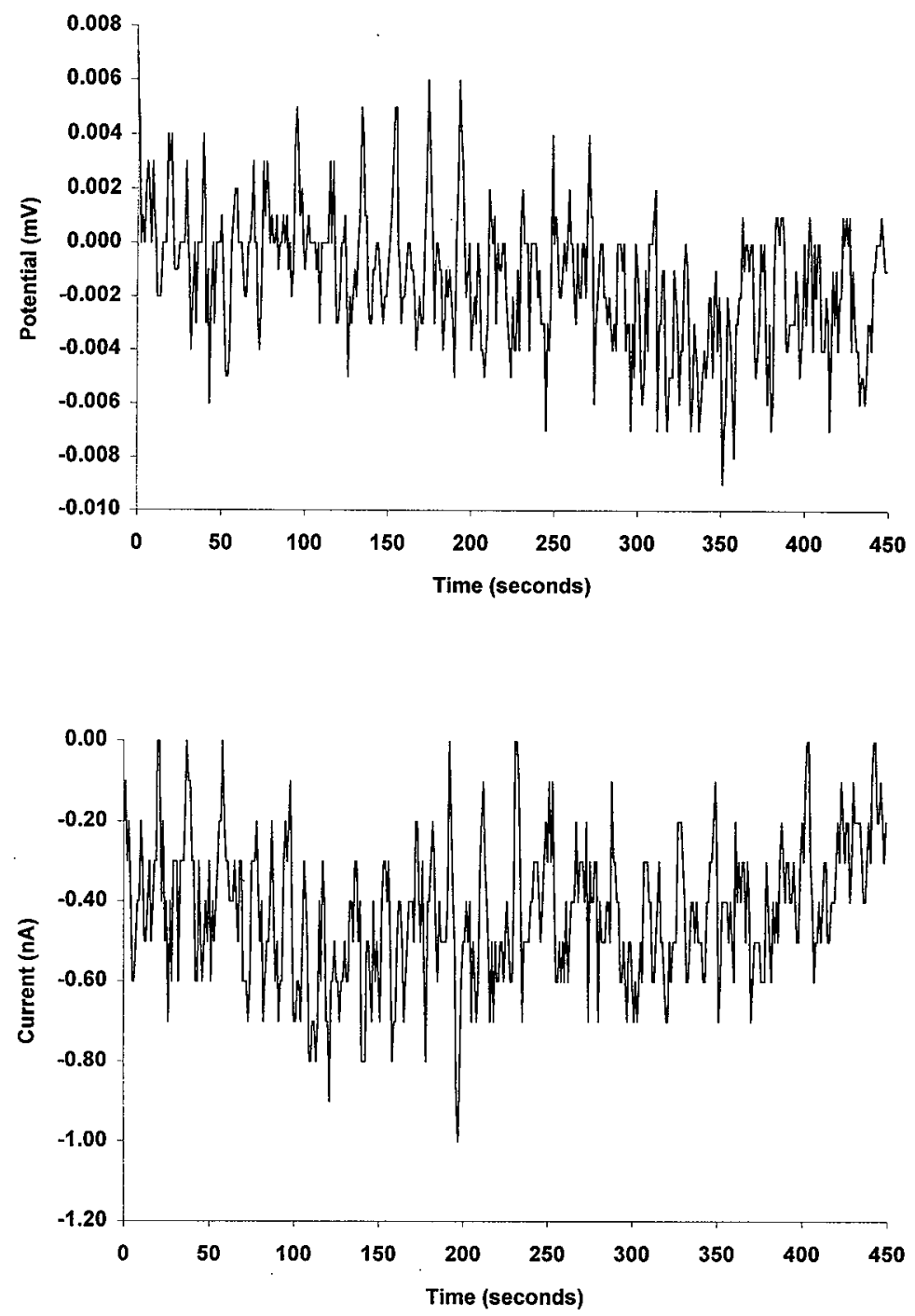

Figure 85: Typical raw potential and raw current data files: C-ring electrodes in vapor space on channel 2 - September 1998 

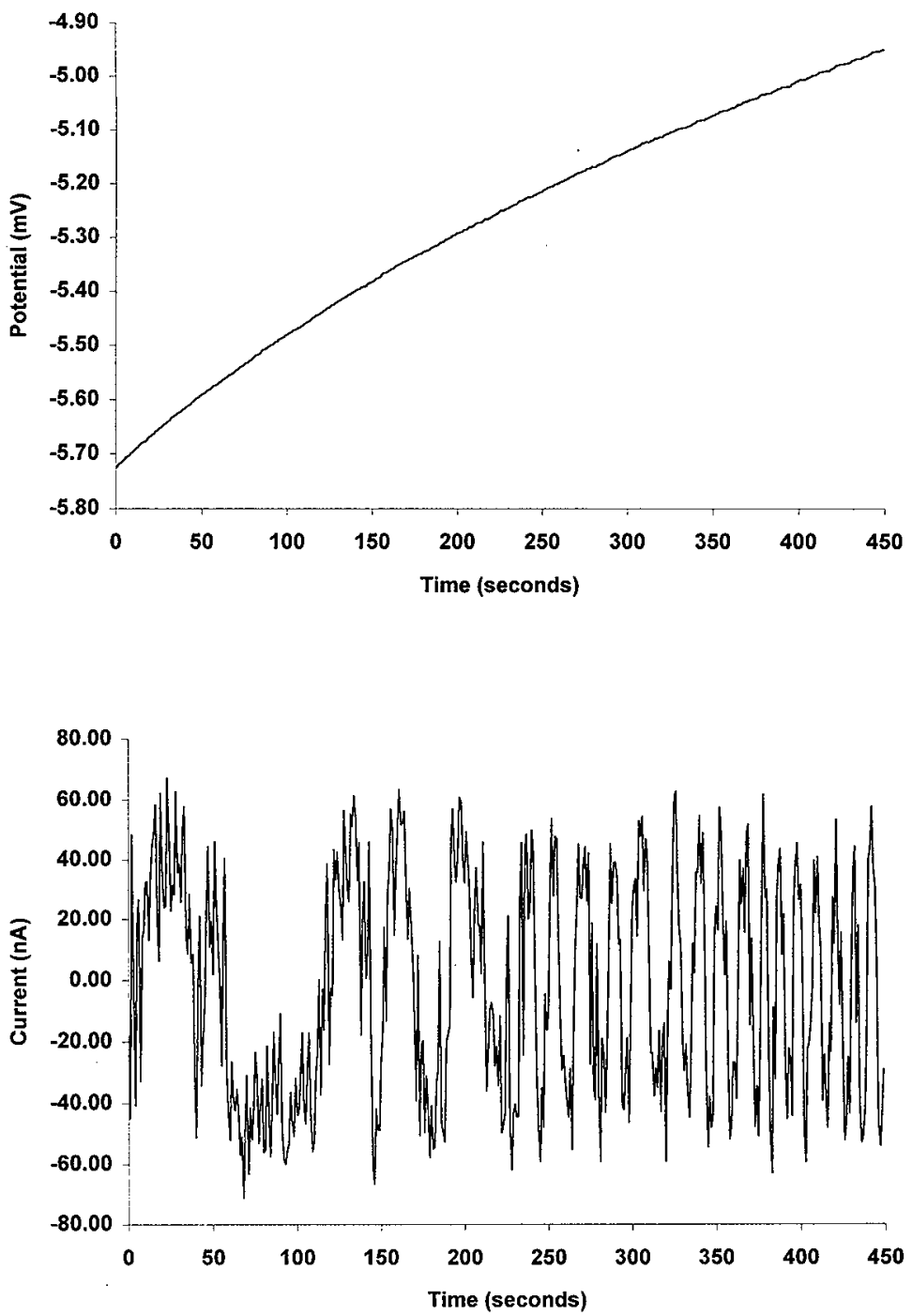

Figure 86: Typical raw potential and raw current data files: pin electrodes in supernate on channel 3 - September 1997 
HNF-3414, Rev. 0
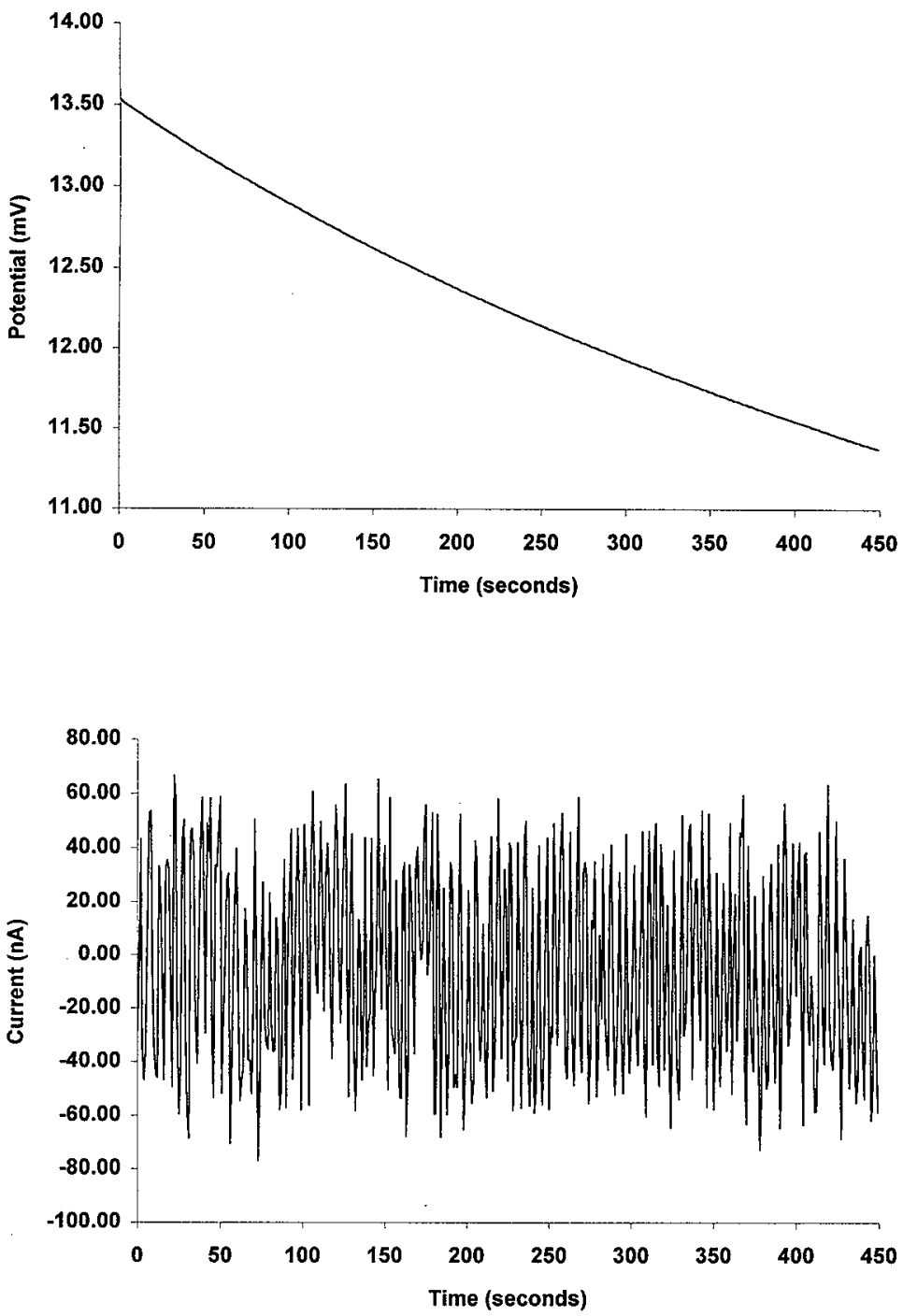

Figure 87: Typical raw potential and raw current data files: pin electrodes in supernate on channel 3 - October 1997 
HNF-3414, Rev. 0
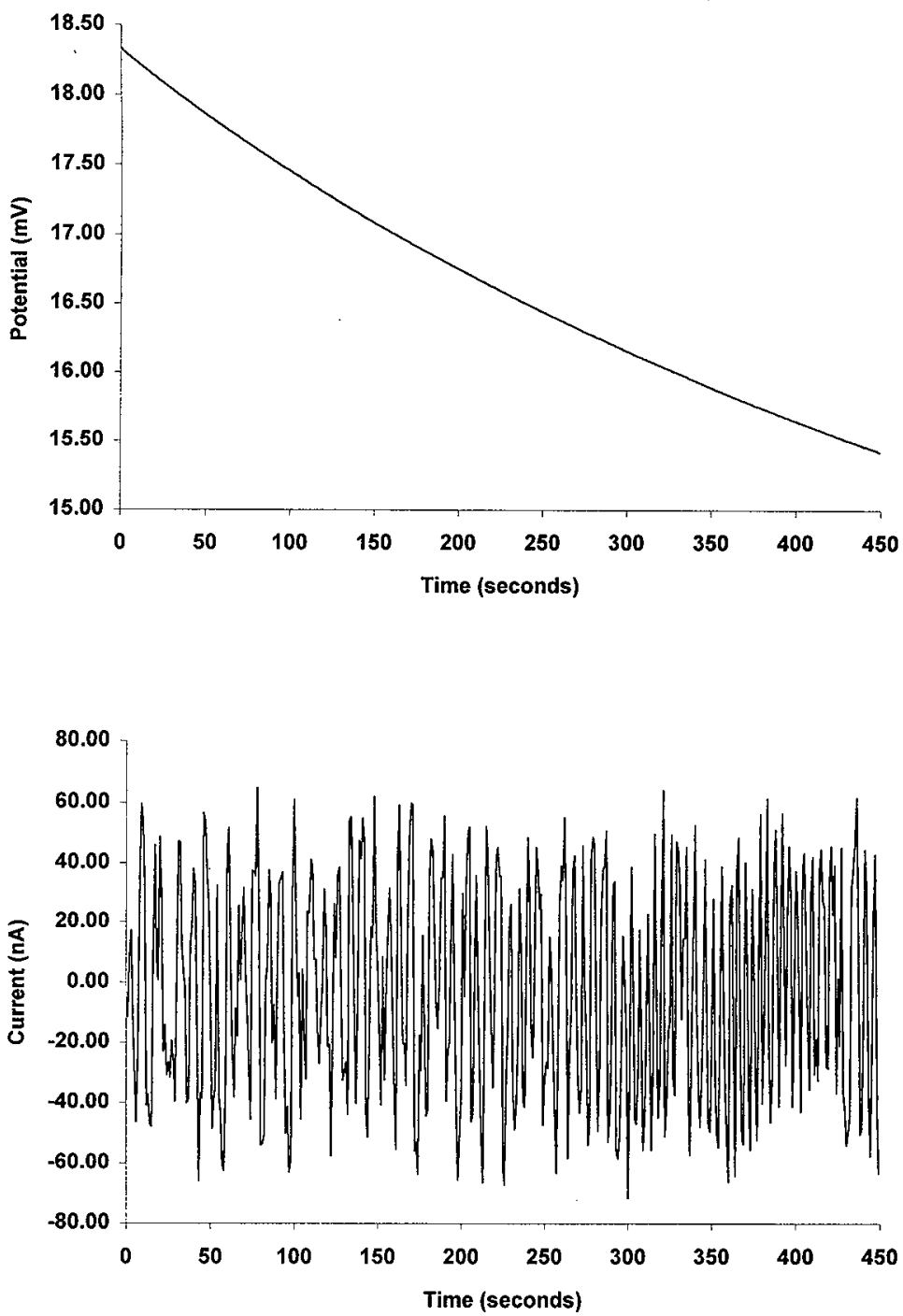

Figure 88: Typical raw potential and raw current data files: pin electrodes in supernate on channel 3 - November 1997 
HNF-3414, Rev. 0
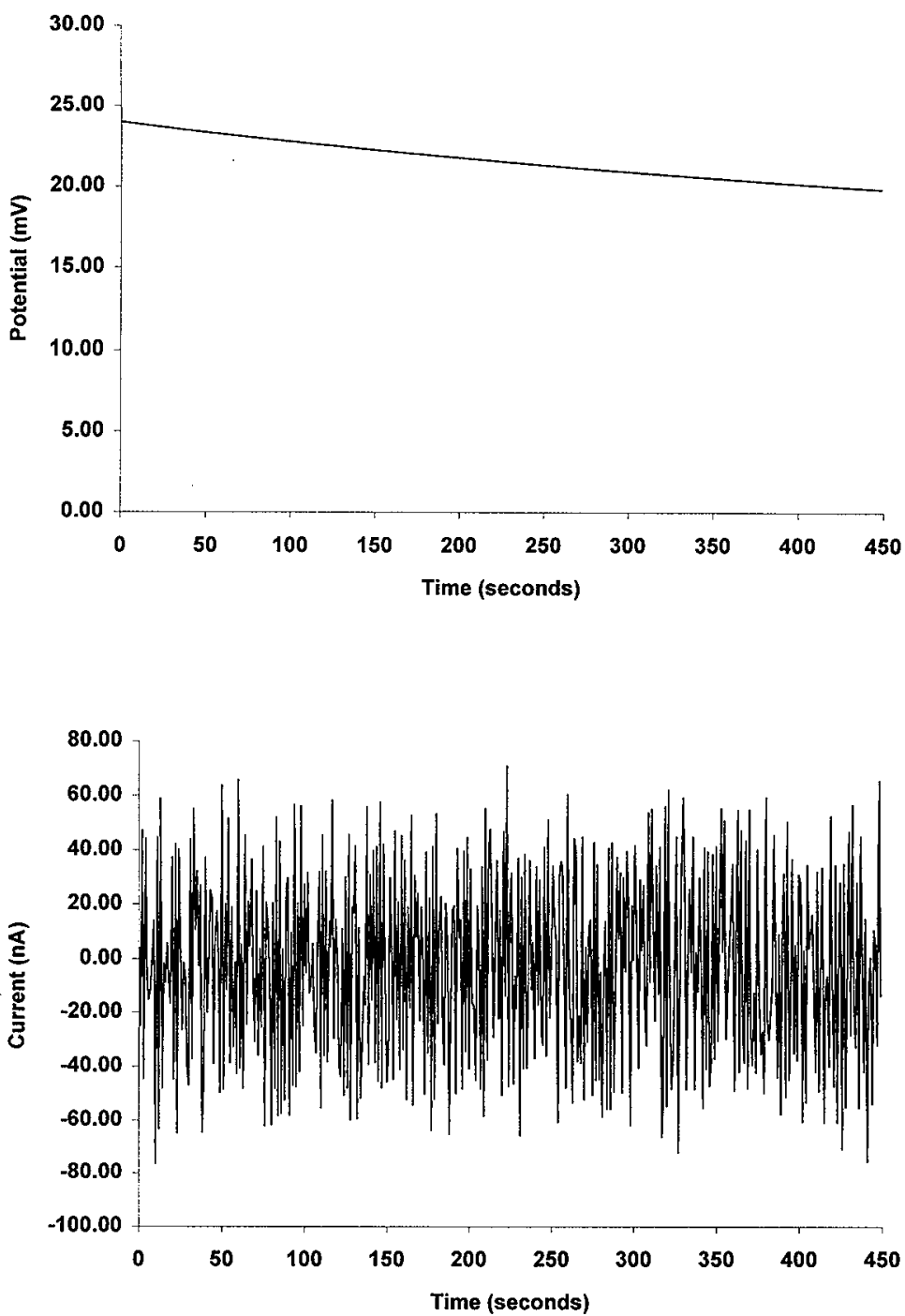

Figure 89: Typical raw potential and raw current data files: pin electrodes in supernate on channel 3 - December 1997 

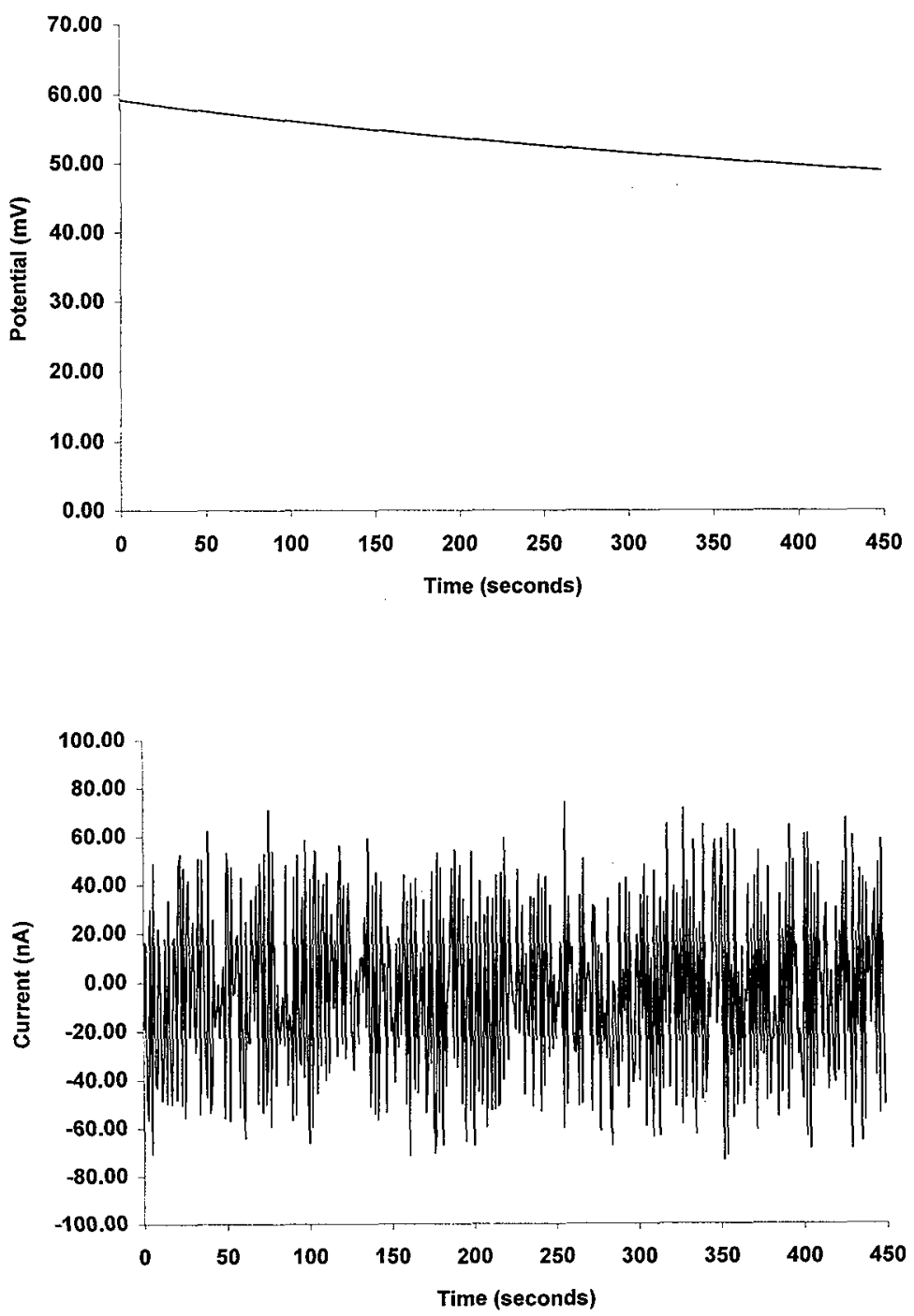

Figure 90: Typical raw potential and raw current data files: pin electrodes in supernate on channel 3 - January 1998 

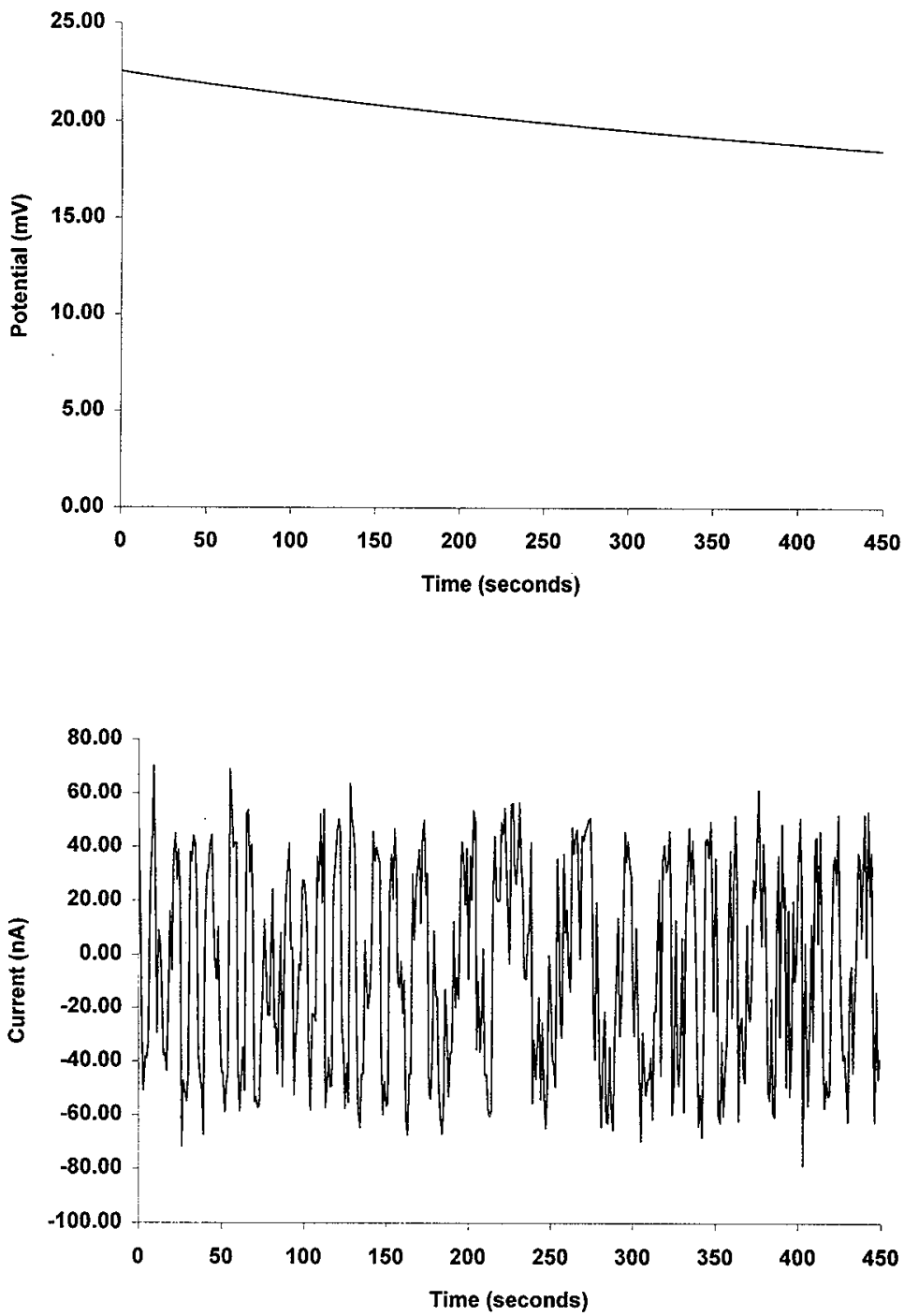

Figure 91: Typical raw potential and raw current data files: pin electrodes in supernate on channel 3 - February 1998 

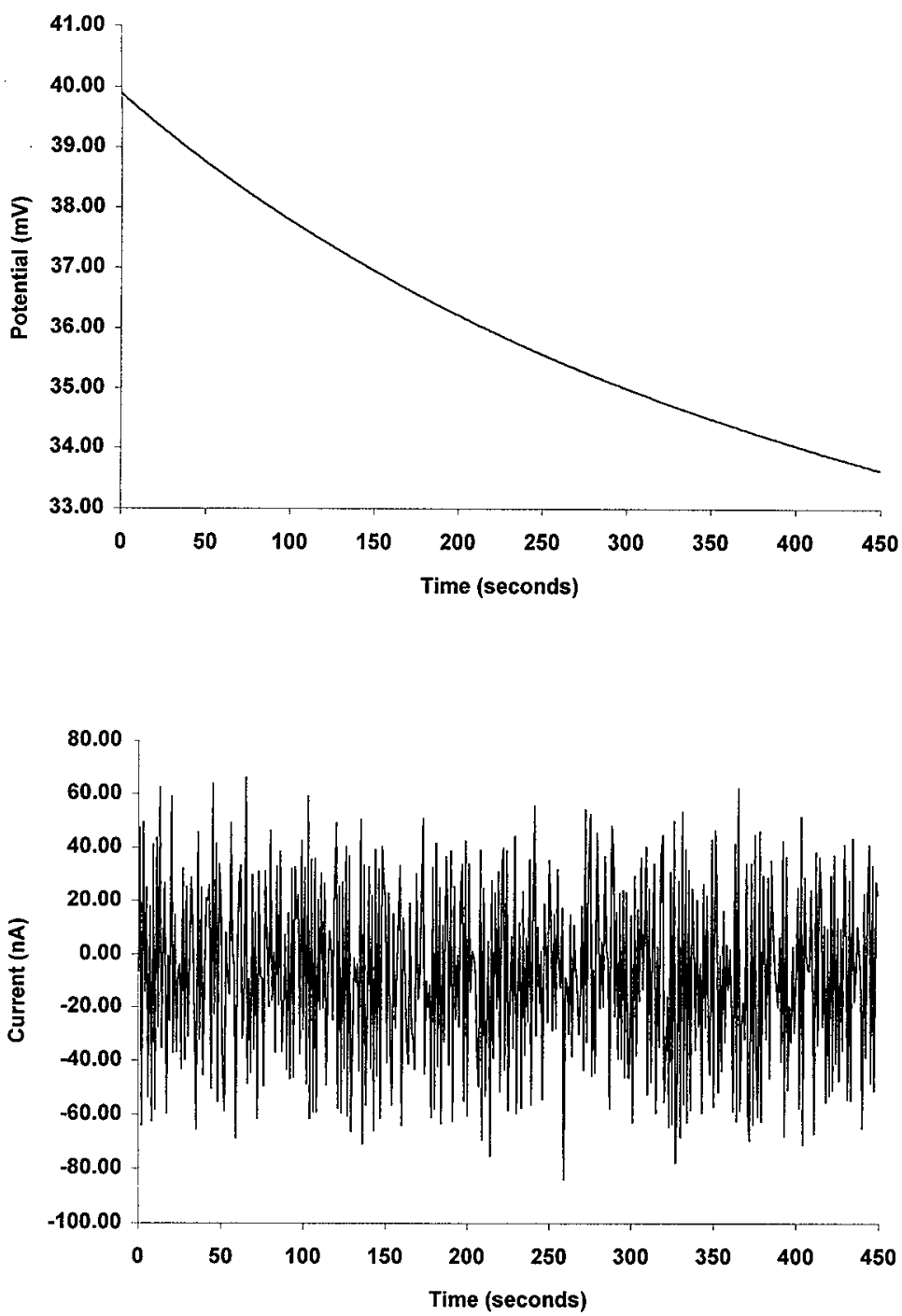

Figure 92: Typical raw potential and raw current data files: pin electrodes in supernate on channel 3 - March 1998 
HNF-3414, Rev. 0
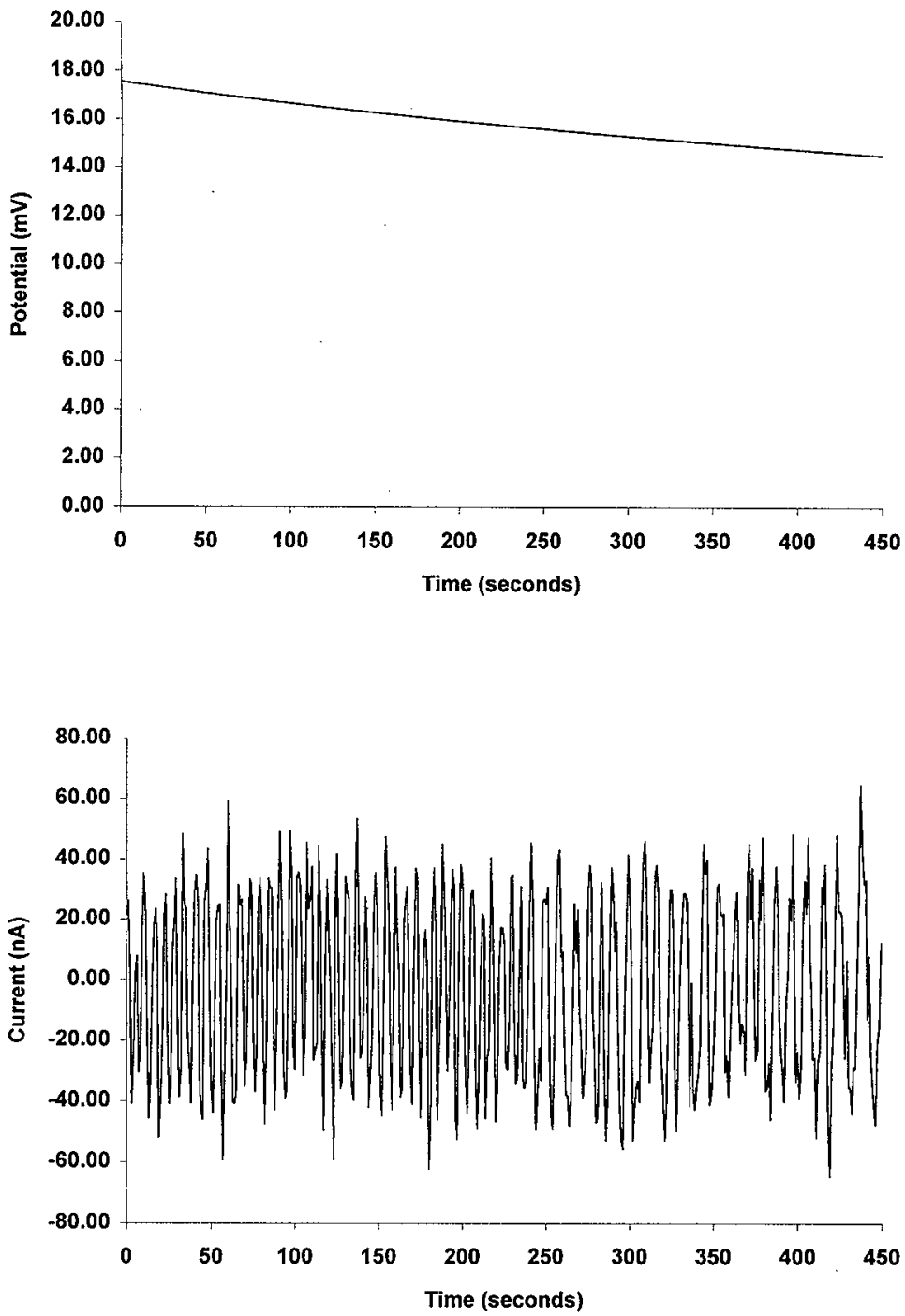

Figure 93: Typical raw potential and raw current data files: pin electrodes in supernate on channel 3 - April 1998 

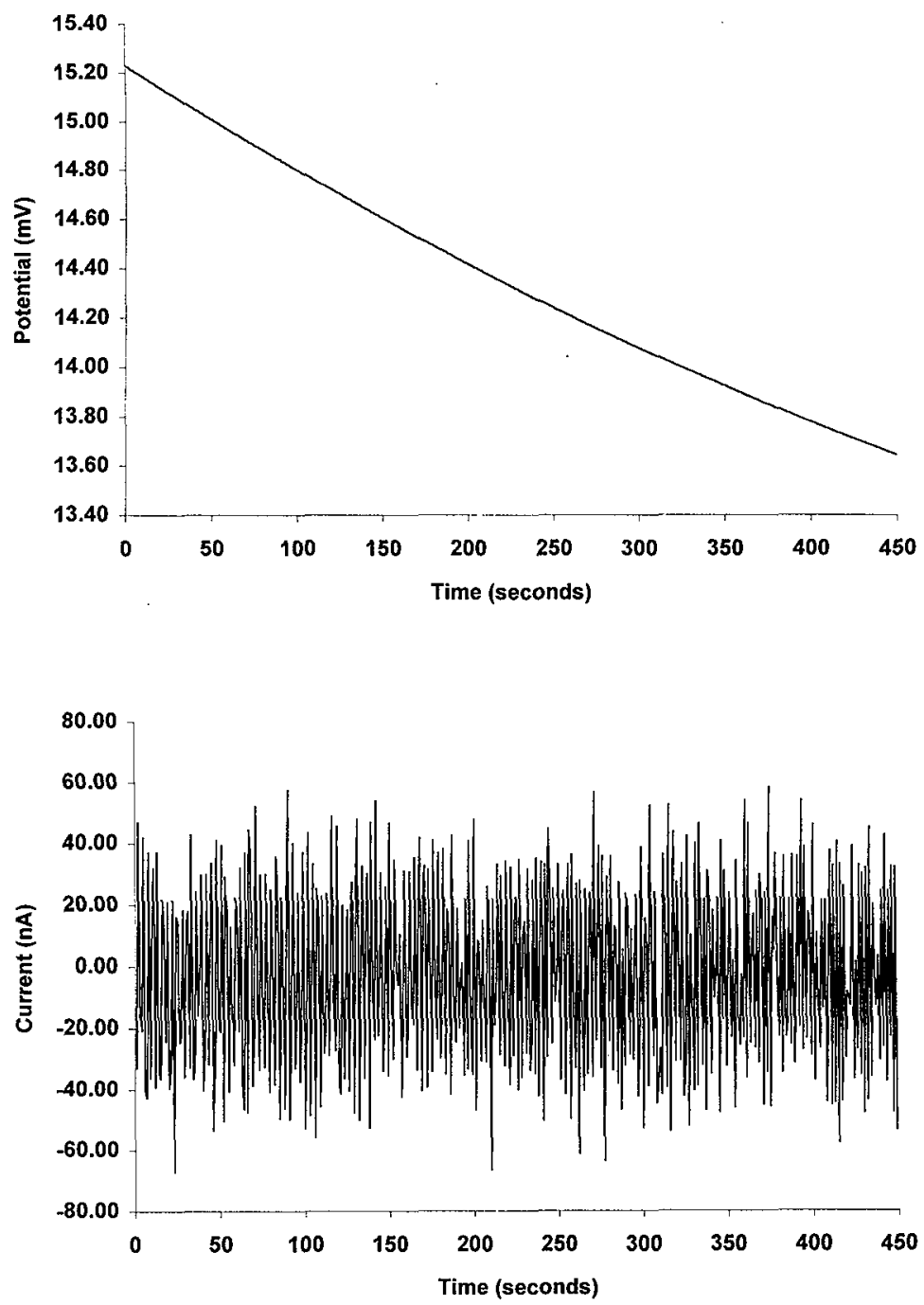

Figure 94: Typical raw potential and raw current data files: pin electrodes in supernate on channel 3 - May 1998 
HNF-3414, Rev. 0
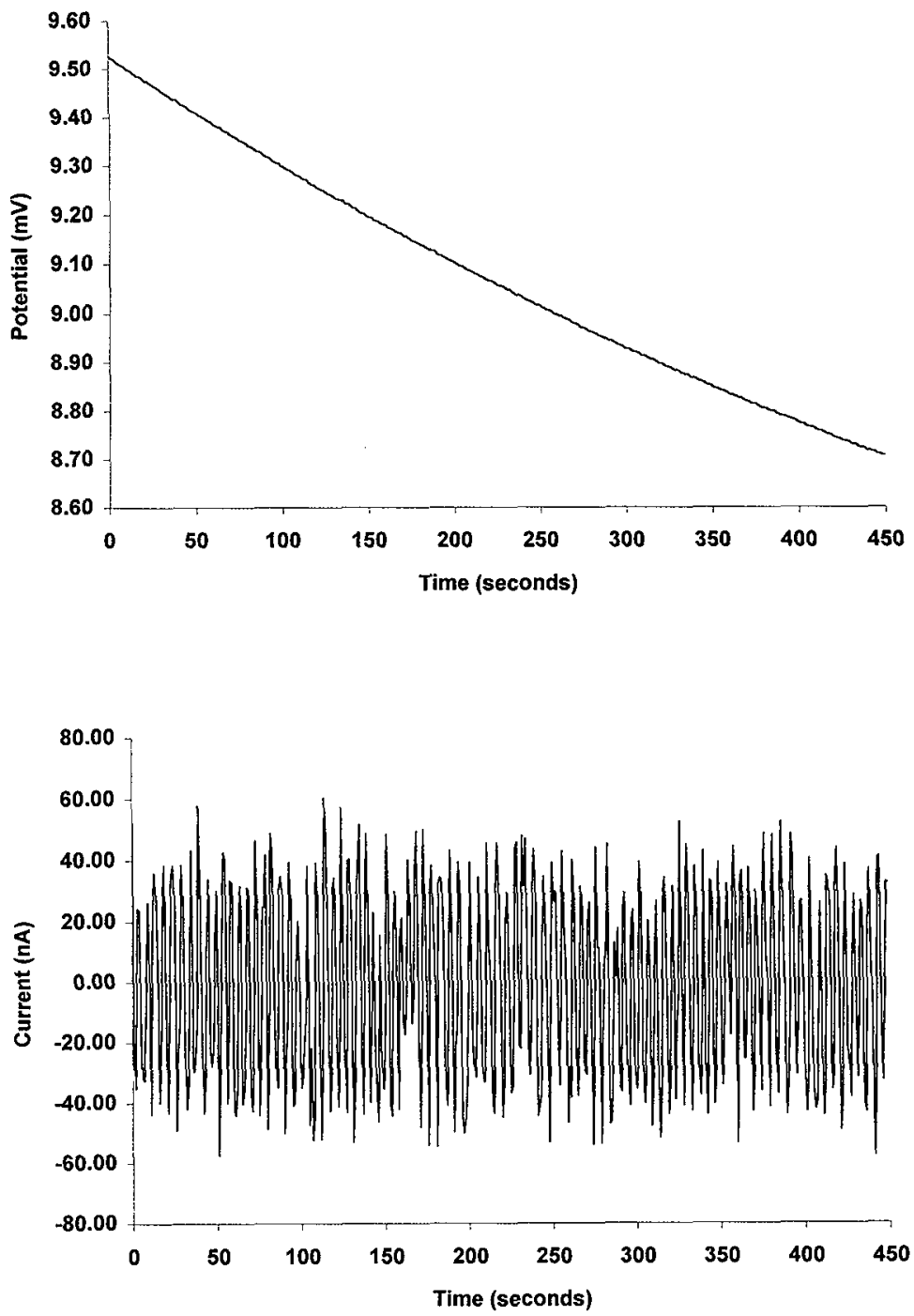

Figure 95: Typical raw potential and raw current data files: pin electrodes in supernate on channel 3 - June 1998 

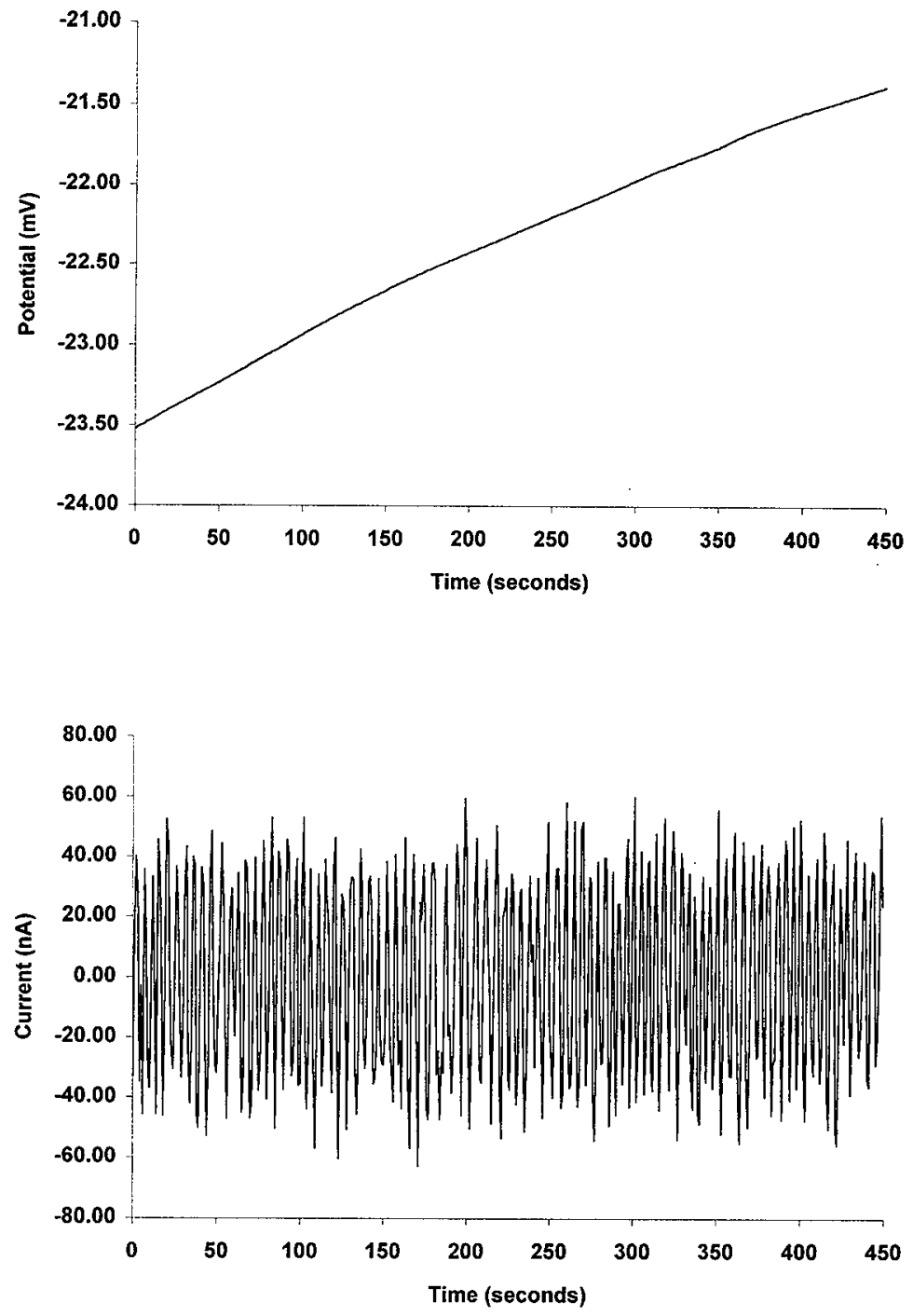

Figure 96: Typical raw potential and raw current data files: pin electrodes in supernate on channel 3 - July 1998 
HNF-3414, Rev. 0
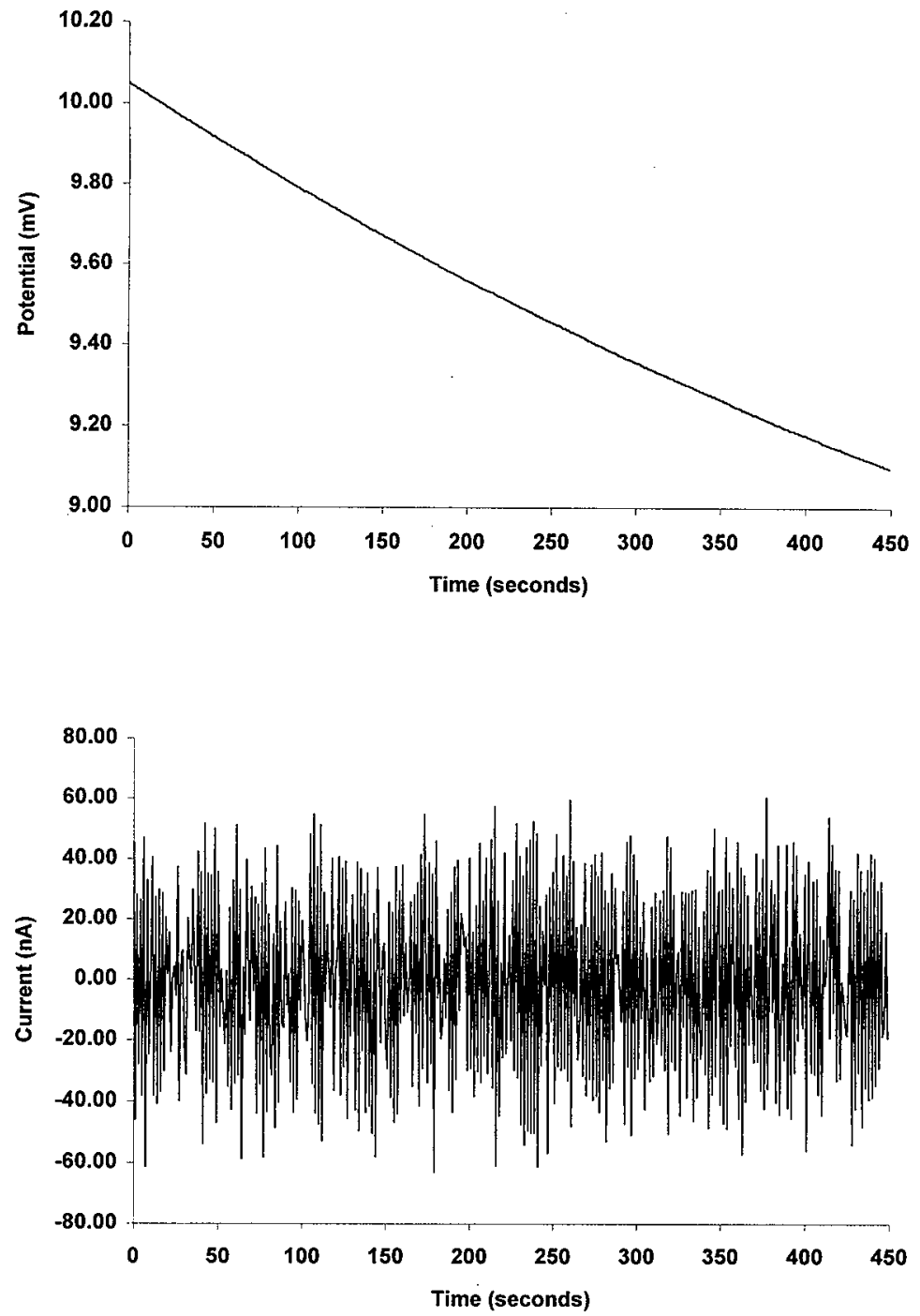

Figure 97: Typical raw potential and raw current data files: pin electrodes in supernate on channel 3 - August 1998 

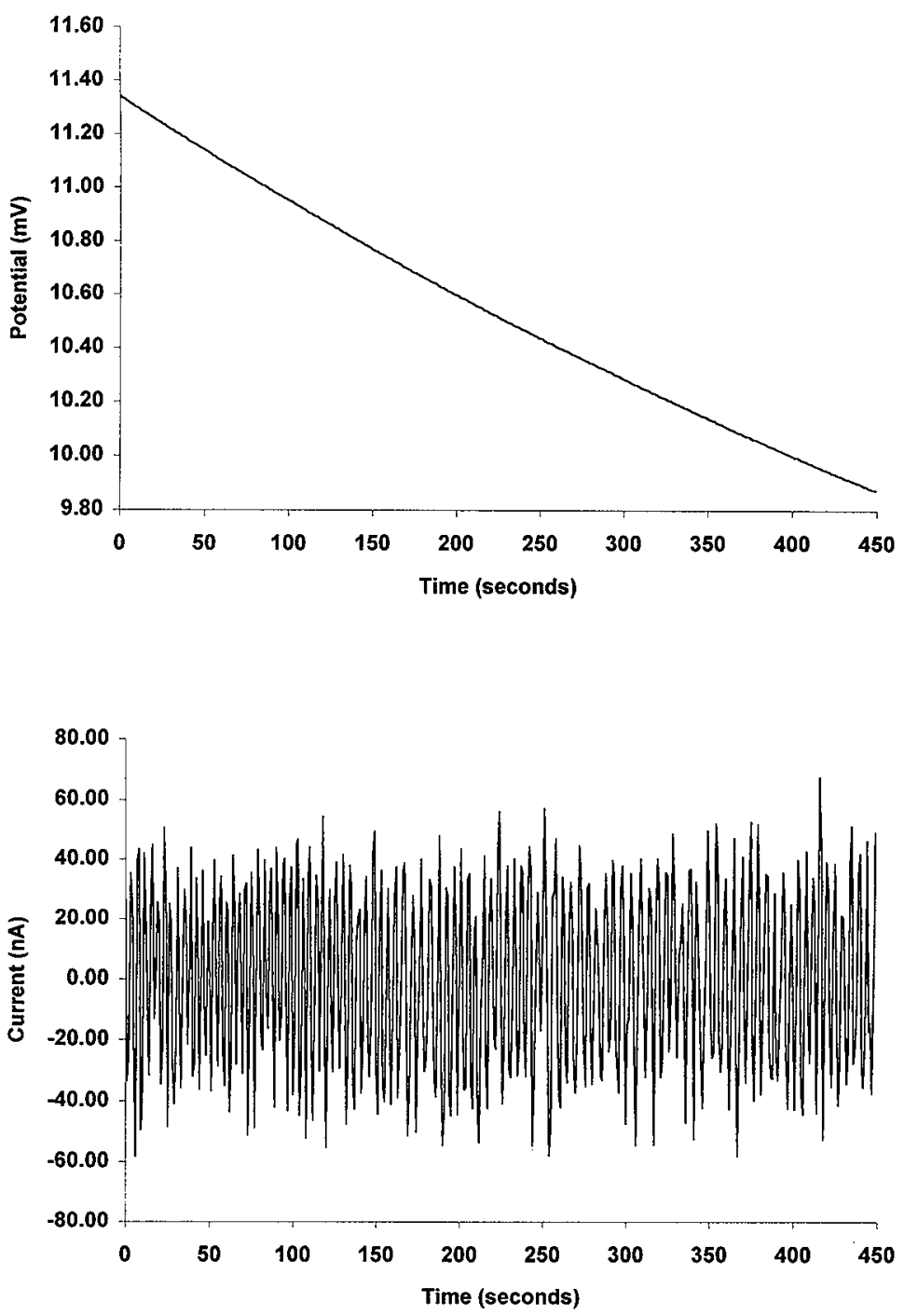

Figure 98: Typical raw potential and raw current data files: pin electrodes in supernate on channel 3 - September 1998 

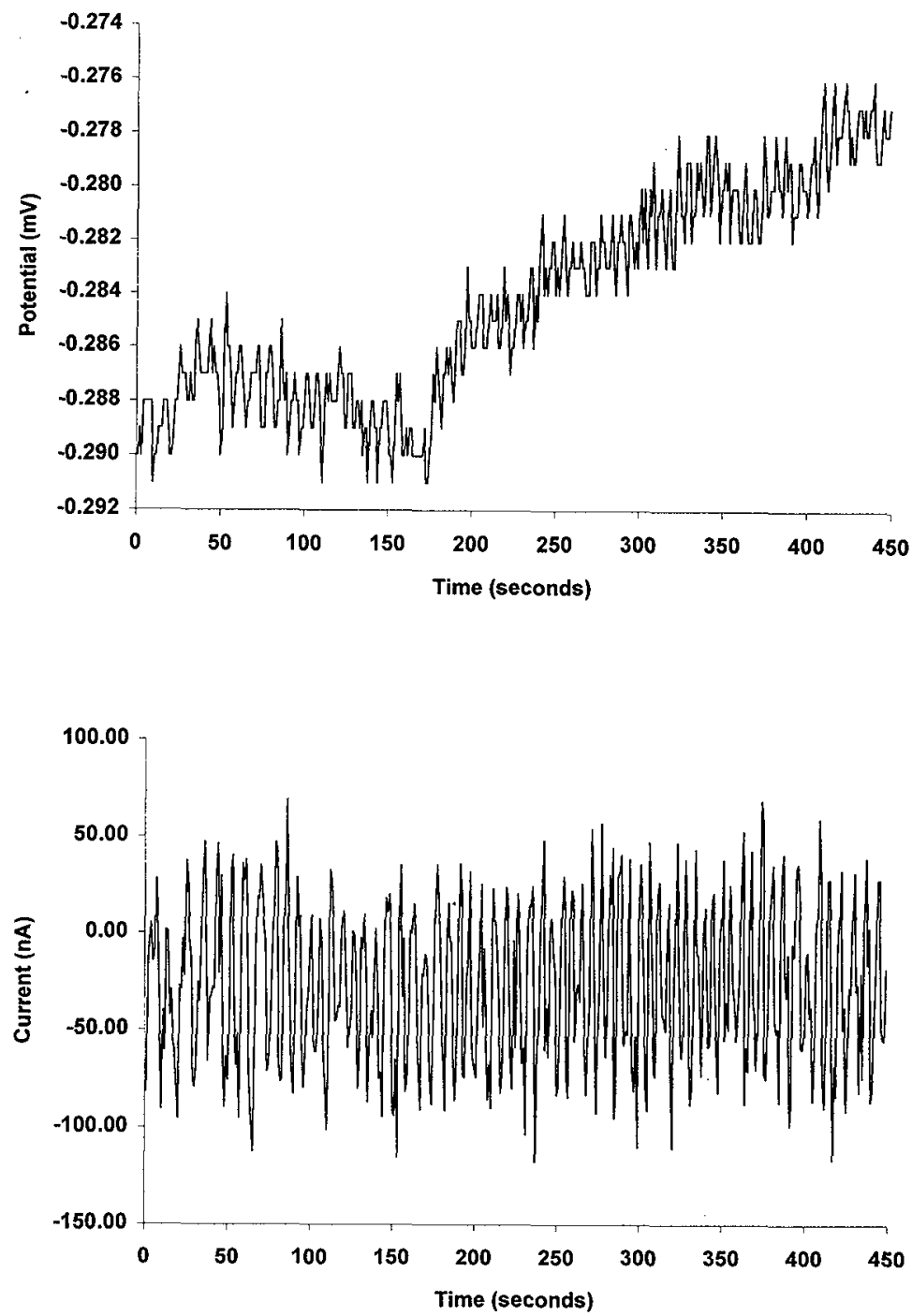

Fìgure 99: Typical raw potential and raw current data files: C-ring electrodes in supernate on channel 4 - September 1997 

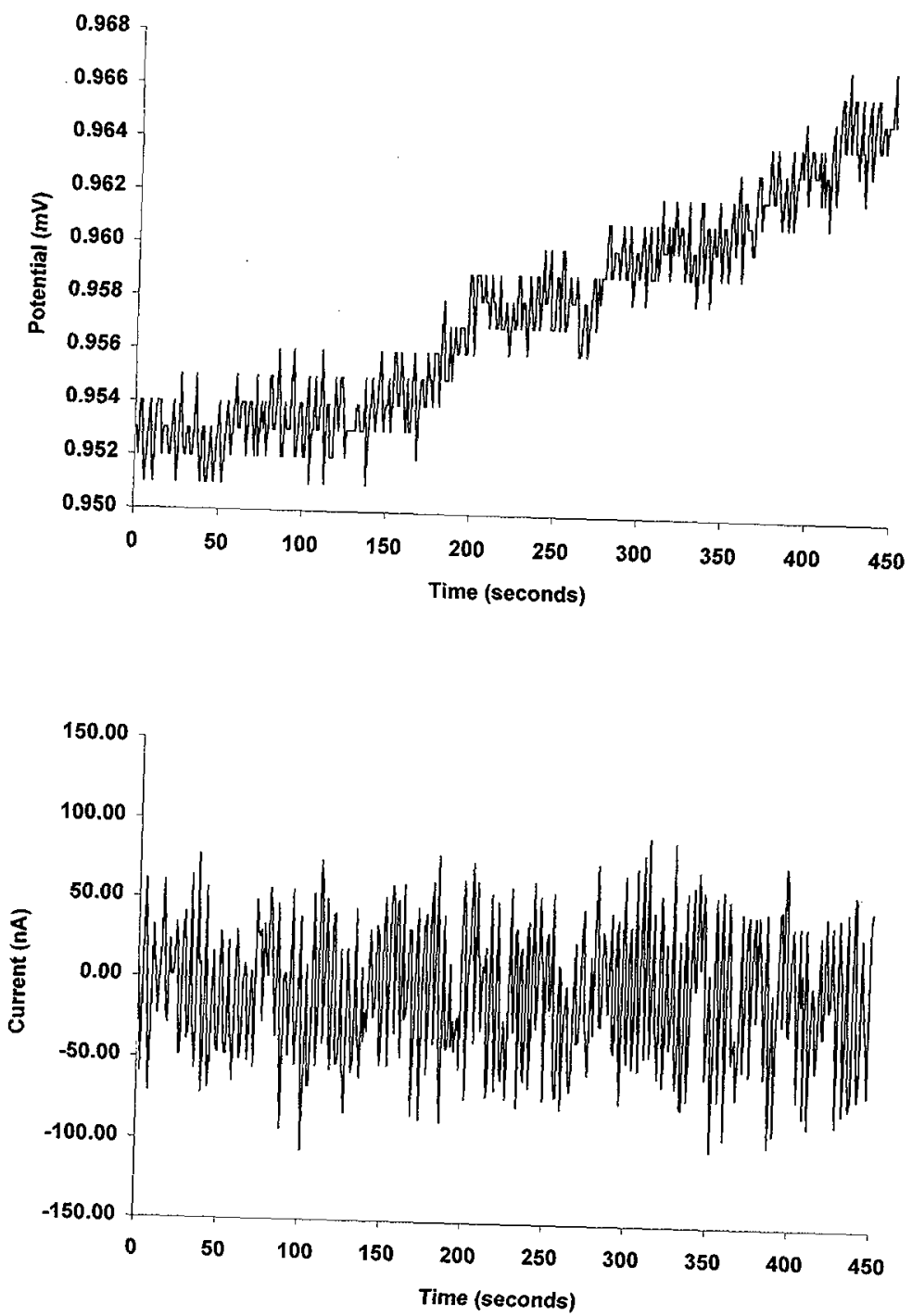

Figure 100: Typical raw potential and raw current data files: C-ring electrodes in supernate on channel 4 - October 1997 
HNF-3414, Rev. 0
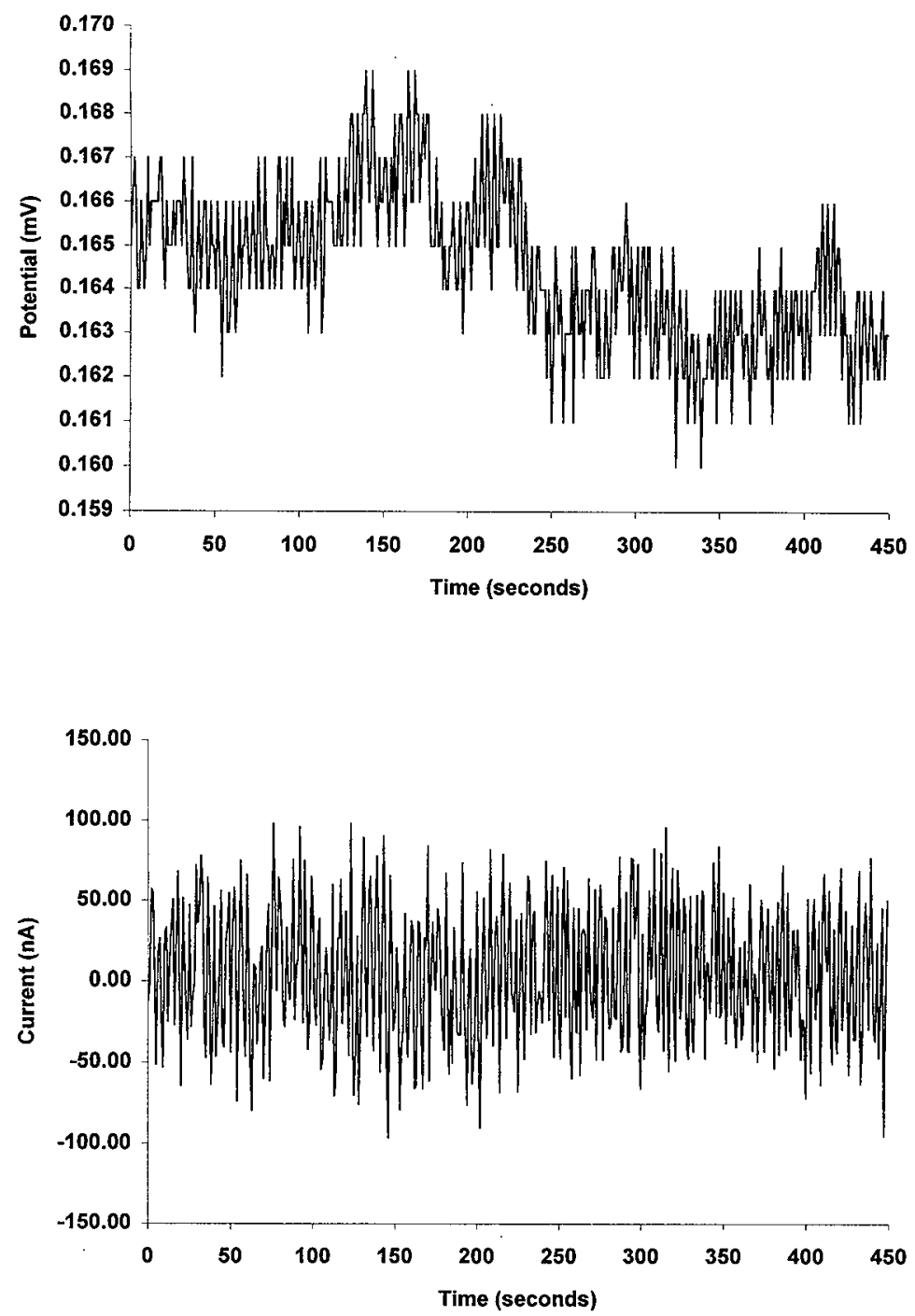

Figure 101: Typical raw potential and raw current data files: C-ring electrodes in supernate on channel 4 - November 1997 

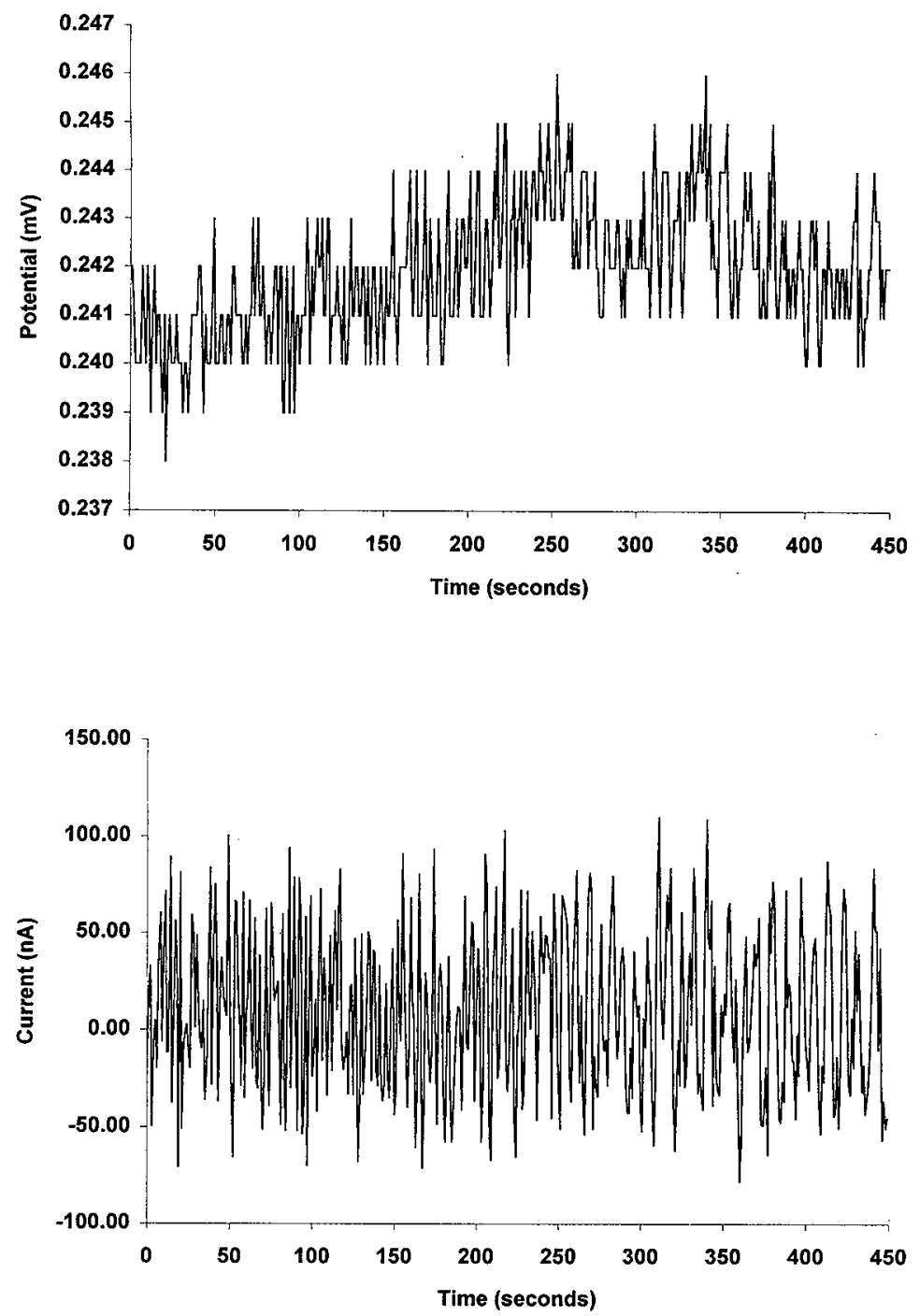

Figure 102: Typical raw potential and raw current data files: C-ring electrodes in supernate on channel 4 - December 1997 
HNF-3414, Rev. 0
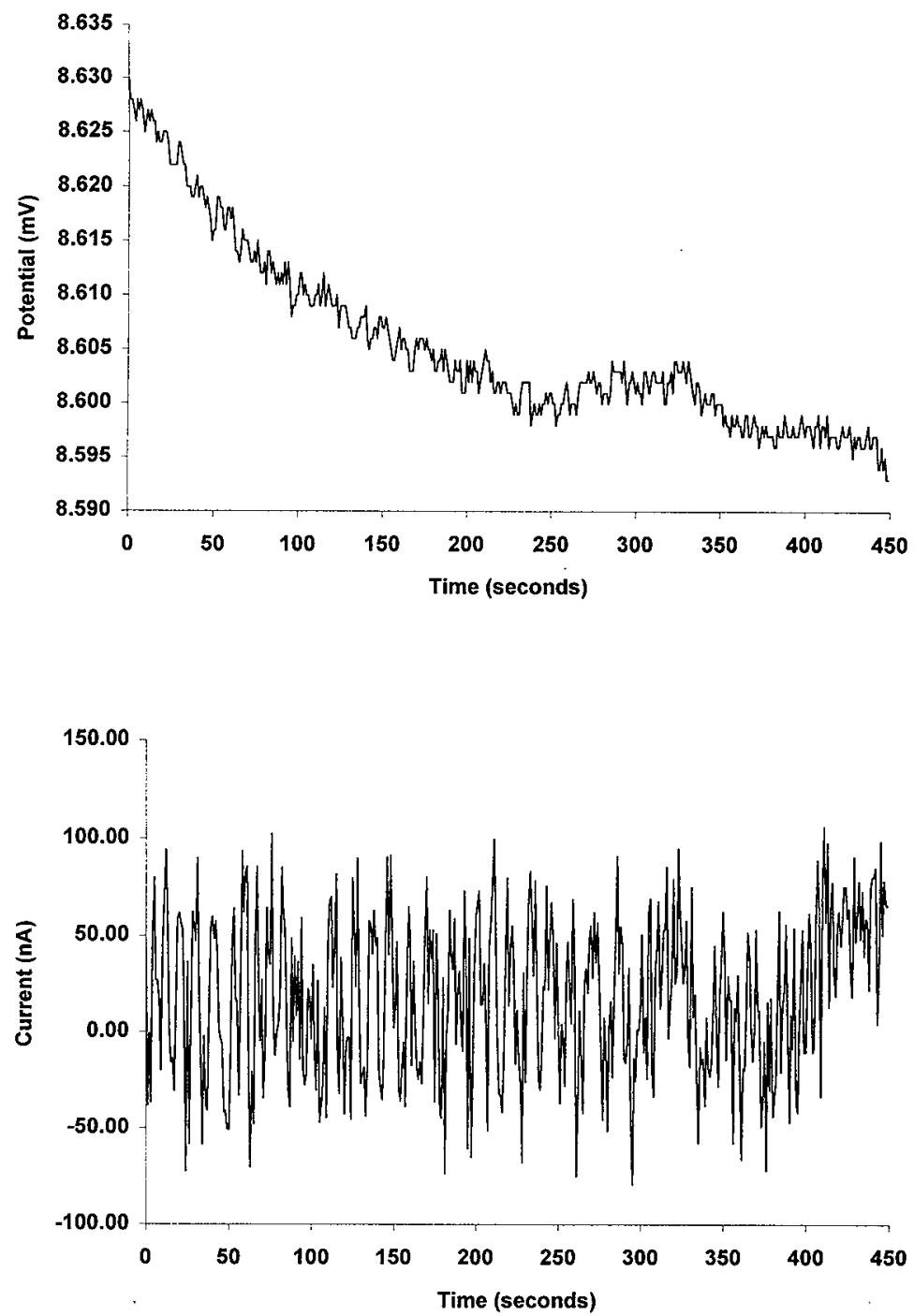

Figure 103: Typical raw potential and raw current data files: C-ring electrodes in supernate on channel 4 - January 1998 

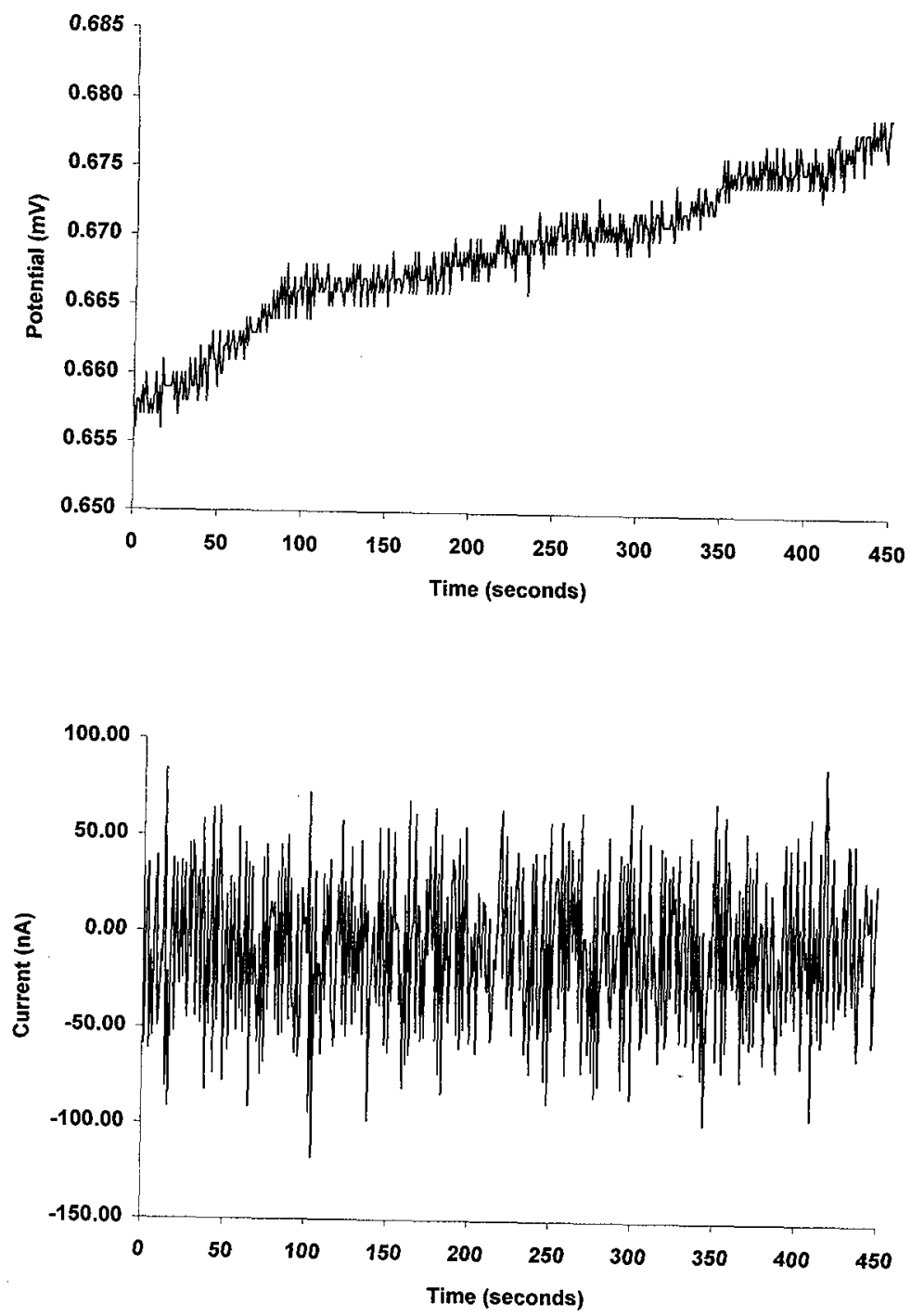

Figure 104: Typical raw potential and raw current data files: C-ring electrodes in supernate on channel 4 - February 1998 

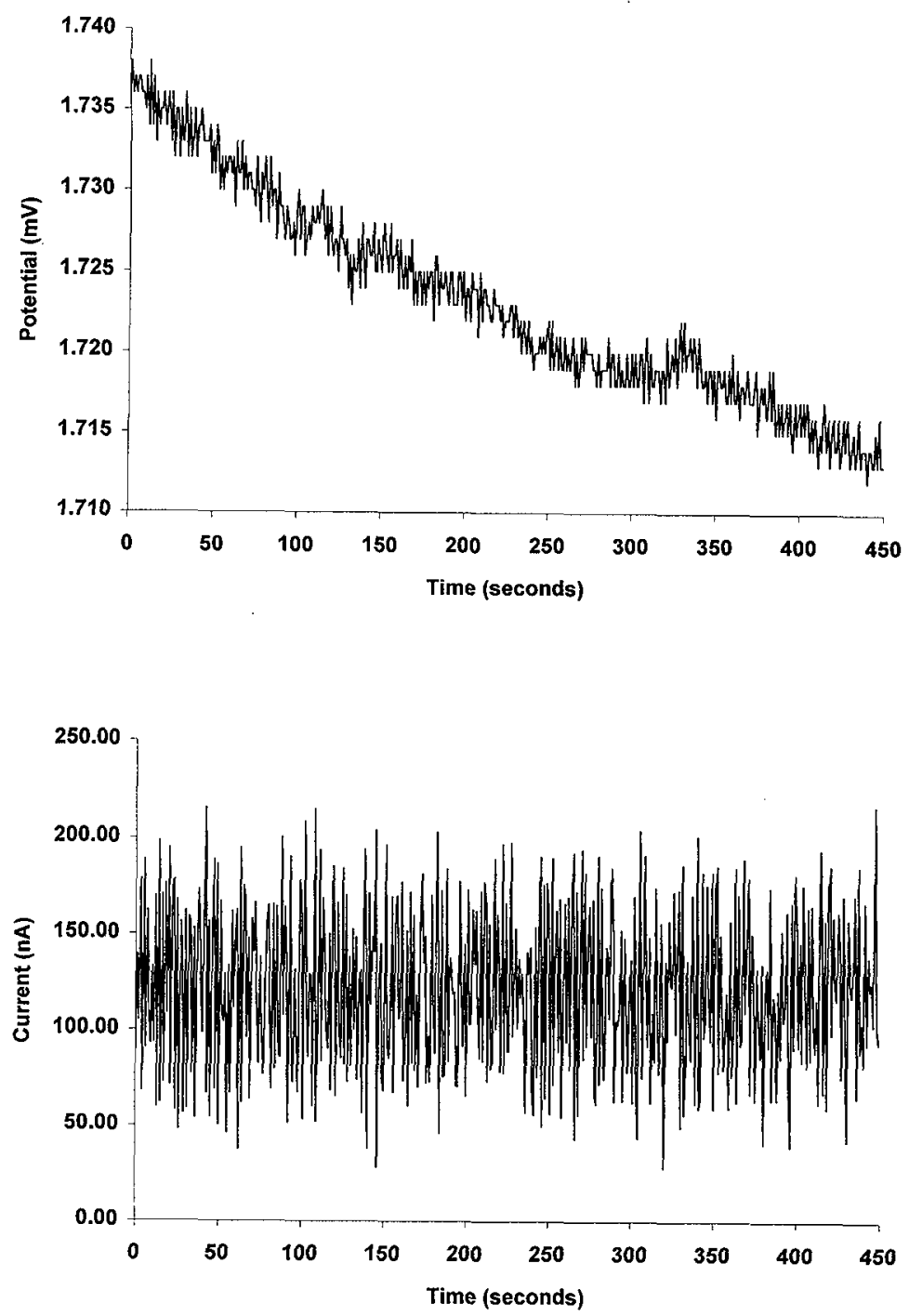

Figure I05: Typical raw potential and raw current data files: C-ring electrodes in supernate on channel 4 - March 1998 

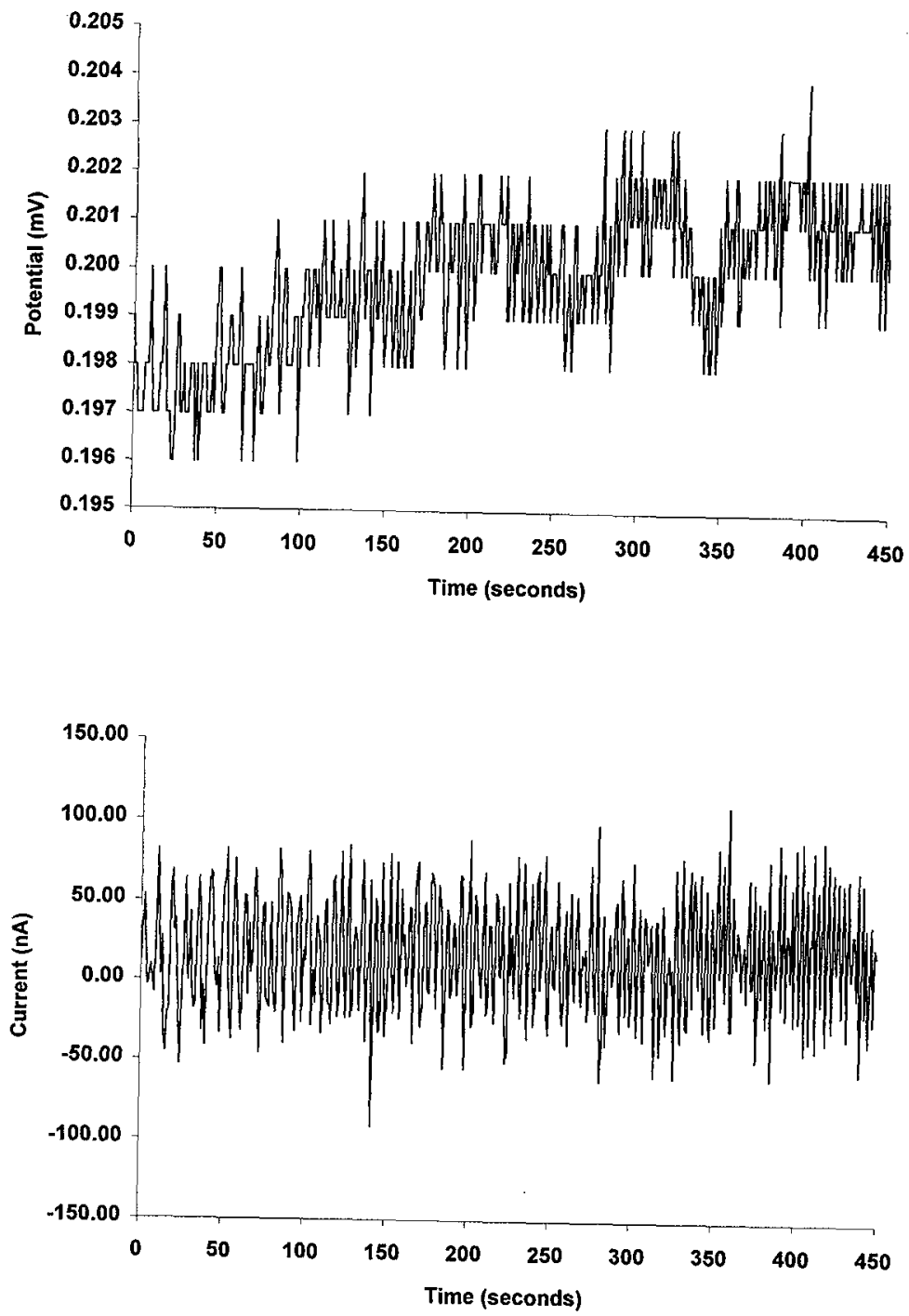

Figure 106: Typical raw potential and raw current data files: C-ring electrodes in supernate on channel 4 - April 1998 

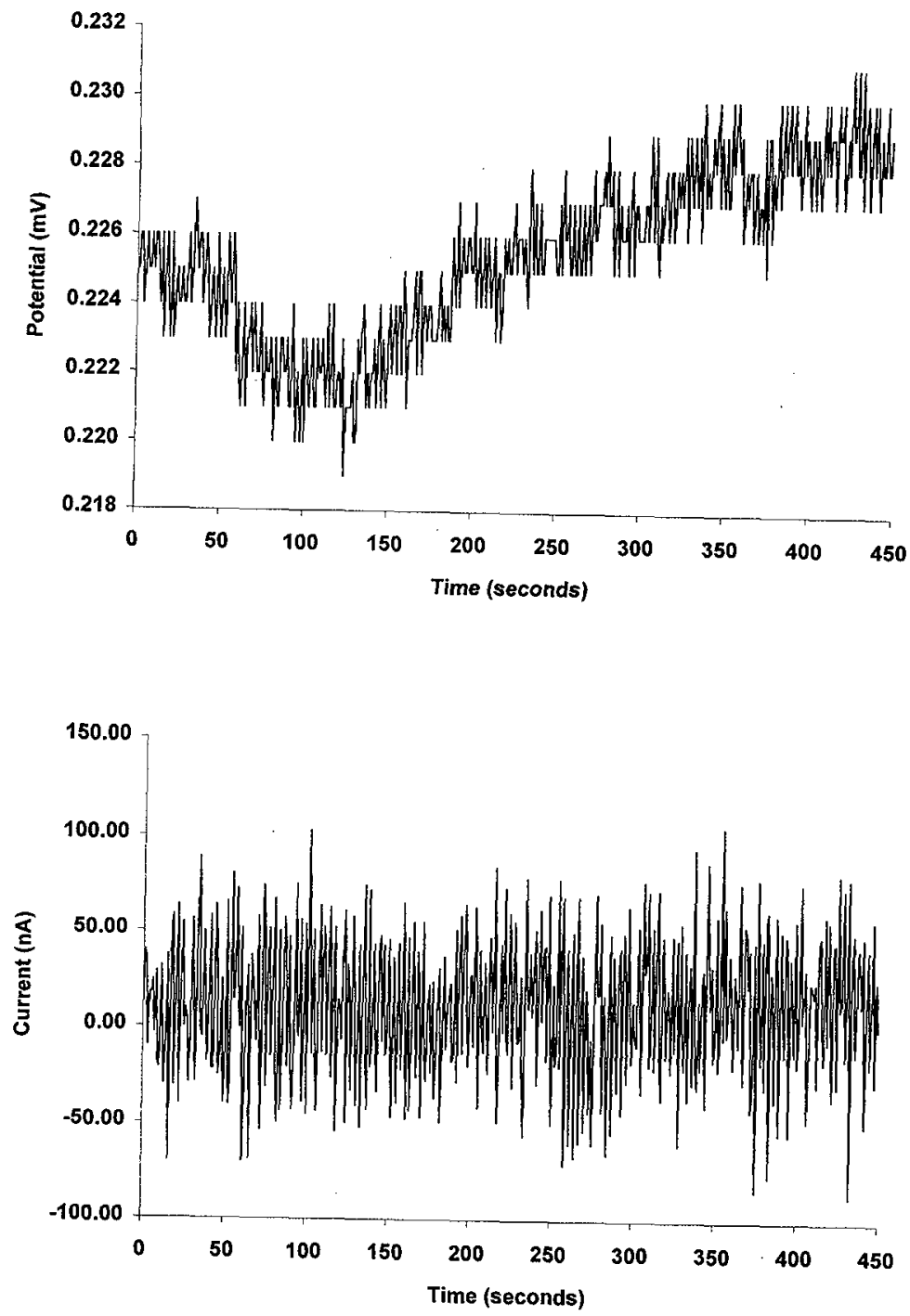

Figure 107: Typical raw potential and raw current data files: C-ring electrodes in supernate on channel 4 - May 1998 
HNF-3414, Rev. 0
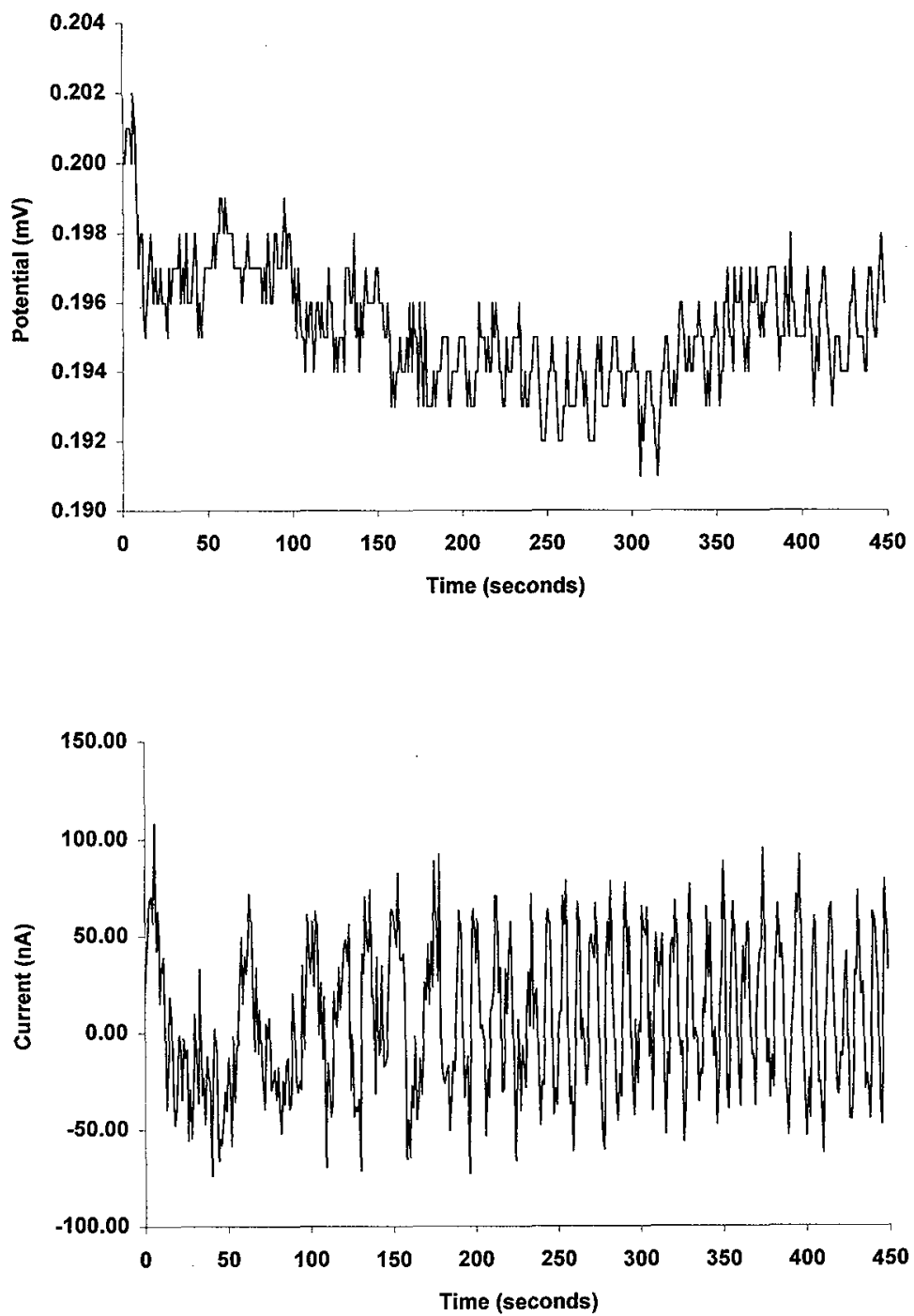

Figure 108: Typical raw potential and raw current data files: C-ring electrodes in supernate on channel 4 - June 1998 

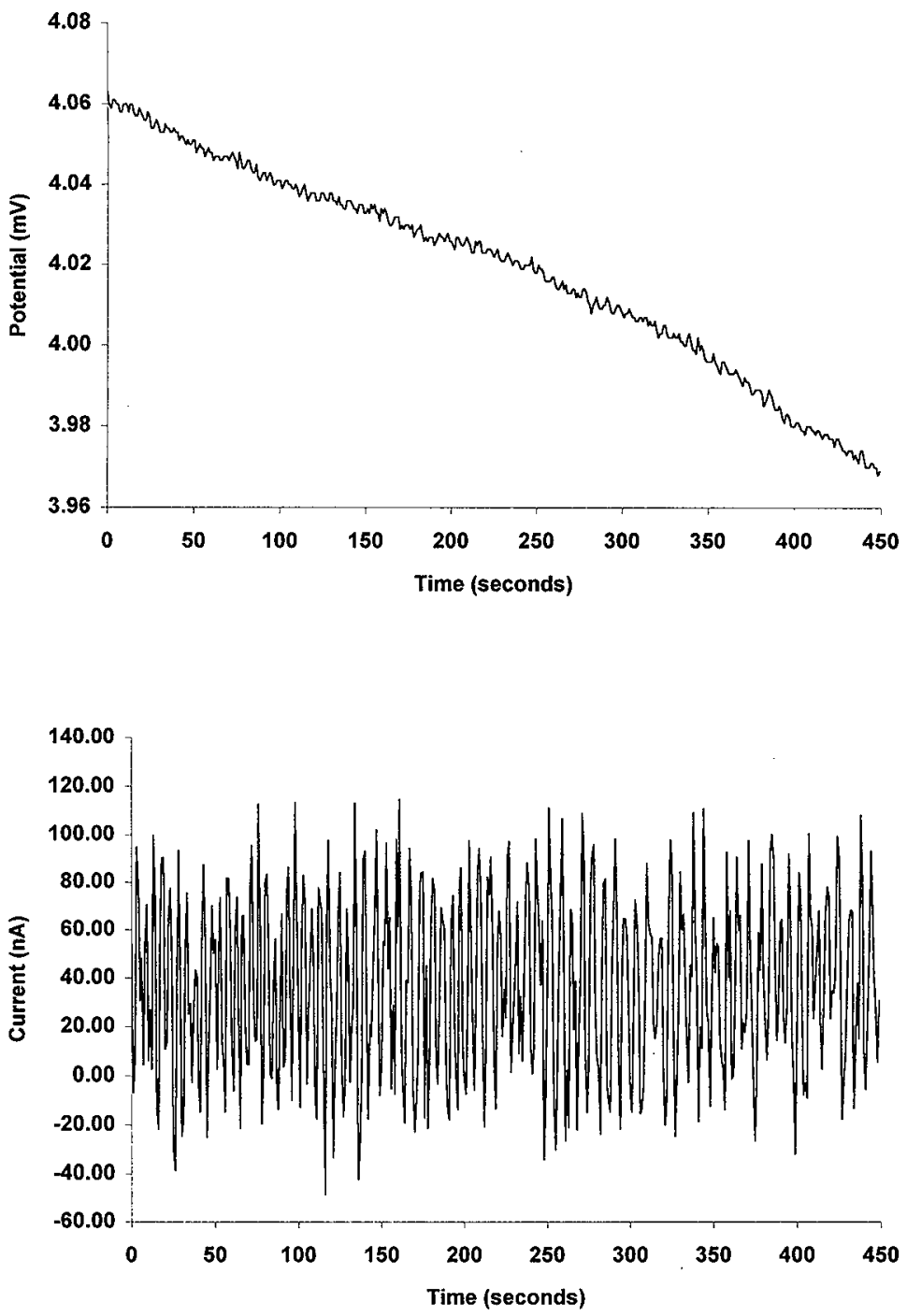

Figure 109: Typical raw potential and raw current data files: C-ring electrodes in supernate on channel 4 - July 1998 

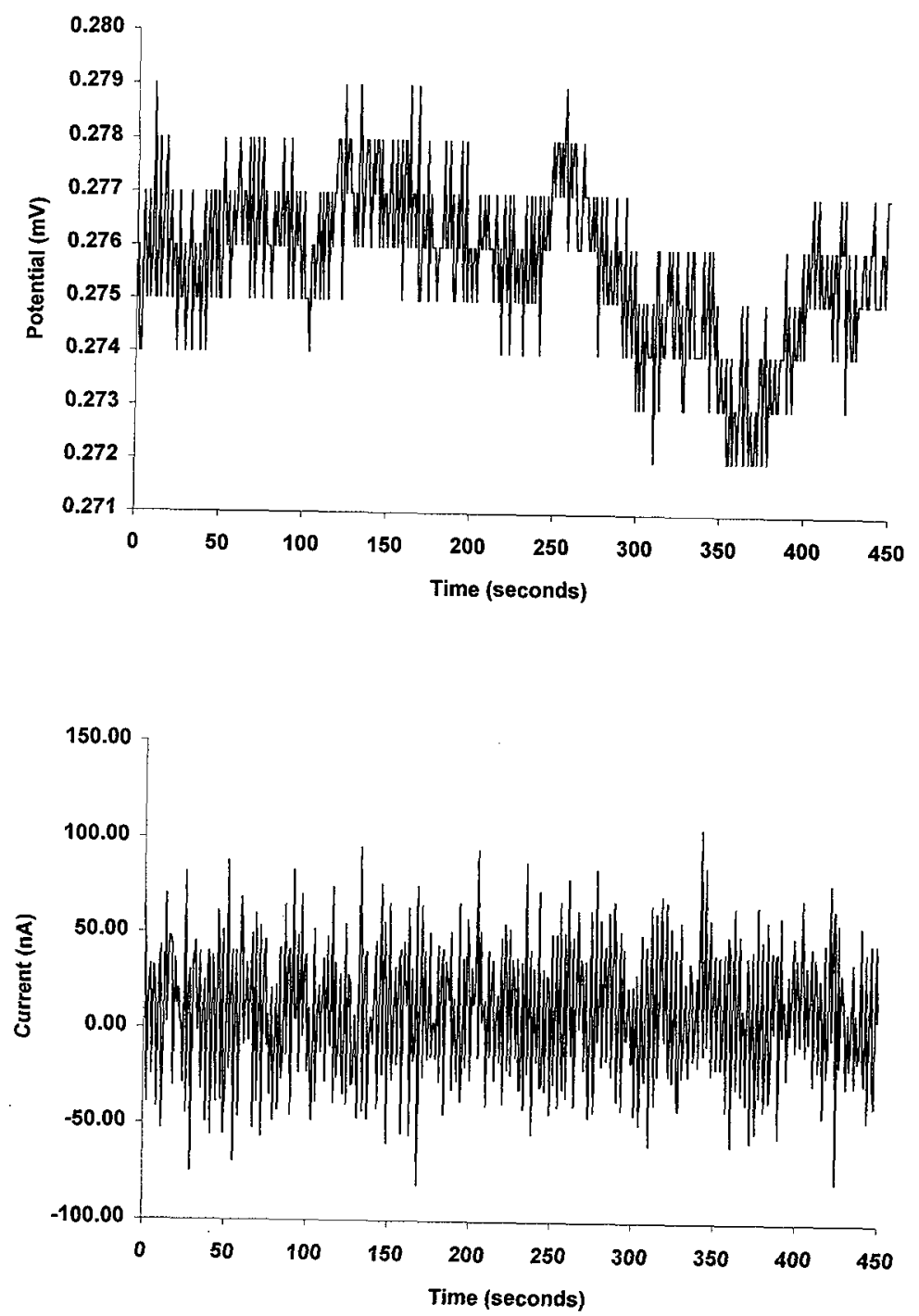

Figure 110: Typical raw potential and raw current data files: C-ring electrodes in supernate on channel 4 - August 1998 
HNF-3414, Rev. 0
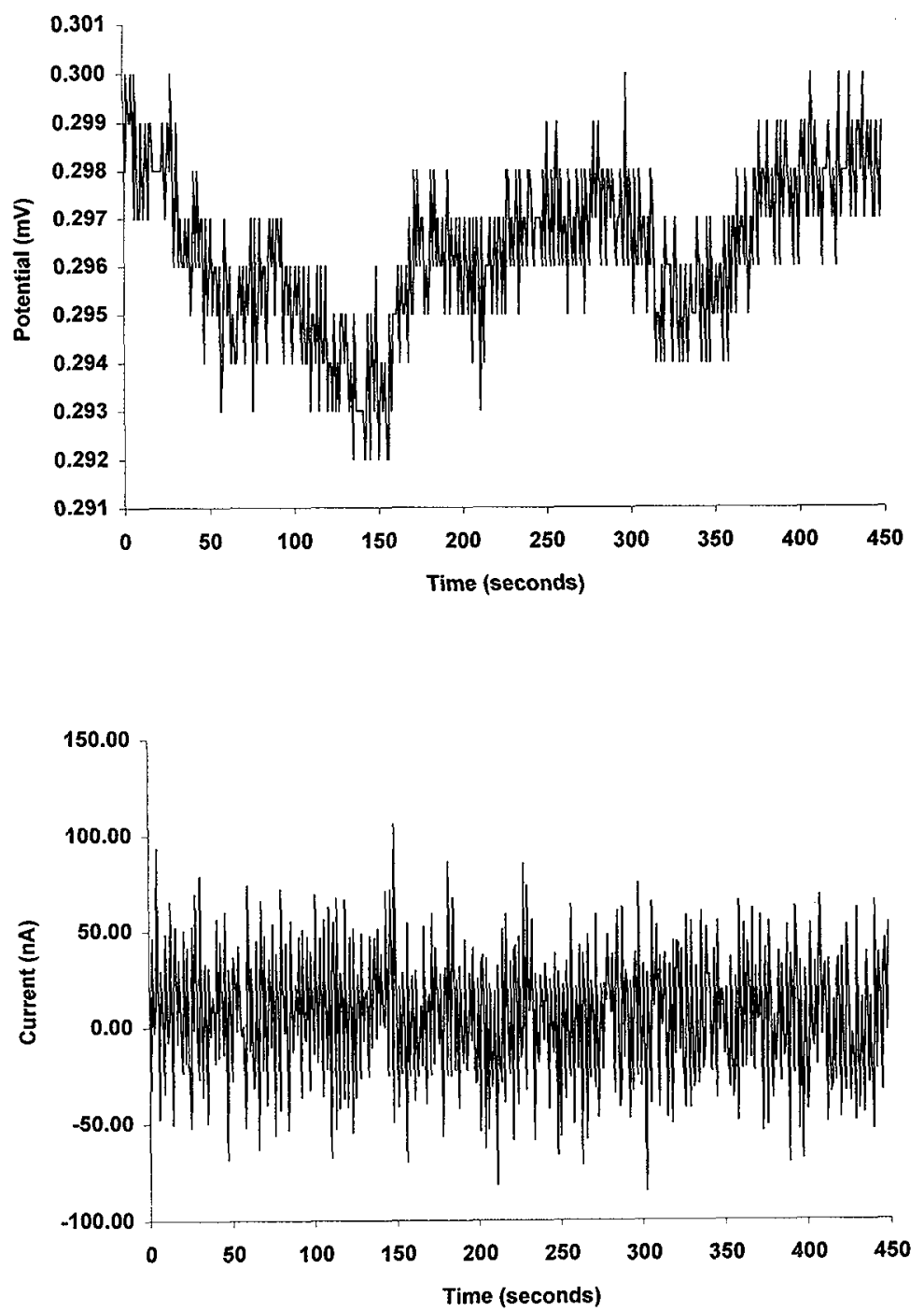

Figure 111: Typical raw potential and raw current data files: C-ring electrodes in supernate on channel 4 - September 1998 

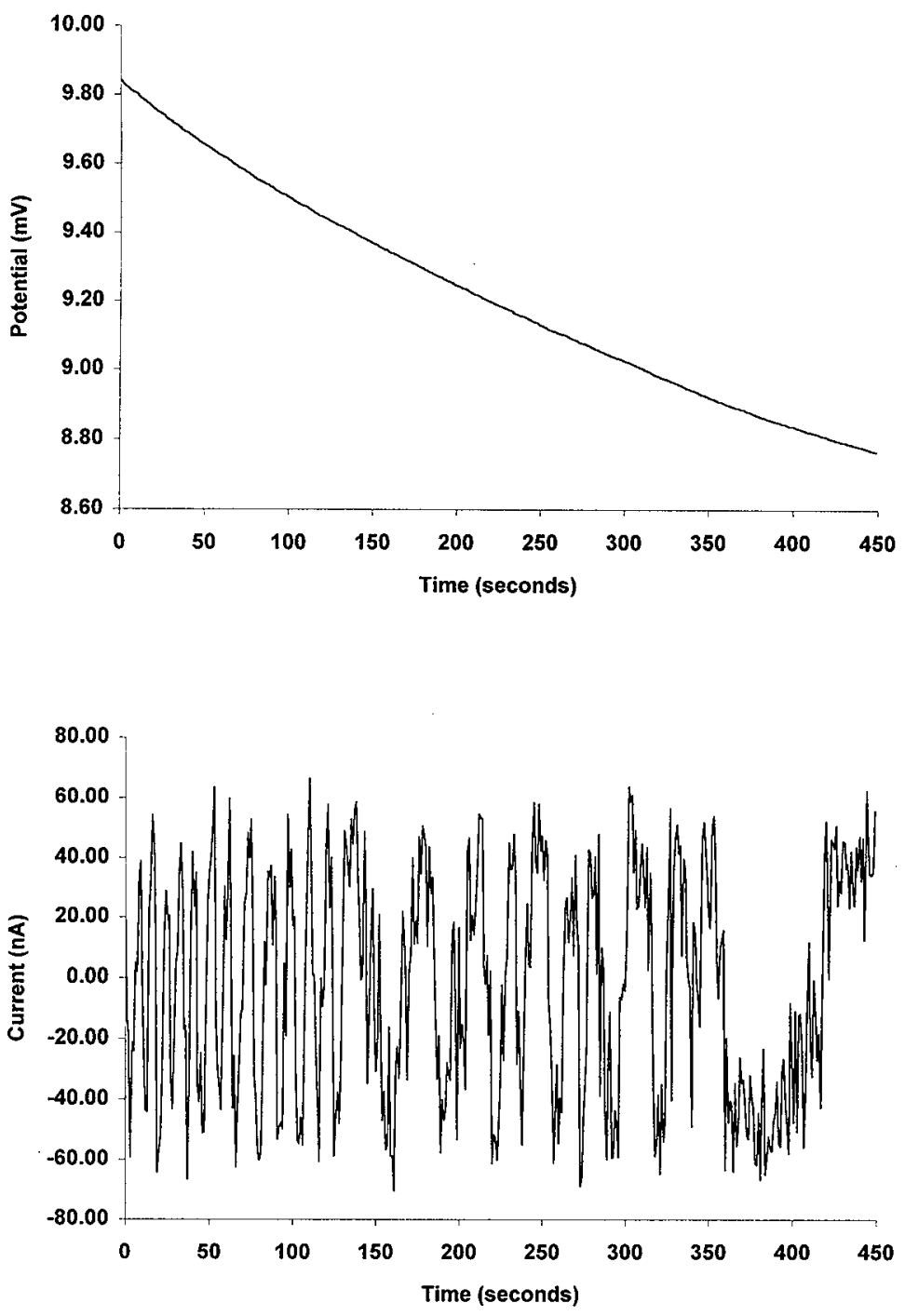

Figure 112: Typical raw potential and raw current data files: pin electrodes in supernate on channel 5 - September 1997 
HNF-3414, Rev. 0
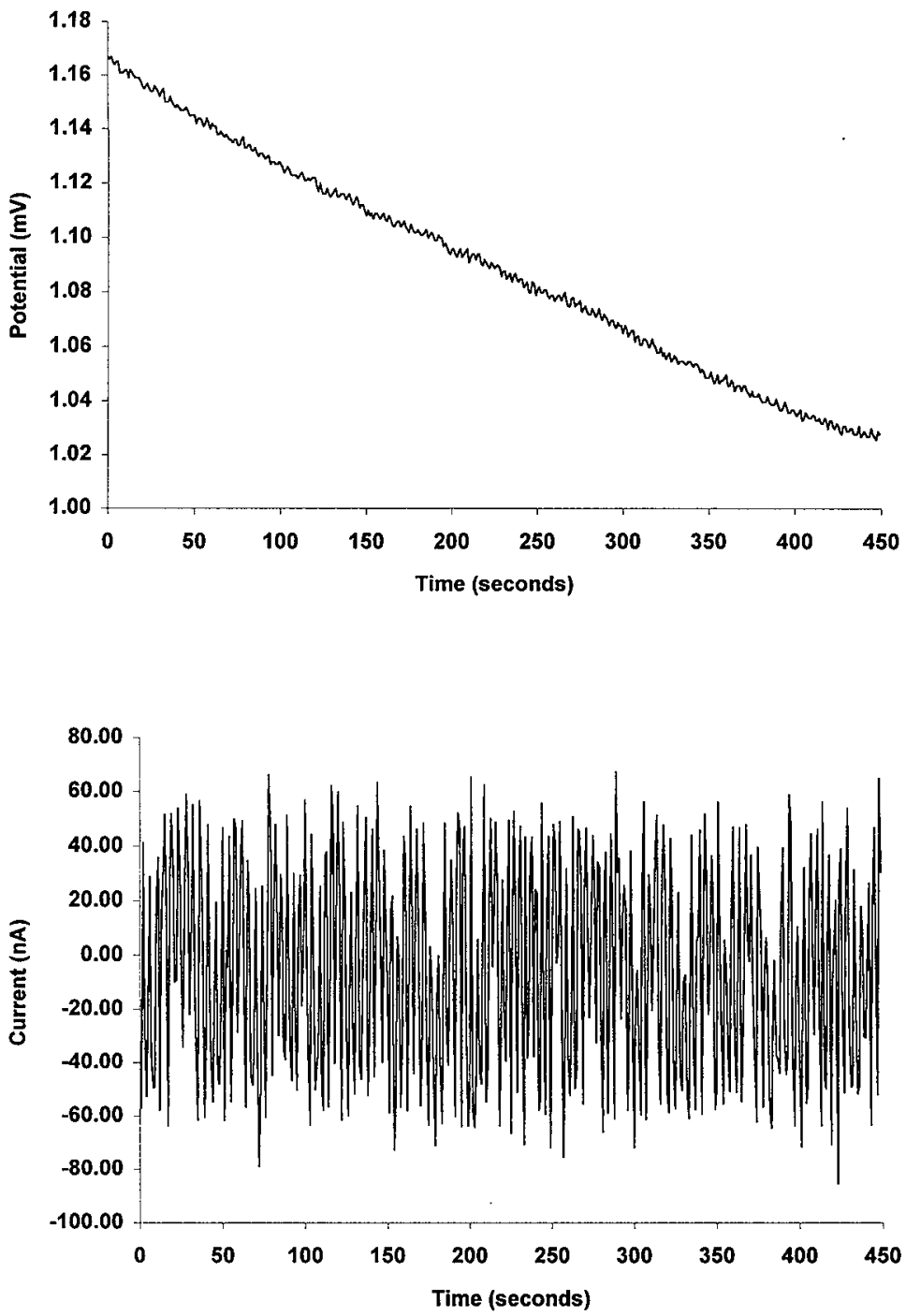

Figure 113: Typical raw potential and raw current data files: pin electrodes in supernate on channel 5 - October 1997 
HNF-3414, Rev. 0
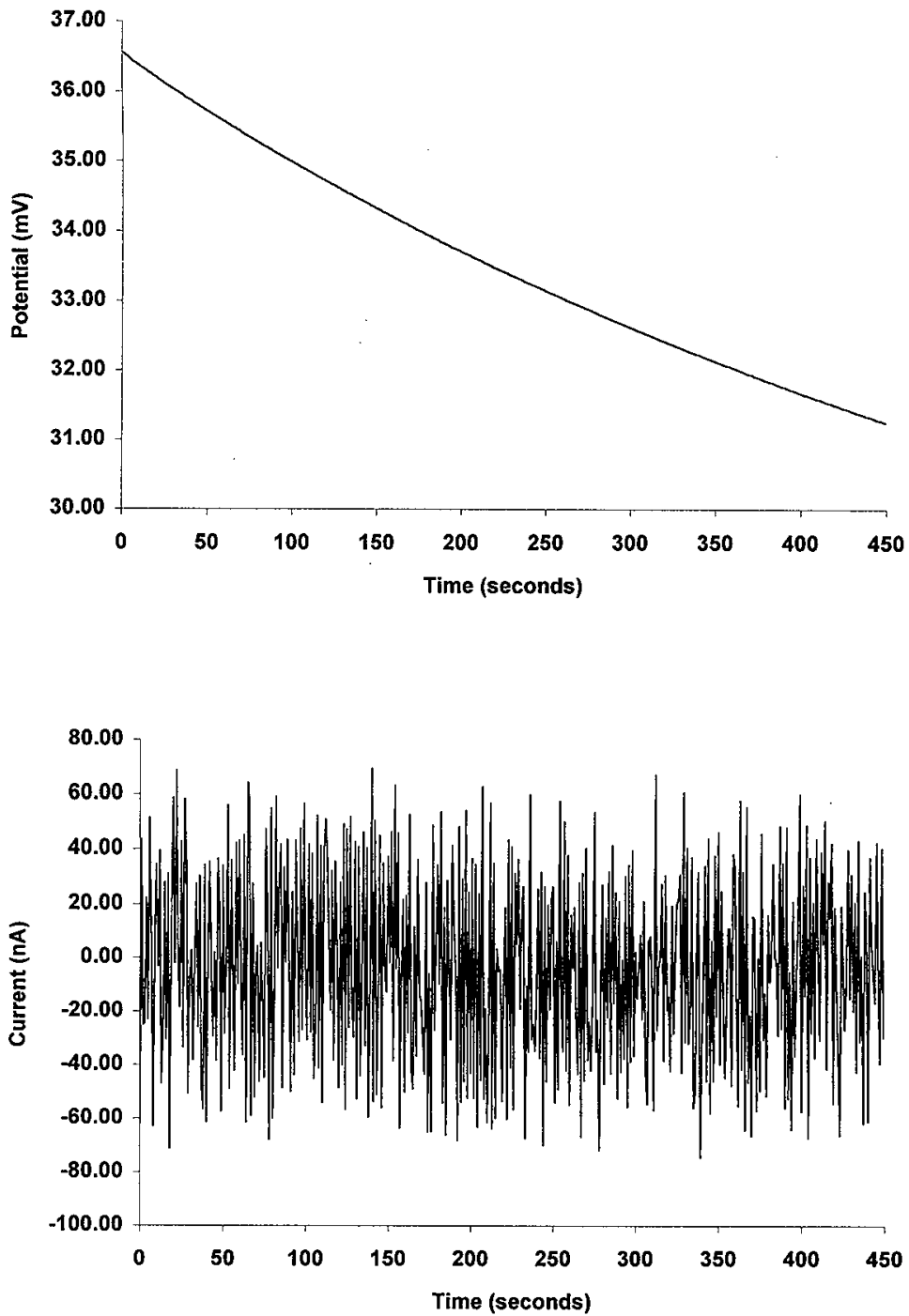

Figure 114: Typical raw potential and raw current data files: pin electrodes in supernate on channel 5 - November 1997 
HNF-3414, Rev. 0
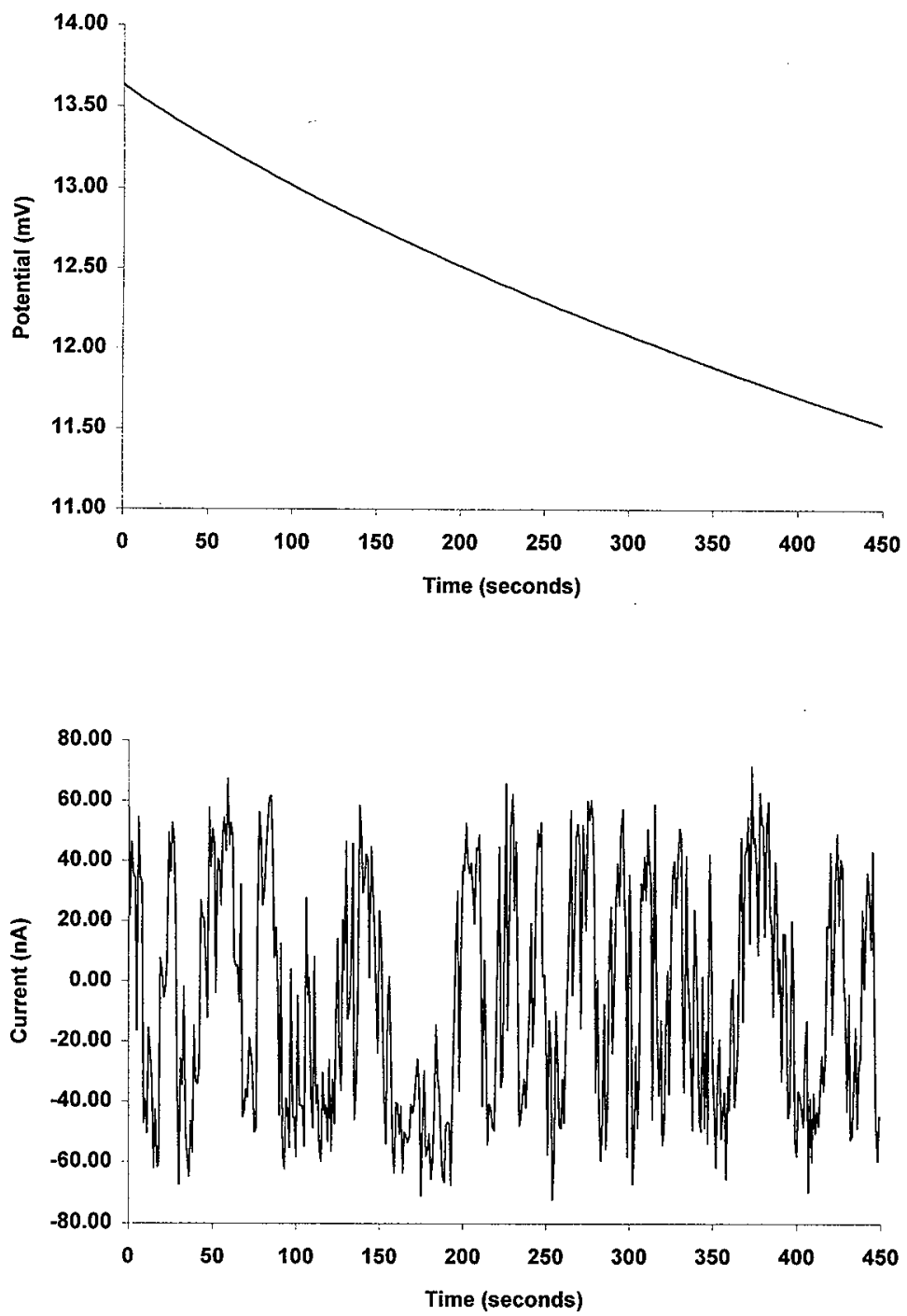

Figure 115: Typical raw potential and raw current data files: pin electrodes in supernate on channel 5 - December 1997 

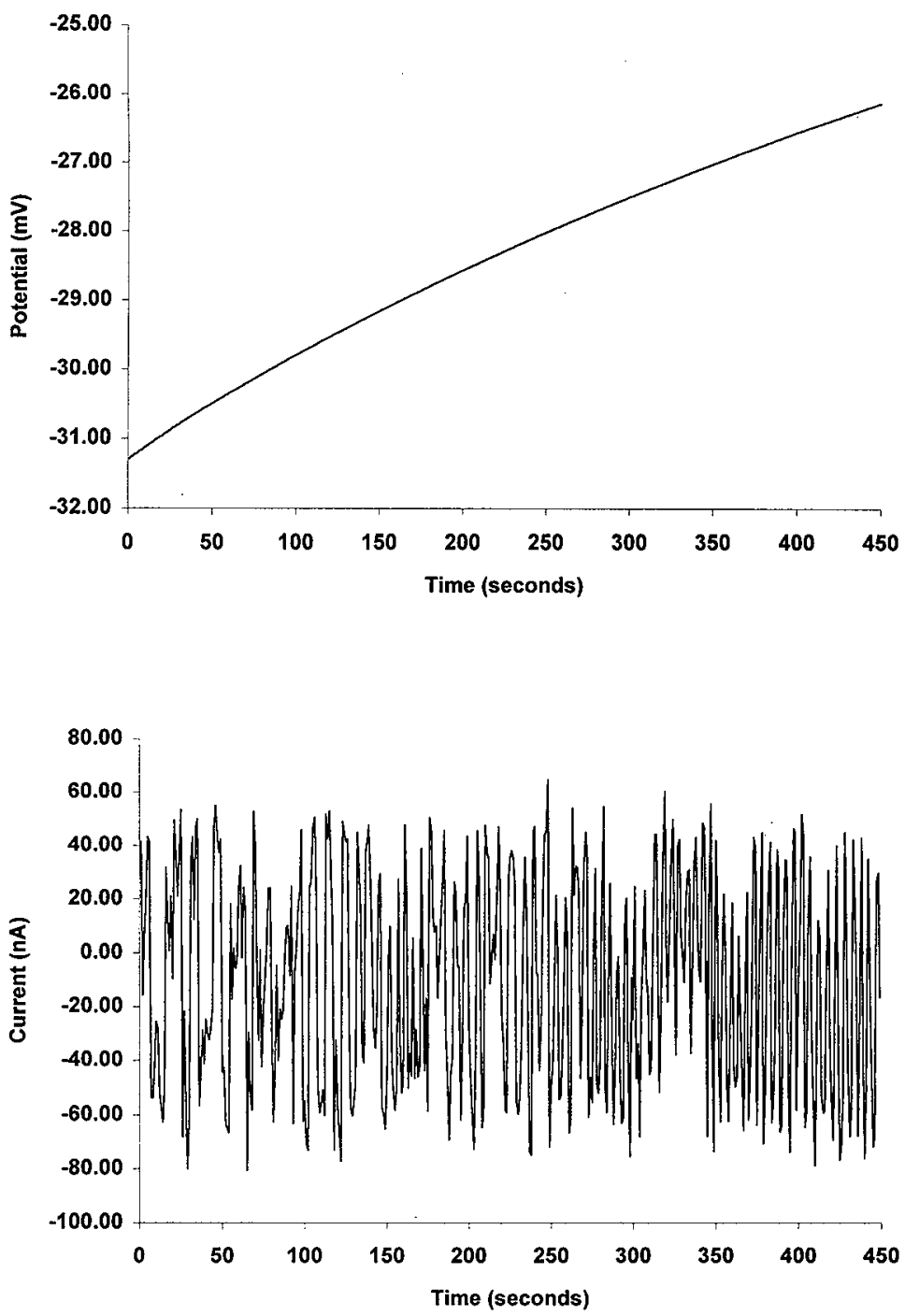

Figure 116: Typical raw potential and raw current data files: pin electrodes in supernate on channel 5 - January 1998 

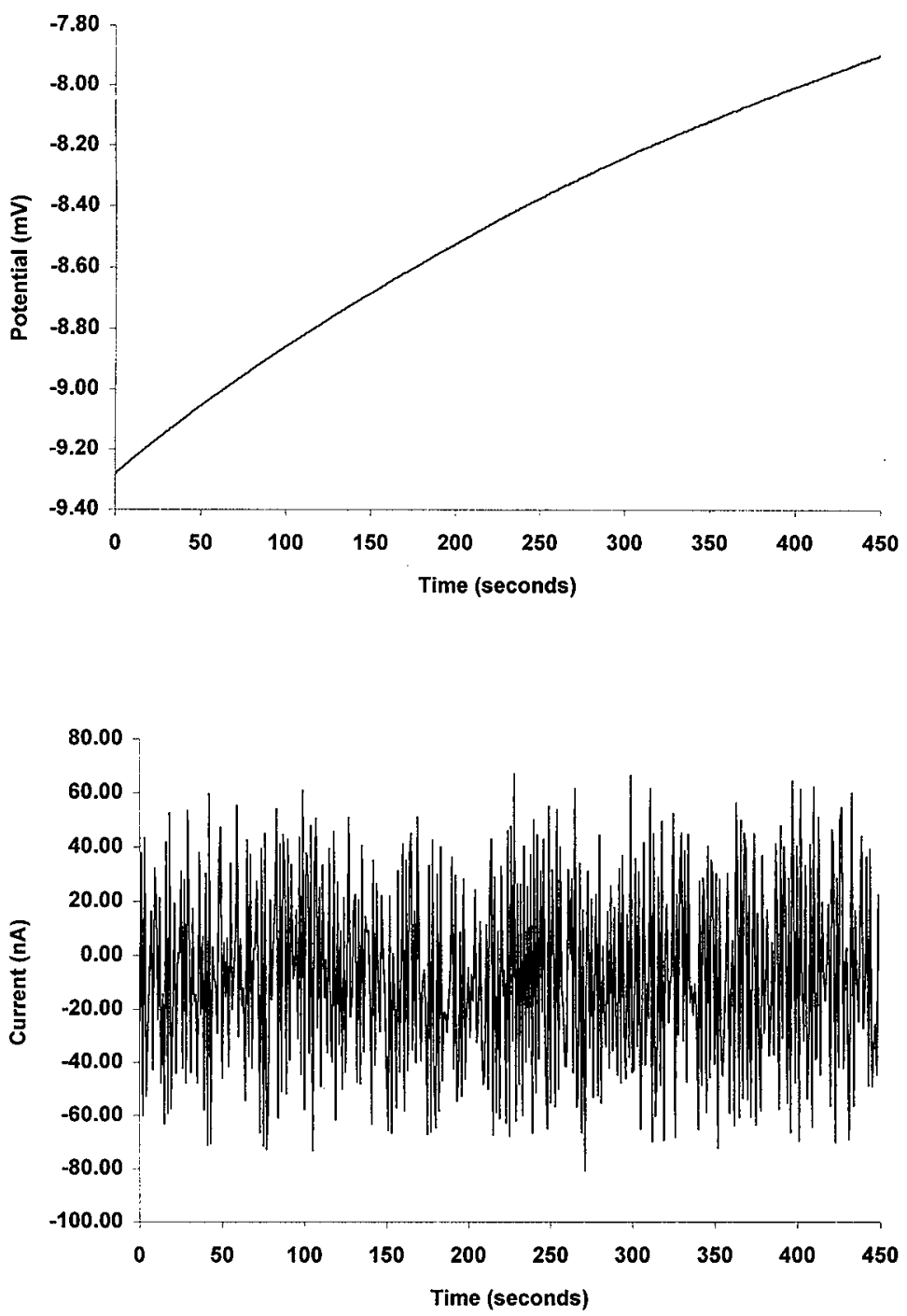

Figure 117: Typical raw potential and raw current data files: pin electrodes in supernate on channel 5 - February 1998 

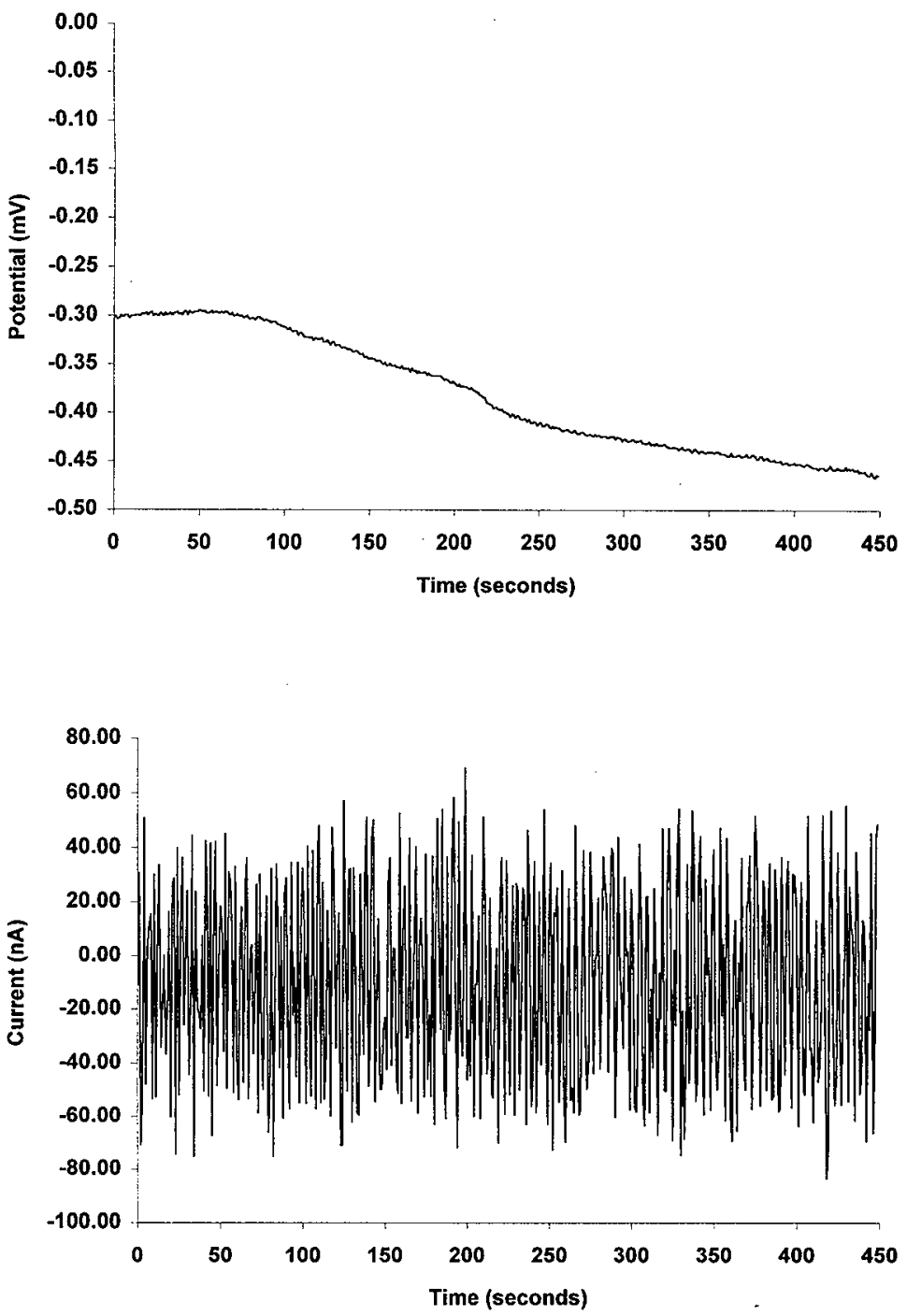

Figure 118: Typical raw potential and raw current data files: pin electrodes in supernate on channel 5 - March 1998 
HNF-3414, Rev. 0
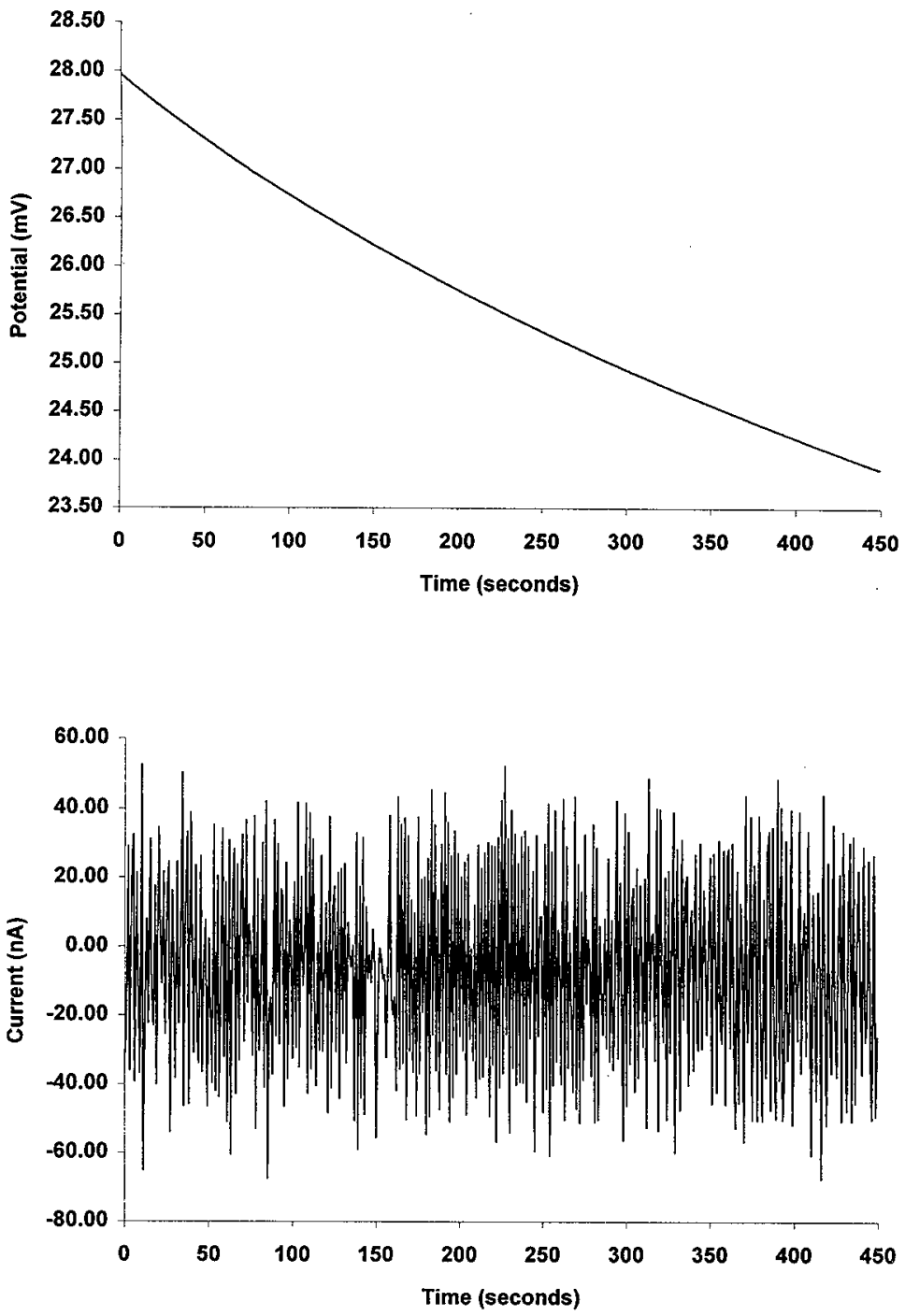

Figure 119: Typical raw potential and raw current data files: pin electrodes in supernate on channel 5 - April 1998 
HNF-3414, Rev。 0
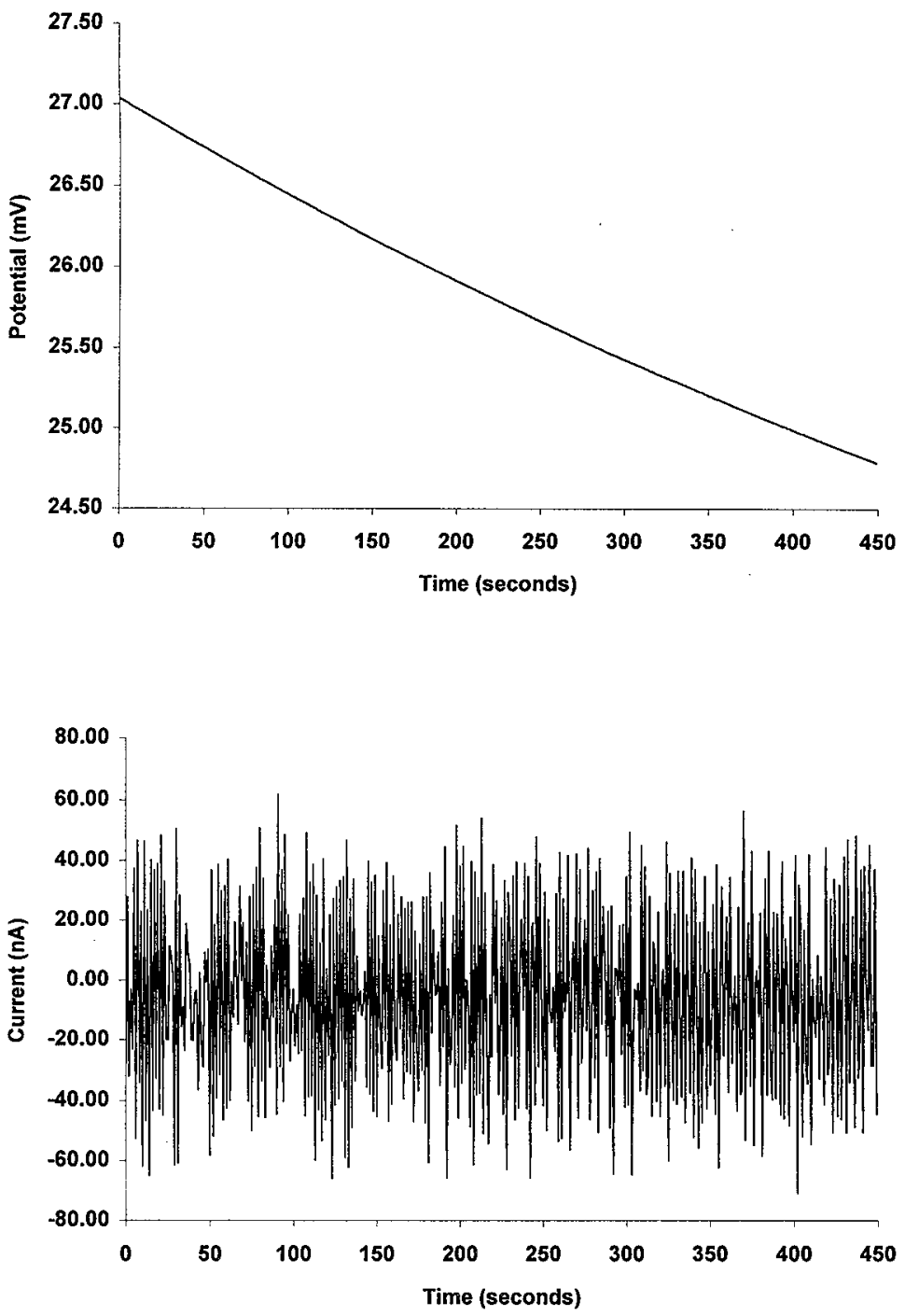

Figure 120: Typical raw potential and raw current data files: pin electrodes in supernate on channel 5 - May 1998 
HNF-3414, Rev. 0
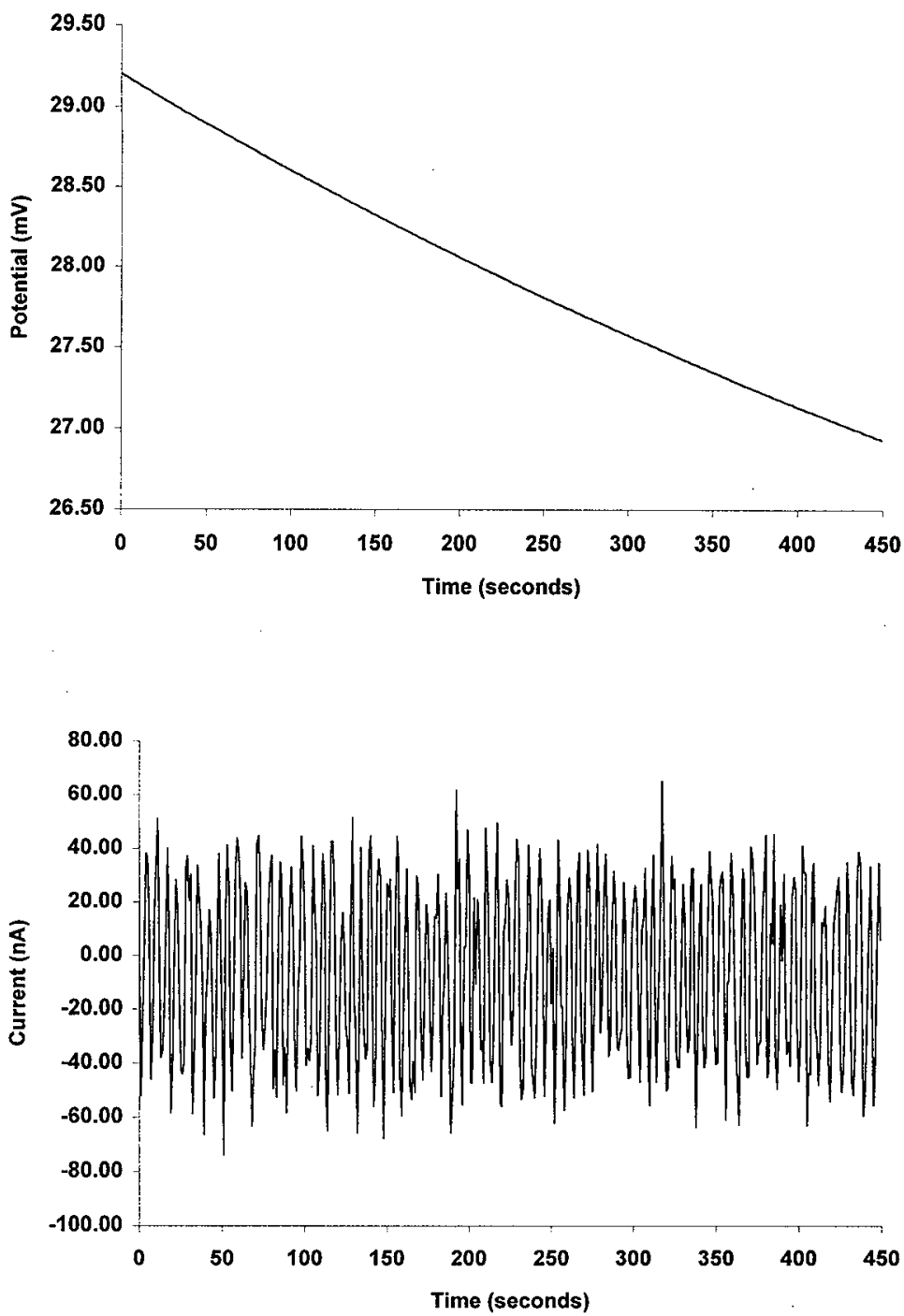

Figure 121: Typical raw potential and raw current data files: pin electrodes in supernate on channel 5 - June 1998 
HNF-3414, Rev. 0
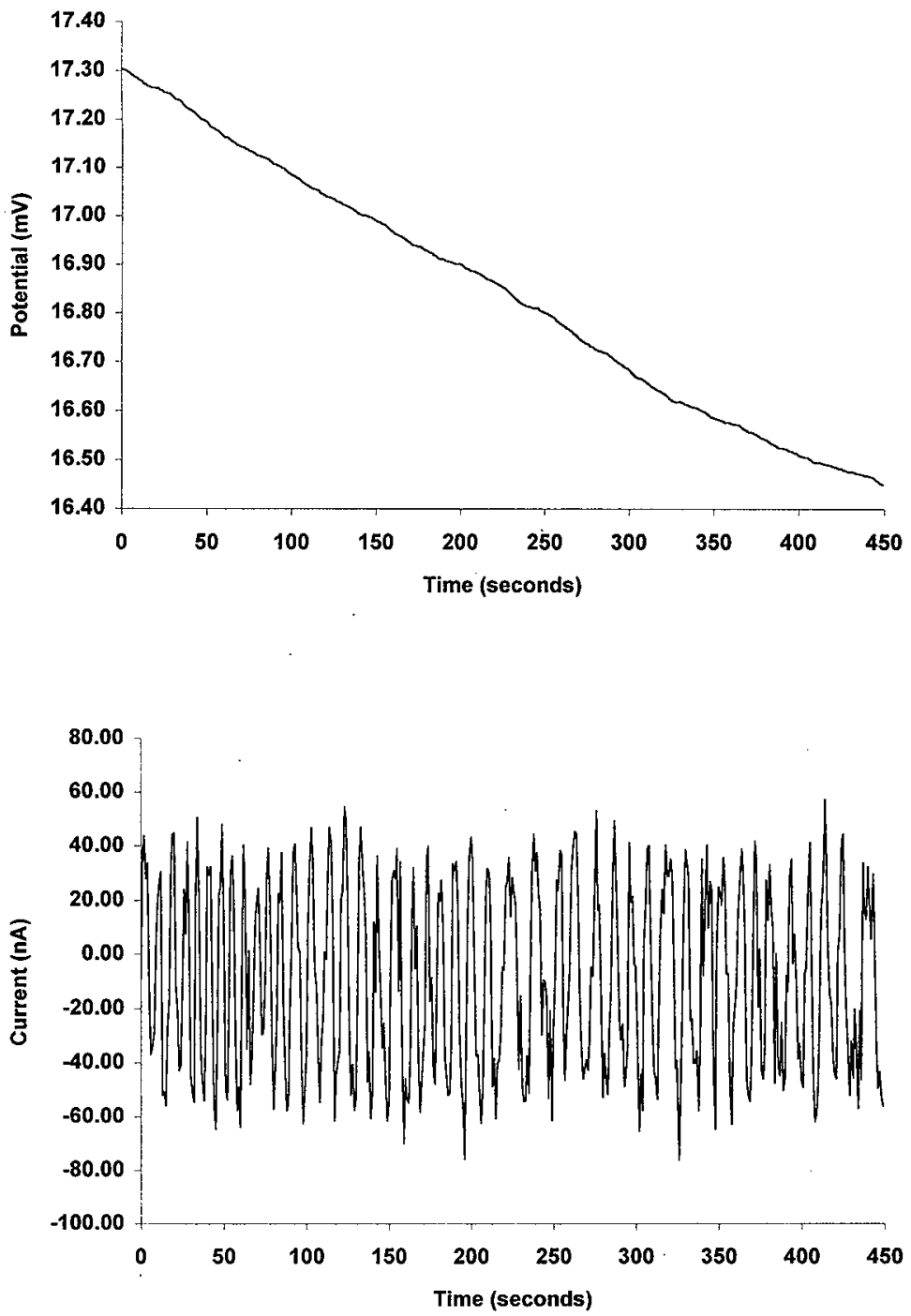

Figure 122: Typical raw potential and raw current data files: pin electrodes in supernate on channel 5 - July 1998 
HNF-3414, Rev. 0
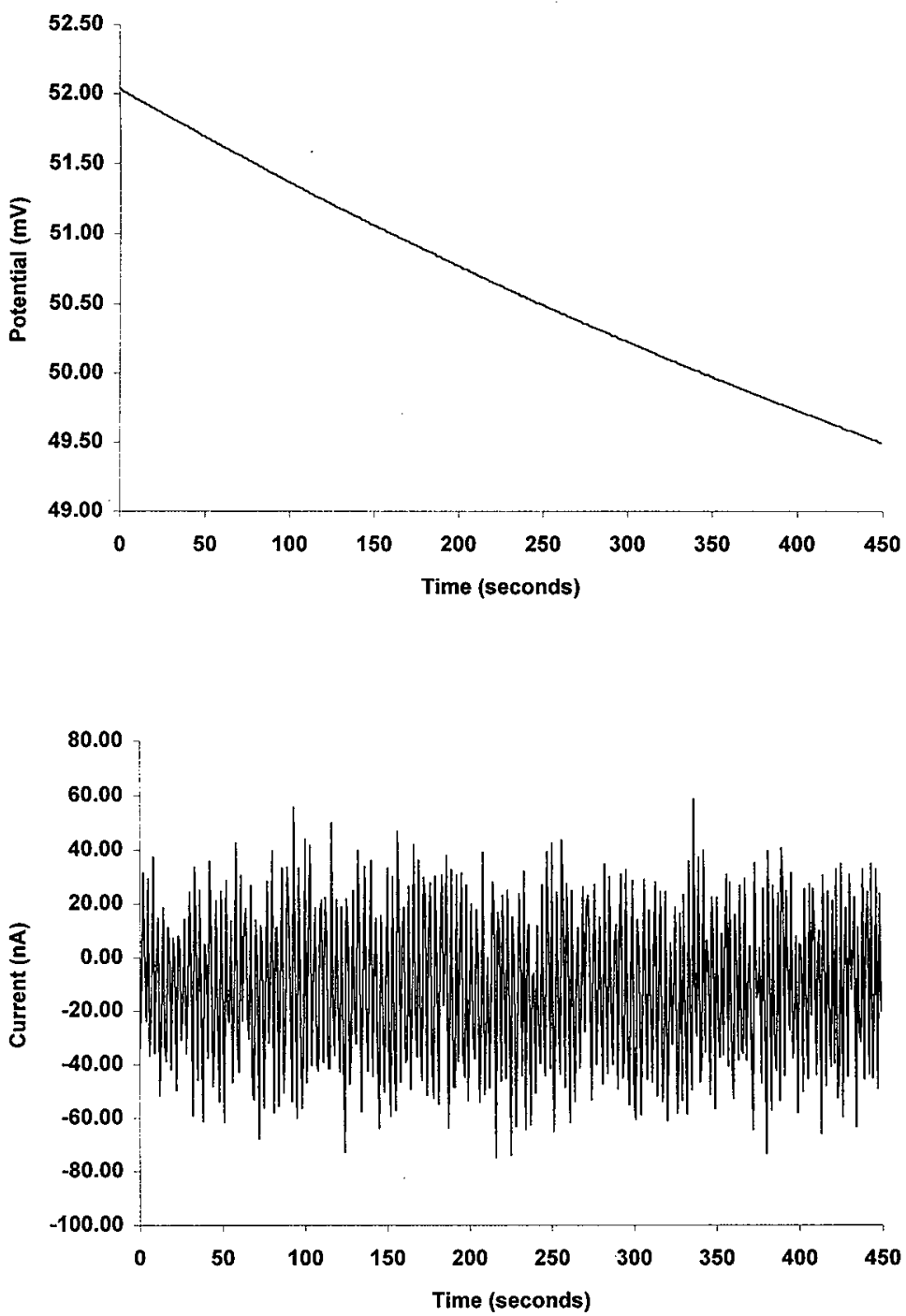

Figure 123: Typical raw potential and raw current data files: pin electrodes in supernate on channel 5 - August 1998 
HNF-3414, Rev. 0
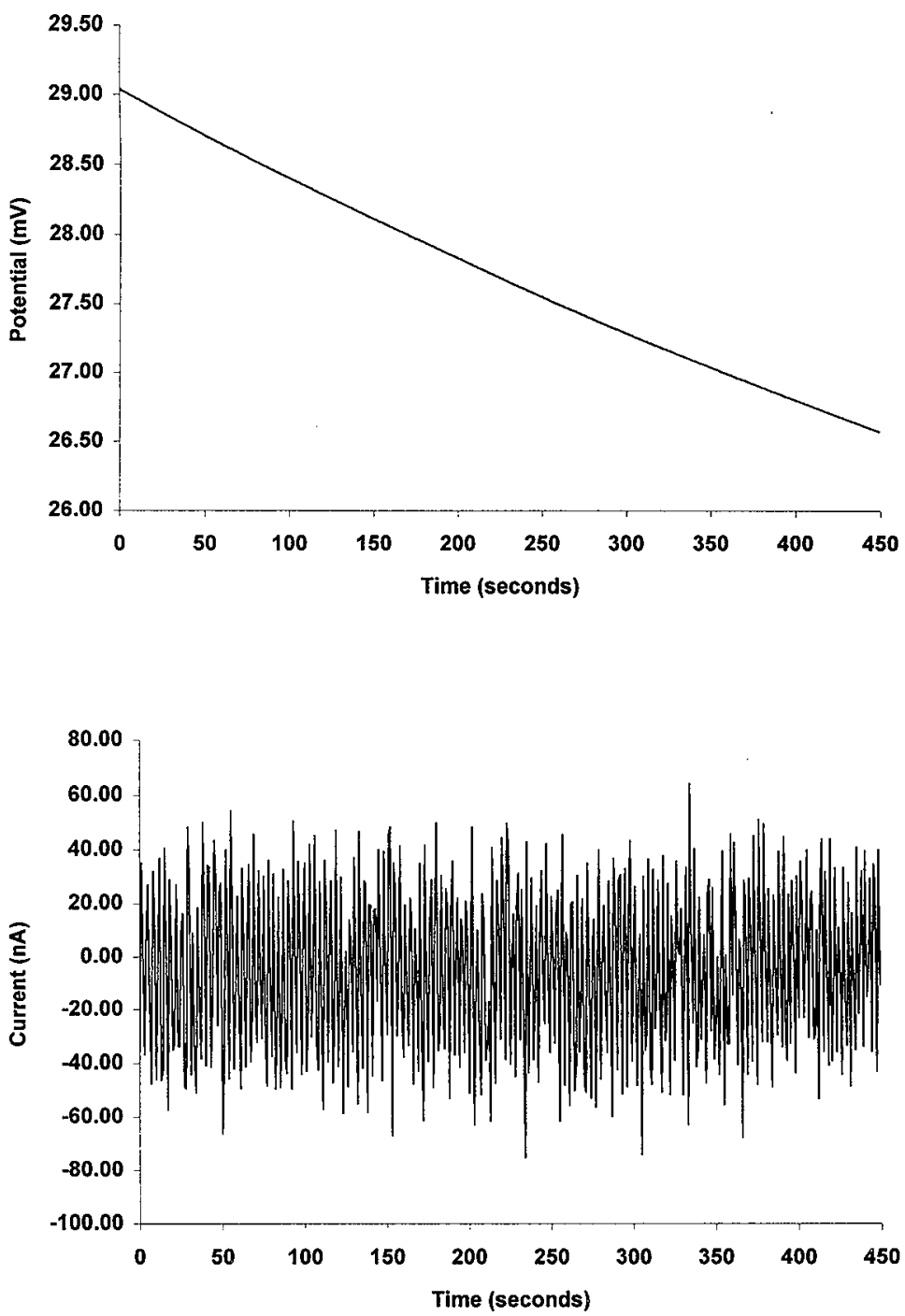

Figure 124: Typical raw potential and raw current data files: pin electrodes in supernate on channel 5 - September 1998 

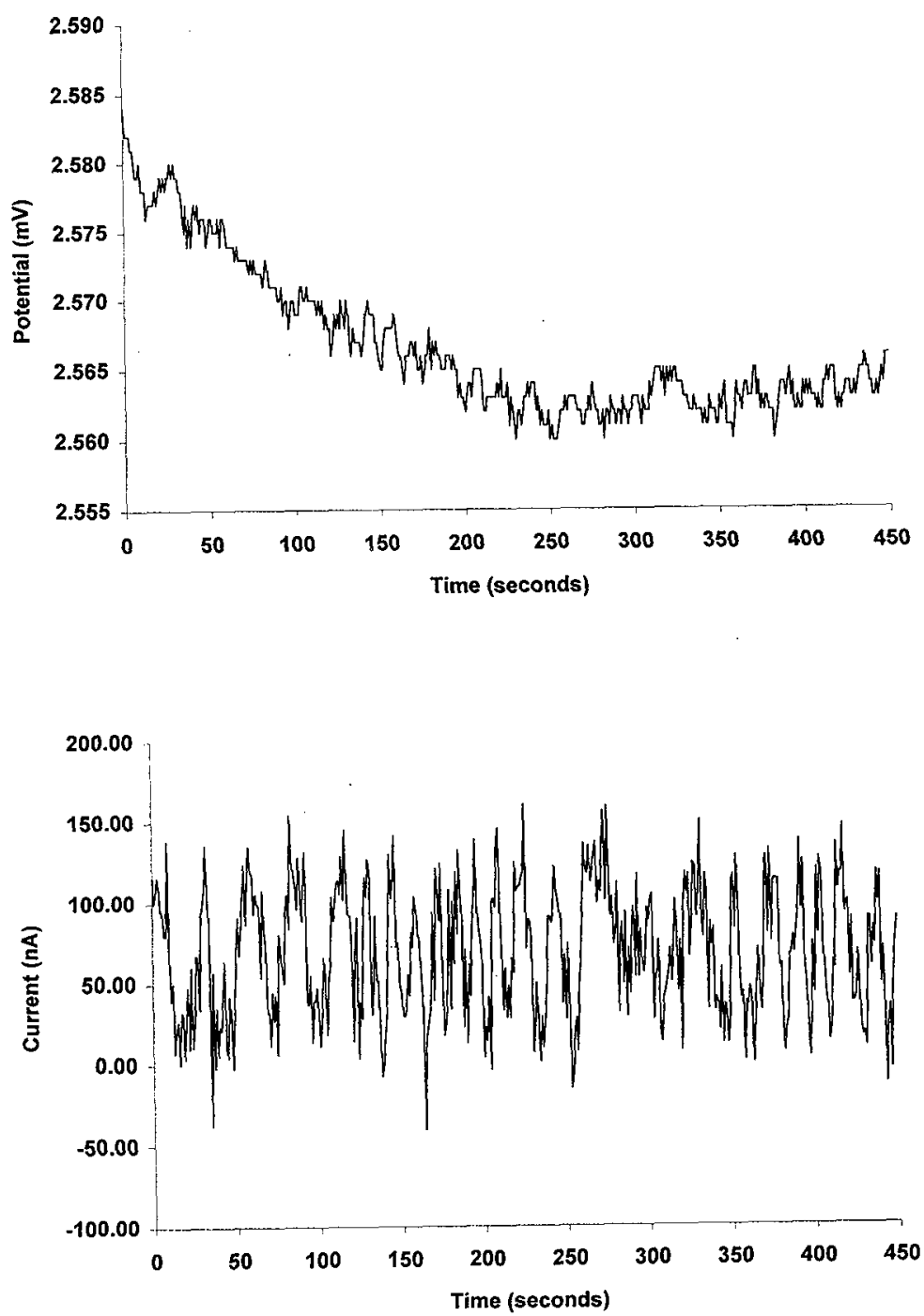

Figure 125: Typical raw potential and raw current data files: C-ring electrodes in supernate on channel 6 - September 1997 

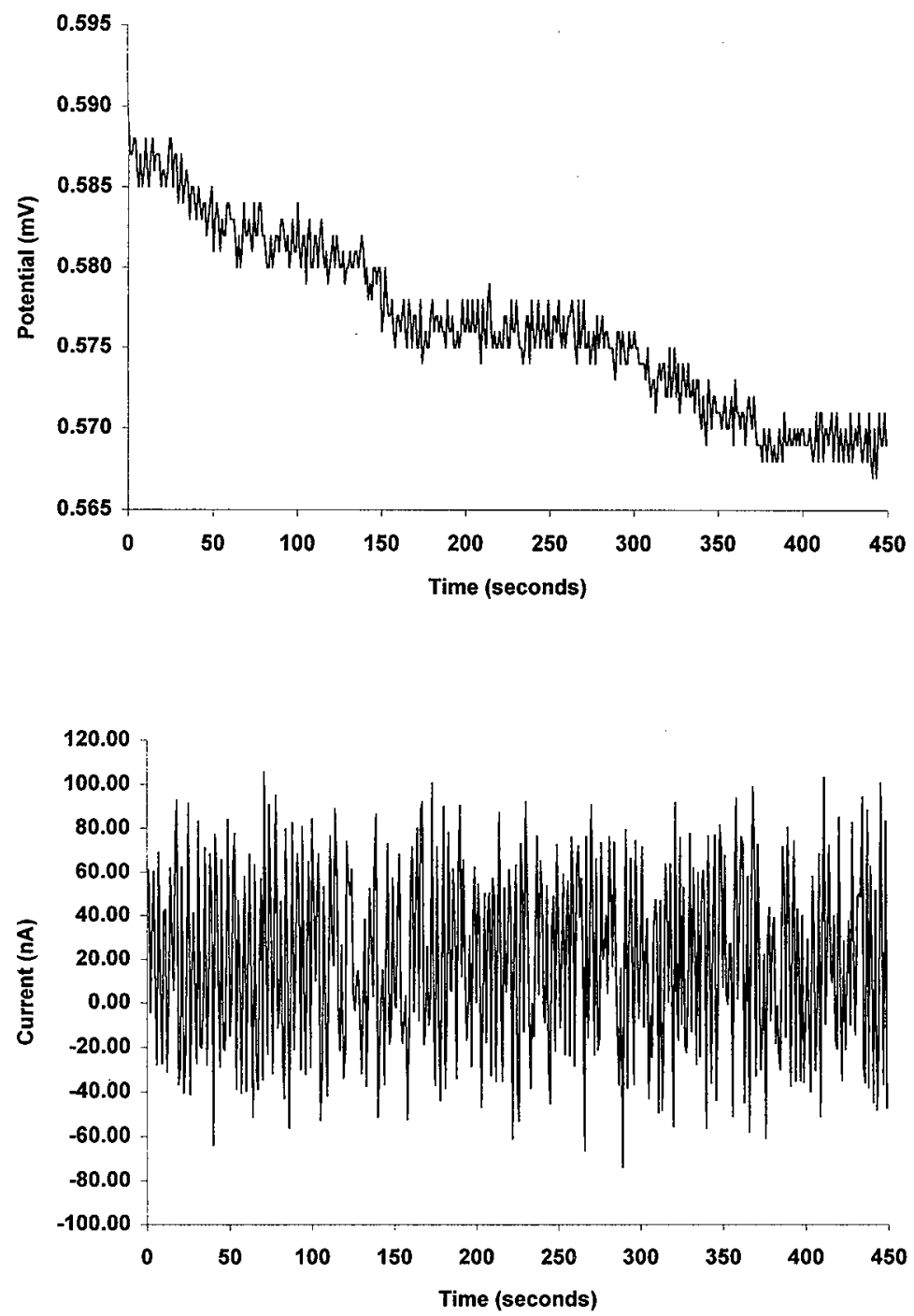

Figure 126: Typical raw potential and raw current data files: C-ring electrodes in supernate on channel 6 - October 1997 

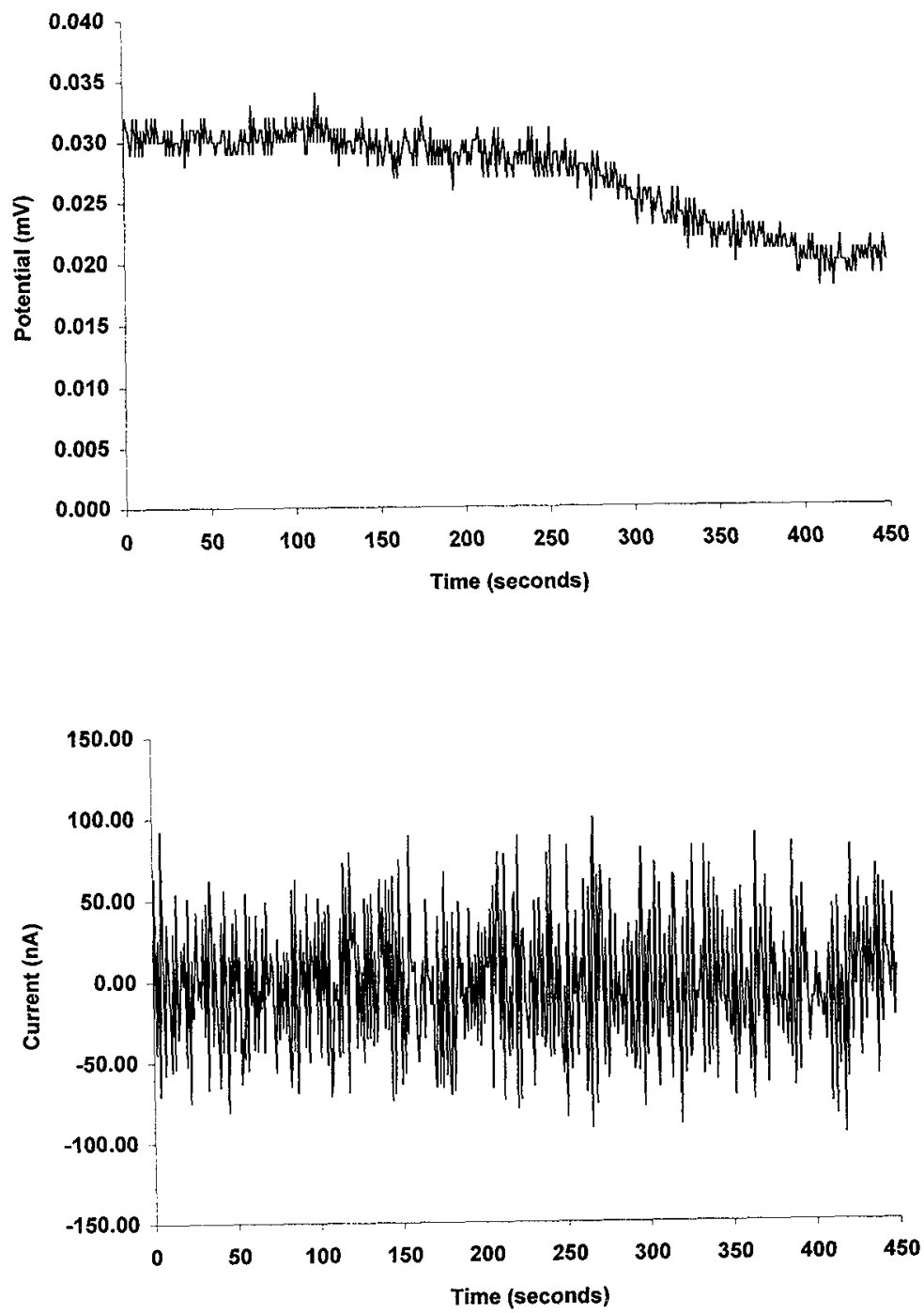

Figure 127: Typical raw potential and raw current data files: C-ring electrodes in supernate on channel 6 - November 1997 

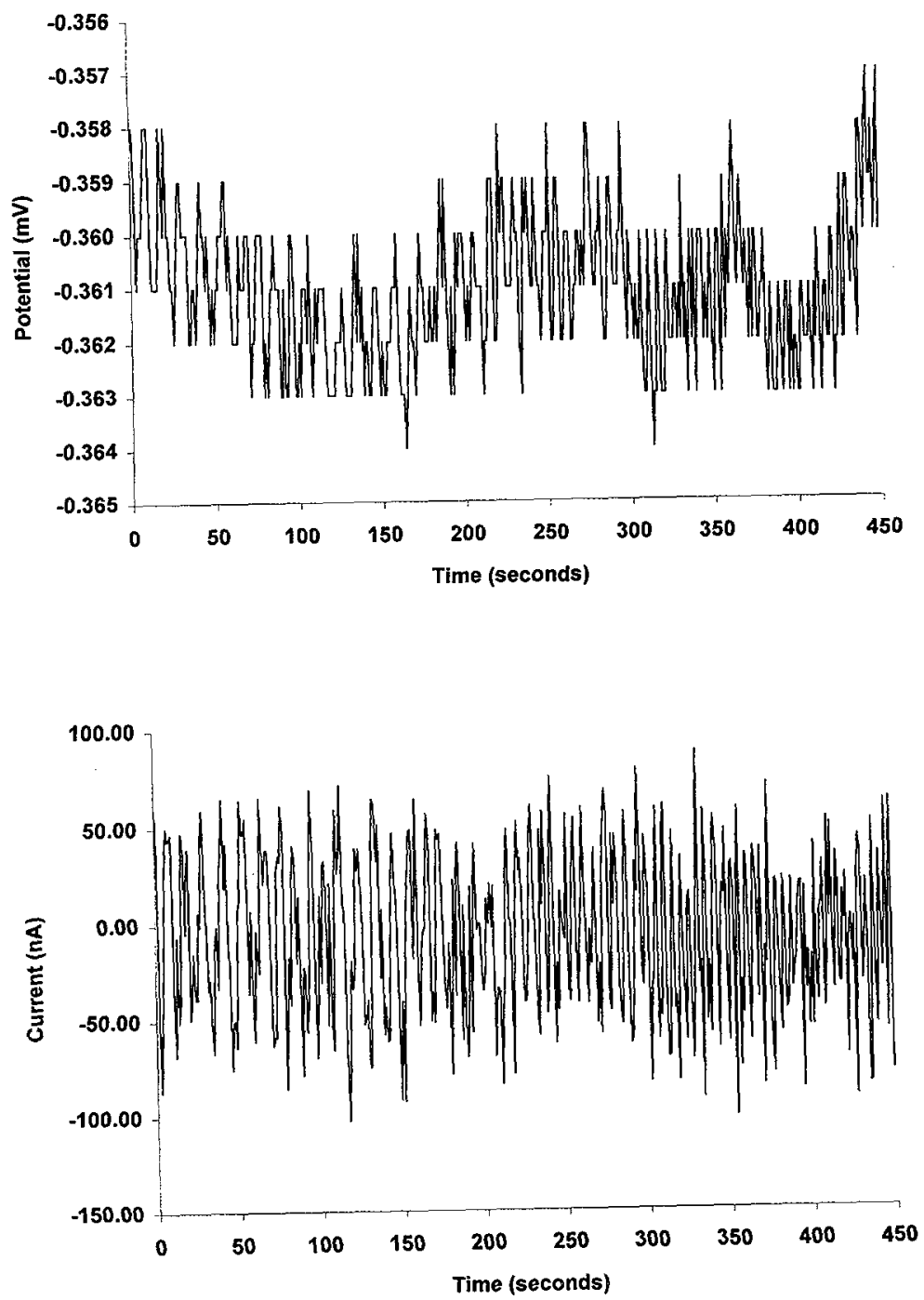

Figure 128: Typical raw potential and raw current data files: C-ring electrodes in supernate on channel 6 - December 1997 
HNF-3414, Rev. 0
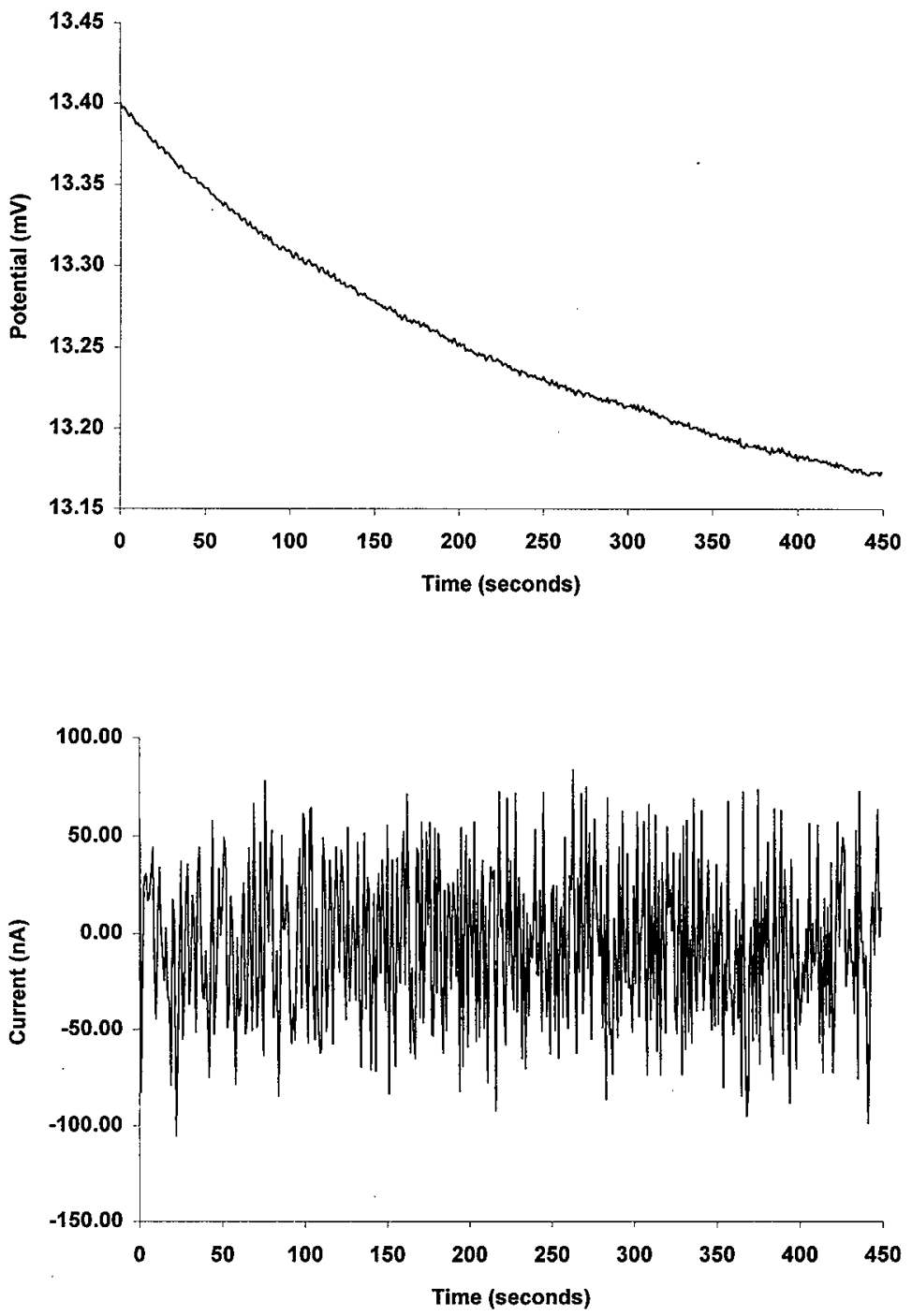

Figure 129: Typical raw potential and raw current data files: C-ring electrodes in supernate on channel 6 - January 1998 
HNF-3414, Rev. 0
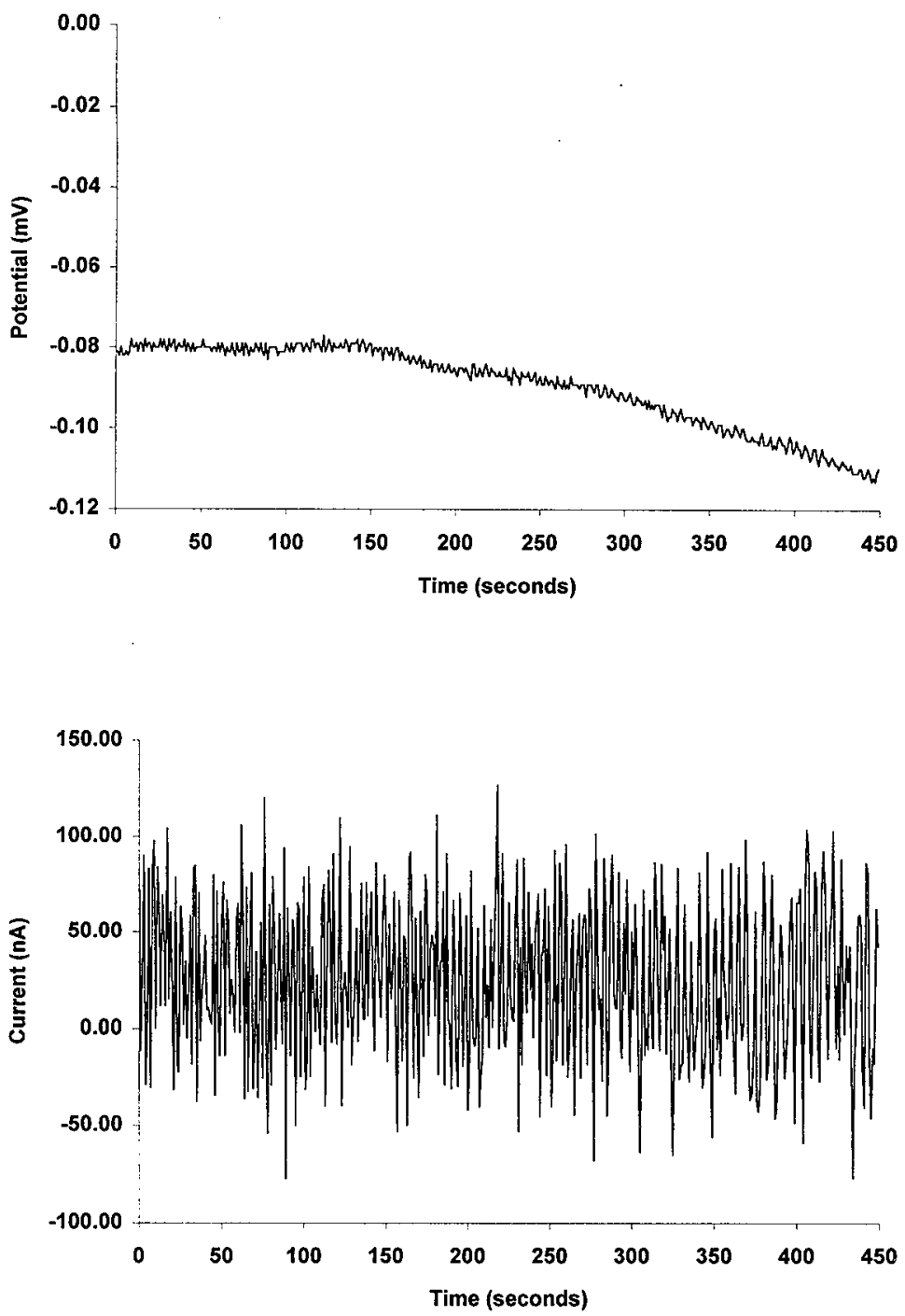

Figure 130: Typical raw potential and raw current data files: C-ring electrodes in supernate on channel 6 - February 1998 
HNF-3414, Rev. 0
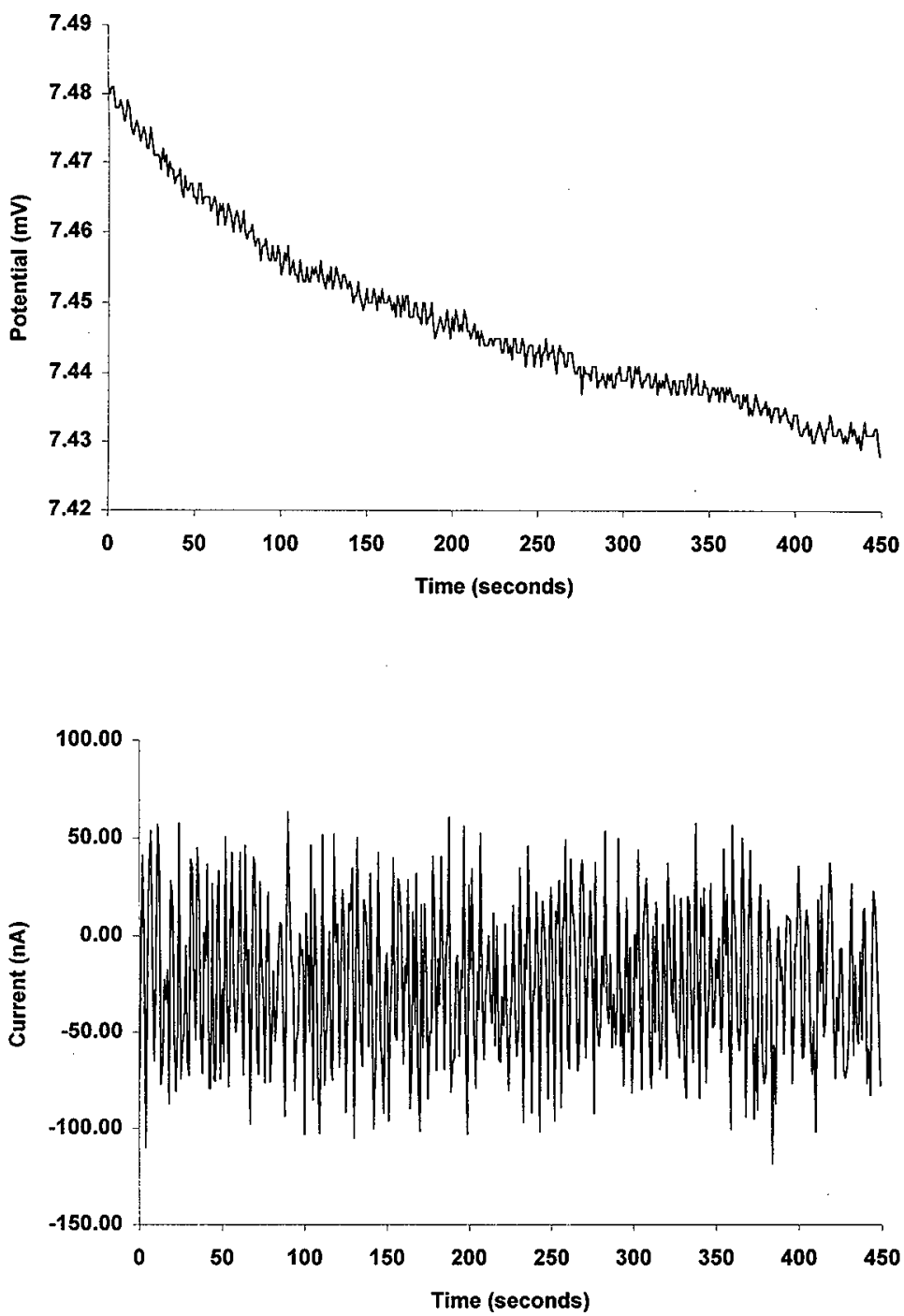

Figure 131: Typical raw potential and raw current data files: C-ring electrodes in supernate on channel 6 - March 1998 

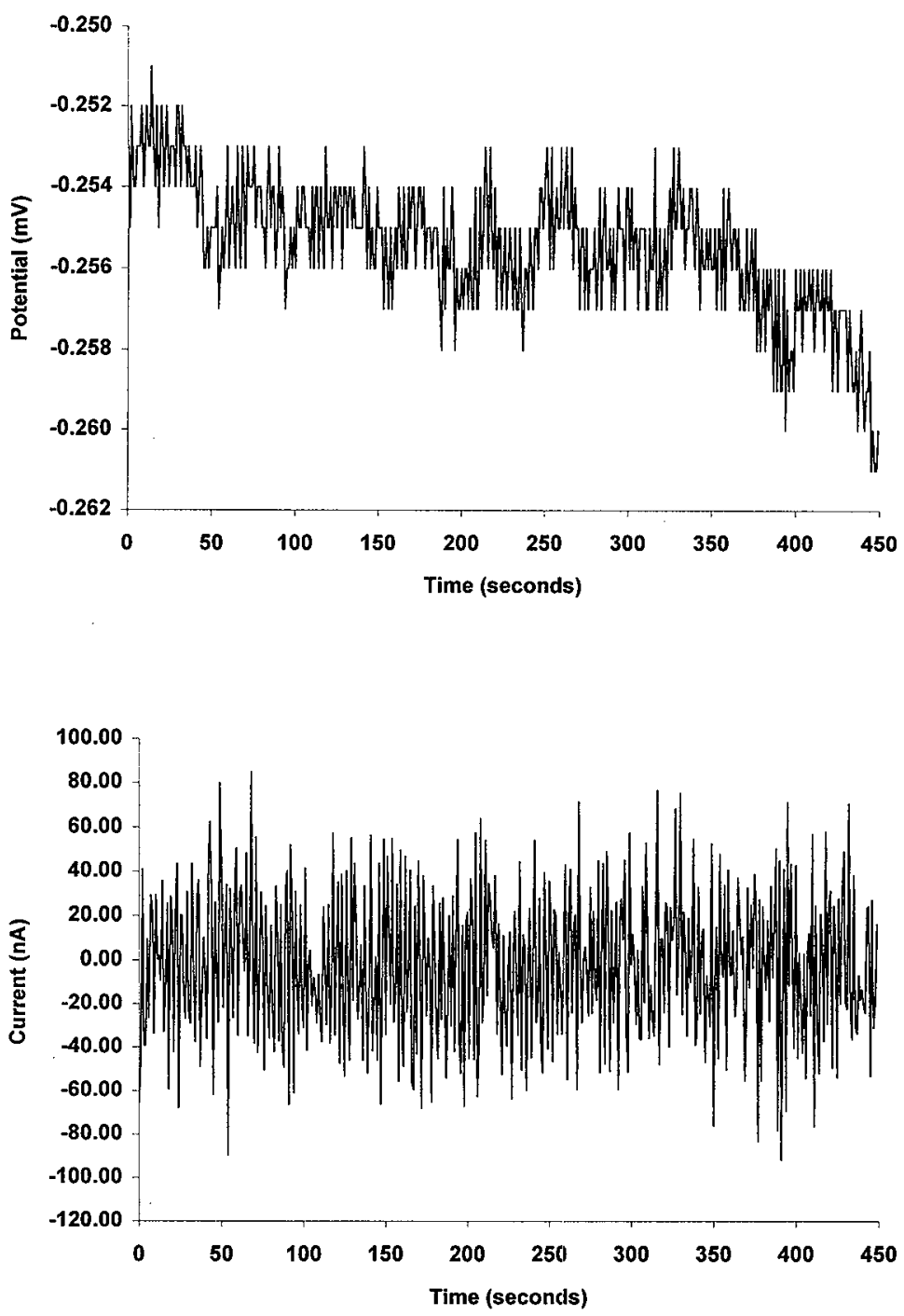

Figure 132: Typical raw potential and raw current data files: C-ring electrodes in supernate on channel 6 - April 1998 

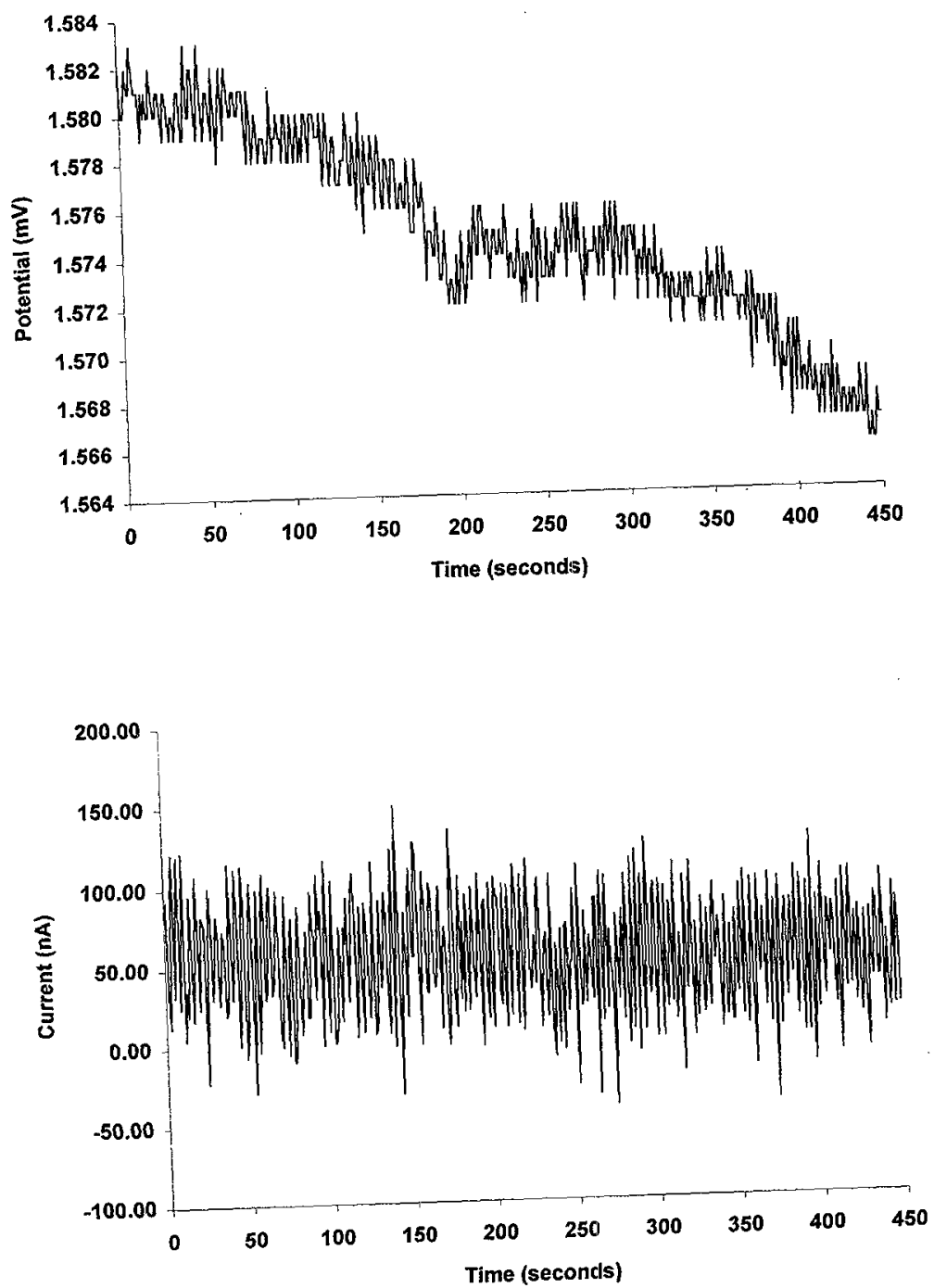

Figure 133: Typical raw potential and raw current data files: C-ring electrodes in supernate on channel 6 - May 1998 

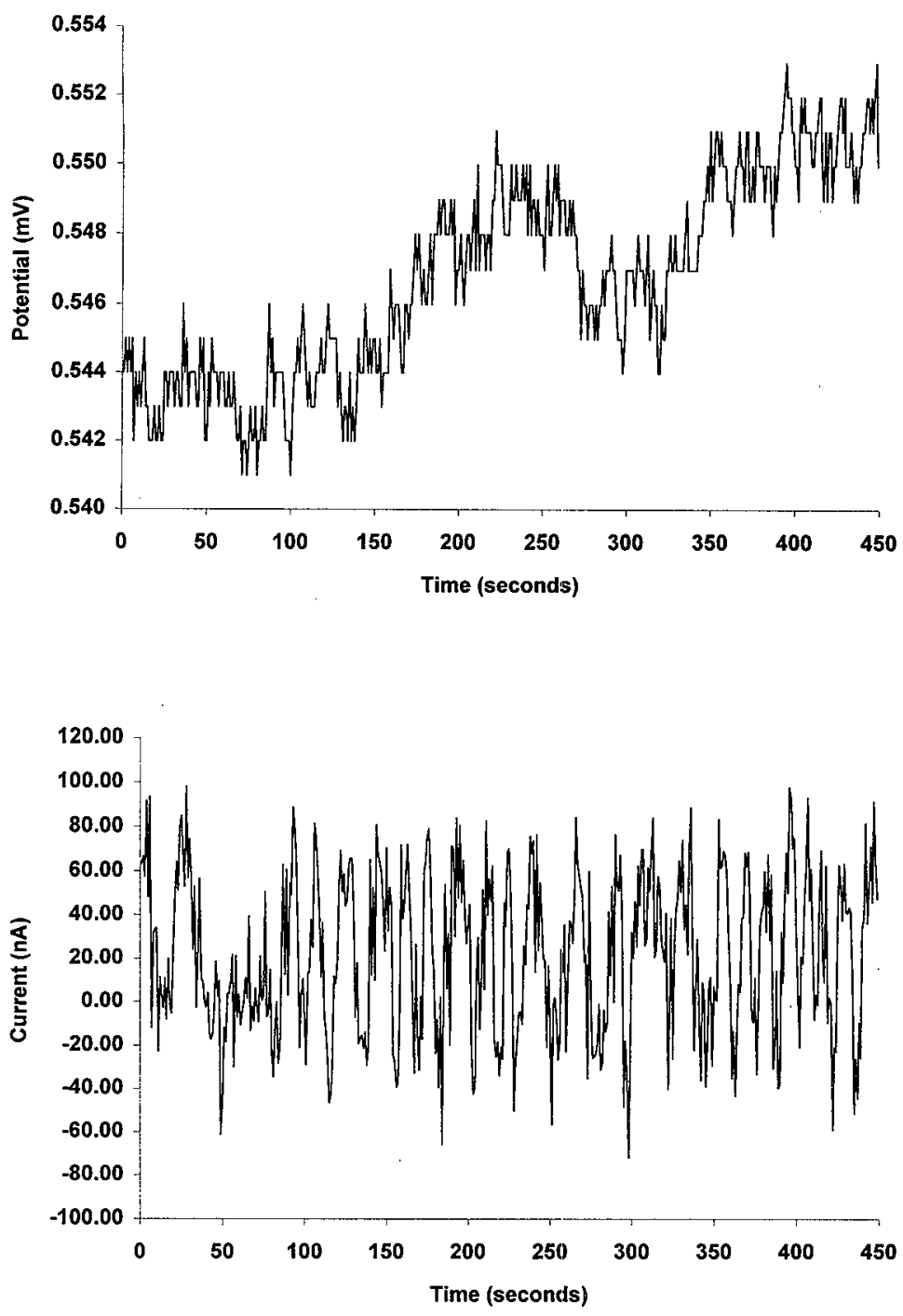

Figure 134: Typical raw potential and raw current data files: C-ring electrodes in supernate on channel 6 - June 1998 
HNF-3414, Rev, 0
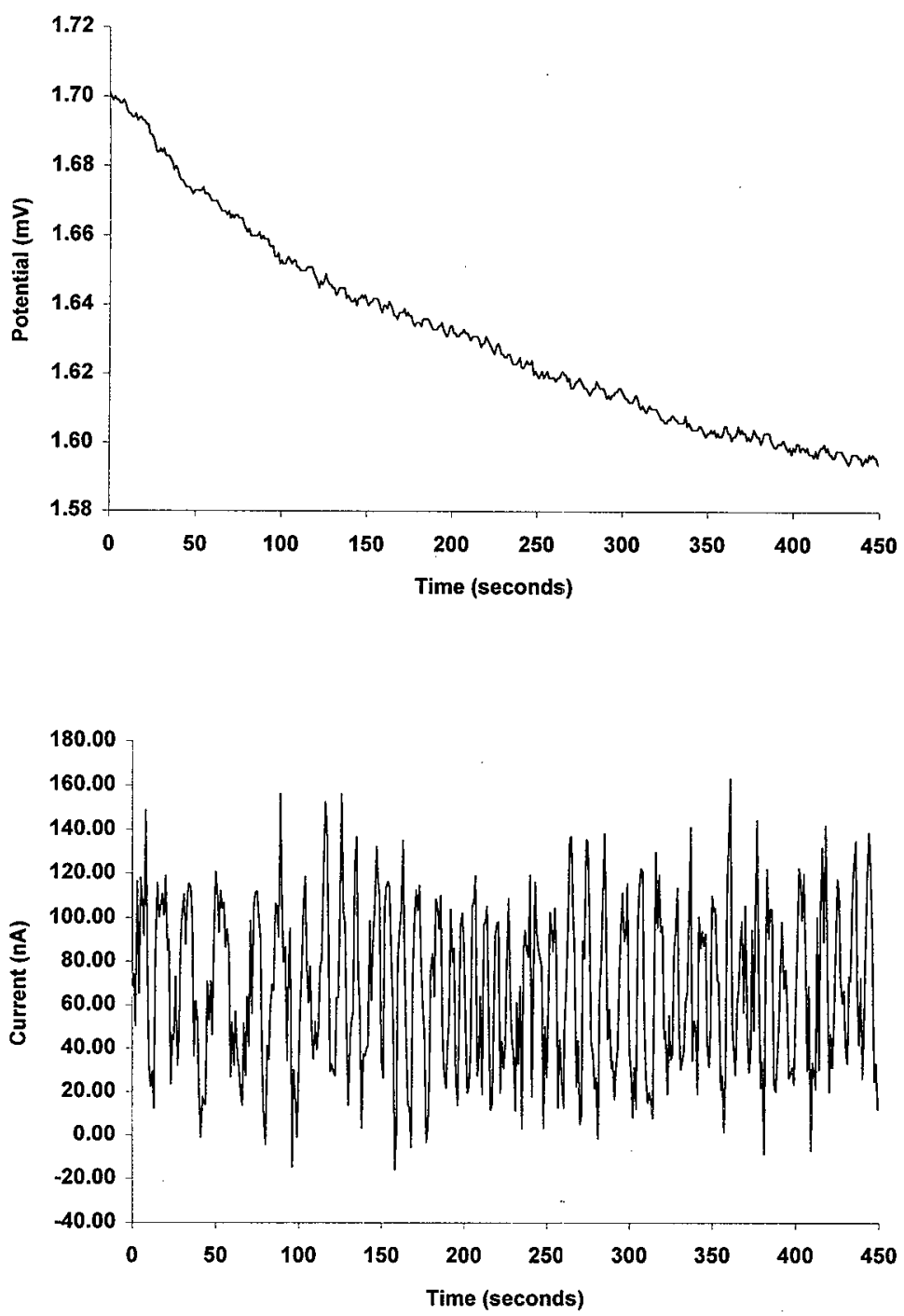

Figure 135: Typical raw potential and raw current data files: C-ring electrodes in supernate on channel 6 - July 1998 
HNF-3414, Rev. 0
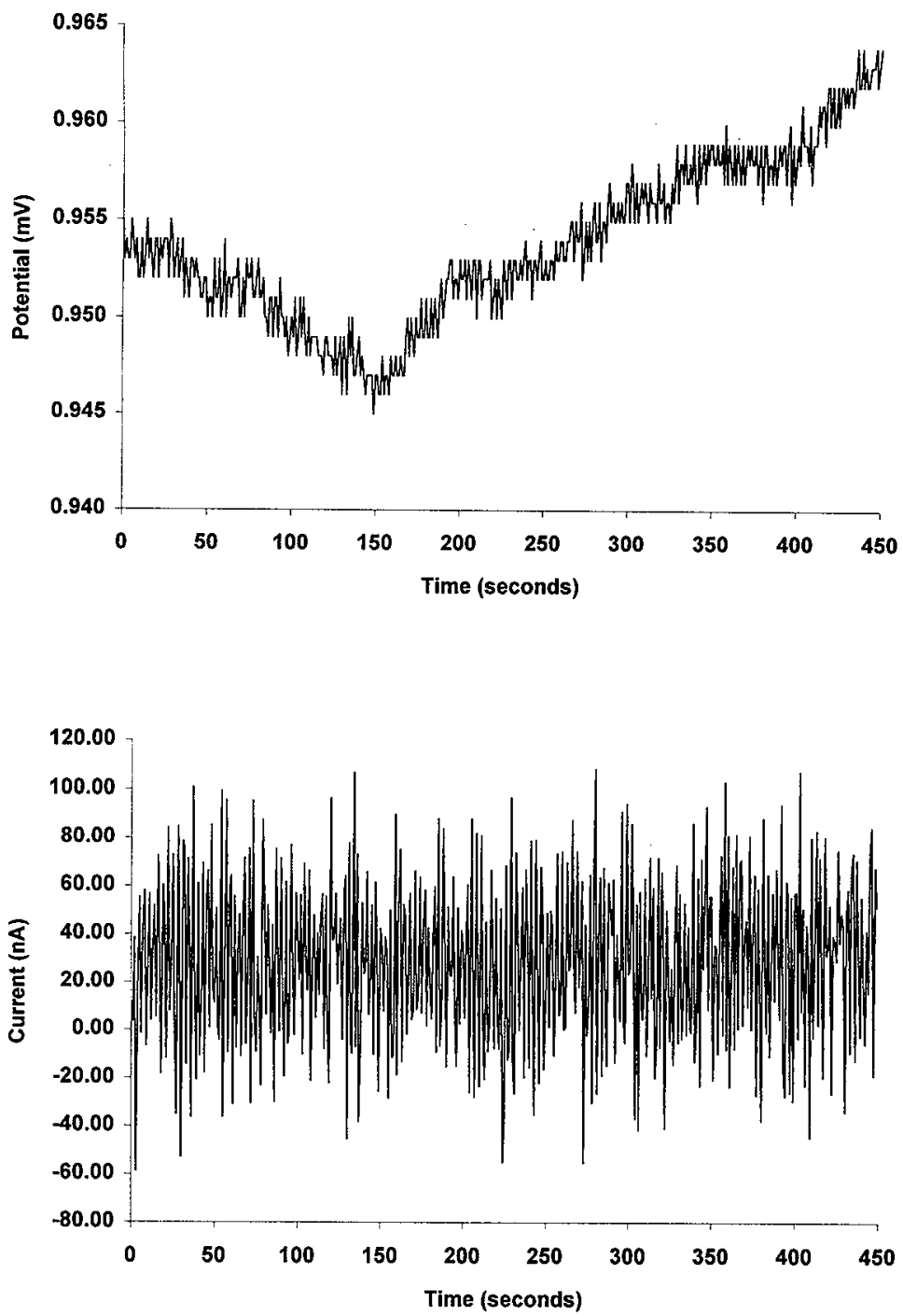

Figure 136: Typical raw potential and raw current data files: C-ring electrodes in supernate on channel 6 - August 1998 

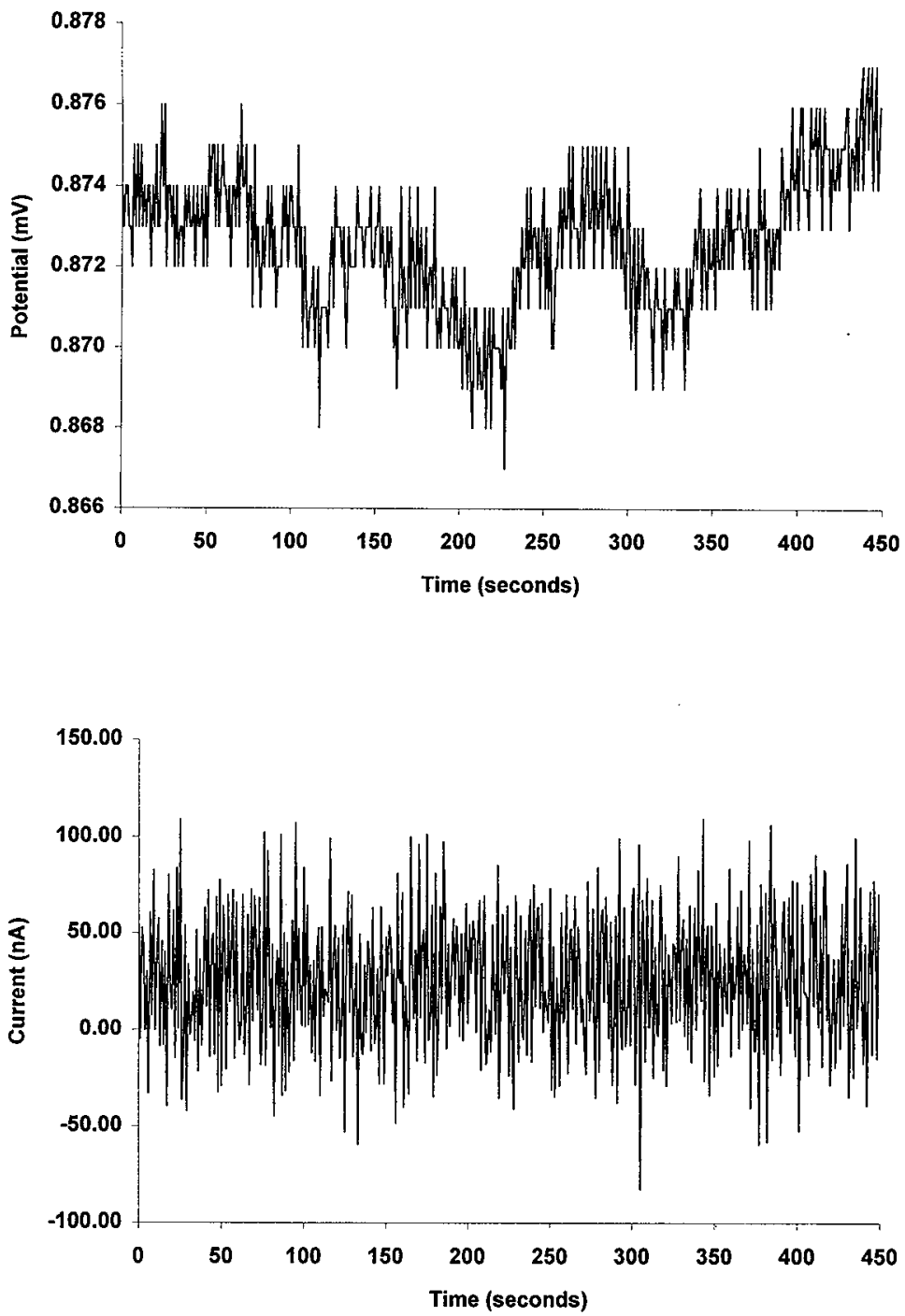

Figure 137: Typical raw potential and raw current data files: C-ring electrodes in supernate on channel 6 - September 1998 
HNF-3414, Rev. 0
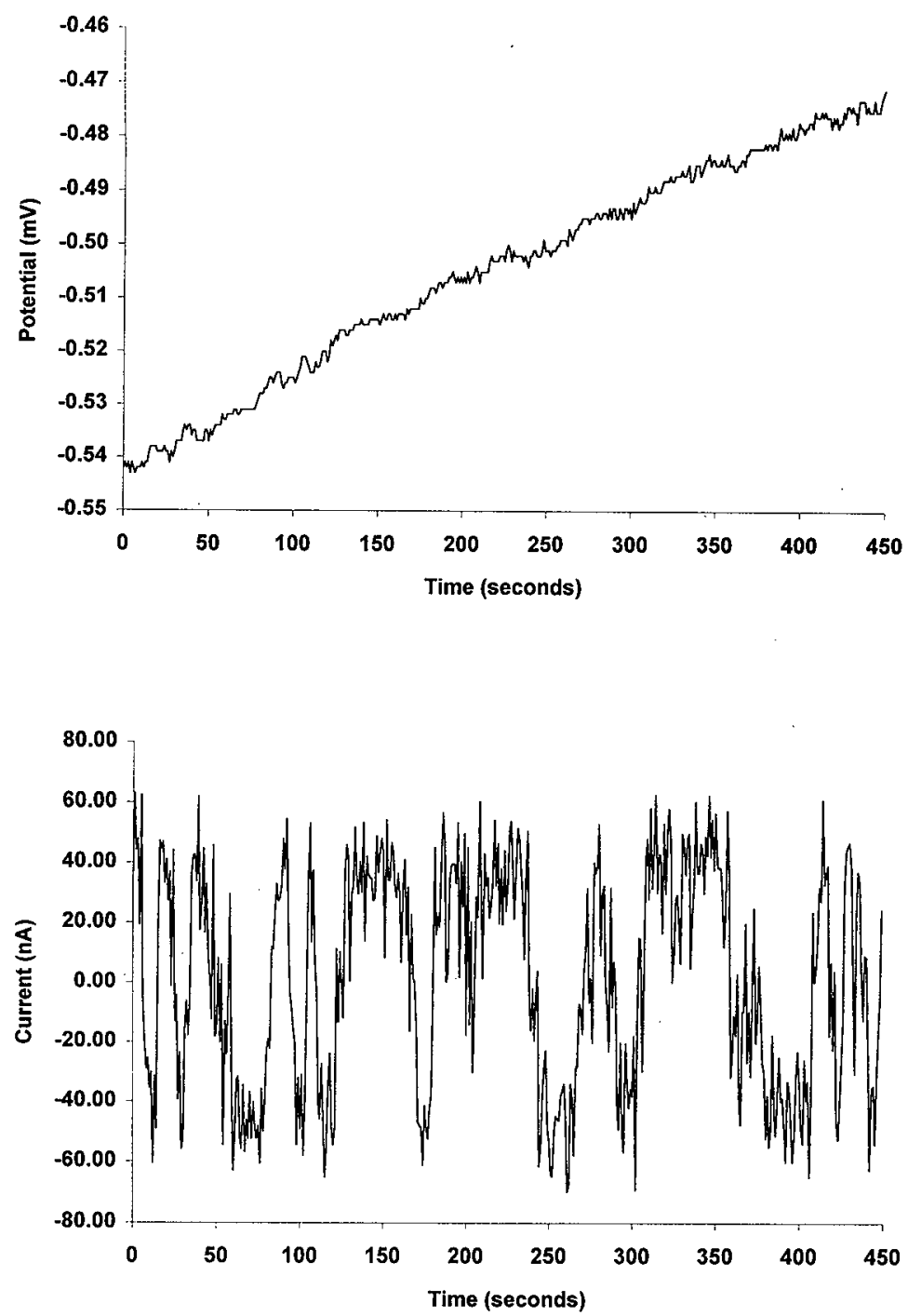

Figure 138: Typical raw potential and raw current data files: pin electrodes in supernate on channel 7 - September 1997 

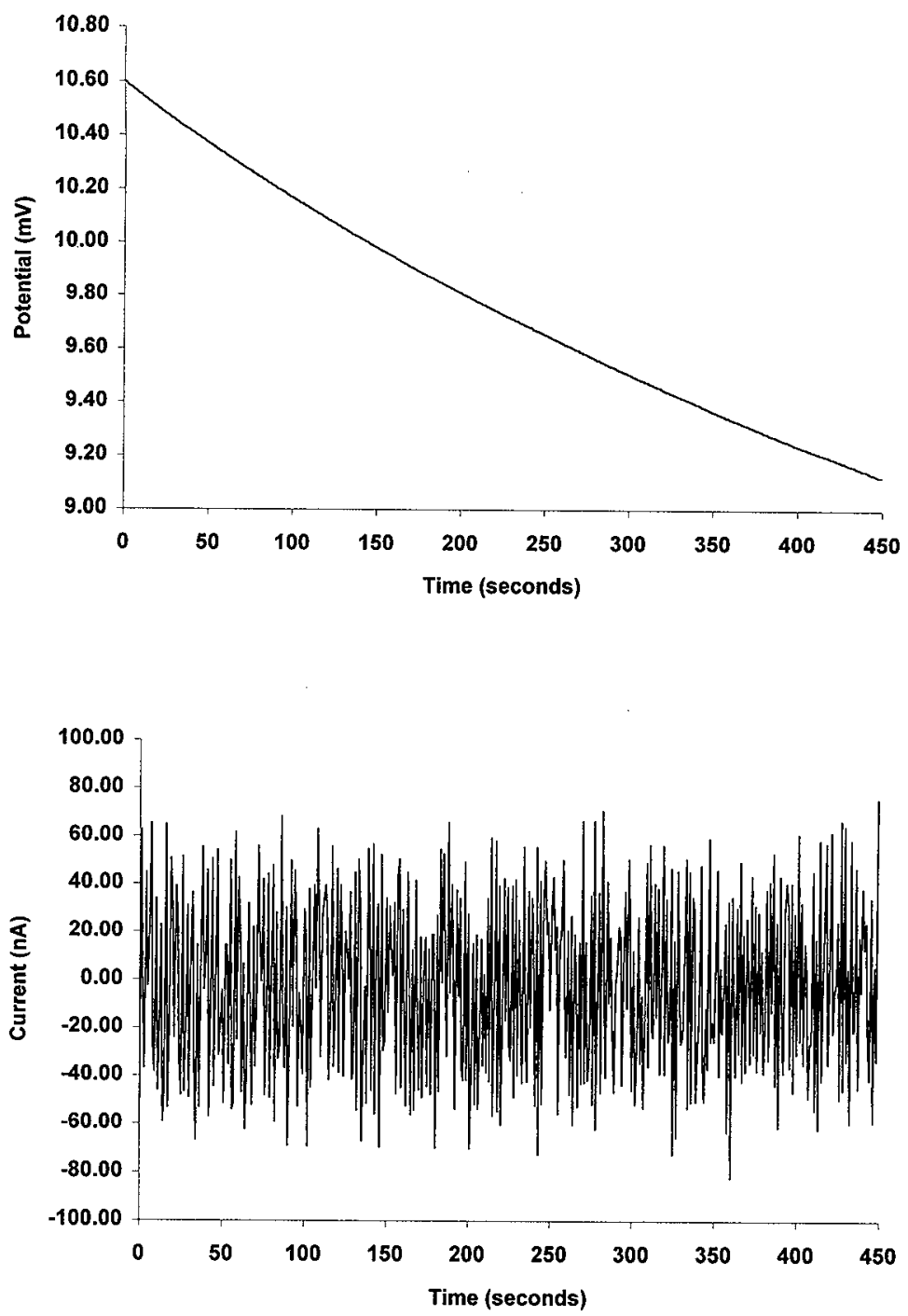

Figure 139: Typical raw potential and raw current data files: pin electrodes in supernate on channel 7 - October 1997 

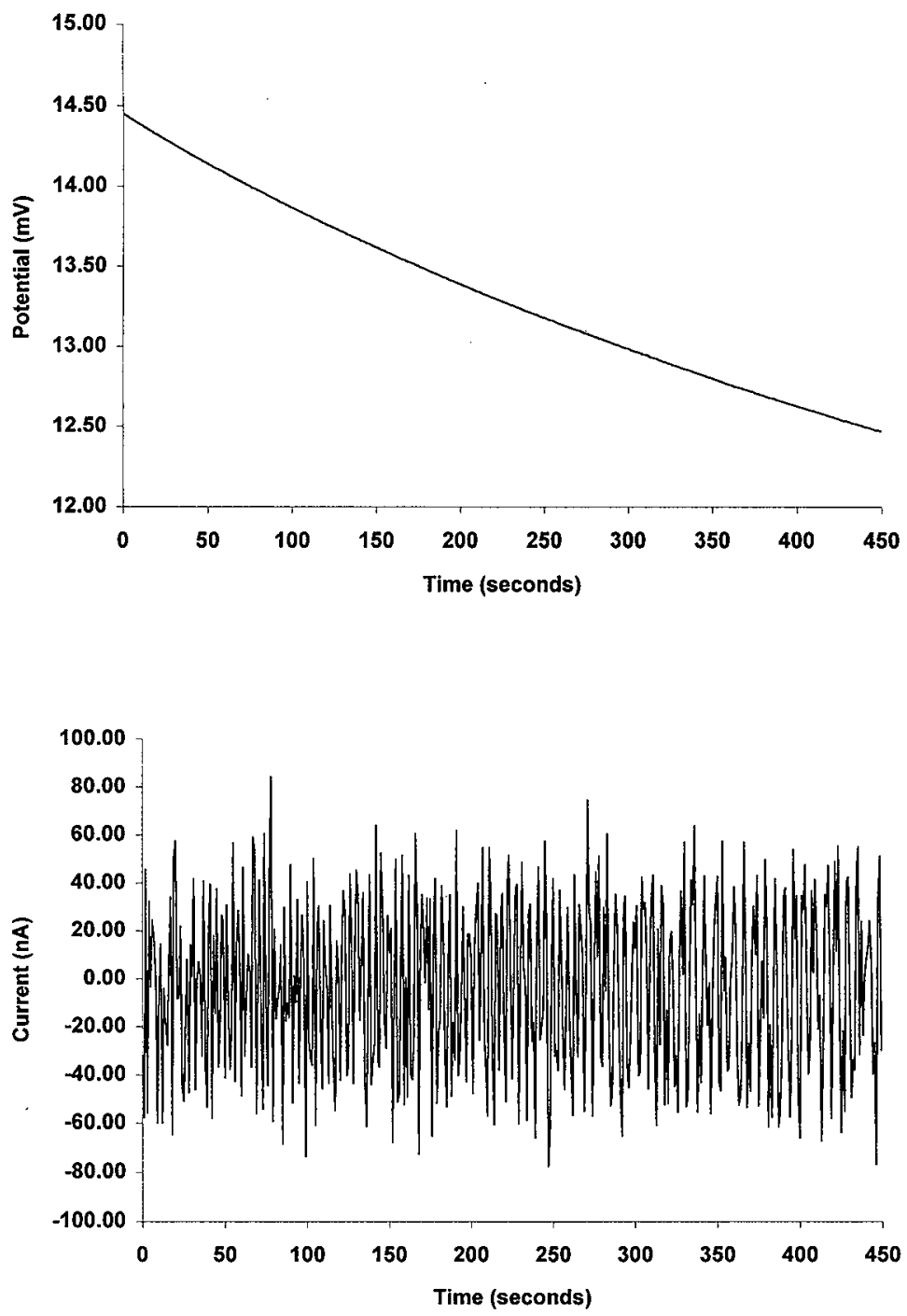

Figure 140: Typical raw potential and raw current data files: pin electrodes in supernate on channel 7 - November 1997 

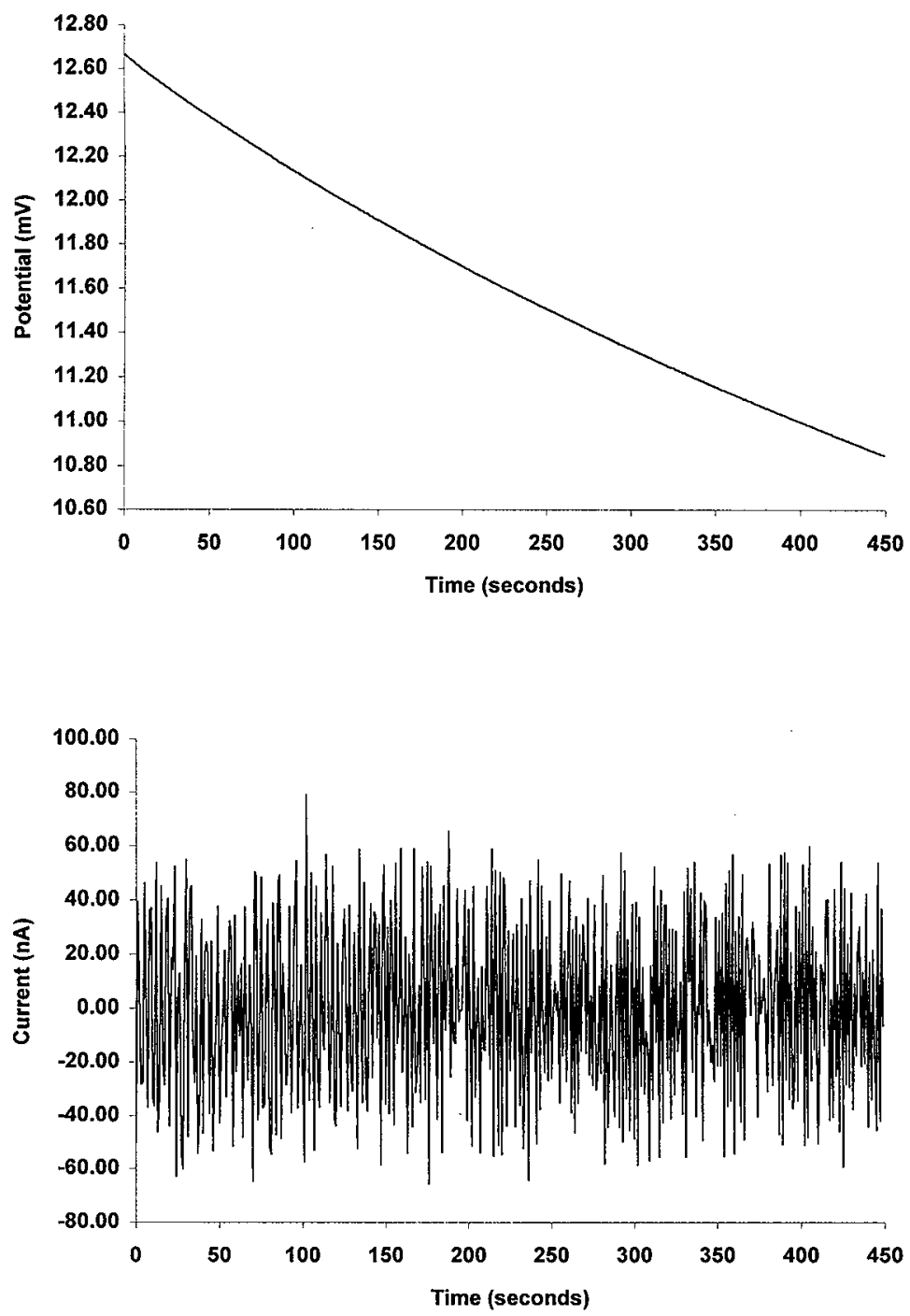

Figure 141: Typical raw potential and raw current data files: pin electrodes in supernate on channel 7 - December 1997 
HNF-3414, Rev. 0
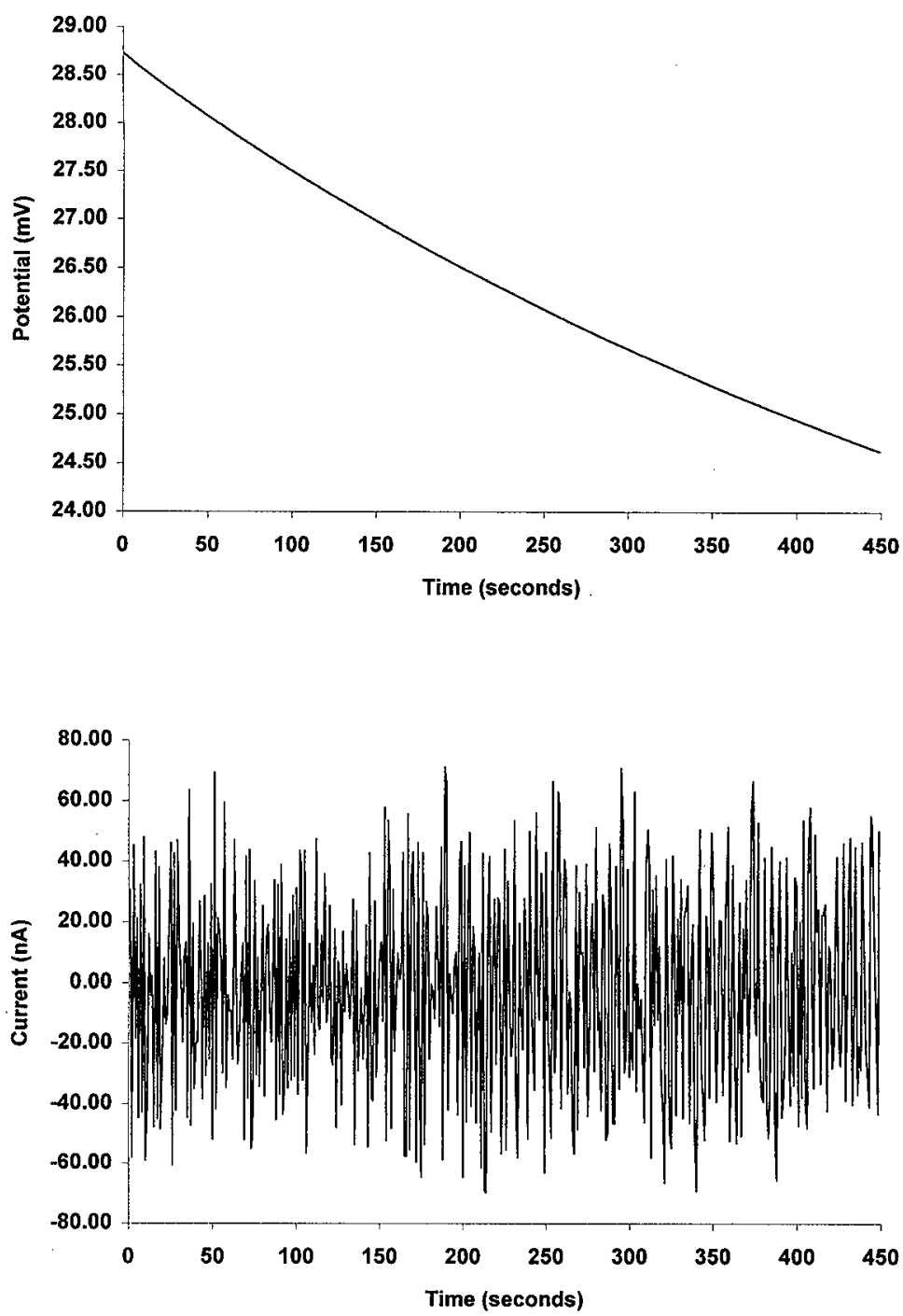

Figure 142: Typical raw potential and raw current data files: pin electrodes in supernate on channel 7 - January 1998 
HNF-3414, Rev. 0
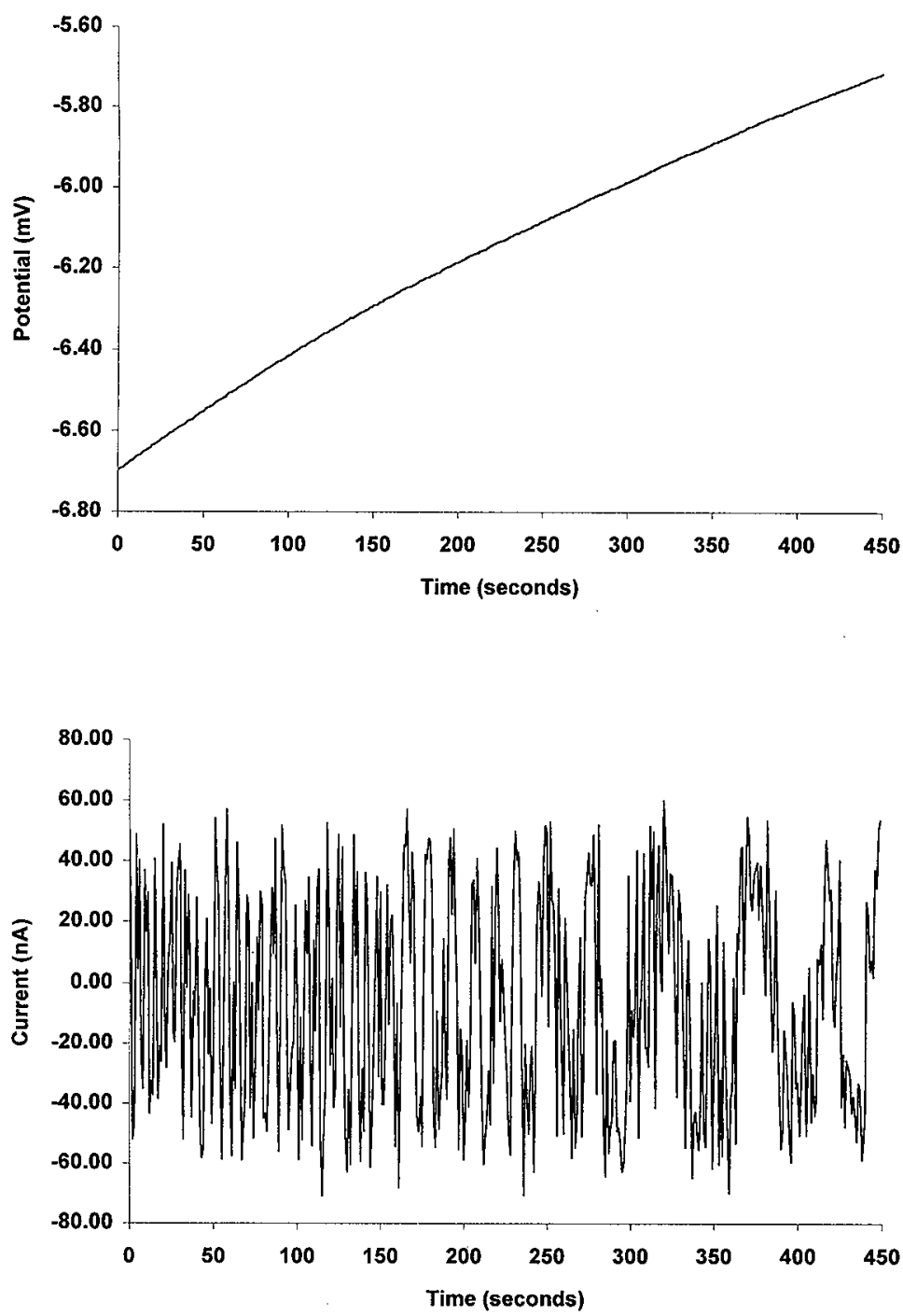

Figure 143: Typical raw potential and raw current data files: pin electrodes in supernate on channel 7 - February 1998 . 

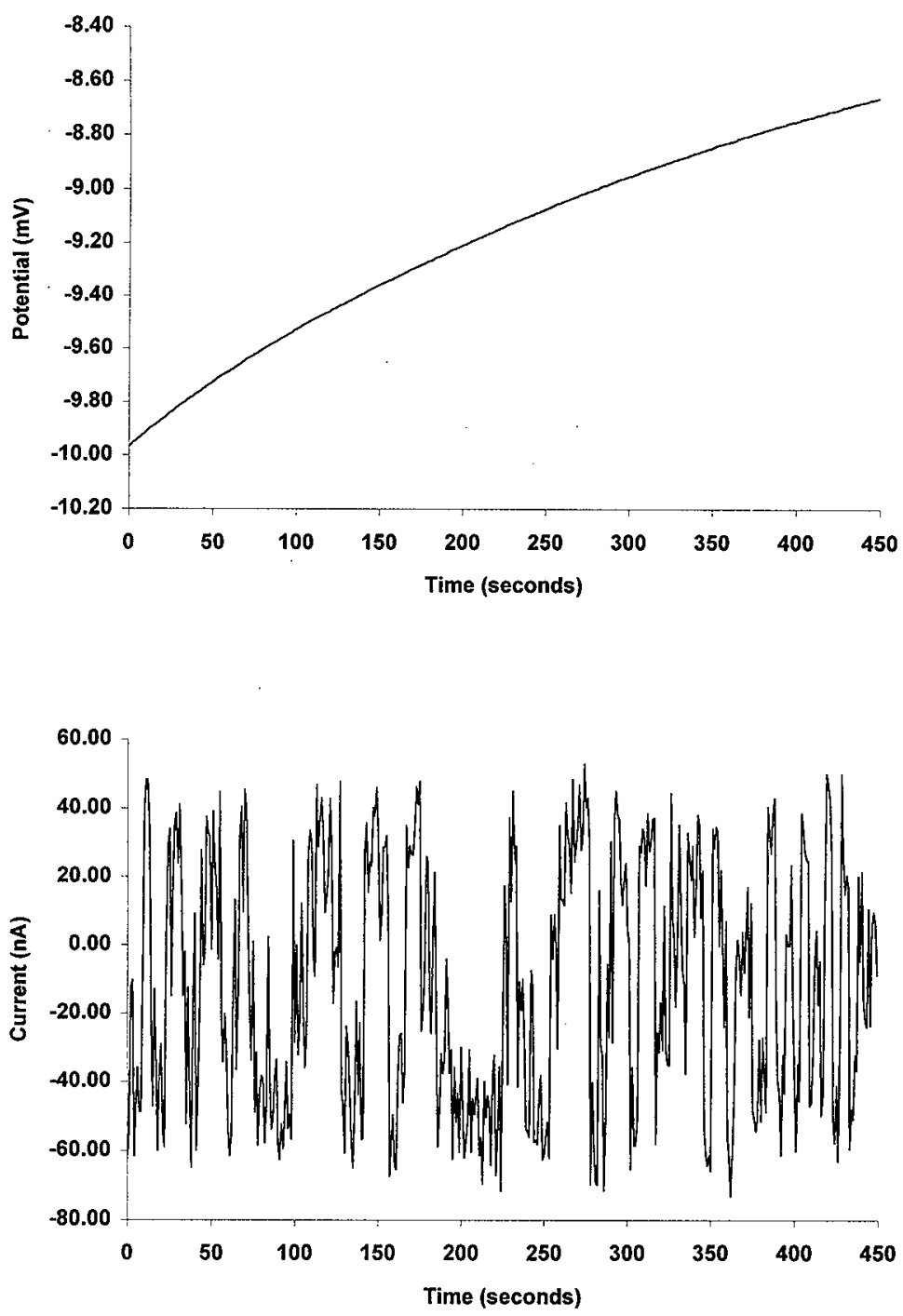

Figure 144: Typical raw potential and raw current data files: pin electrodes in supernate on channel 7 - March 1998 

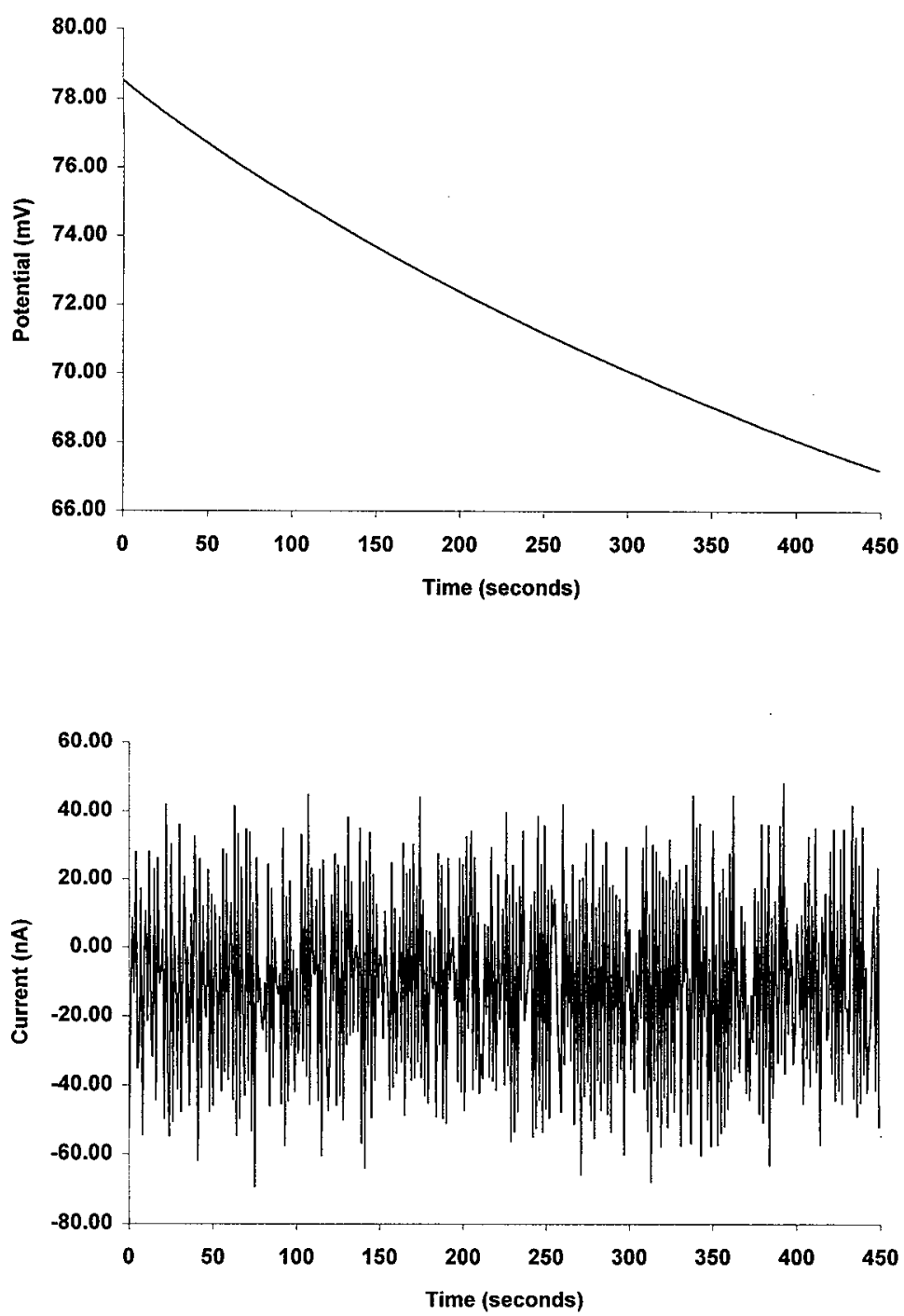

Figure 145: Typical raw potential and raw current data files: pin electrodes in supernate on channel 7 - April 1998 

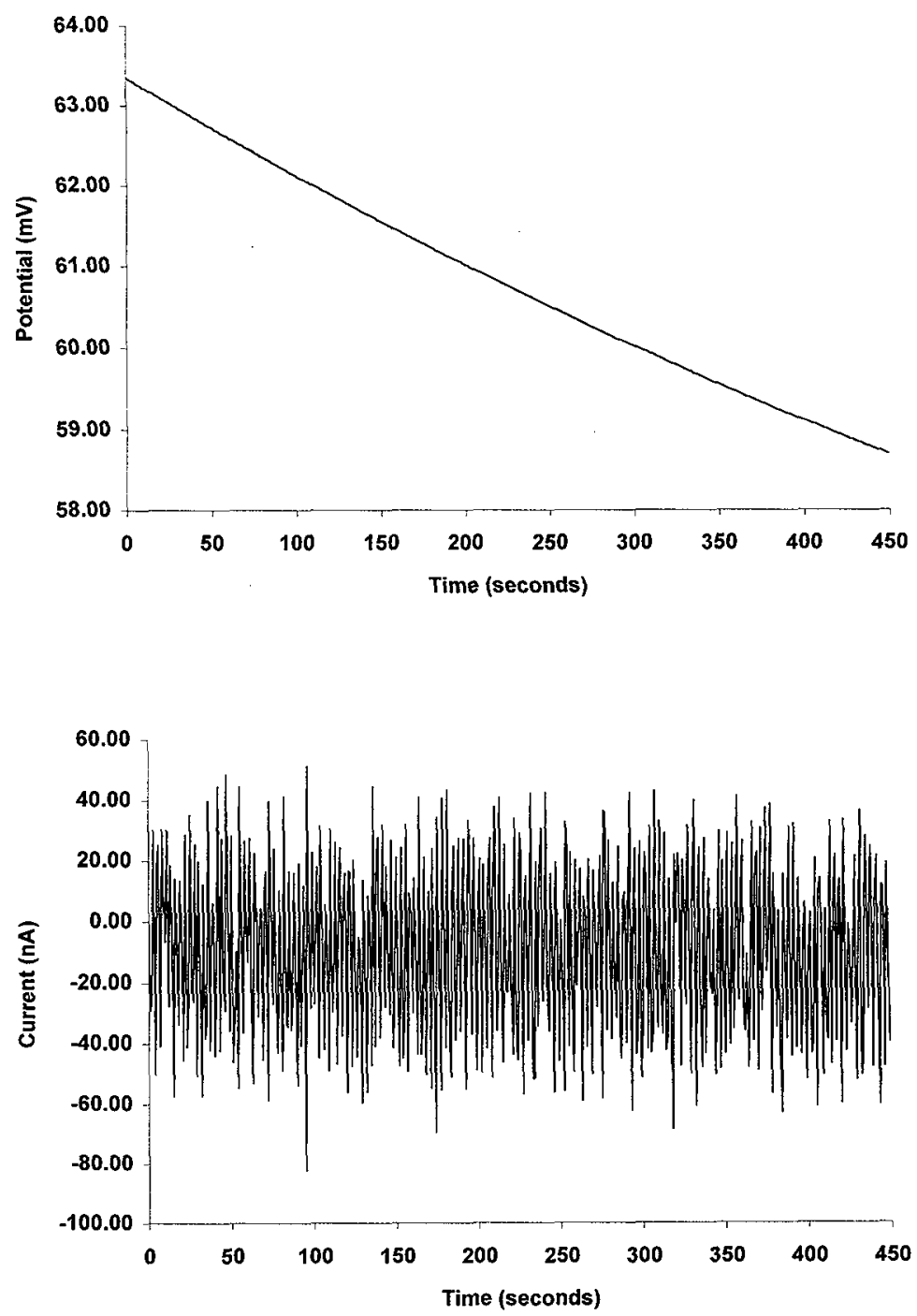

Figure 146: Typical raw potential and raw current data files: pin electrodes in supernate on channel 7 - May 1998 
HNF-3414, Rev. 0
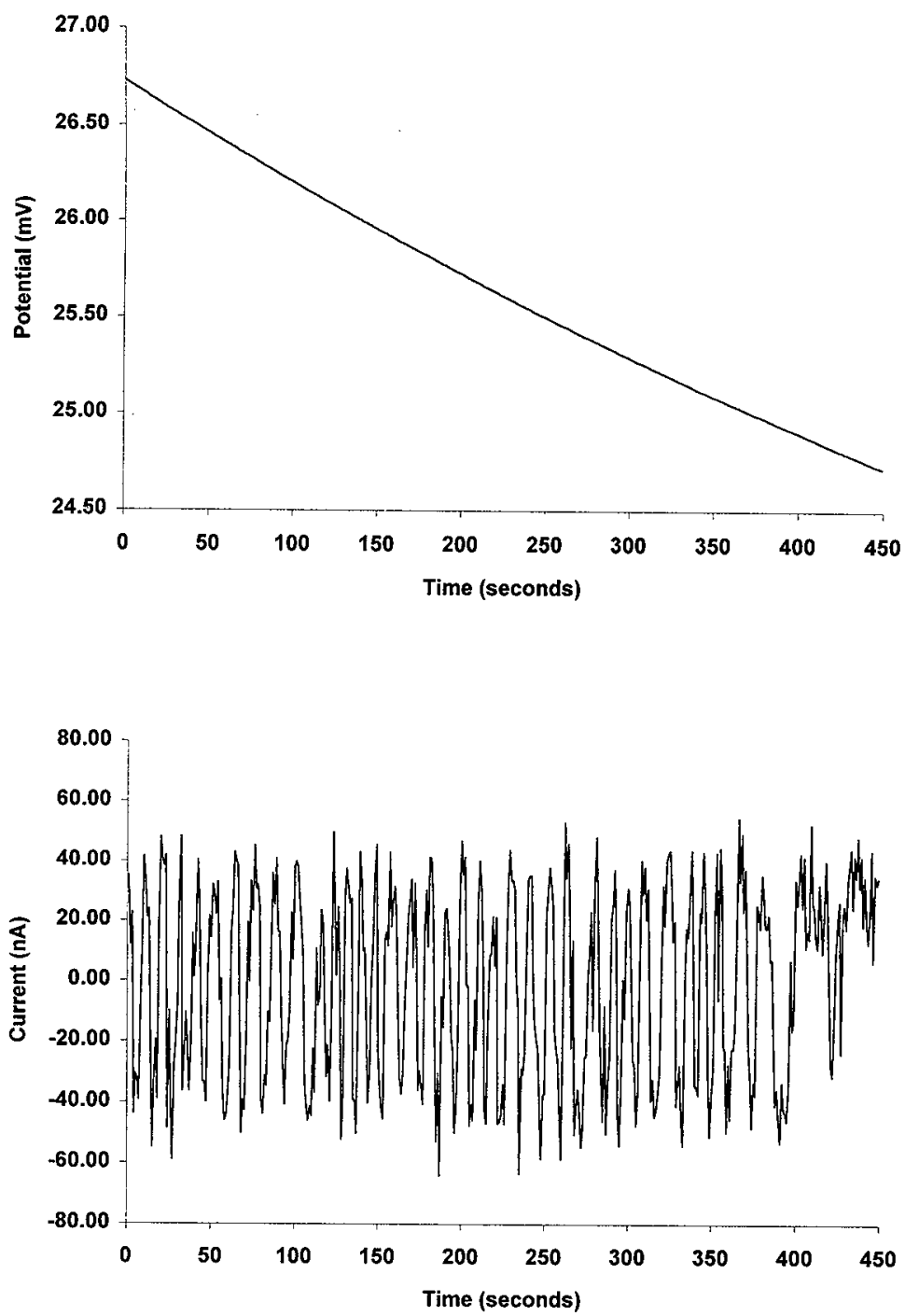

Figure 147: Typical raw potential and raw current data files: pin electrodes in supernate on channel 7 - June 1998 
HNF-3414, Rev. 0
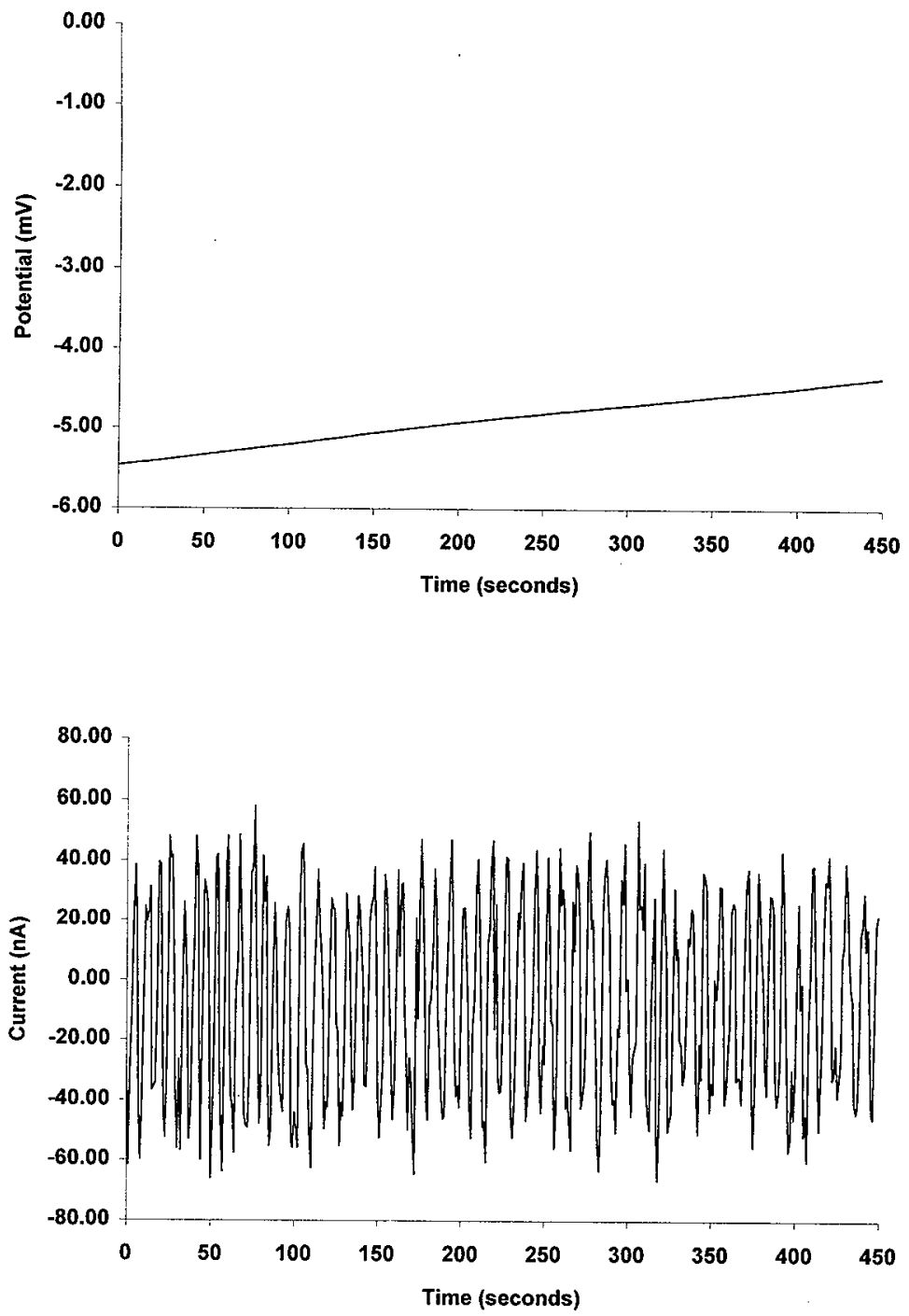

Figure 148: Typical raw potential and raw current data files: pin electrodes in supernate on channel 7 - July 1998 

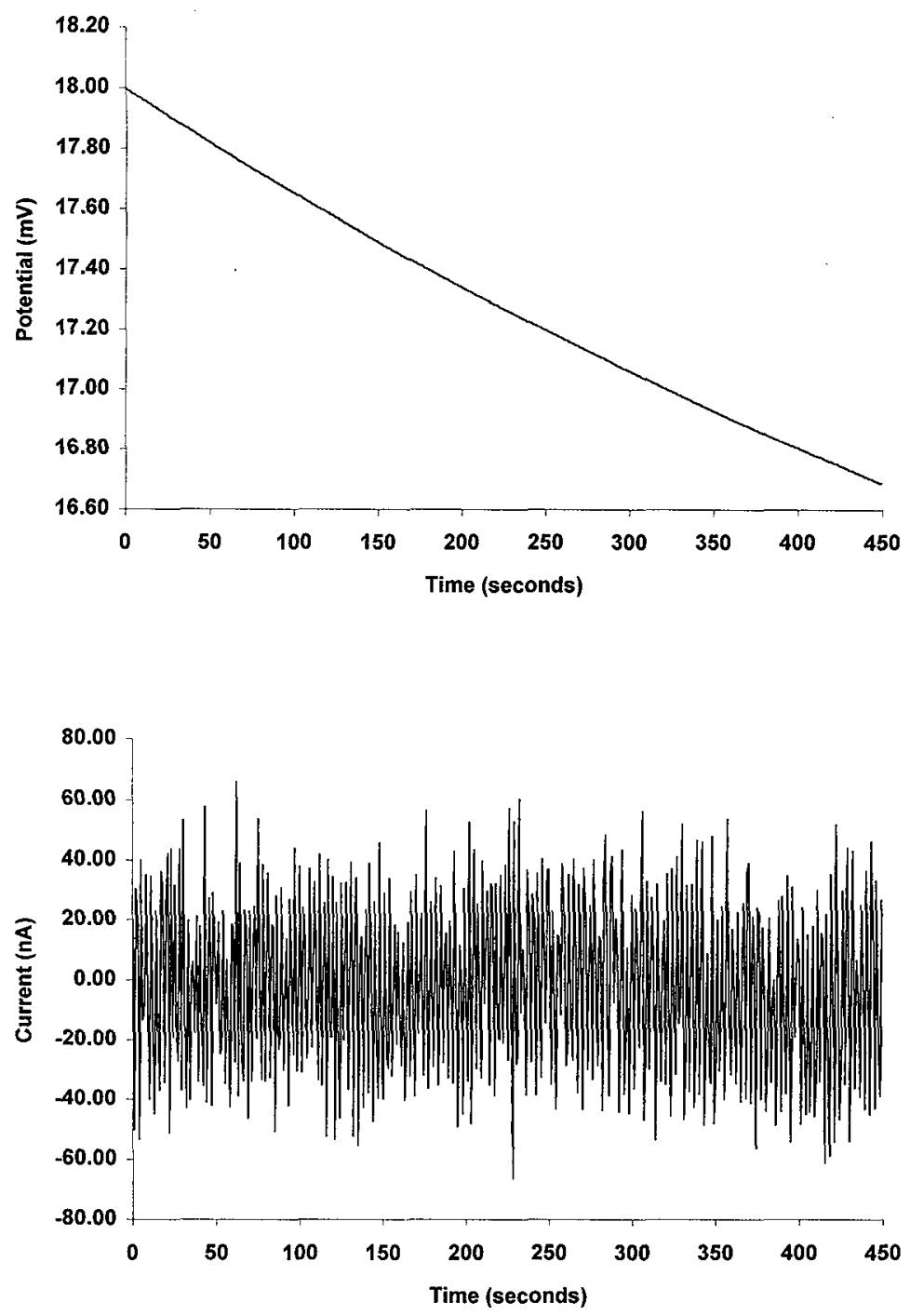

Figure 149: Typical raw potential and raw current data files: pin electrodes in supernate on channel 7 - August 1998 
HNF-3414, Rev. 0
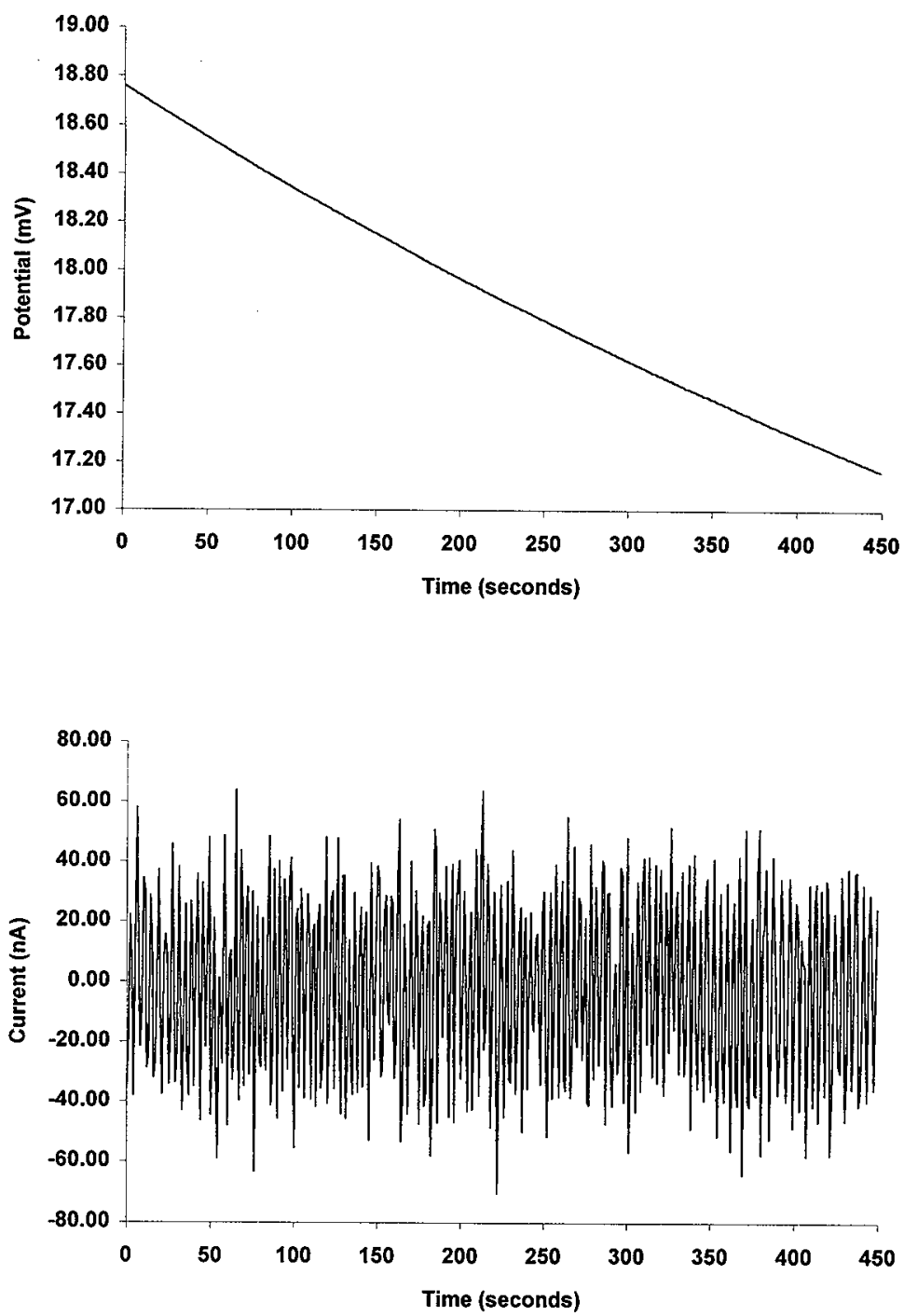

Figure 150: Typical raw potential and raw current data files: pin electrodes in supernate on channel 7 - September 1998 
HNF-3414, Rev. 0
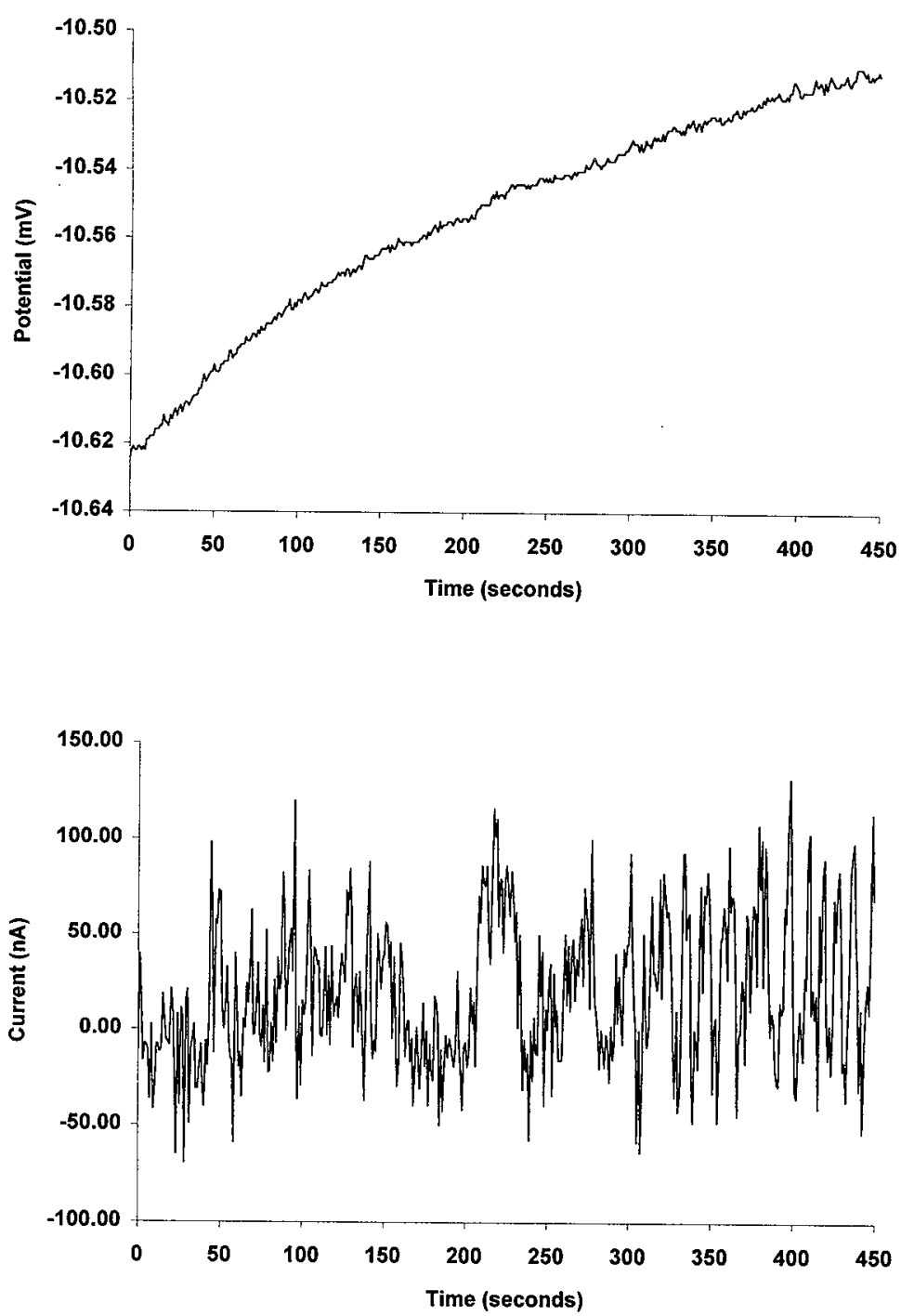

Figure 151: Typical raw potential and raw current data files: C-ring electrodes in supernate on channel 8 - September 1997 

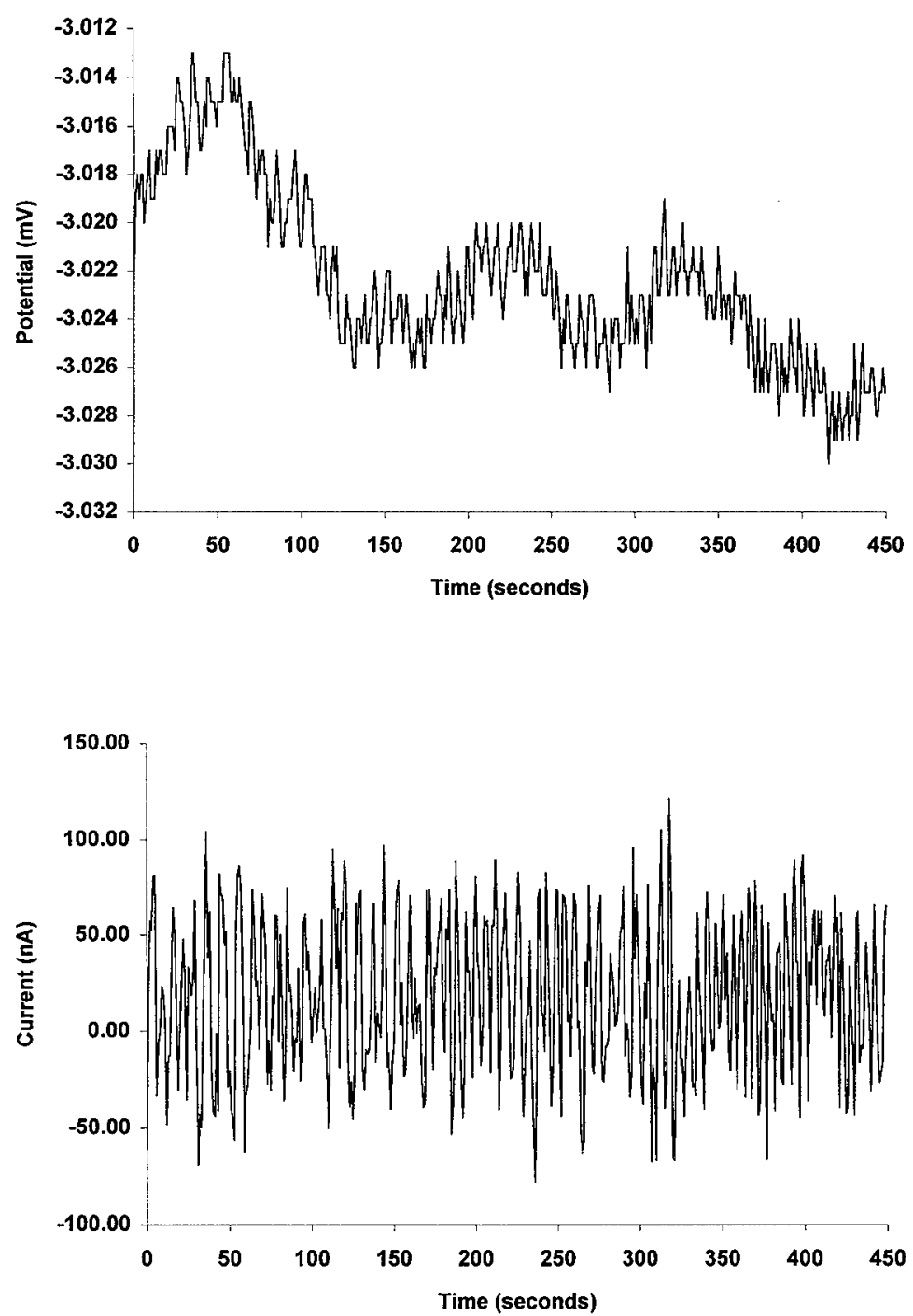

Figure 152: Typical raw potential and raw current data files: C-ring electrodes in supernate on channel 8 - October 1997 

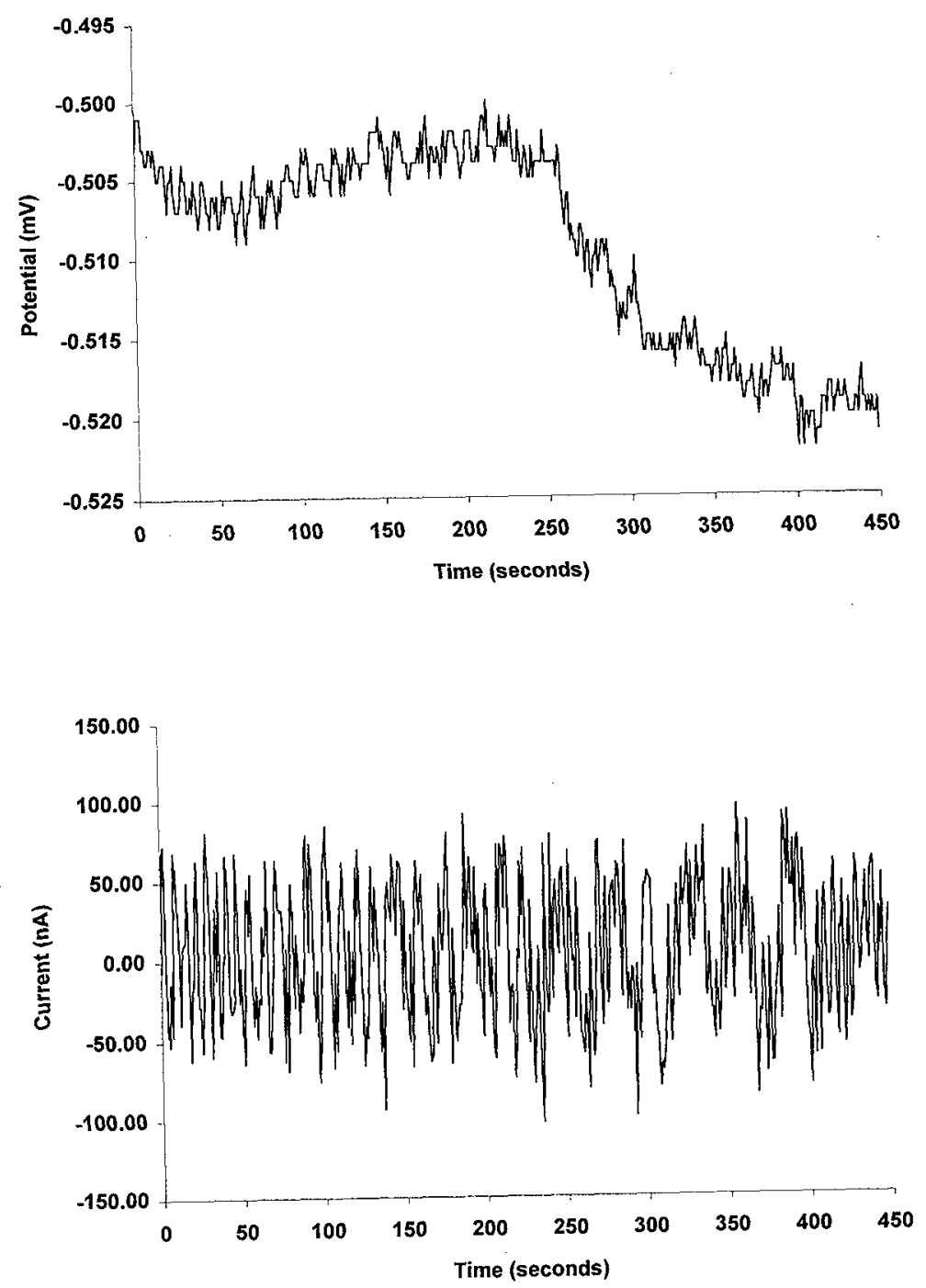

Figure 153: Typical raw potential and raw current data files: C-ring electrodes in supernate on channel 8 - November 1997 

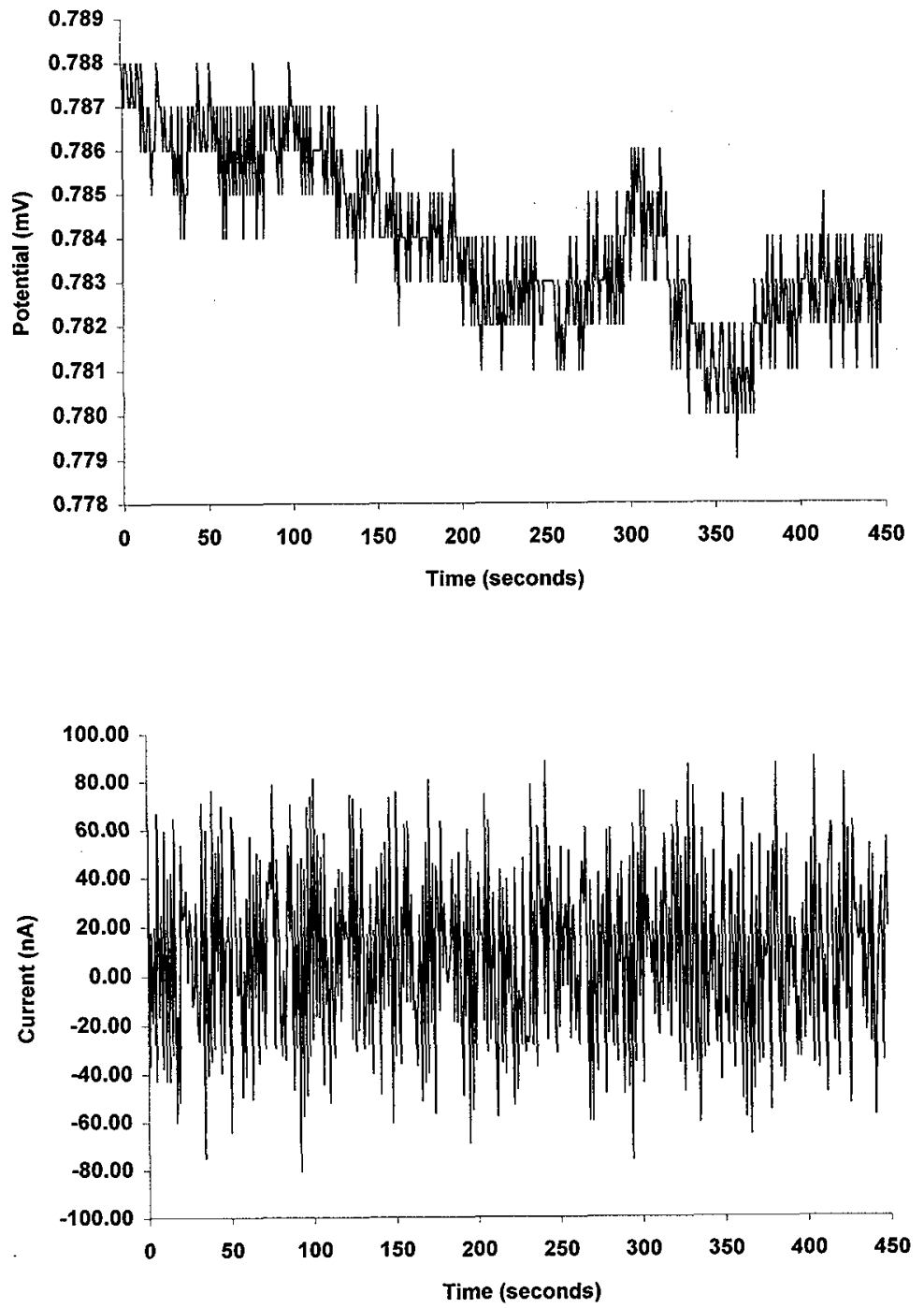

Figure 154: Typical raw potential and raw current data files: C-ring electrodes in supernate on channel 8 - December 1997 
HNF-3414, Rev. 0
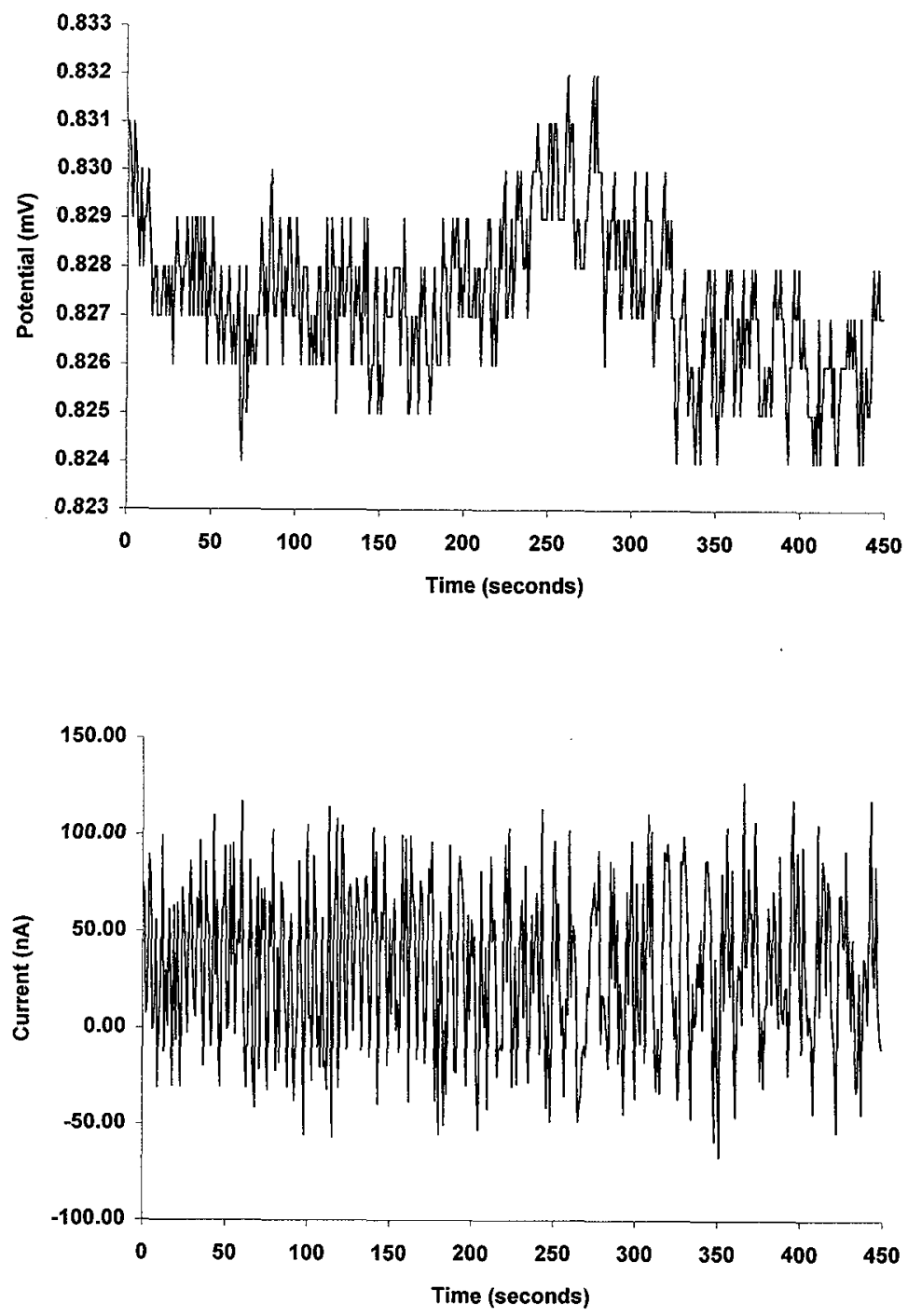

Figure 155: Typical raw potential and raw current data files: C-ring electrodes in supernate on channel 8 - January 1998 

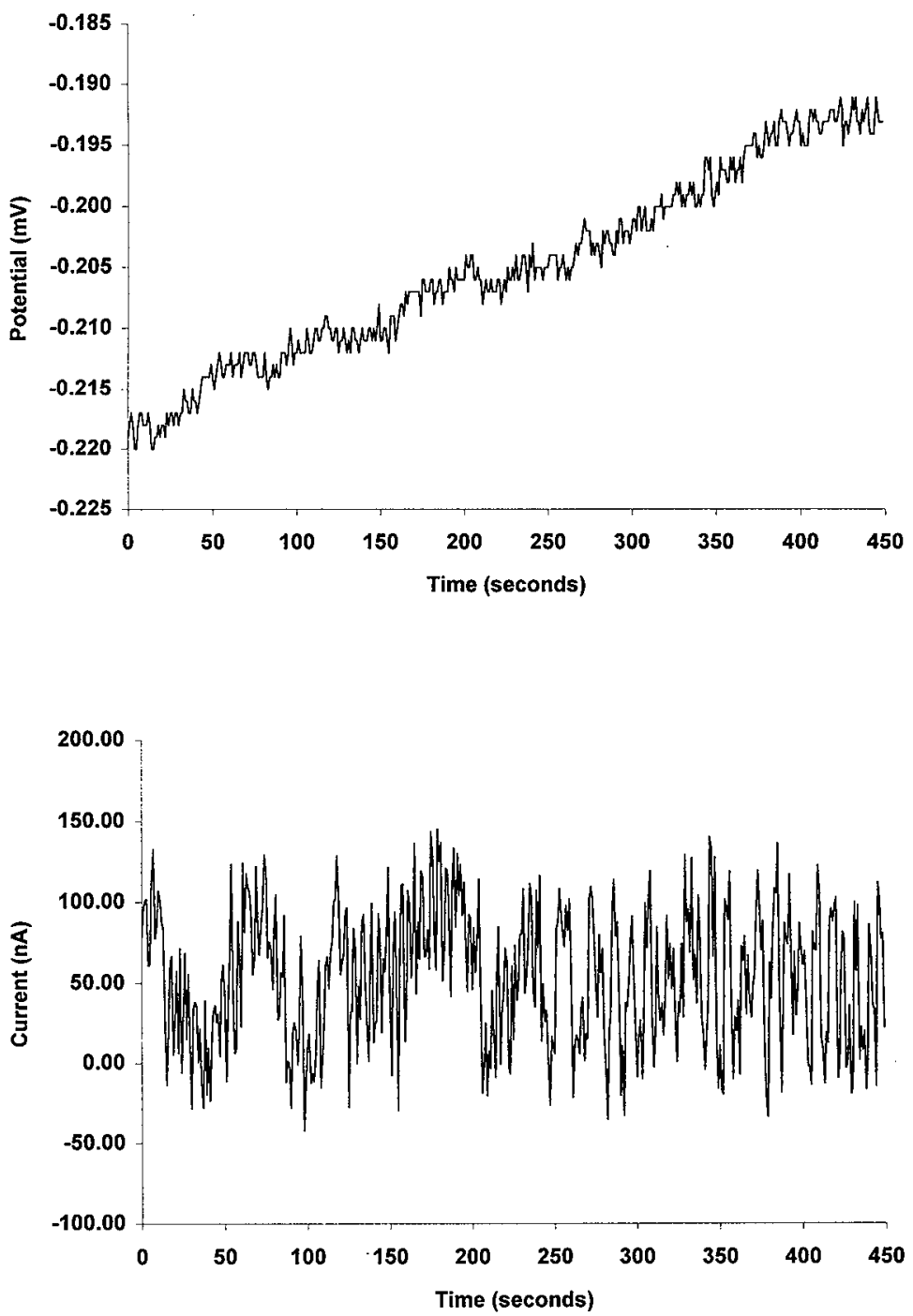

Figure 156: Typical raw potential and raw current data files: C-ring electrodes in supernate on channel 8 - February 1998 

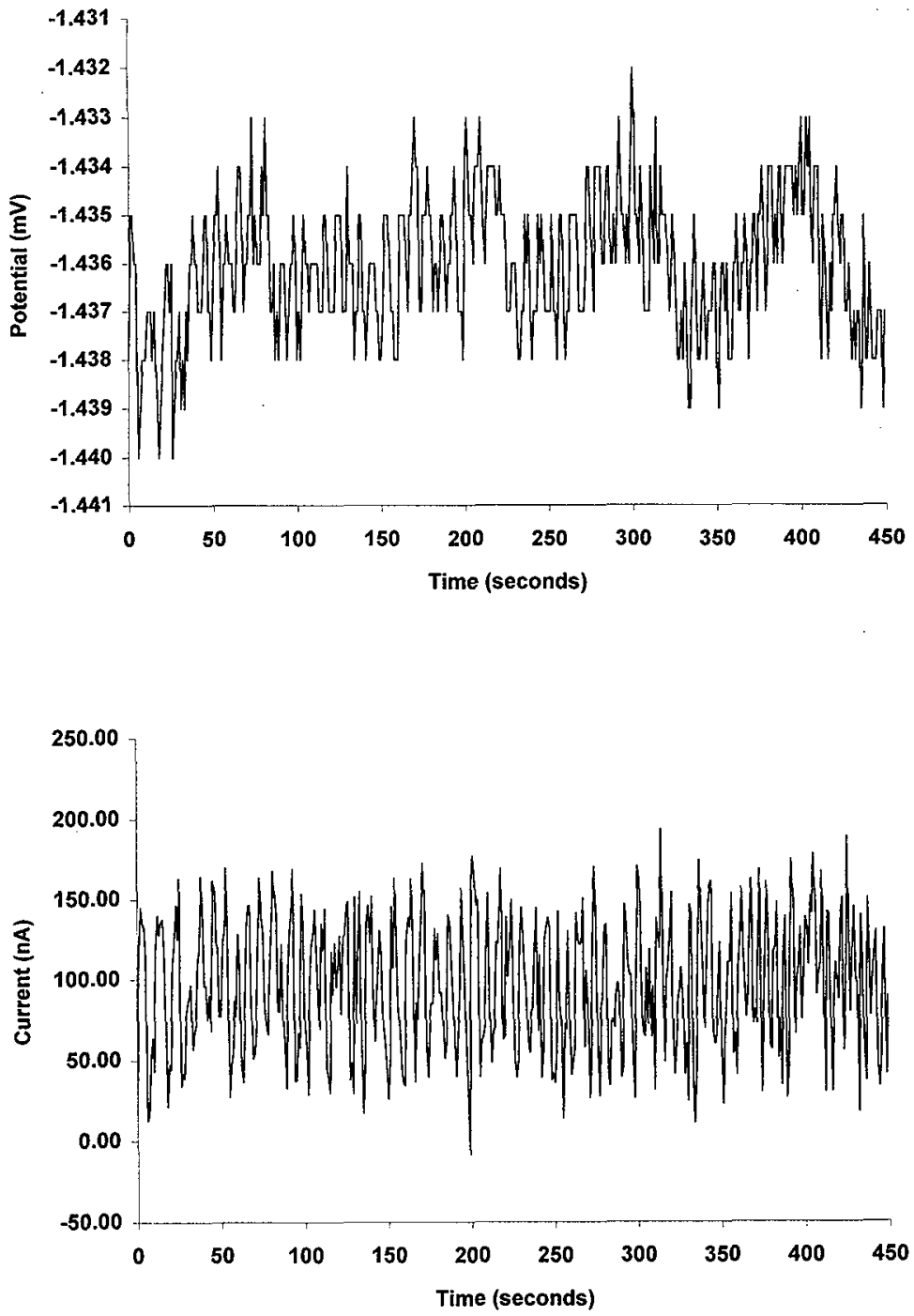

Figure 157: Typical raw potential and raw current data files: C-ring electrodes in supernate on channel 8 - March 1998 

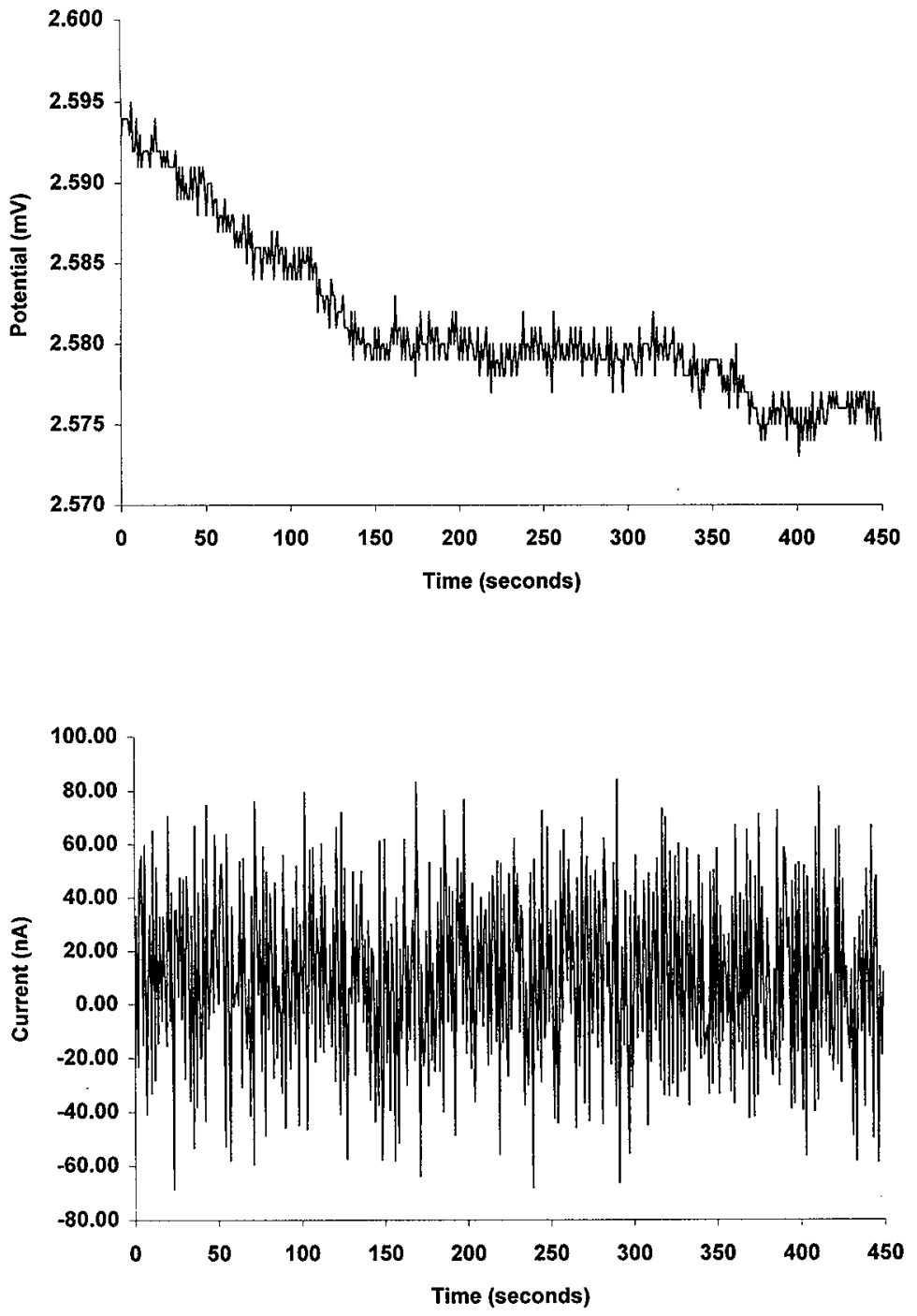

Figure 158: Typical raw potential and raw current data files: C-ring electrodes in supernate on channel 8 - April 1998 

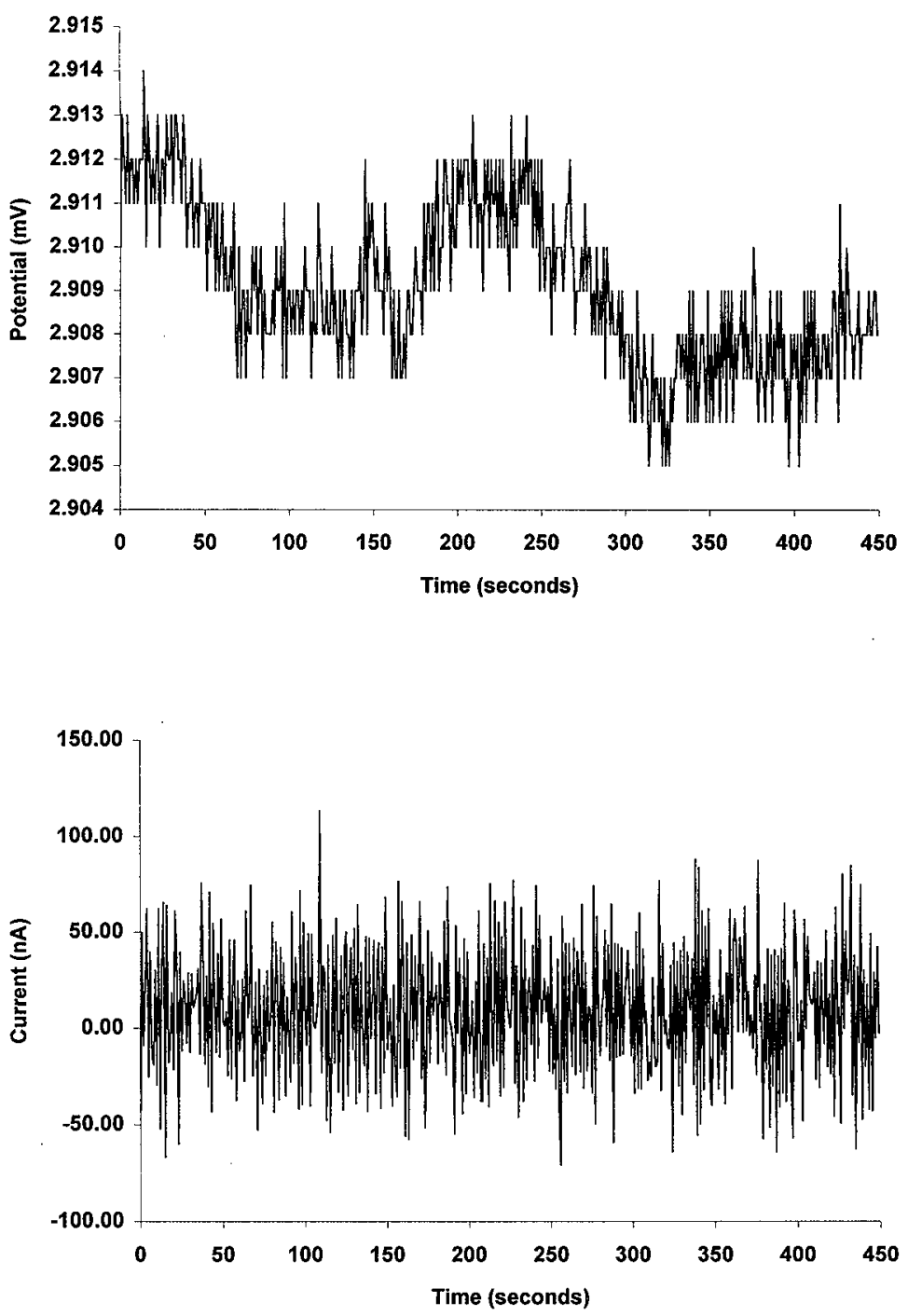

Figure 159: Typical raw potential and raw current data files: C-ring electrodes in supernate on channel 8 - May 1998 

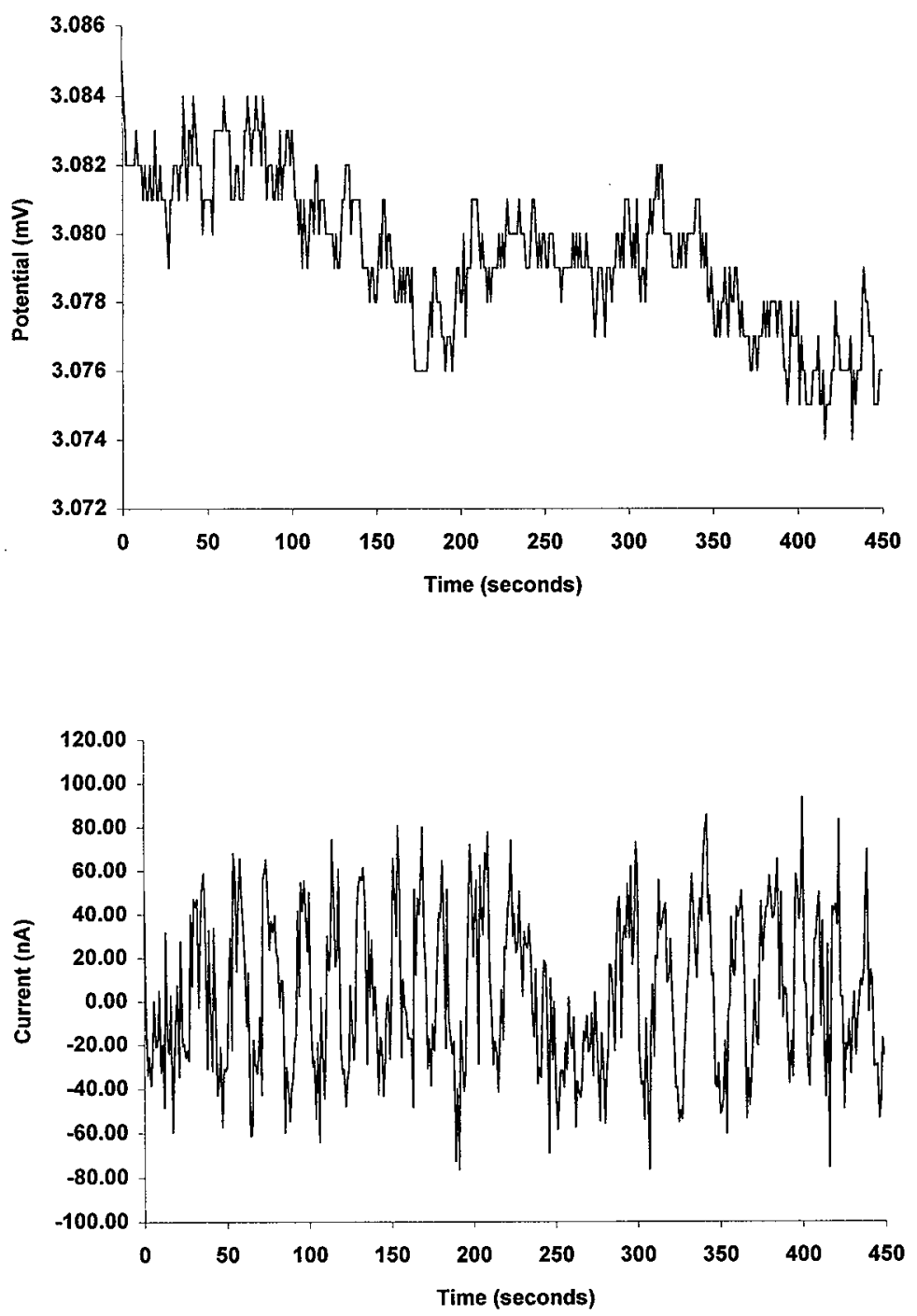

Figure 160: Typical raw potential and raw current data files: C-ring electrodes in supernate on channel 8 - June 1998 

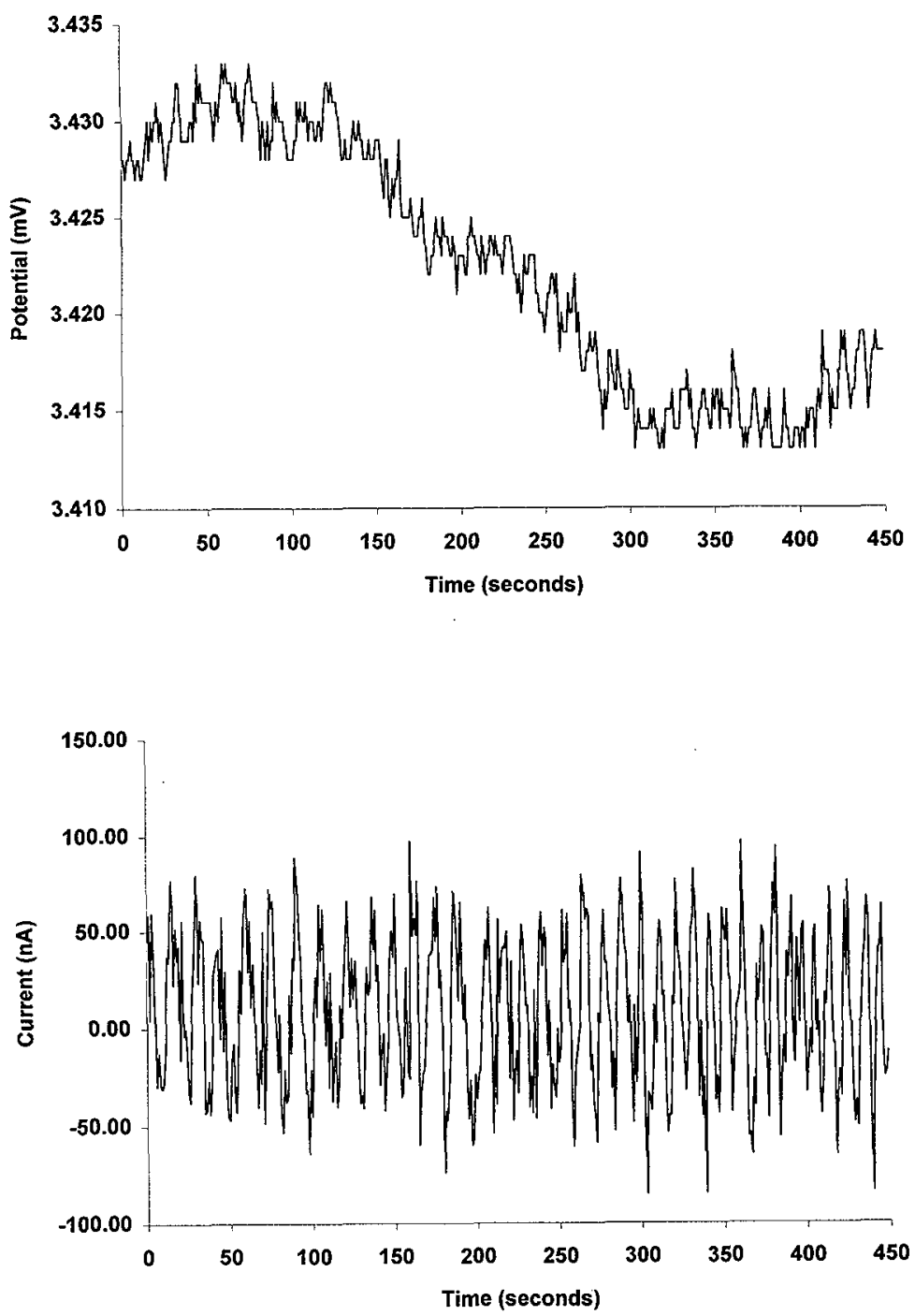

Figure 161: Typical raw potential and raw current data files: C-ring electrodes in supernate on channel 8 - July 1998 

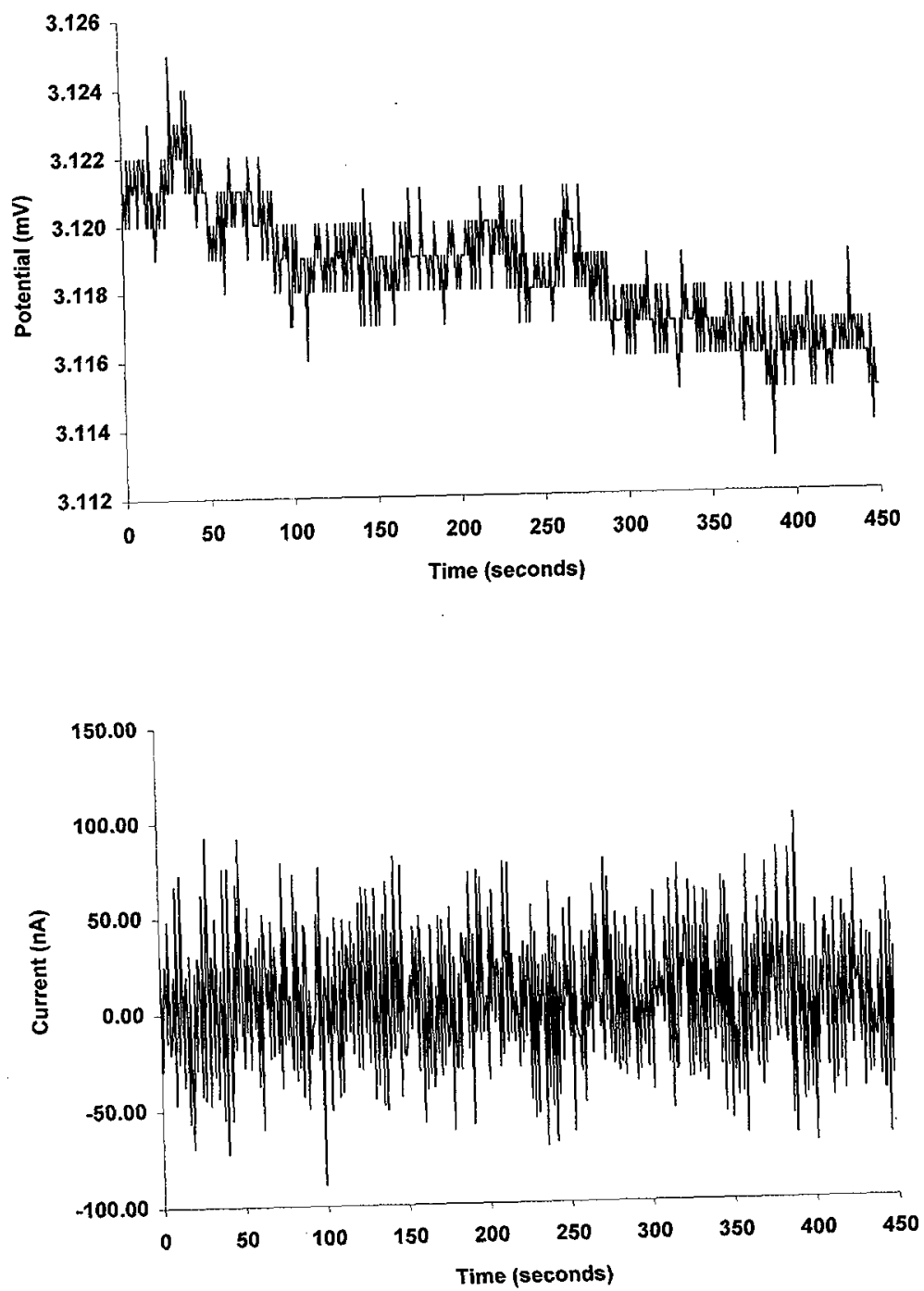

Figure 162: Typical raw potential and raw current data files: C-ring electrodes in supernate on channel 8 - August 1998 

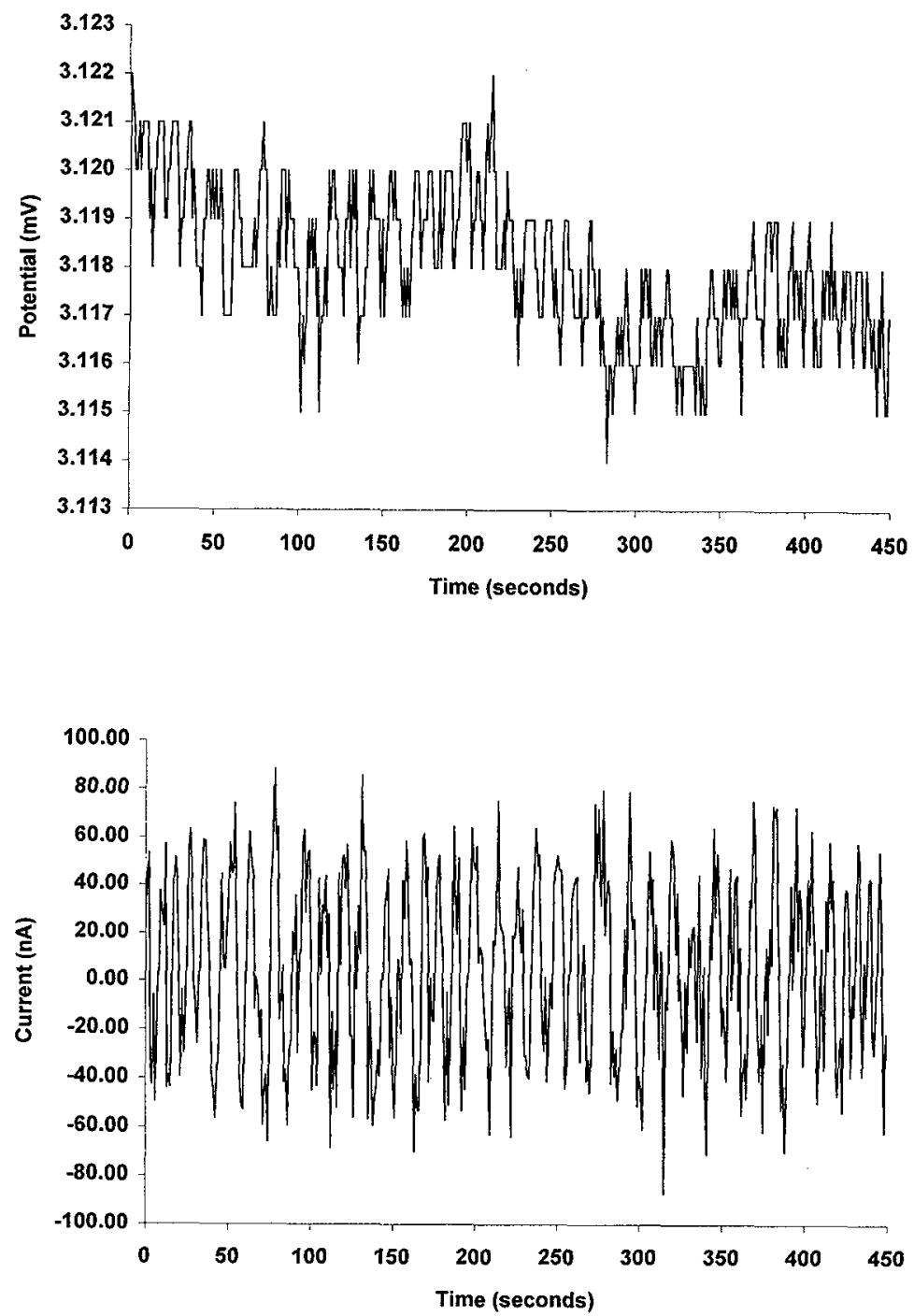

Figure 163: Typical raw potential and raw current data files: C-ring electrodes in supernate on channel 8 - September 1998 